\title{
FROTÓTIPO PARA O MONITORAMENTO DE SONDAS ROTATIVAS E APLICAÇÃO NA PROSPECÇÃO GEOLÓGICO-GEOTÉCNICA
}

\author{
FLÁVIO ALMEIDA DA SILVA
}

Orientador: Prof. Dr. FÁBIO TAIOLI

\author{
TESE DE DOUTORAMENTO
}

\section{COMISSÃO JULGADORA}

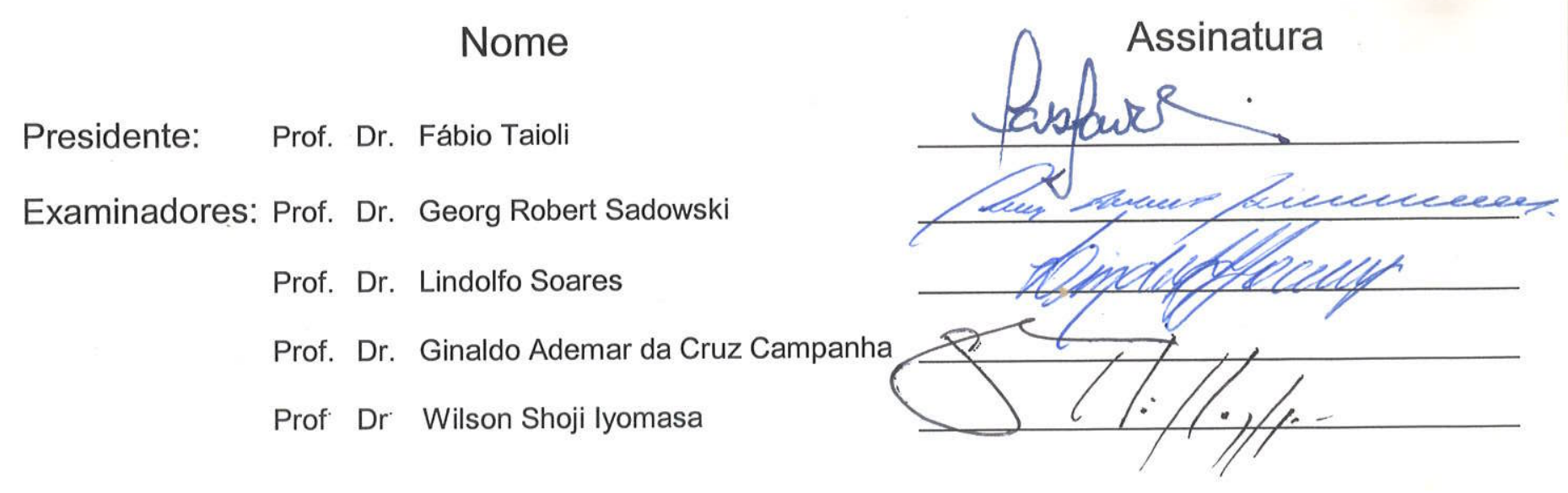

SÃO PAULO

2001 
UNIVERSIDADE DE SÃO PAULO

INSTITUTO DE GEOCIÊNCIAS

\section{“PROTÓTIPO PARA O MONITORAMENTO DE SONDAS ROTATIVAS E APLICAÇÃO NA PROSPECÇÃO GEOLÓGICO-GEOTÉCNICA"}

Flávio Almeida da Silva

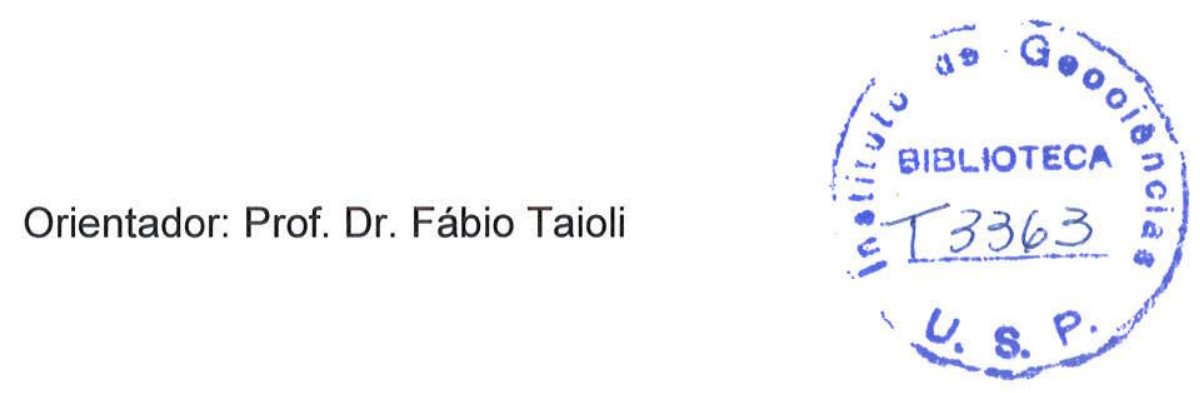

TESE DE DOUTORAMENTO

Programa de Pós-Graduação em Recursos Minerais e Hidrogeologia

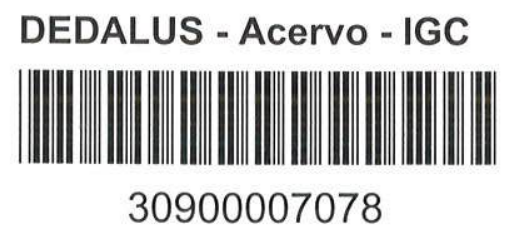

SÃO PAULO 
Aos meus pais Júlio e Laurinda, e ao meu Tio Jayme À minha mulher Regina e às minhas filhas Gabriela e Flávia À sogra e amiga Therezinha (in memorian) 


\section{Agradecimentos}

- ao Prof. Dr. Fábio Taioli pela orientação, sempre precisa e adequada, e pela amizade;

- ao Prof. Dr. Carlos Mendonça pela execução da perfilagem geofísica;

- ao Prof. Dr. Jorge Kazuo Yamamoto do IG-USP pela disponibilização de infraestrutura para o Projeto;

- ao Centro de Pesquisa de Águas Subterrâneas (CEPAS), na pessoa do Prof. Dr. Uriel Duarte, pela disponibilização da sonda rotativa para o monitoramento;

- à CAPES pela bolsa de custeio no período de maio a novembro de 2.000;

- à CDHU, através do Dr. Nelson Baeta, Diretor de Planejamento e Projetos, da Arq. Marilisa Targa Fernandes, Superintendente de Terras, da Arq. Lucila Dias Carrilho Soares, Gerente de Planejamento e Controle de Terras, da Arq. Regina Célia Silva de Almeida, Líder da Coordenadoria de Planejamento de Terras, pelo apoio ao projeto;

- ao Instituto Geológico (IG - SMA), através dos geólogos Sônia Nogueira e Hélio Shimada, pela disponibilização de material de sondagem;

- ao Prof. Dr. Lindolfo Soares, da Escola Politécnica da USP e ao Dr. Wilson Shoji Iyomasa, do IPT, pelas discussões e criticas nos assuntos relativos à classificação geológicogeotécnica de rochas e maciços rochosos e técnicas de sondagens;

- ao Prof. Dr. Maurício A. Trielli da Escola Politécnica da USP pela orientação, discussões e revisão dos textos relativos ao torsiômetro desenvolvido;

- ao Geól. Ivan Delatin, da empresa Geotécnica, pelas discussões e críticas nos assuntos relativos à execução de sondagem rotativa;

* ao Instituto de Pesquisas Tecnológicas do Estado de São Paulo pela realização dos ensaios mecânicos e, especificamente, aos colegas MSc. Antônio Marrano, pela revisão geral do texto; MSc. Maria Heloísa B. de O. Frasca, pela discussão e orientação na descrição das lâminas petrográfica; Geol. Eduardo B. Quitete; Eng. Eletrônico Vilmondes Ribeiro; MSc. Paulo Roberto Costa Cella; e técnicos Alcides F. Scarpelini e Ademir Magno;

- ao Eng. Plínio Babo, pela parceria no desenvolvimento do torsiômetro eletrônico;

- ao MSc. Adriano Marchioreto e ao Eng. Fábio Tolentino, pelo auxílio na programação do software de aquisição;

- ao Sr. Artur Takashi Onoe do Laboratório de Geocronologia, pela colaboração em diversas etapas do trabalho;

- ao Sr. Cláudio dos Santos (Biotita), pela colaboração na montagem das adaptações dos sensores ao sistema de perfuração;

- à MSc. Valdeneide Regina da Silva; pelos trabalhos de campo compartilhados, pelo material bibliográfico disponibilizado e pela amizade;

- aos amigos e colegas da CDHU, pela paciência, compreensão e solidariedade nos diversos momentos críticos do trabalho;

- aos amigos e colegas do IGc-USP, que dentro de suas atividades, sempre colaboram no possivel;

- $\quad \mathrm{E}$, finalmente, à minha amiga e companheira Regina M. Trindade de Castro Silva, pela sua paciência e apoio moral e financeiro ao projeto. 


\section{ÍNDICE}

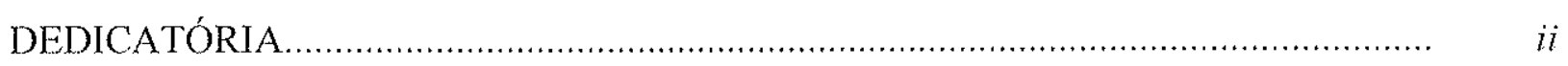

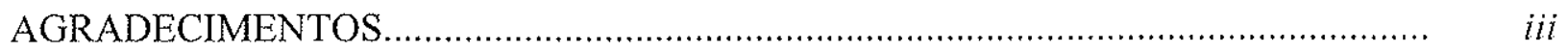

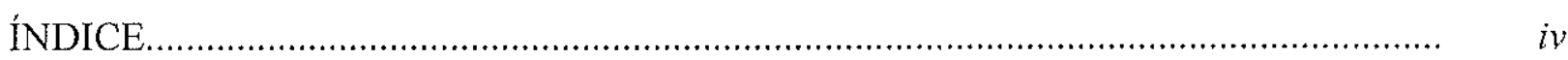

LISTA DE FIGURAS .................................................................................... vii

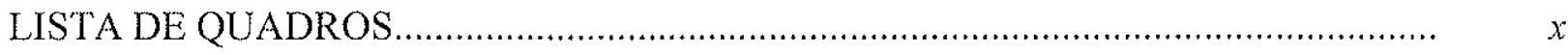

SÍMBOLOS E UNIDADES .............................................................................

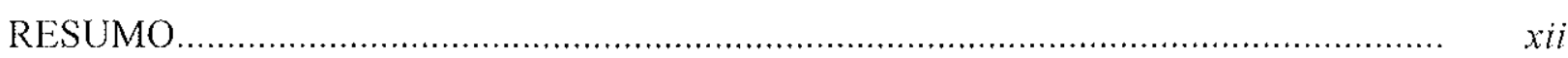

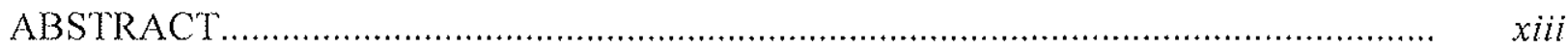

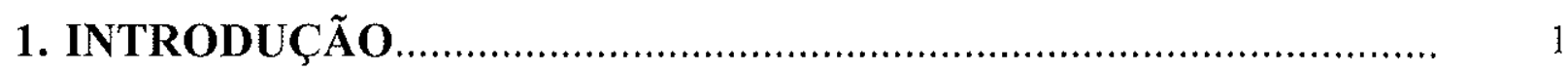

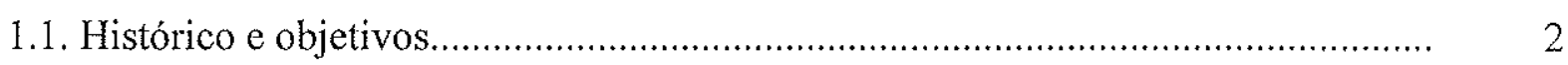

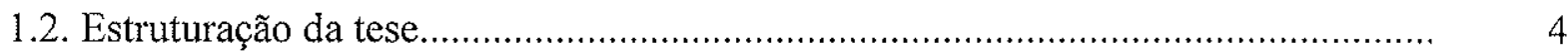

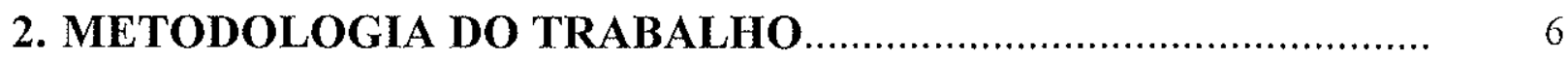

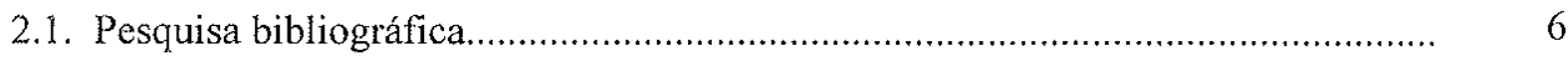

2.1.1. Parâmetros monitorados, instrumentação e tipos de sensores.................... 6

2.1.2. Equipamentos de perfuração rotativo-abrasiva....................................... 7

2.1.3. Técnica do monitoramento de perfuração (diagrafia instantânea).............. 7

2.2. Desenvolvimento do protótipo para o monitoramento........................................... 7

2.2.1. Testes em laboratório......................................................................... 7

2.2.2. Testes com a sonda em funcionamento ( $1^{\underline{a}}$ etapa de testes)........................ 8

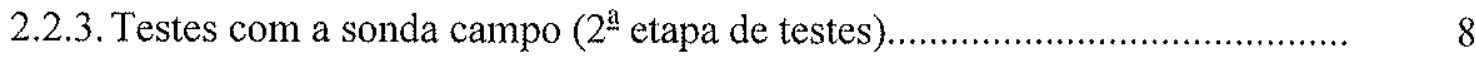

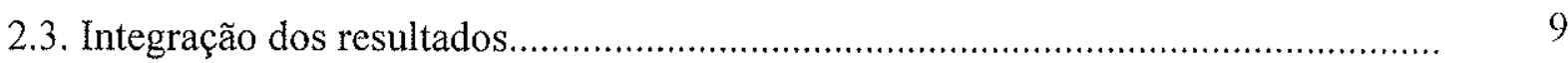

2.3.1. Furos monitorados................................................................... $\quad 10$

2.3.2. Perfilagem geofísica no furo remanescente......................................... 10

2.3.3. Ensaios em laboratório nas amostras obtidas.......................................... 11

3. REVISÃO BIBLIOGRÁFICA.................................................. 13

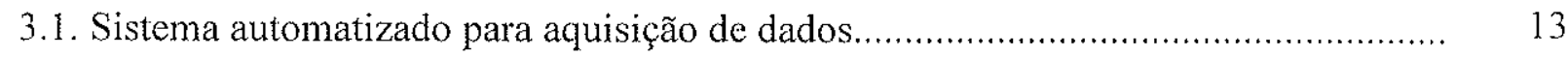

3.1.1. Sensores - conceitos básicos e características....................................... 13

3.1.2. Tipos e arranjos clássicos com sensores.......................................... 17

3.1.2.1. Extensômetro ("strain gage") ............................................. 17 
3.1.2.2. Pontes de Wheatstone.......................................................... 18

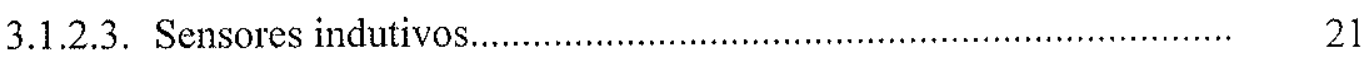

3.1.2.4. Potenciômetros................................................................ 22

3.1.3. Grandezas físicas e sensores utilizados no protótipo............................... 23

3.1.3.1. Velocidade de avanço da perfuração........................................... 23

3.1.3.2. Velocidade e sensores de rotação............................................... 24

3.1.3.3. Torque e sensores de torque ................................................ 26

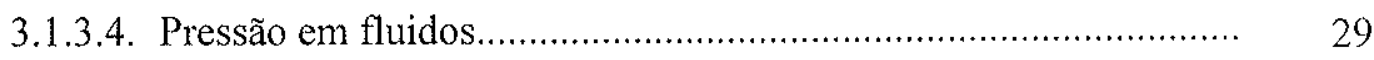

3.1.3.5. Vazão de líquidos em tubulação.............................................. 33

3.1.4. Sistemas de aquisição de dados / conversão analógico-digital................... 36

3.2. Perfuração rotativo-abrasiva - técnica e equipamentos....................................... 37

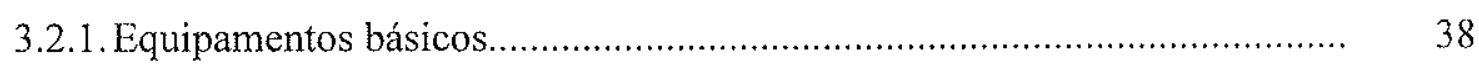

3.2.2. Perfuração abrasiva........................................................................ 47

3.3. Técnica do monitoramento de perfuração (diagrafia instantânea) ........................ 48

3.3.1. Variáveis independentes ou parâmetros de funcionamento...................... 51

3.3.2. Variáveis dependentes ou parâmetros do terreno..................................... 52

3.3.3. Modelos teóricos e empíricos para a interpretação dos parâmetros de perfuração................................................................................. 55

3.3.4. Utilização da diagrafia instantânea na campanha de investigação............. 60

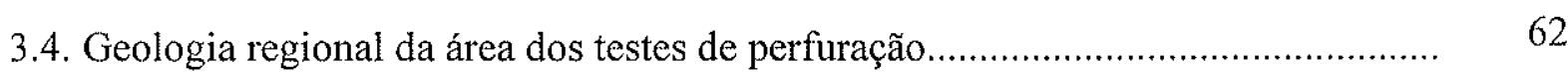

\section{PROTÓTIPO DO SISTEMA DE MONITORAMENTO DA} PERFURAÇÃO

4.1. Parâmetros monitorados, seleção dos sensores e instalação no equipamento de perfuração.

4.1.1. Deslocamento e velocidade de avanço..................................................... 67

4.1.2. Pressões no sistema hidráulico e na linha d'água..................................... 68

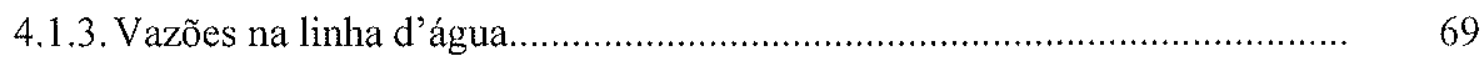

4.1.4. Temperatura do fluido de circulação................................................... 70

4.1.5. Torque aplicado ao processo de perfuração.......................................... $\quad 70$

4.1.6. Sensores de proximidade (velocidades de rotação) .................................. 71

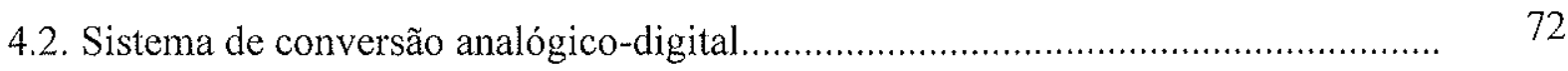

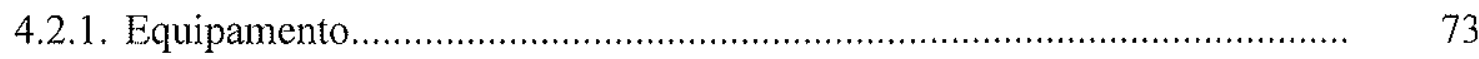

4.2.2. Software para aquisição e tratamento dos dados...................................... 73 
4.3. Testes e calibração dos sensores em laboratório................................................ 74

5. PROTÓTIPO DO SENSOR DE TORQUE.................................. 77

5.1. Dificuldades para a obtenção direta do parâmetro torque...................................... 77

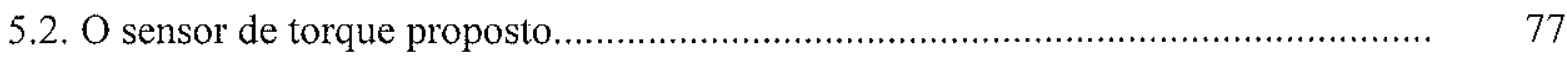

5.3. Procedimentos para a medida do torque ....................................................... 81

6. ANÁLISE E DISCUSSÃO DOS DADOS.......................................... 84

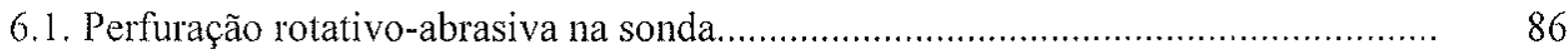

6.2. Análise dimensional da perfurabilidade .......................................................... 91

6.3. Estimativa de energia transferida utilizando o acréscimo de torque...................... 91

6.4. Condições reais dos parâmetros medidos........................................................ 92

6.4.1. Posição do furo e velocidade de avanço................................................. 92

6.4.2. Pressão efetiva sobre a ferramenta de corte (Po).................................... 93

6.4.3. Velocidade de rotação da coluna e torque................................................... 94

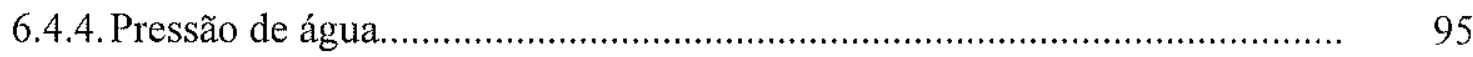

6.4.5. Vazão de entrada no furo .................................................................... 95

6.4.6. Vazão de retorno do furo .................................................................... 95

6.5. Tratamento dos dados coletados no protótipo..................................................... 96

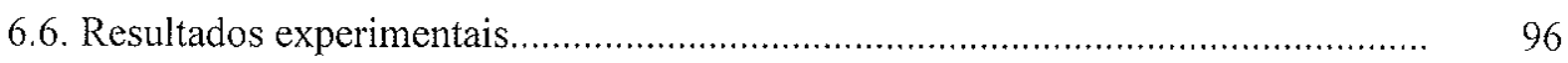

6.6.1. Sondagens a percussão e furos rotativos monitorados............................. 97

6.6.1.1. Testes de funcionamento $\left(1^{\text {a }}\right.$ etapa)...................................... 100

6.6.1.2. Testes de campo ( $2^{\text {a }}$ etapa) ................................................... 108

6.6.2. Monitoramento da perfuração e a perfilagem geofísica............................. $\quad 110$

6.6.3. Ensaios de mecânica das rochas............................................................ 113

6.6.3.1. Ensaios de resistência à compressão puntiforme........................ 113

6.6.3.2. Ensaios de resistência à compressão uniaxial............................. 116

6.7. Análise dos resultados obtidos e do comportamento da sonda............................... 120

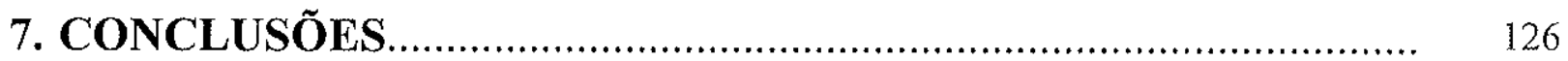

REFERÊNCIAS BIBLIOGRÁFICAS............................................ 129

\section{ANEXOS}

A.1 - Resultados dos testes de perfuração

A.2 - Sondagens realizadas nas áreas dos testes de perfuração - perfis individuais de sondagem e fotografias

A.3 - Ensaios de mecânica das rochas 
Figura 2.1 - Vista do Geologger 3030 (BOLOGNA, 1996).................................................

Figura 2.2 - Configuração básica de perfilagem utilizando a sonda GW 3433 (BOLOGNA, 1996)

Figura 3.1 - Diferença entre os conceitos de precisão e exatidão (DUNNICLIFF, 1988)...................

Figura 3.2 - Representação dos erros de histerese, linearidade (a) e repetitividade (b)............. 16

Figura 3.3 - Extensômetro ("strain gage") de lâmina colada uniaxial (DUNNICLIFF, 1988)......... 18

Figura 3.4 - Arranjo em Ponte de Wheatstone (ISMAlL et al., 1998)........................................ 18

Figura 3.5 - Sensor transversal indutivo de proximidade (A) Sensor com a frente

"shieldada"(B), Sensor não "shieldado" (C)(FRADEN, 1993).

Figura 3.6 - Sensor de proximidade transversal indutivo com um disco auxiliar $(A)$ e o sinal de saída em função da distância (B) (FRADEN, 1993).

Figura 3.7 - Ponteciômetro como um sensor de posição (FRADEN, 1993)

Figura 3.8 - Erros causados por potenciômetros montados com bobinas (FRADEN, 1993).......

Figura 3.9 - Representação vetorial da posição $(A)$, velocidade $(B)$ e aceleração $(B)$ de um

Figura 3.10 - Representação vetorial da velocidade de rotação (NUSSENZVEIG, 1981).............

Figura 3.11 - Valores do erro porcentual em função da velocidade de rotação...

Figura 3.12 - Representação do vetor torque na coluna de perfuração (NUSSENVEIG, 1981).. 27

Figura 3.13 - Instalação do torsiômetro no eixo de um motor (HBM, s.d.) ................................... 27

Figura 3.14 - Curva de torque fornecida pelo fabricante do motor da sonda.............................. 28

Figura 3.15 - Escalas de pressão (ISMAlL et al., 1998)............................................................... 29

Figura 3.16 - Tubos de Bourdon (a), diafragmas de pressão (b) e foles (c) (ISMAlL et al.,op. cit)

Figura 3.17 - Diafragmas de pressão. Placa fina (A) e membrana (B)

Figura 3.18 - Tubo de Fluxo $(A)$ e fluxo através de um plano $(B)$ e perfil de velocidade de fluxo

Figura em tubulação (C) (FRADEN, 1993).

Figura 3.19 - Operação do medidor eletromagnético de vazão (BASILE \& SANTOS, 1989)....... 34

Figura 3.20 - Princípio do medidor de vazão eletromagnético (FRADEN, 1993)......................... 35

Figura 3.21 - Posição dos sensores em um sistema de aquisição de dados e controle

(FRADEN, 1993).

Figura 3.22 - Vista da ferramenta tipo "rotary"(a), ação hidráulica durante a perfuração (b), detalhe da ação da força de compressão no esmagamento da rocha (c)(HARTLE, 1994).

Figura 3.23 - Sistema de avanço hidráulico em sonda rotativa: (a) ilustração tridimensional

(PEREDA, 1998) e (b) esquema ilustrativo com os sensores instalados (b)....

Figura 3.24 - Elementos estruturais e funcionais das coroas diamantadas (MARX, 1967 apud SERRA Jr., 1991)

Figura 3.25 - Perfis da face de corte - coroas diamantadas (DIAMANTEGEO, s.d. e MAQUESONDA, s.d.).

Figura 3.26 - Tamanho relativo das pedras em função do $P P Q$ (pedras por quilate) (MAQUESONDA, s.d.)....

Figura 3.27 - Bomba SB-75 e sonda para prospeç̧ão geológica SS-21 (SONDEQ, s.d.)..........

Figura 3.28 - Torque e penetração por revolução para sondagens rotativas em folhelho (TEALE, 1965)....

Figura 3.29 - Torque e velocidade de avanço para sondagens rotativas (CLARK, 1979)... 54

Figura 3.30 - (a) Perdas por britagem para determinação do valor de friabilidade $S_{20}$ e (b) teste em perfuratriz miniaturizada para determinação do Valor SJ (TAMROCK, 1986)... 
Figura 3.31 - Ábaco para determinação do Indice de Perfuração $(D R I)$, a partir dos valores de $\mathrm{S}_{20}$ e SJ (TAMROCK, 1986)

Figura 3.32 - Classificação da rocha segundo o valor do DRI e faixas de valor de DRI para alguns tipos litológicos (TAMROCK, 1986).

Figura 3.33 - Princípio dos testes de raspagem realizados em DEKETH (1995) ....................... 59

Figura 3.34 - Modos de desgaste (DEKETH, 1995)

Figura 3.35 - Forças instantâneas de corte em função do tempo. Velocidade de corte -0.4 $\mathrm{m} / \mathrm{s}$. (a) Avanço $0.07 \mathrm{~mm} / \mathrm{rev}$ (MODO 1); (b) $0,57 \mathrm{~mm} / \mathrm{rev}$ (MODO III) (DERETH, op.cit)..

Figura 4.1 - Esquema de instalação do conjunto de sensores/ sistema de conversão no sistema de perfuração (sonda/bomba).

Figura 4.2 Fotografia de sensores instalados na sonda: (a) deslocamento, pressões (b) descendente e (c) ascendente do hidráulico, e proximidade (d).

Figura 4.3- Fotografia do sistema de aquisição (a) caixa de alimentação e recepção dos sinais, (b) conversor AD e (c) Notebook

Figura 4.4 - Detalhe do (a) sensor de deslocamento e (b) das peças do seu suporte.

Figura 4.5 - Detalhe do sensor de pressão utilizado no monitoramento

Figura 4.6 - Detalhe dos sensores de vazão e suas respectivas flanges de adaptaçăo na linha d'água, (a) $1 \frac{1}{2}$ ", (b) $1 \frac{1}{2}$ ", (c) $1 \frac{1}{2}$ " instalado na saida do furo e (d) reservatório para medida da vazão de saida.

Figura 4.7 - Instalação dos sensores (a) de vazão $\left(1 / 2{ }^{\prime \prime}\right)$ e (b) de pressão na linha d'água (entrada).

Figura 4.8- Detalhe do sensor de proximidade (a) instalado na sonda, através de seu suporte (b). Anteparos (c) e respectivo suporte (d) instalados em peça solidária à coluna, defronte ao sensor de proximidade.

Figura 4.9 - Calibração do sensor de deslocamento

Figura 4.10 - Calibração do sensor de pressão do sistema hidráulico (descendente).

Figura 4.11 - Calibração do sensor de pressão do sistema hidráulico (ascendente)

Figura 4.12 - Calibração do sensor de pressão da linha d'água.

Figura 4.13 - Calibração do sensor de vazão de entrada no

Figura 4.14 - Calibração do sensor de vazão da saída (VazaoS) (1 1/2").

Figura 5.1 - Acoplamento original da sonda (a) e acoplamento elástico do sensor de torque desenvolvido (b). Sensores de proximidade e respectivo suporte (c).

Figura 5.2 - Esquema do acoplamento elástico.

Figura 5.3 - Fotografias da calibração estática do acoplamento elástico (a). Detalhe do laser utilizado para medida do deslocamento angular (b).

Figura 5.4 - Taxa de deformação do acoplamento com o torque aplicado (a) e trajetórias de carregamento e descarregamento dos mesmos pontos (b).

Figura 5.5 - Sinais dos sensores instalados no acoplamento da sonda. Periodo de rotação do motor (a) e defasagem proporcional ao torque aplicado (b).

Figura 5.6 - Teste do sistema eletrônico para medida da defasagem (anteparos fixos)................... a perfuração.

Figura 6.1 - Elementos envolvidos na perfuração.

Figura 6.2 - Influência da pressão efetiva na ferramenta de corte $\left(P_{0}\right)$, considerando a transferência de energia da sonda para o processo de perfuração.

Figura 6.3 - Ferramentas de corte utilizadas na perfuração em solo: brocas de arraste diâmetros $\mathrm{Hx}$ (a), Bx (b) e a broca sem especificação $(\phi=20 \mathrm{~cm})(\mathrm{c})$

Figura 6.4- Ferramentas de corte utilizadas na perfuração em rocha: coroa impregnada $\mathrm{Nw}$ (10quilates) (a), calibrador (b) e coroa cravada Nw (70-80 ppq) (c).

Figura 6.5-Localização e locação das sondagens monitoradas e das sondagens a percussão. 
Figura 6.6. - Seção geológica esquemática na área de estudo. Região dos furos rotativos monitorados e das sondagens a percussão.

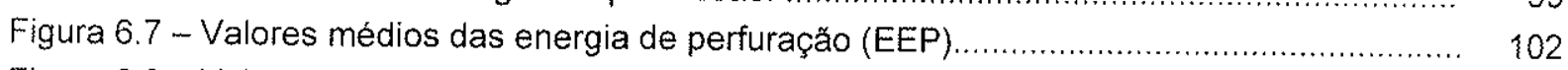

Figura 6.8 - Valores médios da velocidade de avanço...................................................... 102

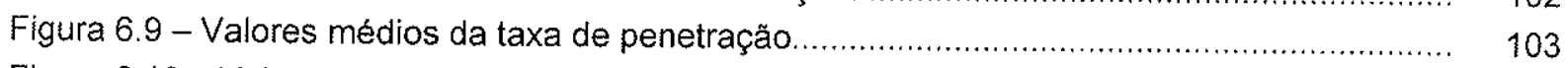

Figura 6.10 - Valores da pressăo na ferramenta de corte ...................................................... 103

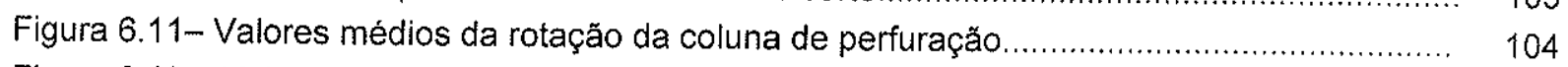

Figura 6.12 - Valores médios da rotação do motor ............................................................. 104

Figura 6.13 - Detalhe da correlação do SPT (furos SP. 1 e 2) com a energia especifica de perfuração.

Figura 6.14 - Valores de deflexão medidos nas perfurações em solo.

Figura 6.15 - Comparação entre os perfis de EEP, textura e resistência SPT.

Figura 6.16 -.Vista geral do equipamento utilizado para a subida e descida das sondas (a) e detalhe do "Geologger" (b).

Figura 6.17 -.Detalhe da sondas para a perfilagem caliper (a) e eletrorresistividade (b).....................

Figura 6.18 - Sonda que realiza a perfilagem de microrresistividade (a) e detalhe dos sensores(b).

Figura 6.19 - Faixa de variação dos indices físicos. Amostras dos ensaios de resistência à compressão puntiforme.

Figura 6.20 - Correlação entre energia especifica de perfuração (EEP) e resistência à compressão puntiforme $\left(\mathrm{I}_{(50)}\right)$. Compressão paralela à xistosidade.

Figura 6.21 - Correlação entre energia especifica de perfuração (EEP) e resistência à compressão puntiforme $\left(\mathrm{IS}_{(50)}\right)$. Compressão perpendicular à xistosidade.

Figura 6.22 - Variação dos indices físicos (Ensaios RCU)

Figura 6.23 - Correlação entre a velocidade de ultra-som e a absorção de água (Ensaio RCU).

Figura 6.24 - Correlação entre a energia especifica de perfuração e o volume estimado de quartzo nas amostras

Figura 6.25 - Correlação entre a resistência à compressão simples e o volume estimado de quartzo nas amostras

Figura 6.26 - Correlação entre energia específica de perfuração (EEP) e resistência à compressão uniaxial (RCU). Compressão paralela à xistosidade.

Figura 6.27 - Detalhe do processo incipiente de alteração das amostras: argilização dos feldspatos. Amostra RCU-7. Aumento 20x (a) polarizadores descruzados e (b) polarizadores cruzados.

Figura 6.28 - Detalhe das fratura preenchidas por óxidos/hidróxidos de ferro. Amostra RCU-3. Aumento $20 \times$ (a) polarizadores descruzados e (b) polarizadores cruzados. 
Quadro 3.1 - Causas e soluções dos erros de medida (modificado de DUNNICLIFF, 1998)....... 16

Quadro 3.2 - Arranjos de Pontes de Wheatstone (DUNNICLIFF, 1988) .................................... 20

Quadro 3.3 - Relações entre as grandezas lineares e angulares (NUSSENZVEIG, 1981) ........... 25

Quadro 3.4 - Resumo comparativo dos transdutores de pressão (adaptado de ISMAIL et. al., 1998).

Quadro 3.5 - Nomeclatura do sistema americano ou "DCDMA" para equipamentos de sondagem rotativa diamantada (SERRA Jr., 1991).

Quadro 3.6 - Características técnicas da Sonda SS-21 (SONDEQ, s.d.).

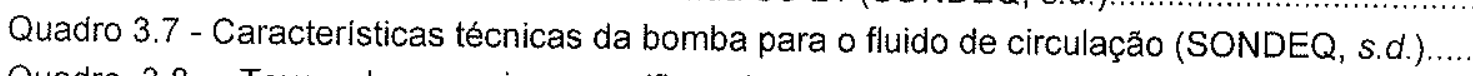

Quadro 3.8 - Taxas de energia especifica obtidas do torque e da força de compressão (HOWARTH \& ADAMSON 1988)

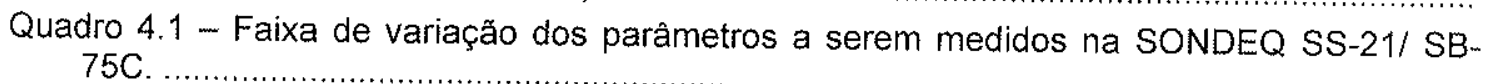

Quadro 4.2 - Características do transdutor de deslocamento.

Quadro 4.3 - Transdutores de pressão (sistema hidráulico da sonda e saída da bomba d'água).

Quadro 4.4 - Características dos sensores de vazão

Quadro 4.5 -

Quadro 4.5 - Sensores de proximidade para medição das velocidades de rotação.................... 71

Quadro 4.6 - Sistema de aquisição de dados Lynx (série ADS-2000) …...................................... 73

Quadro 6.1 - Relação entre grandezas medidas e parâmetros de monitoramento ........................... 84

Quadro 6.2 - Qualidade do material perfurado. Furo rotativo da $1^{\mathrm{a}}$ etapa ...................................... 101

Quadro 6.3 - Testes de campo - arquivos de aquisição (Furo Zero) ........................................ 111 
SÍMBOLOS E UNIDADES

\begin{tabular}{|c|c|c|}
\hline \multirow{2}{*}{ PARÂMETRO } & \multirow{2}{*}{ SÍMBOLO } & UNIDADES \\
\hline & & SI \\
\hline Área da seção transversal da coroa & $A$ & $\mathrm{~m}^{2}$ \\
\hline Avanço por rotação ou taxa de penetração & $\delta$ & $\mathrm{cm} / \mathrm{rev}$ \\
\hline Comprimento total da coluna de perfuração & $l_{c}$ & $\mathrm{~m}$ \\
\hline Comprimento imerso da coluna & $l_{c i}$ & $\mathrm{~m}$ \\
\hline Densidade do fluido de perfuração & $\gamma_{\text {fluido }}$ & $\mathrm{kg} / \mathrm{m}^{3}$ \\
\hline Densidade do fluxo magnético & $B$ & $\mathrm{~T}$ \\
\hline Diâmetro do furo & $D$ & $\mathrm{~m}$ \\
\hline Diâmetro externo da borda da coroa & $D_{2}$ & $\mathrm{~m}$ \\
\hline Diâmetro interno da borda da coroa & $D_{1}$ & $\mathrm{~m}$ \\
\hline Empuxo da coluna imersa & $E i$ & $\mathrm{~N}$ \\
\hline Energia despendida para perfuração & $E_{p}$ & MJ \\
\hline Energia específica de perfuração & EEP ou $E_{v}$ & $\mathrm{MJ} / \mathrm{m}^{3}$ \\
\hline Empuxo da coluna imersa & $E i$ & $\mathrm{~N}$ \\
\hline Força de frenagem das hastes & $F_{t}$ & $\mathrm{~N}$ \\
\hline Perfurabilidade & $P f$ & $\mathrm{MJ} / \mathrm{m}^{3}$ \\
\hline Peso imerso da coluna de perfuração & $P i$ & $\mathrm{~N}$ \\
\hline Peso da coluna & $P_{c o l}$ & $\mathrm{~N}$ \\
\hline Peso efetivo da coluna de perfuração & Pe & $\mathrm{N}$ \\
\hline Peso efetivo sobre a ferramenta de corte & 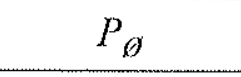 & $\mathrm{N}$ \\
\hline Potência & Pot & W \\
\hline Potência transferida para a perfuração & Pot transf & $\mathrm{W}$ \\
\hline Pressão do fluído de circulação & $P_{f}$ & $\mathrm{MPa}$ \\
\hline Pressão efetiva sobre a ferramenta de corte & $P_{o}$ & $\mathrm{MPa}$ \\
\hline Pressão sobre a ferramenta de corte & $P_{O}$ & $\mathrm{MPa}$ \\
\hline Taxa de penetração & $\delta$ & $\mathrm{cm} / \mathrm{rev}$ \\
\hline Torque ou binário de rotação & $T$ & N.m \\
\hline Vazão do fluido na ferramenta de corte & $Q i$ & $\mathrm{~m}^{3} / \mathrm{s}$ \\
\hline Vazão do fluido que retorna do furo & $Q_{0}$ & $\mathrm{~m}^{3} / \mathrm{s}$ \\
\hline Vazão ou fluxo de um fluido & $\Lambda$ & $\mathrm{m}^{3} / \mathrm{s}$ \\
\hline Velocidade de avanço do furo & $V_{a}$ & $\mathrm{~cm} / \mathrm{min}$ \\
\hline Velocidade de rotação & $W$ & $\mathrm{rad} / \mathrm{s}$ \\
\hline
\end{tabular}




\section{RESUMO}

A sondagem rotativa diamantada para a amostragem de rocha é um método de investigação direto muito utilizado nas áreas em geologia de engenharia e geotecnia. Esse tipo de investigação também é aplicado em pesquisa mineral, para a obtenção de amostra, visando a avaliação de jazidas. Secundariamente, o método também pode ser utilizado na prospecção de água subterrânea e na área de meio ambiente.

O monitoramento de sondagem ou "diagrafia instantânea" é uma técnica, a partir da qual, através do monitoramento de parâmetros ligados ao equipamento de perfuração e as respectivas respostas do terreno, são analisadas e inferidas características geológicas e geotécnicas dos materiais perfurados. $\mathrm{Na}$ área de geotécnica, o método é associado a furos destrutivos (percussivos e rotopercussivos).

Este trabalho desenvolveu um protótipo para monitoramento de sondas rotativas diamantadas, utilizadas em furos para amostragem (testemunhos). Nas etapas de testes, foram monitorados os parâmetros: velocidade de rotação da coluna de perfuração e acréscimo de torque aplicado ao processo de perfuração. Esses dois parâmetros permitiram a estimativa da energia consumida no processo de perfuração. Considerando-se o volume de rocha destruída, tem-se a Energia Específica de Perfuração (EEP) ao longo do furo. Monitorou-se ainda a posição da perfuração (velocidade de perfuração), as pressões no sistema hidráulico, que determinam a contribuição da sonda na pressão sobre a rocha; as vazões do fluido de circulação (injetada e de retorno do furo), a pressão do fluido de circulação e a velocidade de rotação do eixo do motor.

Ensaios de laboratório foram realizados nas amostras de rocha obtidas: ensaios de caracterização, resistência à compressão puntiforme $\left(\operatorname{Is}_{(50)}\right)$ e compressão simples (RCU); além de análises petrográficas. Os resultados desses ensaios foram correlacionados com as informações obtidas nos testes de perfuração do protótipo.

Durante os testes, solos e sedimentos foram perfurados e monitorados pelo protótipo. Os resultados desses testes foram comparados com as informações obtidas por meio de sondagens a percussão e ensaios de resistência à penetração SPT. 


\section{ABSTRACT}

Diamanted rotative drilling for rock sample is a direct investigation method used in engineering geology and geotechnical studies. This type of investigation is also used in mineral research, to obtain samples, aiming at mine evaluation. Secondarily, this method can also be used in underground water research and in environmental studies.

The monitoring of drilling or "instantaneous diagraph" is a technique which, by means of the monitoring of parameters related to the drilling equipment and to the respective ground responses, can analyze and infer geological and geotechnical characteristics of drilled materials. In geotechnical studies, the method is associated to destructive bore holes, (percussive and roto-percussive.) This study has developed a prototype to monitor rotative diamanted drills used in holes to obtain samples (cores.)

During test stages, the following parameters were monitored: angular velocity of the drilling string and torque addition applied to the drilling process. These two parameters make it possible to estimate the energy spent on the drilling process. Considering the volume of the destroyed rocks, it is possible to calculate the Specific Drilling Energy along the hole. The following parameters were also monitored: drilling position (drilling velocity), pressures on the hydraulic system, which establishes the role that the drill exerts on the pressure on the rock, inflow and outflow of the drilling fluid, pressure of the drilling fluid and angular velocity of the engine axle.

Laboratory tests were carried out on the rock samples obtained, that is, classification tests, point load strength tests (Is $\left.{ }_{(50)}\right)$ and uniaxial comprehensive strength tests (UCS), in addition to petrographic analysis. The results of these experiments were correlated to the information obtained in the prototype drilling tests.

Sediments and soils were drilled and monitored by the prototype during the tests. The tests results were compared to the information obtained by means of percussion drillings and standard penetration tests (SPT). 


\section{INTRODUÇÃO}

O termo "prospecção" é diretamente associado à pesquisa mineral, relacionando-se à descoberta e à avaliação do valor econômico de jazidas. $O$ termo pode ainda ter um sentido mais amplo de pesquisa ou investigação aplicada, desenvolvendo-se em várias escalas. Essas escalas variam desde o detalhe microscópico, em lâminas petrográficas, até estudos em escala global, na crosta terrestre. Quanto à forma, especificamente, a investigação na prospecção geológico-geotécnica pode ser classificada em direta ou indireta. Os métodos indiretos são aqueles onde as formações geológicas e suas litologias são avaliadas segundo algumas propriedades físicas (p.e. velocidade de propagação de ondas elásticas, resistividade elétrica, constante dielétrica), não havendo acesso direto aos materiais. As investigações geofísicas são o exemplo clássico dos métodos indiretos de prospecção. Já os métodos diretos permitem o acesso aos materiais e se constituem num conjunto de técnicas representado pelas sondagens (perfurações), poços, galerias e trincheiras. $O$ acesso possibilita a coleta de amostras e a caracterização em laboratório (ensaios físicos e químicos).

Dentro do conjunto de métodos diretos de investigação existem as sondagens rotativas diamantadas. Apesar de ocasionalmente realizado em solo, este método é essencialmente aplicado a rochas em diversas áreas tecnológicas, como pesquisa mineral, geotecnia, hidrogeologia e geologia ambiental. Baseia-se na aplicação de rotação ao eixo longitudinal de um tubo pressionado sobre a rocha; sendo a superfície de contato do tubo constituída de material com elevada dureza (diamante industrial ou widia), ela, por meio de um processo de abrasão, corta a rocha, avançando a perfuração. A vantagem dessa técnica é a possibilidade de preservação de amostras pouco perturbadas no interior do tubo. Quando a sondagem apresenta altas taxas de recuperação, as amostras obtidas são um importante subsídio para a caracterização do material, tanto pela análise táctil-visual quanto pelos ensaios laboratoriais que permitem.

As sondagens para prospecção são geralmente descendentes e, em muitos casos, verticais. A geologia, através do comportamento espacial das estruturas, pode determinar uma direção e um mergulho diferentes da vertical em sondagens, tentando obter a maior perpendicularidade possível do furo em relação a essas estruturas. Furos ascendentes, executados principalmente a partir de galerias, são restritos a tipos muito especiais de empreendimentos, como barragens, por exemplo. Geralmente, esses furos são realizados 
para tratamento de maciços (p.e. cortinas de injeção).

Altas taxas de recuperação não ocorrem sempre nesse tipo de investigação. Existem diversas técnicas e equipamentos para que a amostragem represente todo o trecho perfurado (recuperação de 100\%). Ainda assim, ocorrem situações, tanto pelas características da litologia como pela sua posição no perfil de intemperismo, que determinam perda de amostras e diminuição nas taxas de recuperação da sondagem. Quando isso acontece, a sondagem rotativa carece de elementos para a classificação das rochas e dos maciços. Mesmo em maciços que possibilitam altas taxas de recuperação, é comum a intercalação de materiais de baixa resistência, difíceis de serem amostrados e precisamente posicionados. Dependendo da obra de engenharia a que se destina a sondagem, as características desses materiais seriam de grande interesse para o projeto, uma vez que geralmente representam "fraquezas" do maciço. Todas as possibilidades de obtenção de parâmetros em laboratório para esses materiais também ficam comprometidas, devido à ausência das amostras.

Apesar dessas dificuldades na interpretação dos resultados das sondagens rotativas diamantadas, existem sempre dados relativos às condições de perfuração e às respectivas "respostas" do terreno que não são sistematicamente aproveitados na classificação. Essas informações constituem os chamados "parâmetros de perfuração" ou "parâmetros de sondagem".

\subsection{Histórico e objetivos}

O monitoramento da perfuração originou-se na indústria do petróleo, onde existem processos e técnicas desenvolvidos para a perfuração de poços exploratórios e de produção com grandes diâmetros e profundidades de até milhares de metros. A partir da década de 1970, a idéia do monitoramento da perfuração foi adaptada para a área de prospecção geológico-geotécnica, utilizando-se de perfuratrizes destrutivas rotopercussivas pneumáticas.

O presente trabalho adaptou a idéia desse monitoramento já realizados em furos destrutivos, para uma sondagem com amostragem, ou seja, uma sondagem rotativa diamantada. Inicialmente, a aplicação do sistema de monitoramento foi direcionada para a utilização na identificação e classificação de zonas fraturadas em maciços rochosos (aqüiferos fraturados), para a prospecção de água subterrânea em terrenos cristalinos.

A aplicação mais direta dos resultados em geotecnia e as limitações dos recursos determinaram alterações no escopo do projeto. O trabalho passou a concentrar-se na utilização desses parâmetros na classificação geotécnica dos materiais perfurados e na 
obtenção de correlações com outros parâmetros de laboratório, tais como resistência à compressão uniaxial (RCU), resistência à compressão puntiforme $\left(\mathrm{Is}_{(50)}\right)$, velocidade de propagação de ondas ultra-sônicas, além dos índices físicos das rochas. Esses parâmetros de laboratório são freqüentemente utilizados em modelos geomecânicos.

Um dos furos remanescentes permitiu a realização de perfilagens geofísicas. Os testemunhos recuperados forneceram as amostras para a realização dos ensaios de laboratório. A verificação de correlações entre essas duas fontes distintas de informações do maciço e os parâmetros de perfuração passou a ser um dos objetivos do trabalho.

Como objetivo intermediário, foram necessários o desenvolvimento e os testes do equipamento para o monitoramento da perfuração rotativa.

Para atendimento dos objetivos iniciais (hidrogeologia de aquíferos fraturados), a pesquisa bibliográfica englobou tópicos relacionados a maciços fraturados e a sua hidrogeologia: (a) fatores determinantes do fluxo, técnicas de investigação direta e indireta, ensaios de campo etc. Da mesma forma, foram realizados estudos para a caracterização física da área onde havia o "interesse hidrogeológico". A área escolhida, na zona leste do município de São Paulo, era uma antiga fazenda, com 1,7 milhões de metros quadrados, onde a Companhia de Habitação e Desenvolvimento Habitacional do Estado de São Paulo CDHU vem implantando conjuntos habitacionais populares. Apesar de a área hoje não apresentar mais problemas de abastecimento pela rede pública, a região já possuiu essa restrição, atestada pelo seu histórico na CDHU e pela grande quantidade de poços tubulares profundos existentes no entorno, principalmente a oeste do terreno. Nessa região, existem porções com usos rural (chácaras, áreas de cultivo hortifrutigranjeiro) e industrial. A manutenção e manipulação de materiais perigosos (classe 3) em instalações clandestinas também foi justificativa para o interesse da hidrogeologia dessa região.

Na região, foi realizado o mapeamento geológico-estrutural para a identificação dos reflexos locais dos eventos tectônicos mais recentes e, conseqüentemente, do estado de tensão dos maciços. As condições de abertura das fraturas e o fluxo da água subterrânea que elas geram nos maciços fraturados são diretamente determinados por esse histórico recente. Toda a pesquisa sobre a área selecionada para os testes e sobre o fraturamento de maciços e hidrogeotecnia foi retirada do presente texto, com a mudança do escopo do trabalho.

O estudo propõe ainda a utilização de um sistema para o monitoramento de sondagens rotativas, visando o registro das condições de execução da perfuração rotativa: 
velocidade de rotação e torque aplicados à coluna de perfuração. Também são registrados o deslocamento durante o avanço da perfuração, a rotação do eixo do motor, as pressões no sistema hidráulico da sonda, a pressão na linha de água, as vazões de entrada e saída e a temperatura do fluido de refrigeração. A variável tempo é controlada por meio da freqüência de amostragem do sistema.

A pesquisa procurou investigar se a própria perfuração poderia ser tratada como um ensaio contínuo através do maciço, nas suas variações petrográficas e mineralógicas e nos seus variados graus de alteração, coerência e fraturamento, contribuindo com novas informações para a determinação das condições geológico-geotécnicas. A comprovação dessa tese é buscada por meio da montagem do sistema de monitoramento, realização de testes e execução de ensaios no campo e em laboratório, para a obtenção de correlações significativas com os parâmetros obtidos com a execução do furo.

Além das informações adicionais de caráter classificatório, os parâmetros de perfuração podem também ser considerados uma forma de controle da qualidade executiva da sondagem.

Cita-se ainda a possibilidade da aplicação do monitoramento em outras áreas que utilizam esse tipo de sondagem, tais como pesquisa mineral, meio ambiente e hidrogeologia (aqüíferos fraturados).

\subsection{Estruturação da tese}

No presente trabalho, a divisão dos capítulos separa os assuntos e atividades da seguinte forma:

O Capítulo 2 apresenta e discute a metodologia do trabalho, desde a pesquisa bibliográfica dos assuntos envolvidos, até os trabalhos de gabinete e de campo; os testes individuais em laboratório, com os sensores, e em campo, com o sistema completo de monitoramento.

O Capítulo 3 resume os trabalhos levantados na pesquisa bibliográfica. Os temas de interesse acabaram abrangendo assuntos diversos: (a) descrição dos instrumentos e métodos de medida das grandezas físicas envolvidas; (b) perfuração rotativo-abrasiva; (c) técnica da diagrafia instantânea ou monitoramento de sondagem para furos destrutivos (rotativotricônico ou rotopercussivo); e (d) parâmetros de classificação e classificações geomecânicas. 
O Capítulo 4 descreve detalhadamente o protótipo do sistema de monitoramento desenvolvido, as características de cada sensor e os resultados dos testes de calibração em laboratório.

O Capítulo 5 descreve as etapas de desenvolvimento do protótipo do torsiômetro e o seu princípio de funcionamento.

O Capítulo 6 concentra-se na análise e discussão das informações obtidas: resultados dos testes de perfuração, das perfilagens geofísicas realizadas no furo e dos ensaios de caracterização realizados nos testemunhos, discutindo as possibilidades do aproveitamento dos resultados do monitoramento na classificação de maciços.

Finalmente, o Capítulo 7 apresenta as conclusões do trabalho, discutindo as dificuldades de implantação dessa técnica de pesquisa e apresentando propostas para a continuidade do estudo, tanto no que se refere a equipamentos, quanto à aplicação dos resultados. 


\section{METODOLOGIA DO TRABALHO}

O trabalho proposto pode ser dividido em três conjuntos de atividades. O primeiro refere-se à pesquisa bibliográfica dos temas relacionados à proposta ("monitoramento da perfuração" ou "diagrafia instantânea", "sondagens rotativas abrasivas", "caracterização e classificação geomecânica de maciços"). O segundo, à concepção, especificação e aquisição dos equipamentos relacionados ao monitoramento. E, finalmente, o terceiro, aos testes do protótipo de monitoramento da perfuração, que foram realizados em duas etapas: testes de calibração do equipamento (laboratório) e testes do equipamento em condições de operação.

Associada ao último conjunto, destaca-se a atividade de avaliação da técnica do monitoramento de sondagens rotativas com amostragem, ou seja, a determinação das possibilidades e dificuldades de sua aplicação prática, na presente pesquisa, para a classificação geológico-geotécnica.

\subsection{Pesquisa bibliográfica}

O primeiro conjunto de atividades forneceu informações básicas sobre: (a) equipamentos de perfuração rotativa utilizados na prospeç̧ão geológica; (b) técnica do monitoramento da perfuração destrutiva e suas principais aplicações; (c) transdutores (sensores) e a aquisição de dados automatizada; e (d) tratamento dos resultados obtidos.

\subsubsection{Parâmetros monitorados, instrumentação e tipos de sensores}

De modo geral, nas geociências, embora haja grande potencial, principalmente em atividades relacionadas à geologia aplicada, a utilização de instrumentação não pode ser considerada uma ferramenta comum. Especificamente para a geologia de engenharia ou a geotecnia, é mais comum a utilização desse recurso, existindo inclusive bibliografia básica sobre o assunto (DUNNICLIFF, 1988).

Partindo-se do tipo de equipamento de perfuração (sonda e bomba d'água), com base na bibliografia sobre instrumentação, foram levantadas informações e conceitos para o entendimento do sistema de monitoramento.

Foram pesquisados os tipos de aparelhos disponíveis no mercado: princípios de funcionamento, faixas de variação dos parâmetros, precisão, adequação às condições de campo, custos etc. Essa etapa determinou os tipos e características dos equipamentos que foram posteriormente adquiridos. Destacam-se, para esse tema, as abordagens de FRADEN 
(1993), DUNNICLIFF, J. (1988) e WOLFF \& MERCANTI (1974), além de catálogos de diversos fabricantes (LYNX s.d.; TML s.d.; BALLUFF, s.d.; NIKON DWYLER s.d.; HBM, s.d. etc.).

2.1.2. Equipamentos de perfuração rotativo-abrasiva

Objetivando a melhor compreensão do método de perfuração rotativo-abrasiva e dos equipamentos utilizados na sua execução, bibliografias específicas (SERRA Jr., 1991) e catálogos de alguns fabricantes (SONDEQ, s.d.; MAQUESONDA, s.d.; DIAMANGEO, s.d.) foram consultados.

2.1.3. Técnica do monitoramento de perfuração (diagrafia instantânea)

Apesar da técnica do monitoramento da perfuração não ser muito difundida, principalmente no Brasil, existe uma grande quantidade de trabalhos no exterior sobre o método e suas aplicações. A maioria das referências sobre diagrafia instantânea foi selecionada de PEREDA (1998), SILVA (1995), SCARMÍNIO (1988) e GIRARD (1985).

\subsection{Desenvolvimento do protótipo para o monitoramento}

A concepção do sistema de aquisição de dados foi baseada na arquitetura proposta por TAIOLI (1992) e TAIOLI (1999). A partir dessa concepção inicial do sistema, foram selecionadas as possibilidades relativas aos tipos de sensores e, finalmente, escolhidos os mais adequados, considerando, principalmente: (a) a disponibilidade junto a fornecedores nacionais; (b) os custos envolvidos; e (c) os recursos disponíveis. O desenvolvimento do protótipo passou à fase de testes individuais dos transdutores e ao desenvolvimento do programa de aquisição.

\subsubsection{Testes em laboratório}

Essa etapa correspondeu à fase de testes para calibração dos transdutores. Nessa fase, foi também iniciada a adaptação do programa de computador para a comunicação entre o Conversor $\mathrm{AD}$ e o microcomputador. Nessa etapa, foram desenvolvidas as adaptações físicas para a instalação de alguns sensores (em especial, os de deslocamento e velocidades de rotação). A calibração foi realizada correlacionando-se as grandezas físicas monitoradas com o respectivo sinal produzido pelo sensor (tensão na maioria dos casos). Foram consideradas aceitáveis correlações com ajustes lineares e coeficientes de Pearson maiores que 0,95 . 


\subsubsection{Testes com a sonda em funcionamento ( $1^{\text {a }}$ etapa de testes)}

Uma vez desenvolvido o software de aquisição, todos os sensores foram testados em conjunto, nas condições de operação da sonda. Para isso, realizou-se um primeiro furo monitorado na área do Instituto de Geociências (IGc), campus da Universidade de São Paulo. Esse furo permitiu a obtenção dos primeiros parâmetros de perfuração em solos, sedimentos inconsolidados e rocha. Apesar do objetivo dessa etapa relacionar-se apenas ao teste do sistema de monitoramento com a sonda em funcionamento, algumas considerações sobre a aplicabilidade do método na prospecção geológico-geotécnica e ajustes na forma de obtenção dos dados puderam ser realizados. Essa etapa provocou sensíveis alterações no trabalho, tendo sido, então, decidido desenvolver um equipamento específico para avaliar o torque envolvido na perfuração.

Nessa etapa, foi dada ênfase especial à avaliação da pressão sobre a superfície da ferramenta de corte, considerando-se para isso todos os fatores envolvidos: (a) força exercida pelo hidráulico da sonda; (b) peso da coluna de perfuração; e (c) empuxo determinado pela imersão no fluido de perfuração.

\subsubsection{Testes com a sonda em campo ( $2^{\mathrm{a}}$ etapa de testes)}

$\mathrm{Na}$ etapa final do trabalho, realizou-se o teste do equipamento em condições de operação em campo. Essa etapa, inicialmente prevista para ser realizada na zona leste do município de São Paulo, devido às alterações feitas no escopo do trabalho, acabou também sendo realizada na área do $\mathrm{IGc}$, em condições semelhantes às dos "testes do equipamento de perfuração em operação".

Essa alteração objetivou: (a) facilitar o apoio logístico; (b) diminuir os custos de deslocamento; e (c) permitir maior agilidade para ajustes e para a solução dos problemas durante a execução dos furos.

As amostras e os dados relativos às condições de execução dos furos, em conjunto com os dados das perfilagens geofísicas neles realizadas, forneceram os subsídios para a avaliação da potencialidade do método na classificação geológico-geotécnica de rochas e maciços. Devido à descontinuidade dos trechos monitorados, a correlação com a perfilagem geofísica ficou prejudicada.

Todos os furos foram executados segundo a metodologia proposta por ABGE (1990). As classificações de fraturamento e alteração basearam-se em IPT (1984). A classificação de coerência, em GUIDICINI et. al. (1972). 
Diferentemente da primeira etapa de testes, nessa segunda não foi dado destaque à interpretação e nem à avaliação da pressão sobre a ferramenta de corte. O torque, novo parâmetro monitorado a partir dessa etapa, permitiu que esse controle fosse realizado indiretamente. Outros fatores relacionados à forma de operação da sonda contribuíram ainda para essa decisão.

Um fator importante a ser destacado na fase de testes refere-se às dificuldades não previstas na sua real dimensão, e que podem ser resumidas em: (a) falta de infra-estrutura para a realização dos furos no IGc; (b) idade avançada e estado de conservação precário dos equipamentos disponíveis (sonda e bomba); (c) carência de mão-de-obra especializada disponível (sondador); e (d) geologia (cobertura da rocha por solos sedimentares arenosos da Formação Resende). Esses fatores determinaram que fossem despendidos trabalho e recursos para a realização do furos, atividade que não era o objetivo final da pesquisa, mas apenas uma forma de obtenção dos dados.

\subsection{Integração dos resultados}

Os resultados das investigações referem-se, basicamente: (a) aos perfis de sondagens obtidos pela descrição dos testemunhos da perfuração em rocha (sondagem rotativa convencional); (b) aos perfis obtidos por meio da perfilagem geofísica dos furos; e (c) às informações relativas ao monitoramento da perfuração.

Os resultados obtidos em (a) e (b) forneceram, separadamente, informações sobre as respostas do terreno em função das condições de perfuração impostas. O trabalho pretendia correlacionar os dados de (a) e (b) com a interpretação dos resultados do monitoramento (c), visando avaliar o potencial da técnica do monitoramento da perfuração; porém a descontinuidade dos dados obtidos no monitoramento, ou seja, a intercalação de trechos com e sem os dados, comprometeu esse objetivo.

Ensaios de resistência mecânica foram executados nas amostras obtidas, especificamente, Resistência à Compressão Uniaxial (RCU) e Resistência à Compressão Puntiforme $\left(\mathrm{Is}_{(50)}\right)$. Procurou-se estabelecer correlações entre esses resultados e os índices obtidos, pontualmente, durante a perfuração da rocha. 


\subsubsection{Furos monitorados}

Foram avaliados os parâmetros de perfuração dos diversos materiais naturais (solos e rochas), nos seus diferentes graus de alteração e fraturamento. Os parâmetros de classificação utilizados são apresentados e discutidos no trabalho.

A forma de análise dos dados do monitoramento proposta foi desenvolvida no decorrer do trabalho, baseando-se principalmente nas abordagens de CLARK (1979) e TEALE (1965). Com uma finalidade diferente, DEKETH (1995) também apresenta conceitos análogos.

\subsubsection{Perfilagem geofísica no furo remanescente}

O furo realizado no teste de campo (segunda etapa) foi perfilado com uso de métodos geofísicos, com o objetivo de coletar informações que auxiliassem a avaliação da técnica do monitoramento da perfuração.

O levantamento de campo foi realizado com o equipamento do Instituto de Astronomia e Geofísica (IAG) da USP, sob a coordenação do Prof. Dr. Carlos Alberto Mendonça. Os métodos utilizados foram: (a) eletrorresistividade (métrica e microresistividade); (b) gama natural; e (c) caliper.

O equipamento utilizado foi um perfilador portátil Geologger 3030 (Oyo Corporation, Japan - Figura 2.1). O equipamento é composto por: (a) unidade de processamento; (b) bloco conector (transferencia dos dados digitais, gravados em formato específico, do equipamento para um microcomputador); (d) módulo de medida, para a entrada de dados de cada sonda específica; (e) módulo de armazenamento para a gravação dos dados em disquetes 3,5 "; e (f) módulo de impressão para a produção dos perfis, ainda no campo.

O equipamento introduzido no interior do furo a ser perfilado também é denominado sonda. No trabalho foi utilizado um modelo GW 3433 (Figura 2.2), que realiza medidas de raios gama, resistividade elétrica normal, curta e longa, e de potencial espontâneo. $O$ espaçamento entre cada medida pode variar entre 1 e 20 centímetros.

A contagem de emissão de raios gama foi realizada por meio de um cintilômetro de iodeto de sódio ativado com tálio, embutido na sonda. O equipamento contém ainda os eletrodos de potencial $M_{1}$ e $M_{2}$ e o eletrodo de corrente $A$. Entre os eletrodos $N$ e $M_{1}$ e $N$ e $M_{2}$, espaçados de 40,64 e $162,60 \mathrm{~cm}$ (16 e 64 polegadas) do eletrodo $A$, respectivamente, 
medem-se as tensões que, em função da geometria do arranjo, permitirão o cálculo das resistividades normal, curta e longa (Figura 2.2). A velocidade de deslocamento varia normalmente entre três e quatro metros por minuto. Foram realizados perfis descendentes e ascendentes para comparação dos resultados

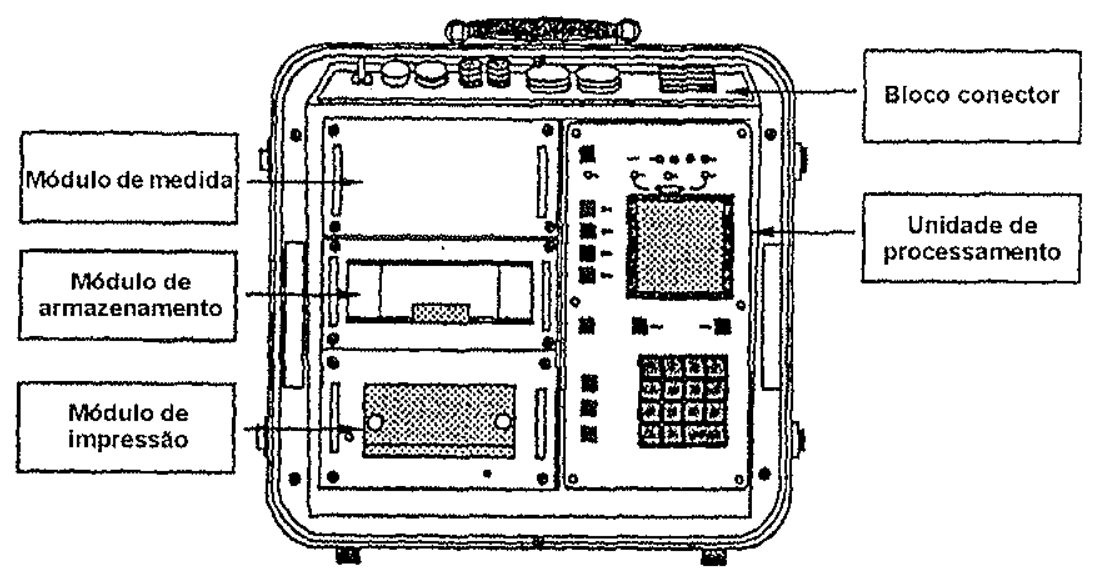

Figura 2.1 - Vista do Geologger 3030 (BOLOGNA, 1996).

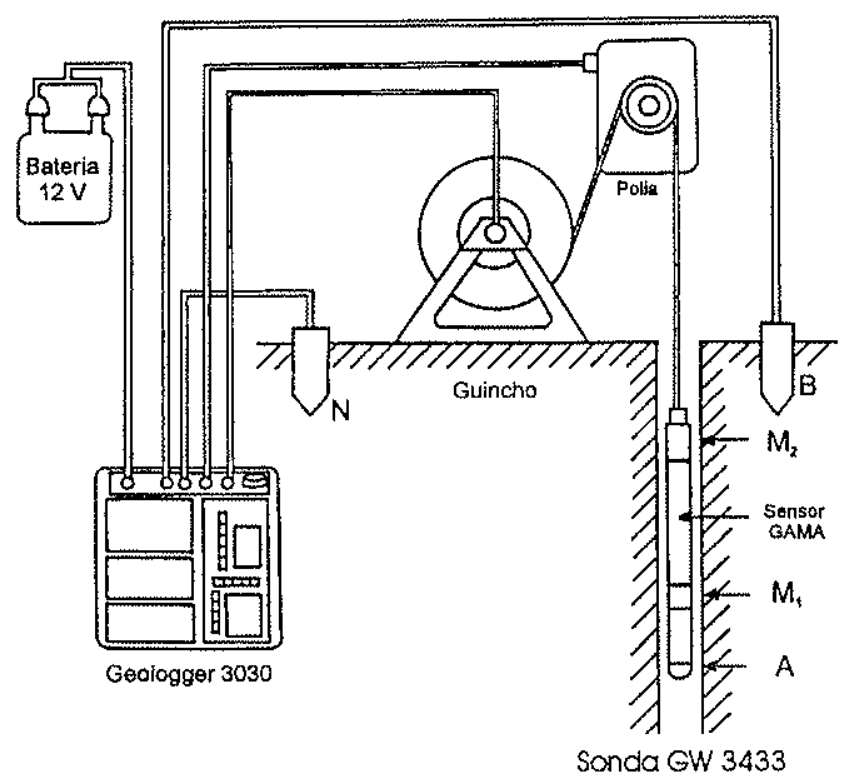

Figura 2.2 - Configuração básica de perfilagem utilizando a sonda GW 3433 (BOLOGNA, 1996).

\subsubsection{Ensaios em laboratório nas amostras obtidas}

Os registros do monitoramento, embora descontínuos, possuem espaçamentos pequenos ao longo do furo, variando, de acordo com a velocidade de avanço, de milimétrico a centimétrico (no caso de rocha). Sendo assim, sua representação pôde ser realizada em 
diversos intervalos. $\mathrm{Na}$ tentativa de obter-se correlações entre os índices propostos no trabalho e outros parâmetros geotécnicos utilizados em classificações geomecânicas, foram realizados ensaios de Resistência à Compressão Uniaxial (RCU) e de Resistência Puntiforme $\left(\operatorname{Is}_{(50)}\right)$ nos testemunhos de rocha obtidos. A determinação dos índices físicos, da resistência à compressão uniaxial e da resistência à compressão puntiforme das amostras foram realizadas segundo as normas NBR 12.766 (ABNT, 1992a), NBR 12.767 (ABNT, 1992b) e segundo a metodologia preconizada em ISRM (1985), respectivamente.

As análises petrográficas basearam-se nas orientações da norma NBR 12.768 (ABNT, 1992c). LE MAITRE (1989) e WINKLER (1976) forneceram os critérios para a classificação petrográfica das lâminas descritas. 


\section{REVISÃO BIBLIOGRÁFICA}

O presente trabalho propõe o desenvolvimento de um protótipo para $o$ monitoramento de uma sonda rotativa, equipamento bastante utilizado em prospecção mineral e geotecnia, procurando aplicar as informações adicionais obtidas na caracterização e classificação dos materiais perfurados. Dessa forma, a revisão bibliográfica concentrou-se nos seguintes tópicos: (a) descrição dos instrumentos e métodos de medida dos parâmetros envolvidos na perfuração; (b) perfuração rotativo-abrasiva; (c) equipamentos e o método executivo da sondagem rotativa; (d) técnica do monitoramento da perfuração ou diagrafia instantânea e (e) geologia regional da área dos testes de perfuração.

\subsection{Sistema automatizado para aquisição de dados}

A aquisição de dados realizada no monitoramento da sondagem rotativa refere-se a uma atividade genericamente denominada instrumentação e controle. A pesquisa bibliográfica mostrou que o tema é mais freqüente em algumas áreas da engenharia. A instrumentação é uma ferramenta utilizada em diversas áreas industriais, geralmente relacionada a acompanhamento e controle de processos. Como exemplo, cita-se a instrumentação na engenharia civil, realizada em estruturas de concreto e em geotecnia, ou ainda, na área química industrial, onde é aplicada no controle dos processos de produção.

A terminologia oficial utilizada na área de metrologia é definida por INMETRO (1995). A partir de uma "grandeza (mensurável)" (INMETRO, op.cit.), ou seja, "do atributo de um fenômeno, corpo ou substância que pode ser qualitativamente distinguido e quantitativamente determinado", por meio de um conjunto de operações, conhecido como medição, determina-se o seu valor, que é a "expressão quantitativa da grandeza específica" (INMETRO, op.cit.).

$O$ início da instrumentação ocorre com a instalação do transdutor ou sensor. $O$ termo transdutor refere-se a "qualquer dispositivo capaz de transformar um tipo de sinal em outro, com o objetivo de transformar uma forma de energia em outra e possibilitar o controle de um processo ou fenômeno, ou realizar uma medição" (FERREIRA, 1986). O termo sensor em português possui um significado mais amplo. Apesar de originalmente relacionado a equipamentos para localização de alvos (p.e. radares, sonares), atualmente o termo refere-se também a dispositivos tipo transdutores. Provavelmente essa abrangência maior deve-se ao termo homônimo em inglês ("sensor") possuir esse significado mais amplo. Apesar dessa sutil diferença nos significados, ambos acabam se tornando equivalentes no presente trabalho.

\subsubsection{Sensores - conceitos básicos e características}

Diversos autores (WOLFF \& MERCANTI, 1974; FRADEN, 1993; ISMAIL et al., 1998; WEBSTER, 1999) tratam especificamente de sensores e instrumentação, apresentando 
definições e conceitos básicos. Segundo FRADEN (1993), sensor é um "dispositivo que recebe e responde a um sinal ou estímulo com um sinal elétrico", onde o estímulo é entendido como uma propriedade física, geralmente, não elétrica. O sinal de resposta é dado na forma de tensão, corrente ou carga elétrica, o que permite sua condução e amplificação por equipamentos eletrônicos. O termo "estímulo" de FRADEN (op.cit.) corresponde ao que WOLFF \& MERCANTI (1974) denominam mensurando ("measurand"), ou seja, a grandeza física submetida à medição (INMETRO, 1995).

Os sensores podem ser divididos em dois tipos básicos: ativos e passivos. Os passivos geram um sinal elétrico diretamente em resposta a uma excitação externa. Assim o estímulo de entrada é convertido pelo sensor em energia de saída, sem a necessidade de uma fonte adicional (e.g. termopares, sensores piroelétricos e sensores piezoelétricos). Já os sensores ativos necessitam de energia externa para sua operação, denominada de sinal de excitação (FRADEN, op.cit.).

A relação teórica ideal entre o estímulo e o sinal de saída do sensor é chamada função de transferência, a qual pode ser uma simples correlação linear ou outro tipo de relação (exponencial, logarítmica ou de potência). Pode ocorrer que nenhuma dessas funções produza um ajuste satisfatório. Nesses casos, podem ser utilizadas funções polinomiais de ordens mais elevadas (FRADEN, op.cit.).

A faixa dinâmica do parâmetro de entrada ou estímulo é freqüentemente representada em "decibel", uma medida logarítmica das relações de potência ou "força" (corrente ou tensão). Decibel não se relaciona à medida de valores absolutos, e sim, à relação entre valores. As relações entre potências $(P)$ ou entre correntes ou tensões $(s)$ são apresentadas pelas expressões 3.1. e 3.2, respectivamente.

$$
d B=10 \log \frac{P_{2}}{P_{1}} \quad(3.1) \quad d B=20 \log \frac{s_{2}}{s_{1}}
$$

Os limites de variação da grandeza física para o sensor são chamados de faixa do sensor ("range") e os respectivos sinais de saída de pontos finais ("end points"). O valor algébrico obtido pela diferença entre esses extremos é a amplitude ("span") do sensor. A correspondente diferença algébrica para o sinal do sensor é chamada de escala completa ("full scale output - FSO"), algumas vezes representada com o sinal $\Perp$, pela metade desse valor (p.e. $\mathrm{FSO}=5,0 \mathrm{~V}$ ou $\pm 2,5 \mathrm{~V}$ ). 
Teoricamente, a presença de um instrumento de medida não deveria alterar o valor do parâmetro medido. Se isso acontecer de forma significativa, ocorre o que DUNNICLIFF (1988) denomina de "baixa conformidade" do sensor.

A realização de medidas sempre envolve erros e incertezas, os quais possuem origens diversas (INMETRO, 1998). Geralmente o erro é definido como a diferença entre o valor medido ou indicado pelo sensor e o "valor verdadeiro de uma grandeza", aquele que seria obtido por uma medição perfeita (INMETRO, 1995). Além do valor absoluto dessa diferença, normalmente o erro é expresso na forma de porcentagem da escala completa (FSO "Full Scale Output"), algumas vezes como porcentagem do próprio valor da leitura.

O erro no sinal possui uma correspondência no parâmetro físico. Dessa forma é definido o grau de correção ou exatidão ("accuracy") do sensor, ou seja, a diferença máxima de uma medida com relação ao seu valor verdadeiro.

Já o conceito de precisão ou repetitividade ("precision" ou "repeatability") relaciona-se à proximidade de cada medida da média aritmética de um conjunto de leituras. INMETRO (op.cit.) define repetitividade como o "grau de concordância entre os resultados de medições sucessivas de um mesmo mensurando, efetuada sob as mesmas condições de medição". O número de algarismos significativos na medida reflete a precisão do instrumento.

Os erros representados nas situações (a) e (b) da Figura 3.1 são chamados de sistemáticos e aleatórios, respectivamente.

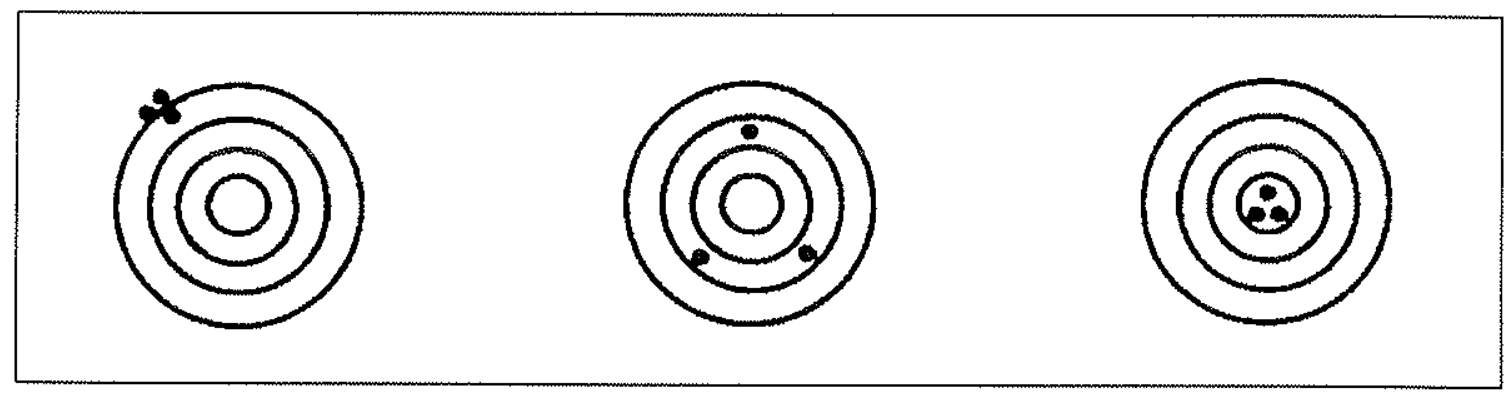

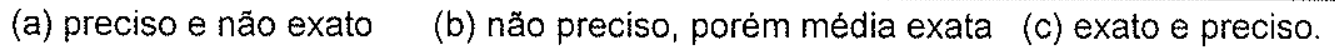

Figura 3.1 - Diferença entre os conceitos de precisão e exatidão (DUNNICLIFF, 1988).

O erro pode possuir outras origens específicas:

- Histerese ("hysteresis") é a diferença máxima do sinal de saída em todos os valores, dentro da escala completa (FSO), quando se compara o ciclo de aumento e o de diminuição do parâmetro medido. Normalmente é apresentada na forma de porcentagem da escala completa (FSO) (Fig. 3.2); 
- Erro de linearidade ("non-linearity") é a deflexão máxima a partir de uma reta dos valores do sinal de saída do transdutor, entre os valores mínimo e máximo da escala nominal, sendo expresso como porcentagem da saída nominal ("rated output") (Fig.3.2).

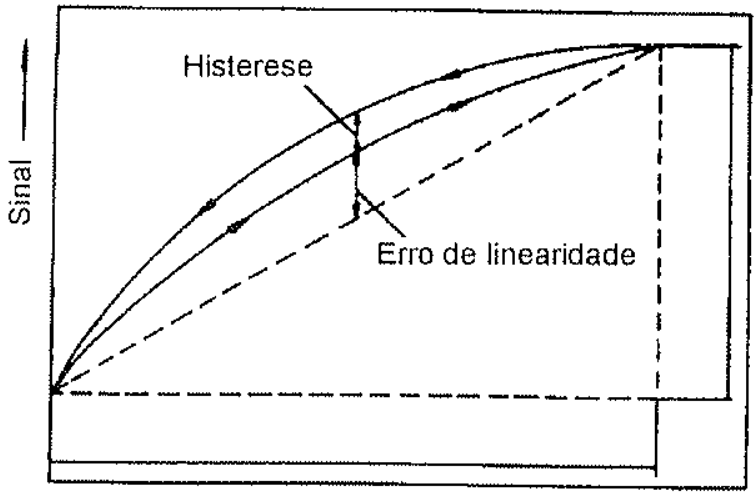

(a)

Carregamento

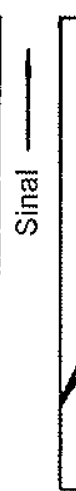

(b)

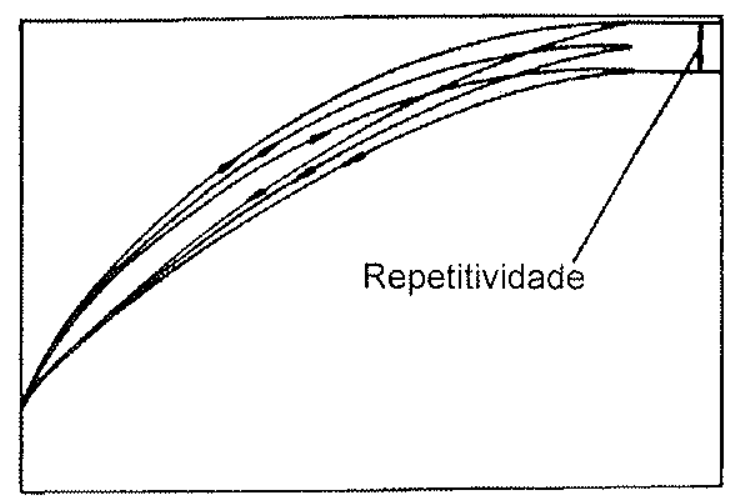

Carregamento

Figura 3.2 - Representação dos erros de histerese, linearidade (a) e repetitividade (b).

DUNNICLIFF (1988) apresenta uma classificação dos erros e sugestões para diminuição de seus efeitos (Quadro 3.1).

Quadro 3.1 - Causas e soluções dos erros de medida (modificado de DUNNICLIFF, 1988).

\begin{tabular}{|c|c|c|}
\hline Tipo de Erro & Causas & Soluções \\
\hline Erros Grosseiros & $\begin{array}{l}\text { - Inexperiencia } \\
\text { - Perda de leitura e } \\
\text { gravaçăo } \\
\text { - Erros computacionais }\end{array}$ & $\begin{array}{l}\text { - Cuidado e treinamento } \\
\text { - Leituras duplicadas } \\
\text { - Checagem com leituras prévias }\end{array}$ \\
\hline Erros Sistemáticos & $\begin{array}{l}\text { - Calibração imprópria } \\
\text { - Perda de calibração } \\
\text { - Histerese } \\
\text { - Erro de linearidade }\end{array}$ & $\begin{array}{l}\text { - Uso da calibração correta } \\
\text { - Recalibração } \\
\text { - Uso de padrões } \\
\text { - Uso de procedimentos de leitura consistentes }\end{array}$ \\
\hline Erros de Conformação & $\begin{array}{l}\text { - Instalação não } \\
\text { apropriada } \\
\text { - Limitação do } \\
\text { instrumento }\end{array}$ & $\begin{array}{l}\text { - Escolha do instrumento certo } \\
\text { - Modificaçăo no procedimento de instalação } \\
\text { - Novo projeto do instrumento }\end{array}$ \\
\hline Erros ambientais & $\begin{array}{l}\text { - Tempo e temperatura } \\
\text { - Vibração e corrosão } \\
\text { - Outras variações } \\
\text { ambientais }\end{array}$ & $\begin{array}{l}\text { - Registro das mudanças ambientais e } \\
\text { aplicação de correçôes } \\
\text { - Escolha correta do material dos instrumentos }\end{array}$ \\
\hline Erro aleatório & $\begin{array}{l}\text { - Ruído } \\
\text { - Atrito } \\
\text { - Efeitos ambientais }\end{array}$ & $\begin{array}{l}\text { - Escolha correta dos instrumentos } \\
\text { - Eliminação temporária do ruído } \\
\text { - Múltiplas leituras } \\
\text { - Análises estatisticas }\end{array}$ \\
\hline Lei de Murphy & $\begin{array}{l}\text { - Se algo errado pode } \\
\text { acontecer, acontecerá }\end{array}$ & $\begin{array}{l}\text { - Nenhuma - qualquer tentativa de remediação, } \\
\text { irá apenas tornar as coisas piores }\end{array}$ \\
\hline
\end{tabular}


A resolução ("resolution") do sensor está diretamente relacionada à sua capacidade de discriminar dois valores próximos do parâmetro físico medido. Quanto menor for essa diferença, maior será a resolução do sensor. Em sistemas digitais, a resolução é usualmente expressa em número de bits utilizados pelo conversor analógico/digital (A/D).

\section{- Fatores ambientais}

FRADEN (1993) define condições de armazenamento como os limites ambientais não operacionais, para os quais um sensor pode ser submetido durante um período específico, sem alterar permanentemente seu funcionamento, em condições operacionais normais. Condições de armazenamento incluem usualmente: valores máximo e mínimo de umidade, e temperatura. Menos freqüentes são limites especificados de pressão máxima ou presença de gases ou vapores contaminados.

Ainda segundo FRADEN (op.cit.), o fator temperatura é muito importante para o desempenho do sensor, tanto que, em alguns casos, a exatidão do aparelho é estabelecida em faixas de temperatura dentro da faixa total de operação do sensor.

\section{- Características dinâmicas}

São características do sensor que variam com o tempo. Se a resposta do sensor não é instantânea, o sensor responde com um erro dinâmico. Esse erro varia com o tempo, diferentemente do que ocorre com o erro estático. O erro dinâmico permite definir o tempo de aquecimento ("warm-up time"), que é o intervalo entre a aplicação do estímulo e o momento em que o sensor passa a operar com a exatidão especificada. $O$ tempo de aquecimento varia de valores despreziveis até alguns minutos.

A resposta em freqüiencia ("frequency response") especifica qual a velocidade de reação à mudança de estímulo. Essa característica é expressa em $\mathrm{Hz}$ ou rad/s.

\subsubsection{Tipos e arranjos clássicos com sensores}

\subsubsection{Extensômetro ("strain gage")}

Extensômetro ("Strain Gage") é um componente ou sensor ativo muito utilizado em diversos instrumentos. Basicamente é um condutor, onde a deformação sofrida resulta em uma correspondente alteração de sua resistência elétrica (efeito piezorresistivo). A relação entre as variações de resistência e comprimento é dada pela expressão:

$$
\frac{\Delta R}{R}=\frac{\Delta L}{L} \cdot G F
$$

onde, $R=$ resistência $(\Omega), L=$ comprimento $(\mathrm{m})$ e $G F=$ Fator gage ou sensitividade (adimensional) 
Existem cinco tipos básicos de extensômetros: (a) Fio colado ("Bonded Wire"), (b) Fio não-colado ("Unbonded Wire"), (c) Lâmina colada ("Bonded Foil"), (d) "Semiconductor" e (e) "Weldable" (DUNNICLIFF, 1988).

O extensômetro ("strain gage") tipo lâmina colada ("bonded foil") é um dos mais comuns, sendo composto por uma delgada lâmina metálica colada num fino filme elástico (Figura 3.3).

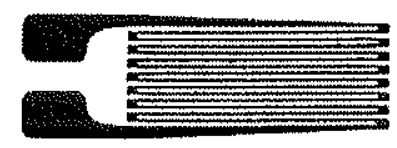

Figura 3.3 - Extensômetro ("strain gage") de lâmina colada uniaxial (DUNNICLIFF, 1988).

\subsubsection{Pontes de Wheatstone}

É comum a utilização de extensômetros ("strain gages") em Circuitos Pontes de Wheatstone (Figura 3.4), para a obtenção de precisão e sensibilidade nos arranjos. A tensão de corrente contínua $V s$ é aplicada nos pontos AC, produzindo um sinal Vo. Quando a ponte está balanceada, ou seja, quando a diferença de potencial $V_{0}$ é igual a zero, é válida a expressão:

$$
\frac{R_{1}}{R_{2}}=\frac{R_{4}}{R_{3}}
$$

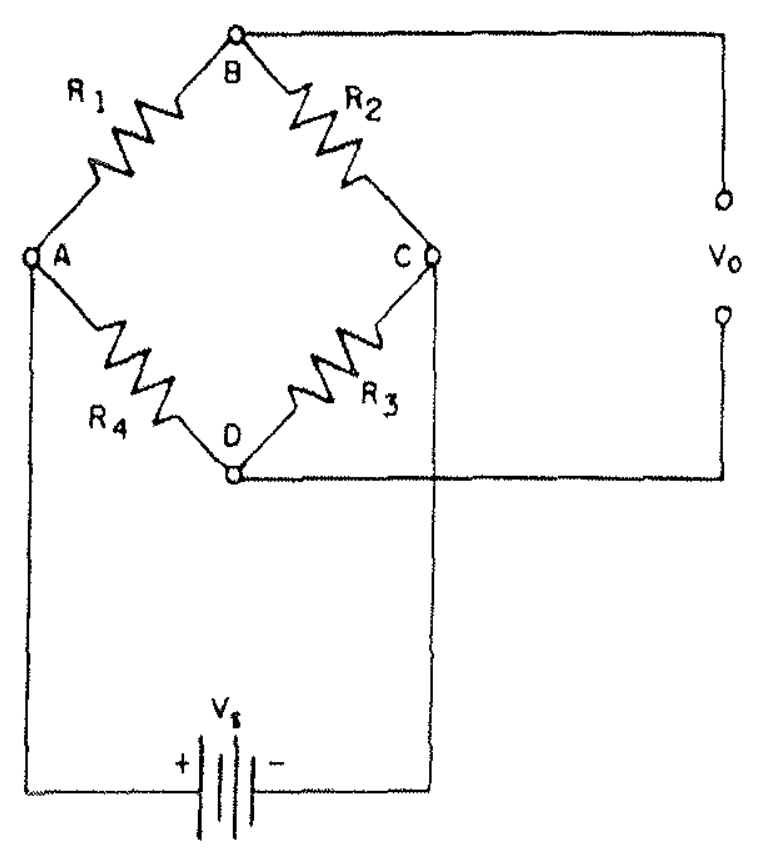

Figura 3.4 - Arranjo em Ponte de Wheatstone (ISMAIL et al., 1998). 
De acordo com o número de sensores ativos no arranjo, eles são classificados em $1 / 4$ de ponte (R1 ativo e R2, R3 e R4 componentes fixos), 1/2 de ponte (R1 e R3 ativos e R2 e R4 componentes fixos) e ponte completa (todos os elementos ativos).

Os arranjos com $1 / 4$ de ponte são os menos sensíveis e mais susceptíveis a variações térmicas, porém, bastante utilizados pela sua simplicidade e baixo custo. Nenhuma delas permite a correção das variações de temperatura no sensor ativo. Na montagem com três fios, é possível eliminar as variações de resistência geradas nos fios pelas variações de temperatura nos cabos.

Os arranjos com $1 / 2$ ponte praticamente eliminam os efeitos da temperatura. $O$ segundo sensor pode ser (a) inativo ou sensor de compensação, que utiliza o mesmo material do sensor ativo, montado fora do campo de tensões que se pretende medir, ou (b) ativo, nesse caso, podendo ser montado paralelo ou perpendicular ao primeiro.

Finalmente, os arranjos com ponte completa aliam alta sensibilidade com a completa compensação das alterações de temperatura nos sensores e ao longo dos cabos. As possibilidades de arranjo com Ponte de Wheatstone, vantagens e limitações estão resumidas no Quadro 3.2.

FRADEN (1993) classifica os sensores que medem posição e deslocamento em: (a) indutivos, (b) potenciométricos, (c) gravitacionais (detectores de inclinação), (d) termais, (e) capacitivos, (f) magnéticos e $(\mathrm{g})$ óticos. Desse grupo, os que foram selecionados para o protótipo do sistema de monitoramento foram os indutivos (velocidade de rotação) e os potenciométricos (posição). 
Quadro 3.2 - Arranjos de Pontes de Wheatstone (DUNNICLIFF, 1988).

\begin{tabular}{|c|c|c|c|c|}
\hline Arranjo & Tipo & Vantagens & Limitaçōes & Aplicações/FP' \\
\hline \multirow{2}{*}{$\begin{array}{c}\text { Quarto de } \\
\text { Ponte }\end{array}$} & $\begin{array}{l}\text { Sistema c/ Dois } \\
\text { Fios }\end{array}$ & $\begin{array}{l}\text { Mais barato e fácil } \\
\text { de usar }\end{array}$ & $\begin{array}{l}\text { Sensivel a mudanças de } \\
\text { temperatura no sensor } \\
\text { ativo e nos cabos. Baixa } \\
\text { linearidade em niveis } \\
\text { altos de deformação }\end{array}$ & $\begin{array}{l}\text { Apenas em laboratório / } \\
1.0\end{array}$ \\
\hline & $\begin{array}{l}\text { Sistema c/ Três } \\
\text { Fios }\end{array}$ & $\begin{array}{l}\text { Elimina erros } \\
\text { causados pela } \\
\text { mudança de } \\
\text { temperatura nos } \\
\text { cabos }\end{array}$ & $\begin{array}{l}\text { Sensivel a mudanças de } \\
\text { temperatura no sensor e } \\
\text { não linearidade em altos } \\
\text { niveis de deformação }\end{array}$ & $\begin{array}{l}\text { Mais comum em análise } \\
\text { de tensão/deformação } \\
\text { em estruturas / } 1.0\end{array}$ \\
\hline \multirow{3}{*}{$\begin{array}{l}\text { Meia } \\
\text { Ponte }\end{array}$} & $\begin{array}{l}\text { Um sensor ativo e } \\
\text { um inativo }\end{array}$ & $\begin{array}{l}\text { Sem efeito da } \\
\text { temperatura }\end{array}$ & $\begin{array}{l}\text { Sensor inativo deve ser } \\
\text { distensionado e colado } \\
\text { no mesmo material e à } \\
\text { mesma temperatura dos } \\
\text { sensores ativos }\end{array}$ & $\begin{array}{l}\text { Teste de longa duração } \\
\text { em estruturas onde as } \\
\text { variações de temperatura } \\
\text { são grandes e a precisão } \\
\text { requerida é elevada / } 1.0\end{array}$ \\
\hline & $\begin{array}{l}\text { Com os dois } \\
\text { sensores ativos } \\
\left(90^{\circ} \text { - Efeito }\right. \\
\text { Poisson })\end{array}$ & $\begin{array}{l}\text { Sem efeito da } \\
\text { temperatura }\end{array}$ & $\begin{array}{l}\text { Impróprios para campos } \\
\text { de tensão biaxial }\end{array}$ & 1.3 \\
\hline & $\begin{array}{l}\text { Com dois } \\
\text { sensores } \\
\text { inteiramente ativos }\end{array}$ & $\begin{array}{l}\text { Sem efeito da } \\
\text { temperatura }\end{array}$ & $\begin{array}{l}\text { Nem sempre é possivel } \\
\text { alcançar esse arranjo de } \\
\text { ponte }\end{array}$ & Sensores de torção / 2.0 \\
\hline \multirow{3}{*}{$\begin{array}{c}\text { Ponte } \\
\text { Completa }\end{array}$} & $\begin{array}{l}\text { Dois sensores } \\
\text { ativos e dois } \\
\text { inativos }\end{array}$ & $\begin{array}{l}\text { Sem efeito da } \\
\text { temperatura }\end{array}$ & Muito caros & Raros / 2.0 \\
\hline & $\begin{array}{l}\text { Todos os sensores } \\
\text { ativos }\left(90^{\circ}-\text { Efeito }\right. \\
\text { Poisson) }\end{array}$ & $\begin{array}{l}\text { Sem efeito da } \\
\text { temperatura }\end{array}$ & $\begin{array}{l}\text { Muito caros e impróprios } \\
\text { para campos biaxiais de } \\
\text { tensão }\end{array}$ & Células de carga / 2.6 \\
\hline & $\begin{array}{l}\text { Com todos os } \\
\text { sensores } \\
\text { inteiramente ativos }\end{array}$ & $\begin{array}{l}\text { Sem efeito da } \\
\text { temperatura e } \\
\text { saida máxima }\end{array}$ & Relativamente caros & "Bending beams" / 4.0 \\
\hline
\end{tabular}

\footnotetext{
${ }^{1}$ Fator de Ponte reflete a sensibilidade do arranjo.
} 


\subsubsection{Sensores indutivos}

Posição pode ser medida por métodos de indução eletromagnética. Os sensores de proximidade escolhidos para a medida da rotação de eixos na sonda foram sensores indutivos.

- Sensores indutivos de proximidade

FRADEN (1993) diferencia dois tipos de sensores de proximidade indutivos: (a) sensores eletromagnéticos de proximidade e os (b) sensores indutivo-transversais. Os sensores de proximidade trabalham com uma distância crítica (distância sensora) entre sua superfície sensível e o objeto detectado, a partir da qual o sensor emite ou interrompe um sinal ("chaveamento do sensor").

Os sensores de proximidade eletromagnéticos permitem a detecção de objetos metálicos não-magnéticos, por meio de um par de bobinas. Enquanto uma bobina funciona como referência, uma segunda é usada para detectar as correntes induzidas pela presença do objeto condutor. A proximidade do objeto metálico produz uma grande alteração na impedância magnética (Figura 3.5). Os sensores de proximidade para determinação das velocidades de rotação no protótipo são eletromagnéticos.

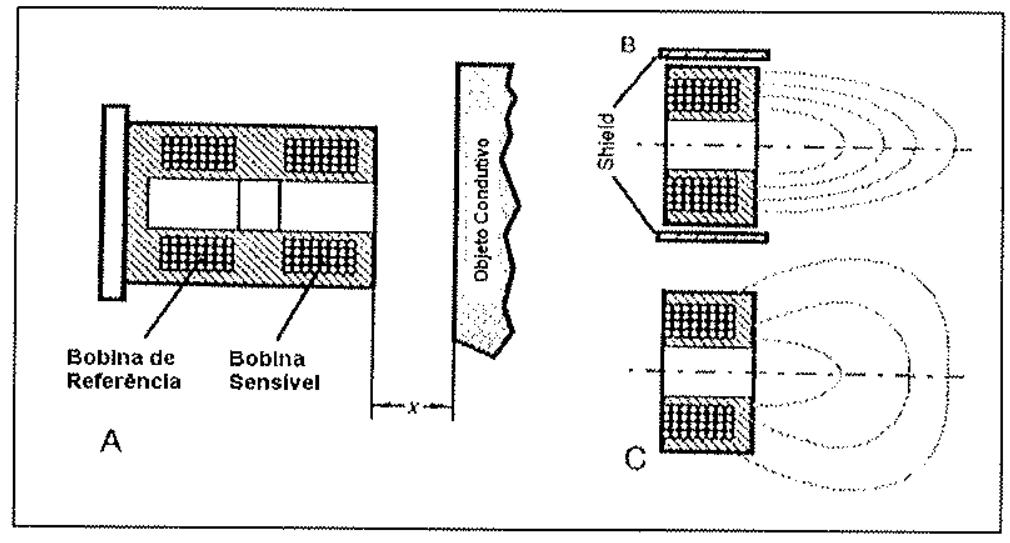

Figura 3.5 - Sensor transversal indutivo de proximidade (A): modelo com a frente "shieldada" (B) e não "shieldada" (C) (FRADEN, 1993).

Já os sensores de proximidade indutivo-transversais necessitam de objetos ferromagnéticos para a sensibilização do sensor. A detecção do objeto ferromagnético realiza-se pela alteração no campo magnético e conseqüente alteração na indutância da bobina, medida por um circuito eletrônico externo. A interação do objeto com o sensor também realiza-se sem necessidade de contato direto. As limitações desse aparelho estão relacionadas à necessidade de utilização de objetos ferromagnéticos e à sua utilização em distâncias relativamente pequenas. (FRADEN, op.cit.) (Figura 3.6). 
A velocidade de chaveamento dos dois tipos de sensor de proximidade apresentados é relativamente alta podendo chegar a $25 \mathrm{kHz}$, permitindo a detecção de objetos com altas freqüências de rotação.

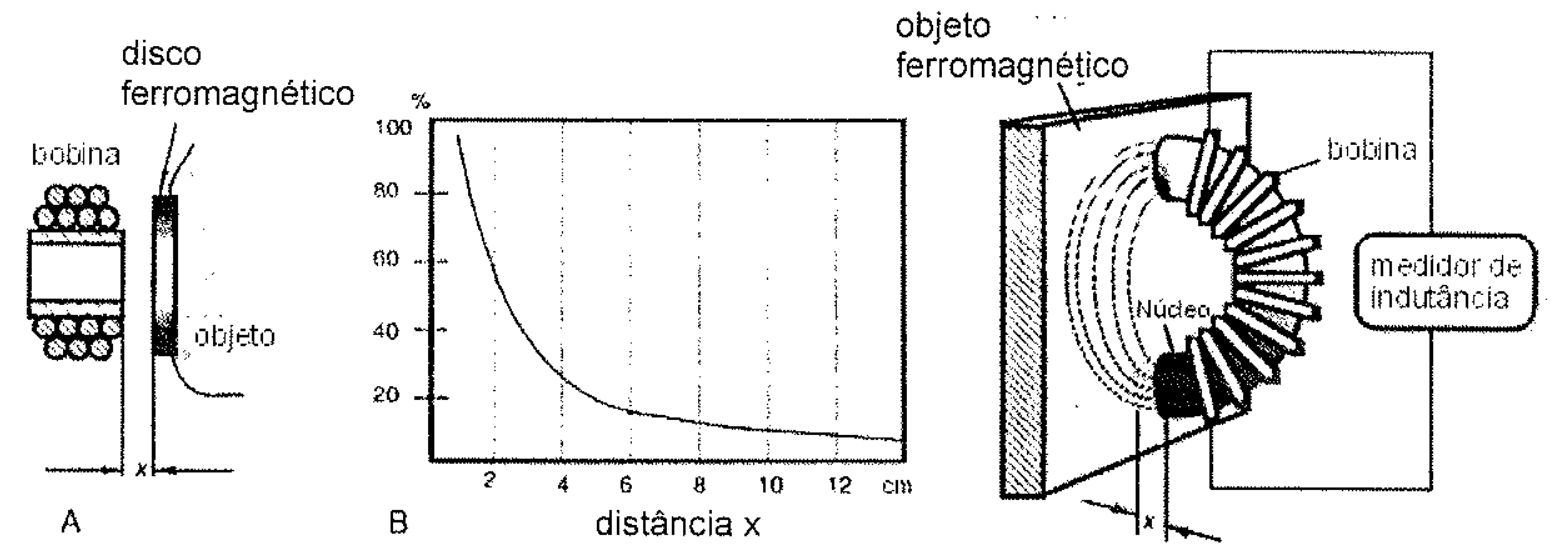

Figuras 3.6 - Sensor de proximidade transversal indutivo com um disco auxiliar $(A)$ e o sinal de saida em função da distância (B) (FRADEN, 1993).

\subsubsection{Potenciômetros}

O potenciômetro é um dispositivo de contato deslizante, que se movimenta sobre uma resistência fixa (Figura 3.7). Com o mesmo princípio de funcionamento, os Potenciômetros Rotativos são usados para a leitura de deformações rotacionais e também para deformações lineares, por meio de um sistema mecânico de conversão (DUNNICLIFF, 1988).

O deslocamento provoca a mudança no comprimento de um fio, gerando uma alteração linear na sua resistência. A aplicação de uma corrente elétrica nesse circuito permite, por meio de uma tensão de excitação $(E)$, o controle do deslocamento, utilizando-se as variações do sinal $V$, de acordo com a expressão 3.5 .

$$
V=E \frac{d}{D}
$$

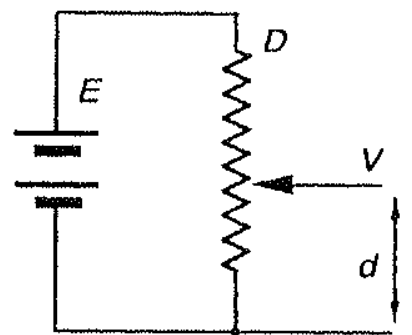

Figura 3.7 - Ponteciômetro como um sensor de posição (FRADEN, 1993).

A variação da resistência em alguns potenciômetros é realizada por meio de bobinas. O contato da resistência do potenciômetro pode ser realizado através de um ou dois fios simultaneamente, resultando numa variação da tensão em "degraus", conforme ilustra a Figura 3.8. 


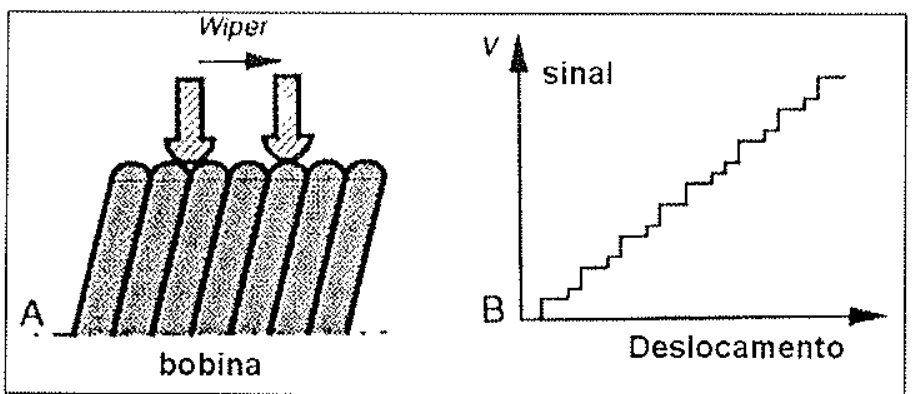

Figura 3.8 - Erros causados por potenciômetros montados com bobinas (FRADEN, 1993).

Segundo FRADEN (1993), as principais desvantagens desse tipo de transdutor são: (a) necessidade de acoplamento físico; (b) aquecimento causado pela tensão de excitação no contato e (c) baixa estabilidade a fatores ambientais.

\subsubsection{Grandezas físicas e sensores utilizados no protótipo}

FRADEN (op.cit.) apresenta as grandezas e princípios físicos relativos aos principais parâmetros medidos por sensores. São relacionados os de interesse ao protótipo desenvolvido.

\subsubsection{Velocidade de avanço da perfuração}

A velocidade é uma propriedade mecânica, analisada no campo da cinemática. Usando a notação vetorial, a posição de um objeto relativo a um dado sistema de coordenadas, pode ser descrito por um vetor $r$, definido por:

$$
r=i x+j y
$$

onde, $i$ e $j$ são as componentes do vetor nas direções $x$ e $y$. Isso significa que a posição do objeto pode ser definida como a distância e a direção a partir do ponto de referência $c$ (Figura 3.9). Quando o objeto desloca-se pela a linha pontilhada, o vetor $r$ altera-se com uma taxa $v$, chamada de velocidade instantânea.

$$
v=\frac{d r}{d t}=i \frac{d x}{d t}+j \frac{d y}{d t}
$$

No caso da velocidade de avanço da perfuração, o movimento na sonda é linear, ao longo da direção do furo e, portanto, a representação pode ser simplificada e representada por apenas um eixo. 

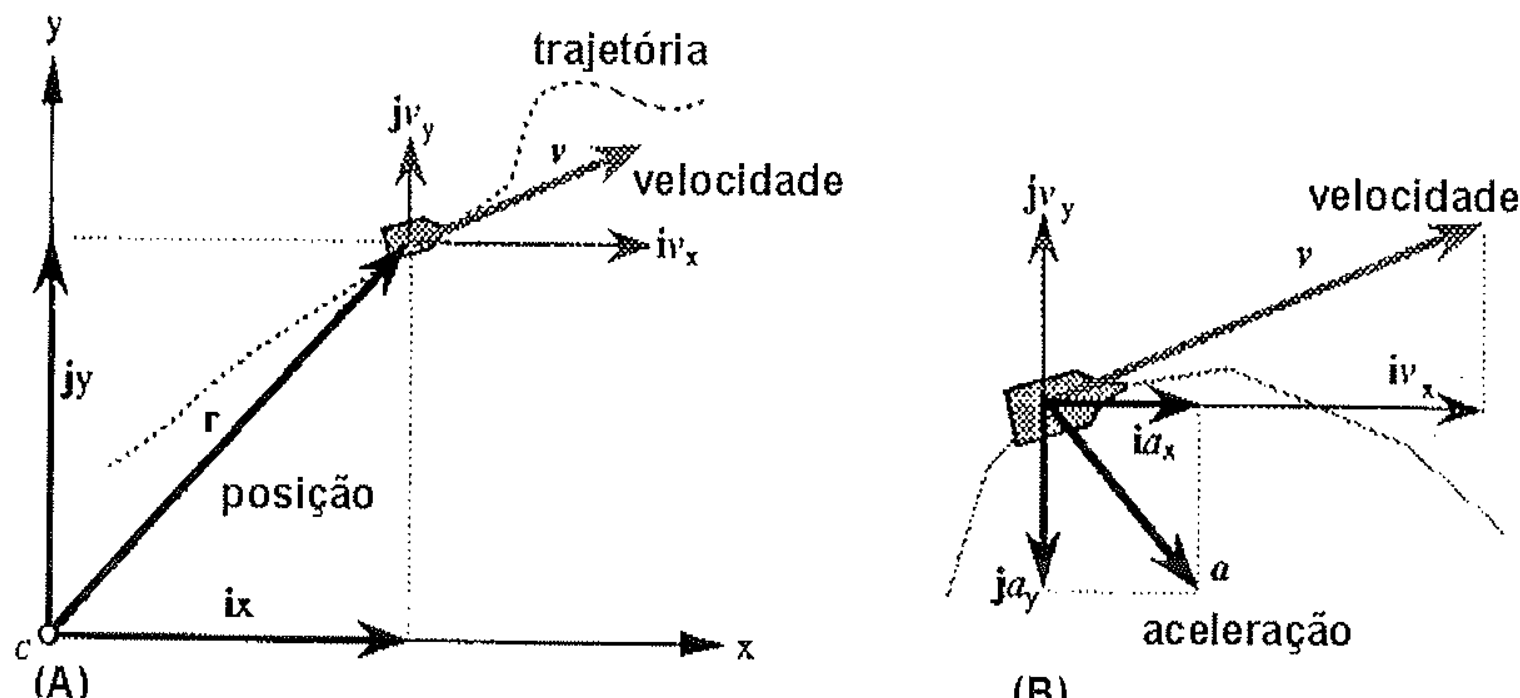

(B)

Figura 3.9 Representação vetorial da posição (A), velocidade (B) e aceleração (B) de um objeto (FRADEN, 1993).

A velocidade será o valor médio, dado pela razão entre a diferença de posição para as sucessivas leituras e o respectivo período de amostragem $(d t)$. O sinal da velocidade indica o sentido do movimento. Apesar do avanço ser contínuo e unidirecional na perfuração, é comum o registro de velocidades negativas, tanto pela forma de operação adaptada, imposta à execução dos furos monitorados, como pelo alívio da compressão e distensão da coluna de perfuração e do sistema de ancoragem da sonda. No protótipo foi adaptado um sensor de deslocamento do tipo potenciômetro rotativo (item 3.1.2.4.)

\subsubsection{Velocidade e sensores de rotação}

O movimento mais simples de rotação de um corpo rígido é a rotação em torno de um eixo fixo. Do ponto de vista cinemático, a descrição desse movimento reduz-se à do movimento circular numa seção transversal ao eixo. Esse é o caso específico do movimento da coluna de perfuração durante a operação da sonda.

Considerando como grau de liberdade de um sistema os parâmetros que se necessita fixar para especificar sua posição, tem-se nesse movimento uma condição com grau de liberdade igual a um, ou seja, a rotação pode ser descrita pelo ângulo de rotação $(\theta)$ no movimento circular. Essa condição permite uma analogia entre esse movimento e o movimento unidimensional, sendo que o fator que correlaciona as variáveis lineares às angulares é o raio $\mathrm{r}$ (módulo do vetor posição), à distância do ponto ou corpo considerado ao eixo de rotação (Quadro 3.3) (NUSSENZVEIG, 1981). 
Quadro 3.3 - Relações entre as grandezas lineares e angulares (NUSSENZVEIG, 1981).

\begin{tabular}{|c|c|c|}
\hline Grandeza & Linear & Angular \\
\hline Posição & $s$ & $s=\theta \cdot r$ \\
\hline Velocidade & $v=\frac{d s}{d t}$ & $v=\omega \cdot r=\frac{d \theta}{d t} \cdot r$ \\
\hline $\begin{array}{c}\text { Aceleração } \\
(a t=\text { componente tangencial })\end{array}$ & $a=\frac{d v}{d t}$ & $a_{t}=\alpha \cdot r=\frac{d w}{d t} \cdot r$ \\
\hline
\end{tabular}

A velocidade angular pode ser tratada de maneira vetorial, já que possui direção e sentido. Sendo assim, define-se vetor velocidade angular $(\vec{\omega})$, a partir da velocidade instantânea de um ponto $\mathrm{P}$ do corpo rígido em rotação, com um deslocamento infinitesimal, $\vec{\delta}$ s, durante um tempo infinitesimal $\delta t$.

$$
\vec{v}=\lim _{\delta t \rightarrow 0}\left(\frac{\overrightarrow{\delta s}}{\delta t}\right)_{\delta t \rightarrow 0}=\lim _{\delta t \rightarrow 0}\left(\frac{\vec{\delta} \theta}{\delta t}\right) \times \vec{r}
$$

Considerando-se $\vec{\delta} s=\vec{\delta}$, então, $\vec{v}=\mathrm{d} \vec{r} / \mathrm{dt}=\vec{\omega} \times \overrightarrow{\mathrm{r}}$, sendo o vetor velocidade angular:

$$
\vec{\omega}=\lim _{\delta t \rightarrow 0}\left(\frac{\overrightarrow{\delta \theta}}{\delta t}\right)=\frac{d \vec{\theta}}{d t}
$$

A magnitude do vetor $\vec{\omega}$ corresponde ao valor já apresentado no Quadro 3.3; sua direção é a do eixo de rotação e o sentido, o de $\vec{\delta} \theta$ (Figura 3.10 ).

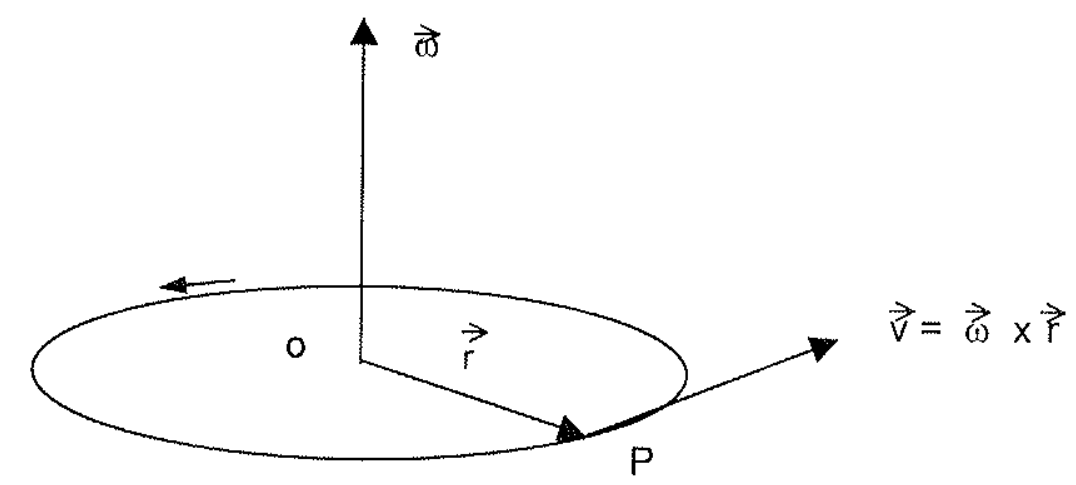

Figura 3.10 - Representação vetorial da velocidade de rotação (NUSSENZVEIG, 1981).

A velocidade angular de rotação ou velocidade de rotação, como os demais parâmetros, também pode ser obtida por meio de diversos métodos físicos. O protótipo do sistema de monitoramento optou pela instalação de anteparos nos eixos monitorados e transdutores sensíveis à sua presença. Com a rotação, a passagem do anteparo na frente do 
sensor produz um pulso. A freqüência desse sinal ou a contagem dos pulsos em um intervalo de tempo predeterminado permite a determinação da velocidade de rotação do eixo.

A precisão da leitura de rotação obtida no arranjo depende da quantidade de anteparos instalados e do valor da velocidade angular, considerando-se uma freqüência de amostragem específica. As condições de medida utilizadas para o eixo do motor (dois anteparos - apenas na $1^{\text {a }}$ etapa de testes) e para o eixo da coluna de perfuração (quatro anteparos) está representada na Figura 3.11.

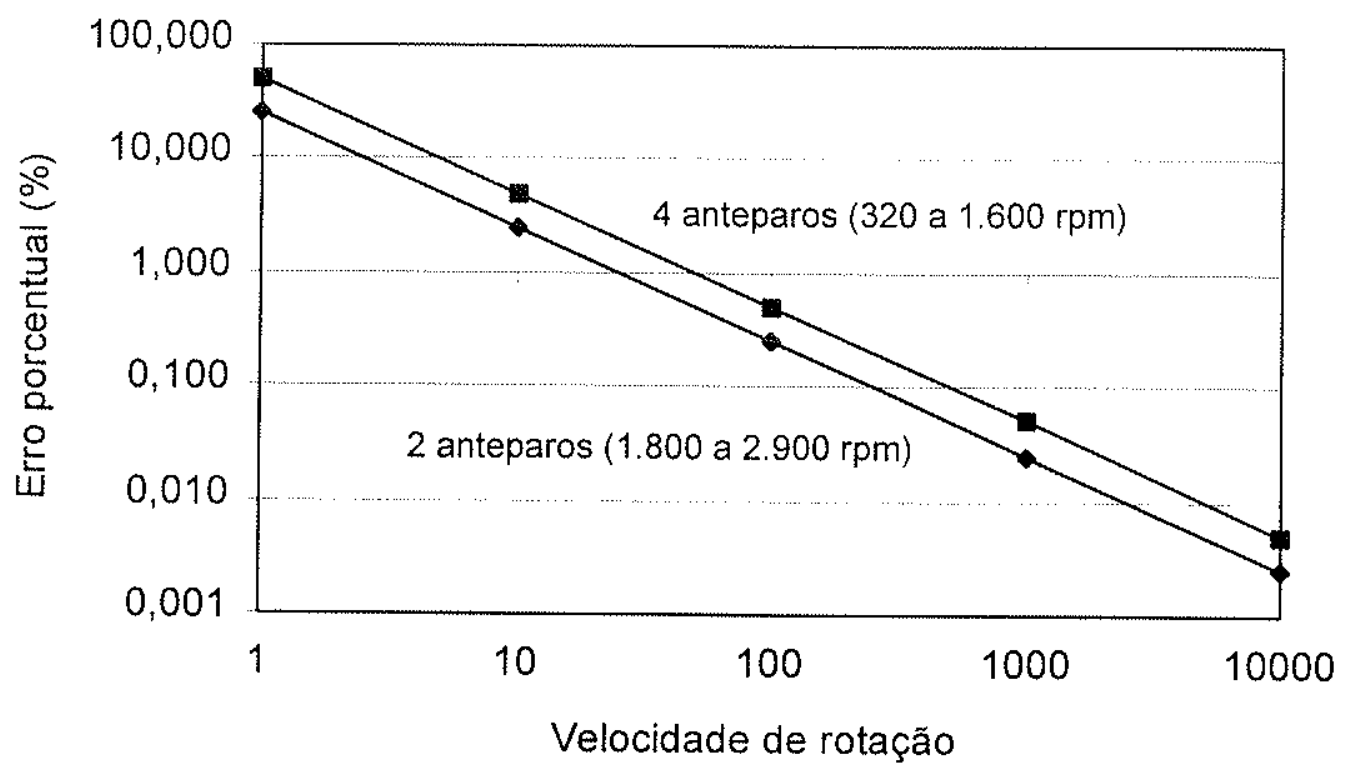

Figura 3.11 - Valores do erro porcentual em função da velocidade de rotação.

Uma precisão razoável $(<1 \%)$ é observada para valores acima de $70 \mathrm{rpm}$. Essa limitação do arranjo com o sensor não atinge as medidas realizadas no protótipo, uma vez que as rotações observadas nos dois eixos possuem valores superiores: 320 a $1.600 \mathrm{rpm}$ na coluna e 1.800 a $2.900 \mathrm{rpm}$.

\subsubsection{Torque e sensores de torque}

O vetor torque ( $\tau$ ) é definido pelo produto vetorial da posição (r) e da componente tangencial força $(\mathrm{F})$ com relação ao movimento:

$$
\vec{\tau}=\vec{r} \times \vec{F}
$$

Dessa forma, o vetor torque também é paralelo ao eixo de rotação, ou seja, perpendicular ao plano do movimento circular (Figura 3.12). 


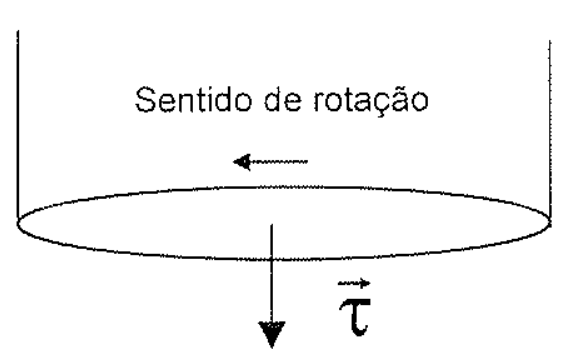

Figura 3.12 - Representação do vetor torque na coluna de perfuração (NUSSENZVEIG, 1981).

Um torque $\tau$ é positivo se produzir uma rotação anti-horária no corpo, e negativo no sentido contrário. O tratamento vetorial para a velocidade angular e o torque somente é possível devido ao eixo do movimento de rotação permanecer fixo. Caso contrário, somente para deslocamentos angulares muito pequenos, a análise vetorial seria válida. Isso se deve às grandezas angulares não obedecerem às regras da adição vetorial, especificamente, a que afirma que a ordem das parcelas não altera a soma.

Basicamente existem dois locais para a medida do torque na sonda: (a) na saída do motor e (b) na coluna de perfuração. Os valores em cada um desses pontos podem ser significativamente diferentes, devido à caixa de câmbio entre ambos. As relações das diversas marchas alteram de maneira inversa o torque e a velocidade de rotação. No protótipo, a medida foi realizada na saída do motor, devido à facilidade na instalação do equipamento, sendo assim, todos os valores obtidos necessitaram ser corrigidos.

O princípio de funcionamento desses sensores baseia-se na determinação das deformações geradas pelo momento de torção sobre um eixo. É possível encontrar no mercado sensores de torque, porém a oferta de modelos e fabricantes é muito menor, quando comparada com os demais parâmetros monitorados. A instalação de um aparelho disponível no mercado é apresentada na Figura 3.13.

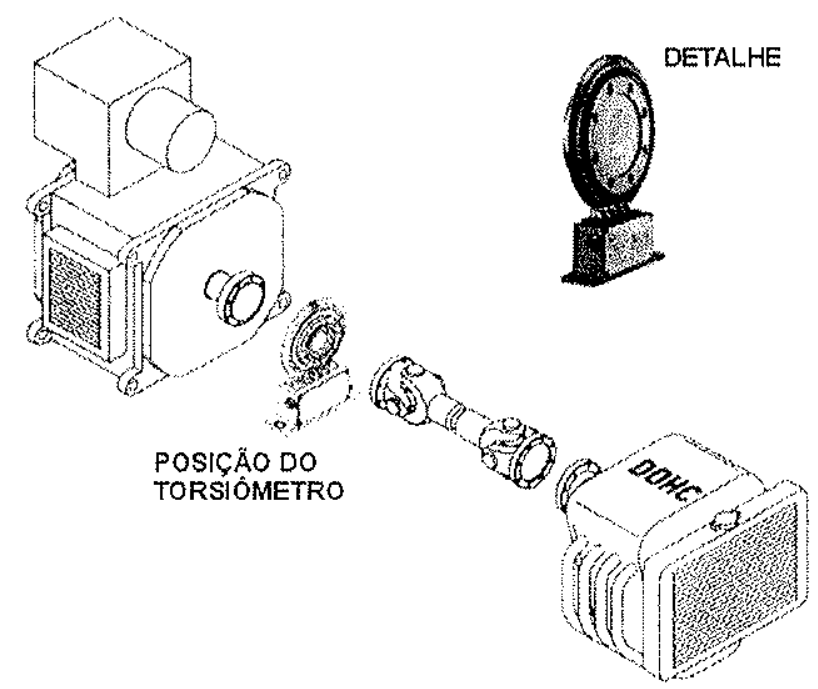

Figura 3.13 - Instalação do sensor de torque (torsiômetro) no eixo de um motor (HBM, s.d.). 
Outra forma de obtenção do torque seria por meio da calibração do motor. Motores como o da sonda permitem o monitoramento do torque aplicado, utilizando-se a posição da alavanca do acelerador e a porcentagem da aceleração total correspondente. Essa condição de operação está relacionada à quantidade de combustível, no caso, óleo diesel, injetado no motor. Para cada nível de potência, as diferentes velocidades de rotação significam diferentes torques impostos pelo motor. No caso do motor M-790 da Agrale, essa curva está representada na Figura 3.14 para a condição de $100 \%$ da potência do motor (plena carga).

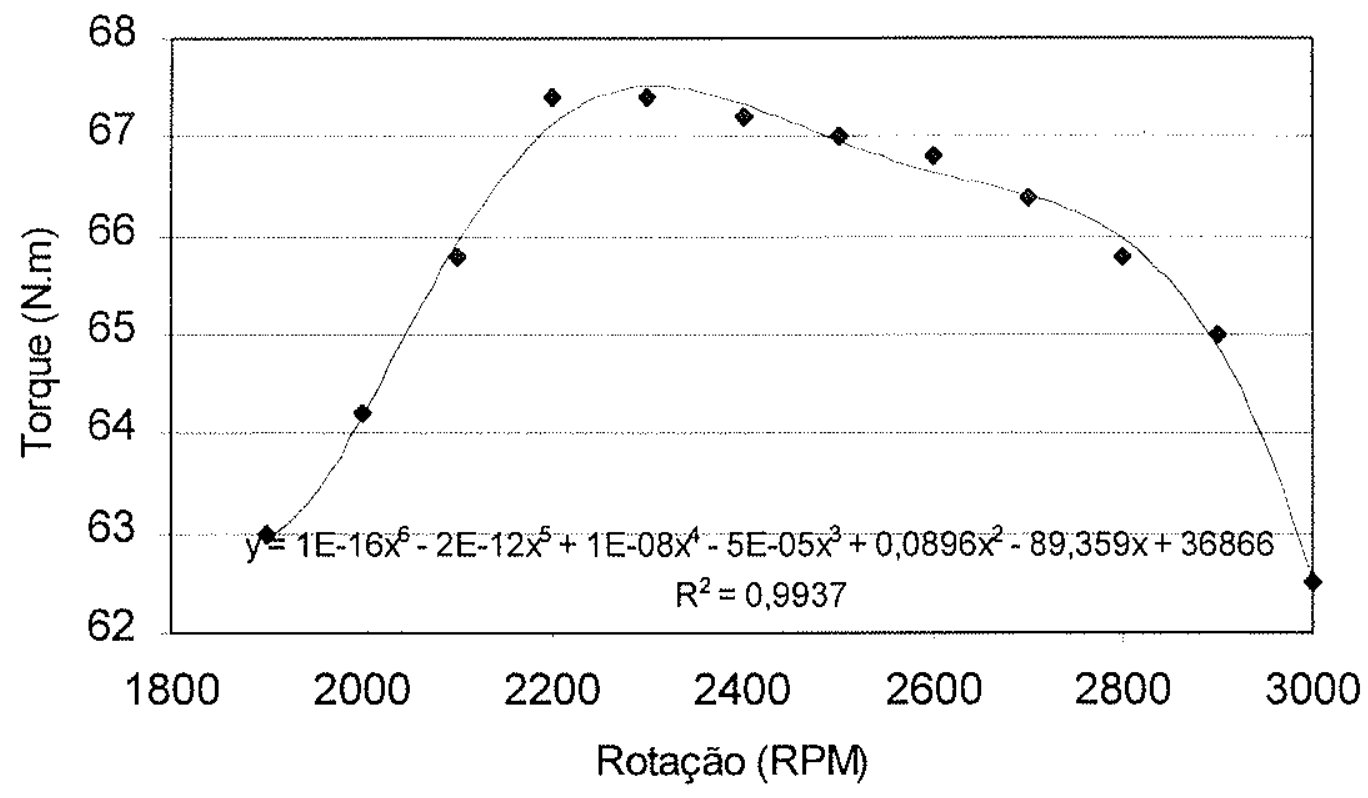

Figura 3.14 - Curva de torque fornecida pelo fabricante do motor da sonda.

A principal dificuldade desse procedimento reside no fato dos fabricantes disponibilizarem esta curva apenas para a condição de $100 \%$ da potência do motor. Muitas vezes a execução do furo exige a operação em condições diferentes. Por esse motivo, serão necessárias curvas para outros níveis de potência do motor, permitindo uma avaliação mais precisa. A porcentagem da aceleração total do motor pode ser controlada utilizando-se um sistema de marcas no acelerador da sonda. Essa forma de estimativa do torque traz uma forte dependência das condições do motor, sendo significativamente alterada pela sua regulagem e manutenção, além de ficar sujeita a outras variáveis, como a qualidade do combustível, pressão atmosférica, etc. Uma desvantagem desse tipo de controle é a necessidade de aferições periódicas e o custo envolvido.

Quando medido antes do sistema de transmissão, o valor do torque necessita ser corrigido pelo valor de redução de suas marchas (relação das marchas no câmbio). O torque na sonda aumenta na proporção inversa da relação de engrenamento. 
A estimativa do torque pode também ser obtida com a instalação direta de "strain gages" no eixo da coluna de perfuração (instrumentação do eixo). Essa solução não é considerada convencional, dependendo do desenvolvimento desse sistema de monitoramento controle e envolvendo custos não previstos no projeto.

\subsubsection{Pressão em fluidos}

Para um fluido em repouso, pressão é definida como a força $F$ exercida perpendicularmente em uma unidade de área com superfície limitada.

Uma vez que pressão $(p=d F / d A)$ pode ser transformada em força, por meio de sua atuação em uma área conhecida, os métodos de medição de ambas as grandezas são essencialmente os mesmos (exceção às medidas de alto vácuo). As escalas mais comuns para a medição de pressão são: pressão relativa e pressão absoluta. A relação entre as três escalas é ilustrada na Figura 3.15 (ISMAIL et al.,1998).

Convenciona-se chamar de pressão atmosférica a pressão do ar ao nível do mar. "pressão Gage" é a pressão relativa à pressão atmosférica, da mesma forma que a pressão absoluta é a pressão total, incluindo a pressão atmosférica local. Portanto, os sensores de "pressão gage" sofrem influência da pressão atmosférica, uma vez que ela própria é o "datum" de referência. Os sensores de pressão do sistema de monitoramento registram a "pressão gage". Os valores medidos serão da ordem de até dezenas de $\mathrm{kgf} / \mathrm{cm}^{2}$, muito superiores à variação barométrica diária ou mesmo àquela originada por variações de altitude local. Para efeitos práticos, essas variações podem ser desprezadas.

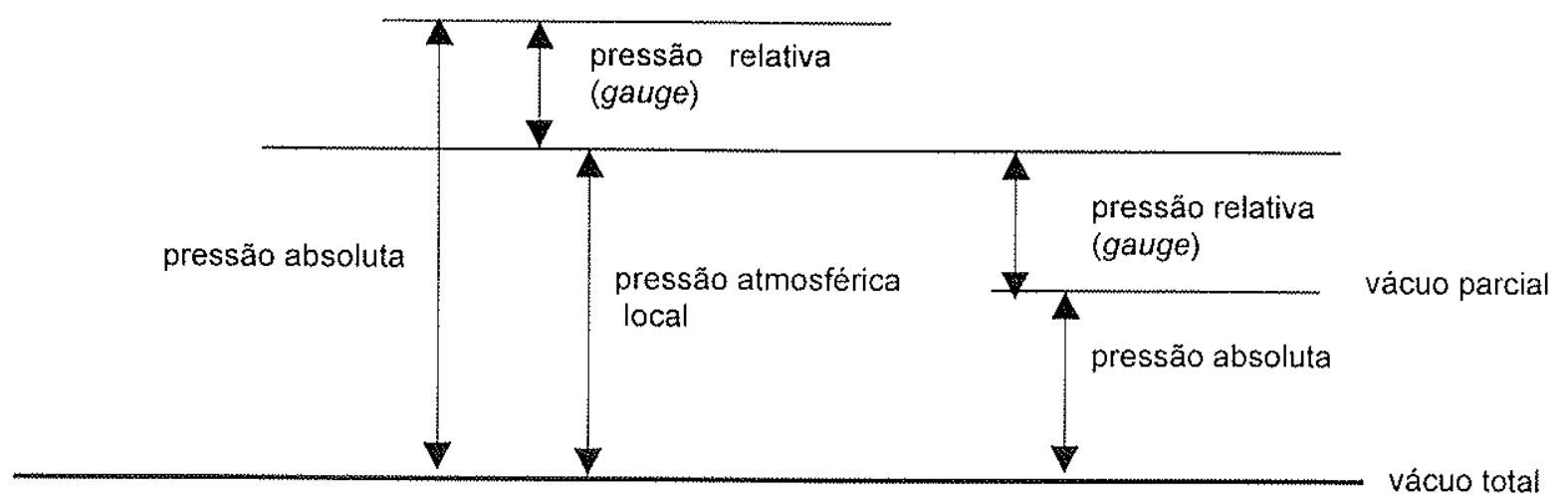

Figura 3.15- Escalas de pressão (ISMAIL et al., 1998).

Para os sensores de pressão existe também grande variedade nos tipos de aparelho. Apesar desse fato, na maioria dos aparelhos o princípio físico está relacionado à deformação imposta pela pressão e sua respectiva medida: 


\section{Medidores e transdutores de pressão elásticos}

Tanto medidores mecânicos, como transdutores elétricos podem utilizar diferentes elementos elásticos para a medida de pressão. Os elementos sensíveis mais comuns são (a) tubos de Bourdon, (b) diafragmas e (c) foles (ISMAIL et al., 1998) (Figura 3.16).

Os foles apresentam a vantagem de possuir linearidade na relação pressão/ deslocamento, quando operando em compressão (ISMAlL et al., op.cit.).

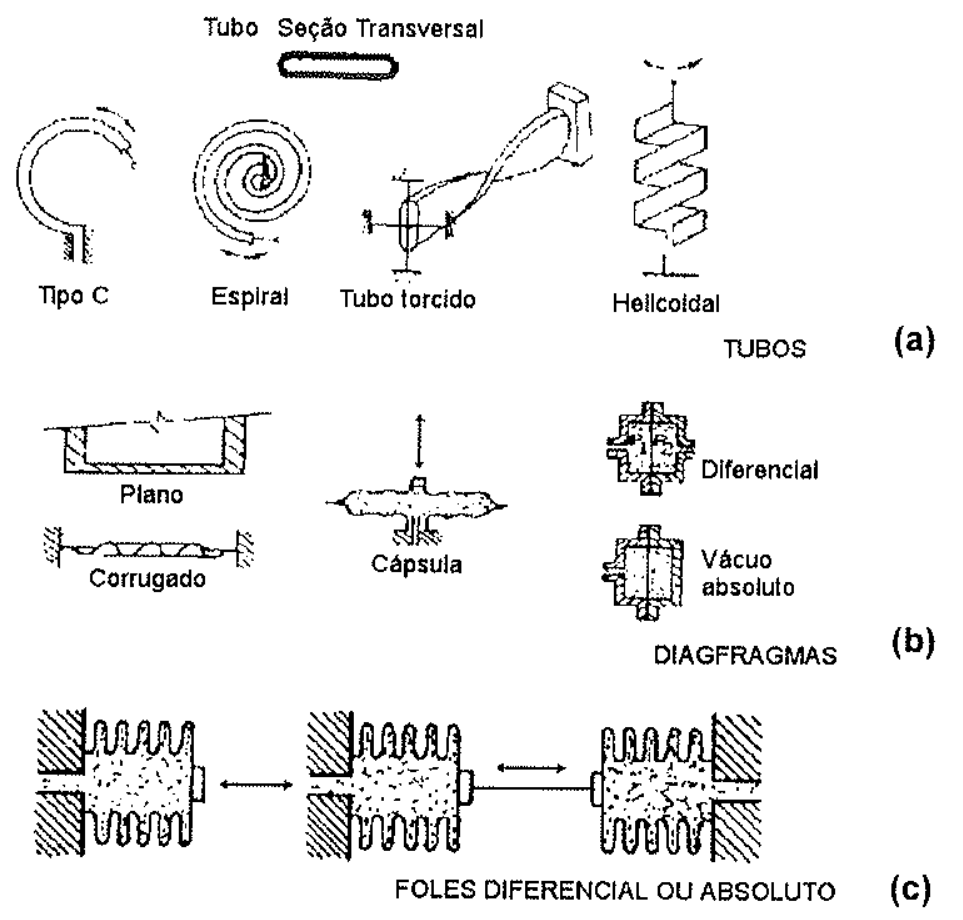

Figura 3.16 - Tubos de Bourdon (a), diafragmas de pressão (b) e foles (c) (ISMAIL et al.,1998).

Os diafragmas metálicos são usados como sensores de medição para pressões relativamente baixas. A geometria mais comum é a de disco plano circular, porém para diâmetros maiores utilizam-se discos corrugados, que fornecem maior resistência mecânica, maior deflexão e boa linearidade na faixa baixa de pressão (ISMAIL et al., op.cit.). Se a espessura da membrana não é desprezível (raio/espessura $\leq 100$ ) a membrana é chamada de placa fina (FRADEN, 1993) (Figura 3.17).

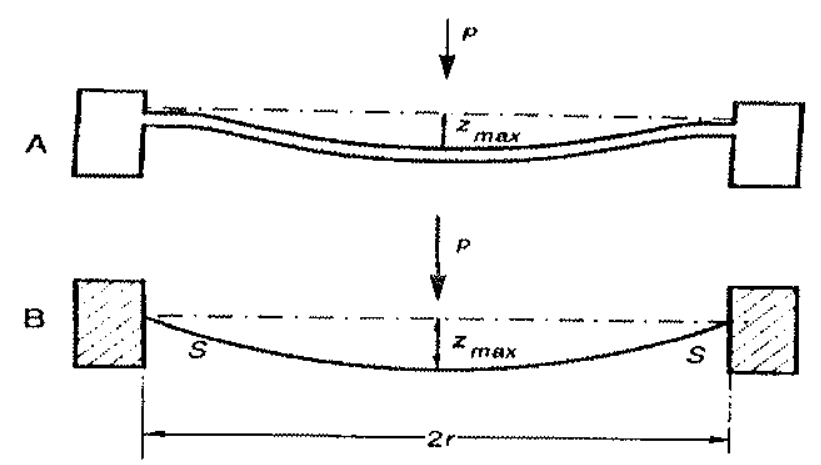

Figura 3.17 - Diafragmas de pressão. Placa fina (A) e membrana (B). 
Diafragmas planos são largamente usados em transdutores elétricos, detectando-se a deflexão de seu centro, ou utilizando-se strain gages na sua superfície.

\section{Potenciômetro (transdutor resistivo de contato móvel)}

O potenciômetro (3.1.2.4), dispositivo para transformação de deslocamento linear ou angular em sinal elétrico, pode ser utilizado, juntamente com outro elemento elástico, para medidas de força ou pressão. Este tipo de transdutor de pressão é composto por três partes: (a) o elemento sensor de pressão, (b) a mola de referência e (c) o elemento de resistência. Utilizando-se foles como elemento sensor é possível eliminar a mola de referência.

O resumo comparativo entre os diversos tipos de transdutores de pressão é apresentado no Quadro 3.4. Segundo ISMAIL et al. (1998), os tipos de sensores de pressão elétricos são: (a) Strain gage; (b) capacitância variável; (c) piezoelétrico; (c) LVDT; (c) relutância variável; (d) resistência variável. Essa classificação considera a forma de medida de deslocamento do elemento elástico do sensor.

O funcionamento dos sensores de pressão escolhidos para o monitoramento das pressões no equipamento (água e óleo) baseia-se em resistências do tipo "strain gage", as quais são coladas sobre uma membrana fina (da ordem de $0,4 \mathrm{~mm}$ ) que se deforma elasticamente na faixa de pressões a que o transdutor se aplica. Essa deformação gera uma variação no valor da resistência do "strain gage", que, ligado em um dos "braços" de uma Ponte de Wheatstone a desbalanceará (3.1.2.1. e 3.1.2.2). Este desbalanceamento é sentido por um amplificador dinâmico que fornecerá um valor em tensão proporcional à pressão aplicada ao sensor. 
Quadro 3.4 - Resumo comparativo dos transdutores de pressão (adaptado de ISMAIL et. al., 1998).

\begin{tabular}{|c|c|c|c|c|c|c|c|c|}
\hline Tipo & Sensores tipicos & $\begin{array}{l}\text { Histerese } \\
(\%)\end{array}$ & $\underset{(\%)}{\text { Linearidade }}$ & $\begin{array}{l}\text { Saida total circuito } \\
\text { aberto }\end{array}$ & $\begin{array}{l}\text { Resposta a } \\
\text { aceleração, } \\
\text { vibração e } \\
\text { ruído }\end{array}$ & Estabilidade térmica & $\begin{array}{l}\% \text { de } \\
\text { sobre- } \\
\text { carga }\end{array}$ & $\begin{array}{l}\text { Comentários: } \\
\text { vantagens e } \\
\text { desvantagens }\end{array}$ \\
\hline "Strain-gages" & $\begin{array}{l}\text { Diafragma, } \\
\text { bourdon ou foles }\end{array}$ & 0,25 & 0,1 & $\begin{array}{lr}\text { Colado: } & 2-4 \mathrm{mV} \\
\text { Descolado: } & 3-6 \mathrm{mV} \\
\text { Semicondutor: } & 25-50 \mathrm{mV}\end{array}$ & $\begin{array}{l}\text { Baixo para alta } \\
\text { pressão }\end{array}$ & $\begin{array}{l}\text { excelente com } \\
\text { compensação }\end{array}$ & 100 & $\begin{array}{l}\text { Resposta rápida; } \\
\text { excitação AC/DC; } \\
\text { fácil calibração; } \\
\text { baixo sinal de saida } \\
\end{array}$ \\
\hline $\begin{array}{l}\text { Capacitância } \\
\text { variável }\end{array}$ & Diafragma & 0,02 & 0,5 & $0,25 \mathrm{~V} / \mathrm{V}$ & $\begin{array}{l}\text { Baixo, mas } \\
\text { observável }\end{array}$ & $\begin{array}{l}\text { Deslocamento de } \\
0,02 \% / \% \mathrm{~F}\end{array}$ & 100 & $\begin{array}{l}\text { Sensivel à } \\
\text { temperatura }\end{array}$ \\
\hline LVDT & $\begin{array}{l}\text { Diafragma, } \\
\text { bourdon ou foles }\end{array}$ & 0 & $0,5-1,0$ & $\begin{array}{l}0,1-5,0 V \quad(p / 6,3 V \\
\text { entrada })\end{array}$ & Baixo & $\begin{array}{l}\text { Na excitação baixa, } \\
\text { variação de } \\
\text { resistência na } \\
\text { bobina }\end{array}$ & - & $\begin{array}{l}\text { Alta amplicidade de } \\
\text { saida; resposta } \\
\text { lenta }\end{array}$ \\
\hline $\begin{array}{l}\text { Resistência } \\
\text { variável }\end{array}$ & Foles ou bourbon & $0,5-1,0$ & $0,2-1,0$ & $<75 \mathrm{~V}$ & $\begin{array}{l}\text { Vibração a } \\
\text { baixa pressão }\end{array}$ & $\begin{array}{l}\text { Deslocamento de } \\
0,02 \% /{ }^{\circ} \mathrm{F}\end{array}$ & 50 & $\begin{array}{l}\text { Custo baixo, } \\
\text { AC/DC, sensivel a } \\
\text { vibração }\end{array}$ \\
\hline Piezoelétrico & $\begin{array}{l}\text { Cristal ou } \\
\text { elemento cerâmico }\end{array}$ & 0 & 0,5 & $35-200 \mathrm{mV} / \mathrm{psi}$ & $\begin{array}{l}\text { Apreciável com } \\
\text { ruido elementar }\end{array}$ & $\begin{array}{l}\text { Deslocamentos } \\
\text { térmicos } \\
\end{array}$ & $50-100$ & $\begin{array}{l}\text { Resposta rápida } \\
\text { sensível à umidade }\end{array}$ \\
\hline $\begin{array}{l}\text { Relutância } \\
\text { variável }\end{array}$ & $\begin{array}{l}\text { Diafragma, } \\
\text { bourdon ou foles }\end{array}$ & $0,2-0,3$ & $0,5-1,0$ & $0,05-0,1 \mathrm{VN}$ & $\begin{array}{l}\text { Baixo } 0,1 \% \text { da } \\
\text { escala }\end{array}$ & $\begin{array}{l}\text { Deslocamento de } \\
0,02 \% /^{\circ} \mathrm{F}\end{array}$ & $<600$ & $\begin{array}{l}\text { Resistente a } \\
\text { choques mecânicos; } \\
\text { AC/DC }\end{array}$ \\
\hline
\end{tabular}




\subsubsection{Vazão de líquidos em tubulação}

Na movimentação de um fluido em regime de escoamento não turbulento, a trajetória dos pontos em movimento define as linhas de fluxo, sendo o vetor velocidade tangente em cada ponto dessa linha. Qualquer limite do fluxo que contenha um conjunto de linhas é denominado de tubo de fluxo (Figura 3.18A). O volume ( $V$ ) é estabelecido pelo deslocamento $(\Delta x)$ de uma determinada área $(d A)$ (Figura 3.18B), perpendicular às linhas de fluxo, em um intervalo de tempo $(\Delta t)$. Esses fatores estabelecem a vazão ou fluxo do fluido $(\Lambda)$, dado por:

$$
\Lambda=\frac{V}{\Delta t}=\int \frac{\Delta x \cdot d A}{\Delta t}=\int v \cdot d A
$$

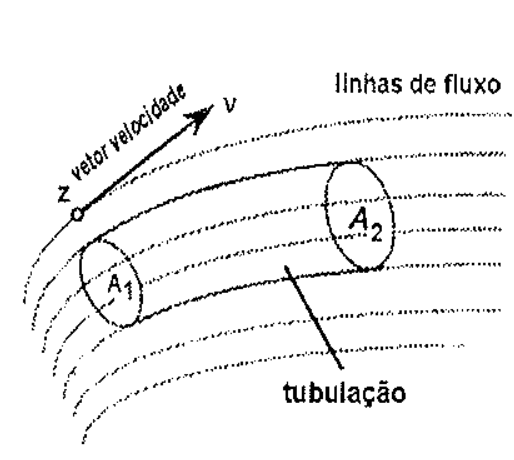

A

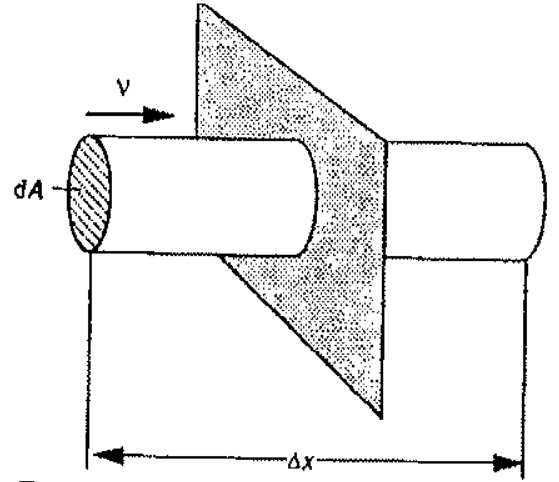

B

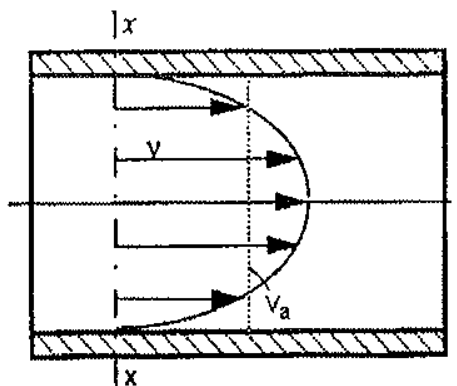

C

Figura 3.18 - Tubo de Fluxo (A) e fluxo através de um plano (B) e perfil de velocidade de fluxo em tubulação (C) (FRADEN, 1993).

Dentro de tubulações, observa-se que a velocidade não é constante ao longo da seção do tubo (Figura $3.18 \mathrm{C}$ ). Dessa forma, é adequado determinar a velocidade média ao longo da seção. Via de regra, os sensores de vazão medem essa velocidade média $\left(v_{a}\right)$, a qual, juntamente com a dimensão da tubulação (diâmetro), permitem a determinação da vazão ou fluxo.

$$
v_{a}=\frac{\int v d A}{A}
$$

A vazão pode ser ainda considerada em termos de escoamento mássico, ou seja, alguns métodos consideram a massa que atravessa a seção da tubulação por unidade de tempo, ao invés do volume.

Da mesma forma que as grandezas físicas anteriores, o controle da vazão em tubulações possui uma grande variedade de aparelhos e de princípios físicos de funcionamento. A classificação dessas técnicas e métodos varia de acordo com os diversos autores. Será apresentada uma classificação baseada principalmente em FRADEN (1993) e ISMAIL et al. (1998). 
(a) Métodos de deslocamento volumétrico: medidores de pistão, pás excêntricas, engrenagem, etc.

(b) Métodos de diferença de pressão (tubos de Venturi, placa de orifícios, etc.).

(c) Métodos de velocidade média global.

Essa categoria de medidores de vazão (c), pertencente à classificação de ISMAlL et al. (1998), engloba os sensores magnéticos, os ultra-sônicos, os do tipo turbina, os medidores de corrente, os do tipo vórtice, etc.

O princípio de funcionamento dos sensores eletromagnéticos de vazão baseia-se na Lei de Faraday, que afirma que um líquido condutor, atravessado por linhas de fluxo de um campo magnético, gera uma força eletromagnética (f.e.m.) com intensidade proporcional à velocidade do líquido (FRADEN, 1993).

O campo magnético é gerado pela passagem de corrente elétrica nas bobinas de excitação (Figura 3.19). O comprimento do condutor corresponde ao diâmetro do tubo, sendo que a tensão é medida por meio de dois eletrodos nele instalados.

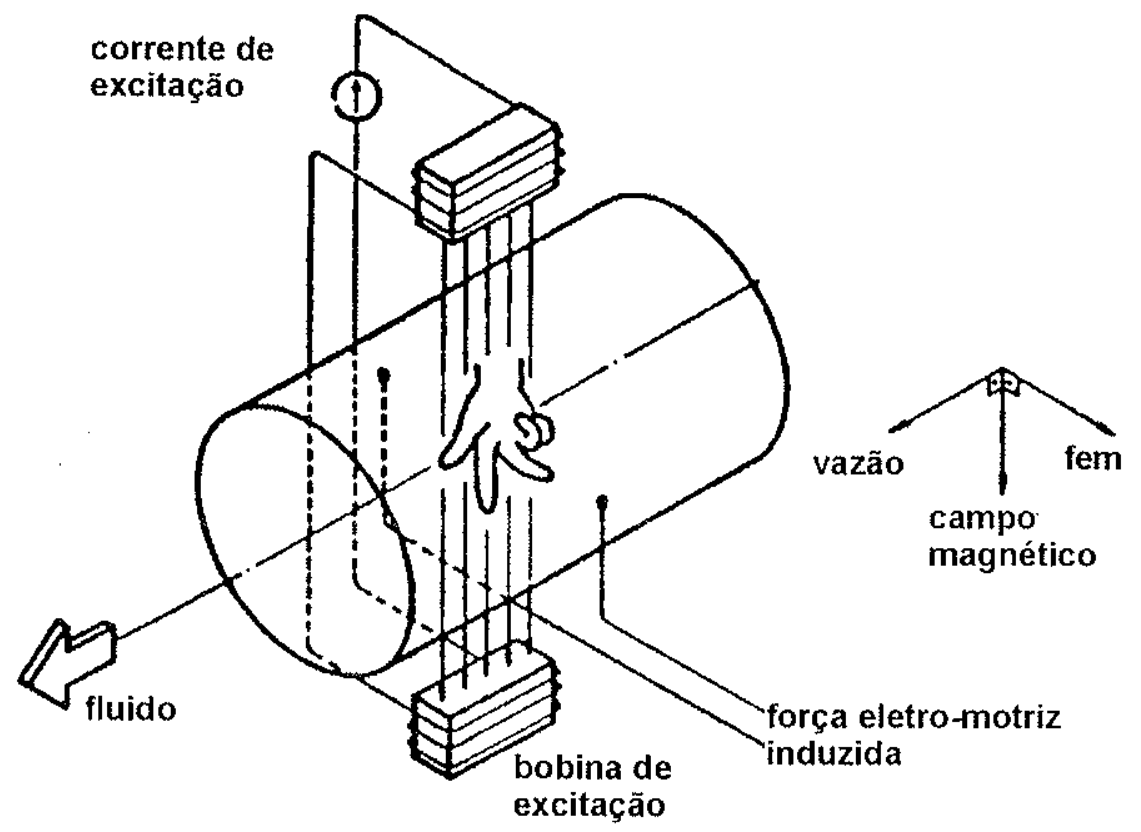

Figura 3.19 - Operação do medidor eletromagnético de vazão (BASILE \& SANTOS, 1989).

A intensidade da f.e.m. (diferença de potencial) é definida pela expressão:

$$
E=e-e^{\prime}=2 a B v
$$

onde: $a$ é o raio do tubo; $B$ o campo magnético (ou densidade do fluxo magnético); $e$ e $e^{\prime}$ os potenciais nos eletrodos de leitura e $v$ a velocidade do líquido ou fluido (Figura $3.20)$. 


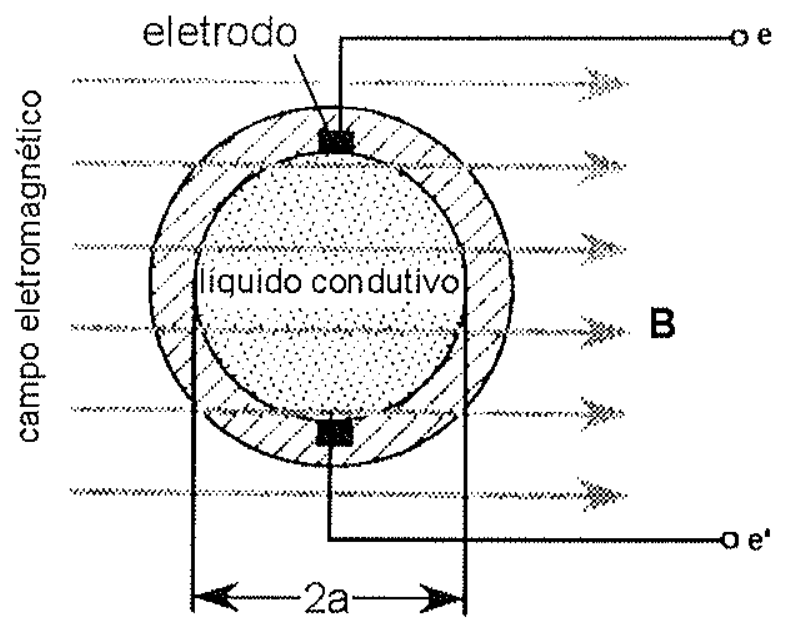

Figura 3.20 - Princípio do medidor de vazão eletromagnético (FRADEN, 1993).

No caso da velocidade do fluido na seção do tubo não ser uniforme, apresentando simetria a partir do eixo, então a f.e.m. gerada será a mesma da expressão (3.12), com a velocidade $(\mathcal{V})$ sendo substituída pela velocidade média $\left(\mathcal{V}_{a}\right)$ (expressão 3.11):

$$
v_{a}=\frac{1}{\pi \cdot a^{2}} \int_{0}^{a} 2 \pi \cdot v \cdot r d r
$$

onde, $r$ é a distância do centro do tubo. A equação (3.11) pode ser expressa em termos da taxa de fluxo volumétrico.

$$
v=\frac{2 . \Lambda . B}{\pi \cdot a} \quad(3.14) \text {, onde } \Lambda \text { é a vazão do fluido. }
$$

Os sensores eletromagnéticos são usados para medida do movimento de líquidos condutivos. Os manuais desses equipamentos preconizam que eles sejam aplicados a líquidos com condutividade igual ou superior a $1 \mu \mathrm{S} / \mathrm{cm}$.

ISMAIL et al. (1998) afirmam que os medidores eletromagnéticos podem ser divididos em dois grandes grupos, definidos segundo o tipo de corrente utilizada para a geração do campo magnético: alternada ou contínua. Encontra-se esse tipo de equipamento com diâmetros variando entre $2 \mathrm{~mm}$ e $1,5 \mathrm{~m}$.

Para a leitura do sinal elétrico nos eletrodos, é necessário o isolamento interno do tubo, uma vez que esses são geralmente construídos em aço inox. O revestimento do interior do tubo com material isolante, geralmente teflon ou borracha de poliuretano, proporciona o 
isolamento (BASILE \& SANTOS, 1989), e estabelece a temperatura máxima do fluido, de acordo com o material utilizado.

ISMAIL et al. (1998) afirmam que as aplicações típicas para esses medidores são: água, água servida, ácidos, lamas, pastas, leite e derivados, cervejas, líquidos contendo até $30 \%$ em sólidos, ou qualquer outro fluido com a condutividade mínima estabelecida pelo fabricante.

\subsubsection{Sistemas de aquisição de dados / conversão analógico-digital}

No sistema de monitoramento, o conjunto de sensores geralmente faz parte de um sistema maior, o qual incorpora ainda: condicionadores e processadores de sinal, dispositivos de memória e gravadores de dados. Quando o sistema tem por objetivo interferir no processo, além de todos esses equipamentos, tem-se ainda os acionadores ou atuadores, programados para agir no sistema, de acordo com as condições detectadas pelo monitoramento. Um sistema de monitoramento e controle mais complexo é apresentado na Figura 3.21. Destaca-se que o protótipo proposto refere-se apenas a um sistema de monitoramento, sem interferência na perfuração.

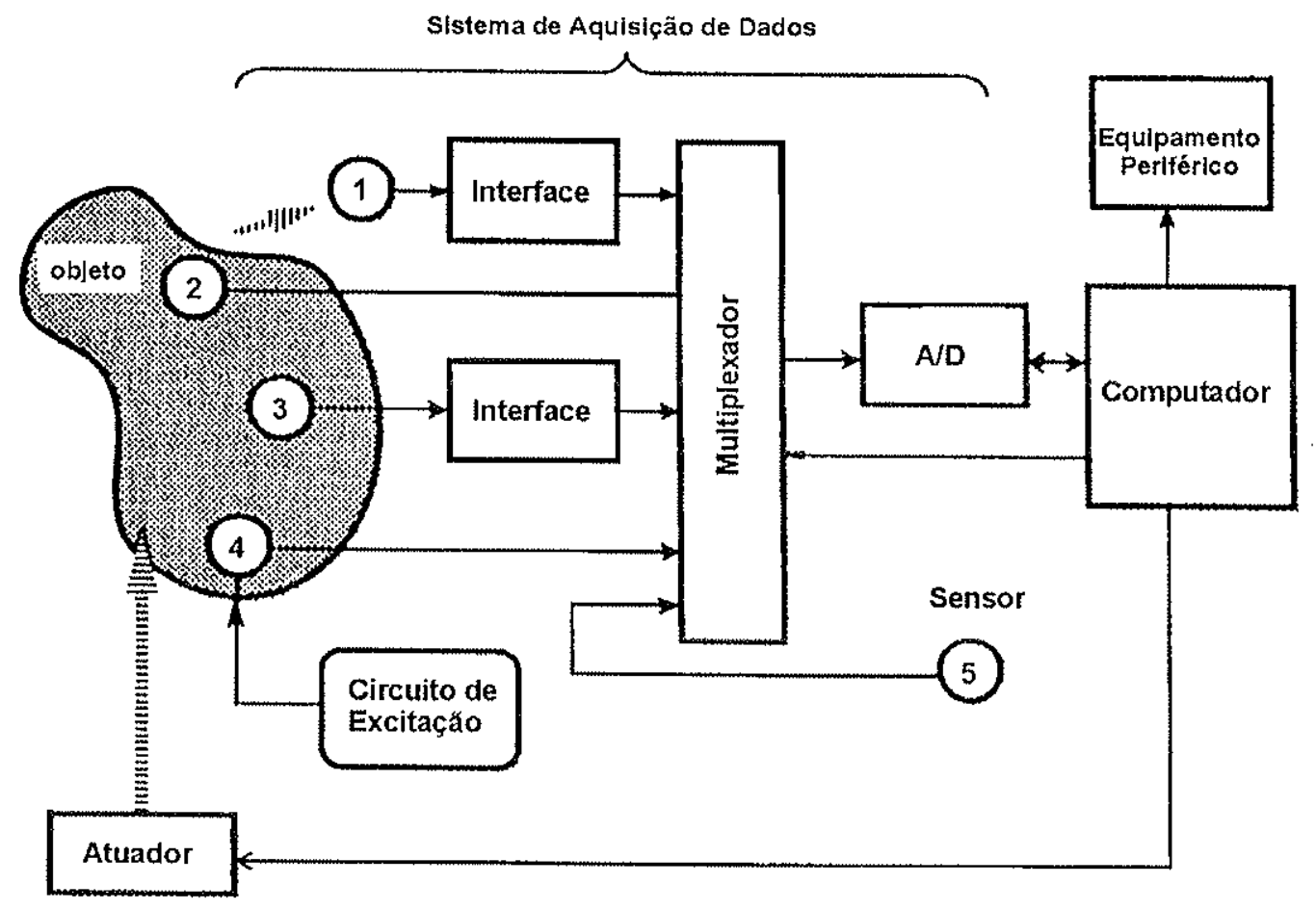

Figura 3.21 - Sensores em um sistema de aquisição de dados e controle (FRADEN, 1993).

Os sinais elétricos gerados nos sensores são enviados a um multiplexador, uma chave ou porta, cuja função é conectar os sensores, um de cada vez, a um conversor analógico- 
digital (A/D), ou diretamente ao computador, no caso do sensor produzir um sinal digital (FRADEN, 1993.).

DUNNICLIFF (1988) refere-se ao Sistema Automático de Aquisição de Dados (ADAS). O sistema possui as seguintes características: (a) programação para coleta automática de dados em seqüência prédeterminada; (b) realização de algum tipo de condicionamento de sinal; (c) gravação e retransmissão de dados para outro equipamento.

Um ADAS pode ser composto por um "data logger", um "data controller" ou um computador. O "data logger" realiza apenas a gravação, enquanto o "data controller" e o computador são programáveis, permitindo também análise dos dados e respostas, ou seja, produção de sinais de saídas para o controle do processo monitorado.

A utilização dos transdutores elétricos em um $A D A S$ é classificada em duas categorias: (a) sensores que requerem um mínimo de interface e condicionamento de sinal, devido à tensão de saída $D C$ ser maior que um volt (p.e. $L V D T \mathrm{~s}, D C D T \mathrm{~s}$, potenciômetros) e (b) sensores que necessitam de um condicionamento de sinal mais complexo. Saídas de baixa resistência elétrica de alguns tipos de "strain gages" são exemplos.

3.2. Perfuração rotativo-abrasiva - técnica e equipamentos

A perfuração em solo e rocha é realizada com diversas finalidades. Os princípios físicos envolvidos e, conseqüentemente, os respectivos equipamentos também são variados, tendo se desenvolvido em função das características dos materiais e da finalidade da perfuração.

STACK (1982) separa os métodos de perfuração em 5 grupos básicos: (a) impacto, (b) abrasão, (c) fragmentação termo-induzida, (d) fusão e vaporização, e (e) reação química, sendo que os dois primeiros são os mais largamente utilizados na prospecção geológica. HARTLEY (1994) apresenta uma divisão das ferramentas de perfuração em 5 categorias: (a) trados, (b) ferramentas a cabo, (c) ferramentas tipo "rotary", (d) ferramentas tipo "martelo" e ferramentas diamantadas.

A perfuração com ferramentas tipo "rotary" utiliza as forças de compressão, de rotação e hidráulica da sonda. A desagregação do material perfurado e o avanço do furo são determinados pela ação de corte e/ou esmagamento dos "dentes" da ferramenta (Figura 3.22). O comprimento e o espaçamento dos "dentes" são determinados pela resistência do material perfurado. 


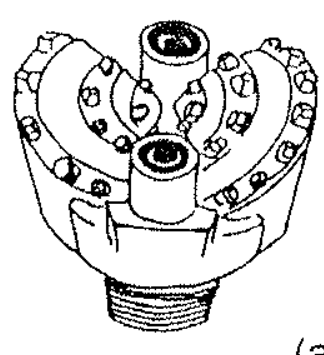

(a)

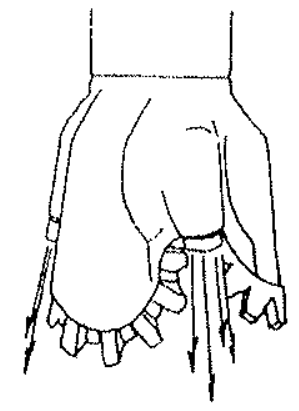

(b)

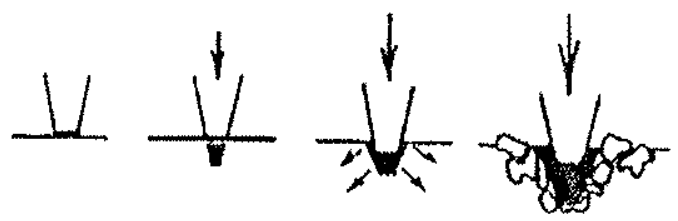

(c)

Figura 3.22 - Vista da ferramenta tipo "rotary" (a), ação hidráulica durante a perfuração(b), detalhe da ação da força de compressão no esmagamento da rocha (c) (HARTLEY, 1994).

Embora não tenham sido utilizadas nos testes, as ferramentas tipo "rotary" possuem interesse especial na técnica do monitoramento de sondagem. Grande parte dos equipamentos que faz esse tipo de controle é adaptada em sondas que utilizam essa ferramenta de corte. O presente trabalho concentra-se na perfuração de rocha com coroas diamantadas, embora alguns testes também tenham sido realizados em solo, utilizando-se brocas de arraste com widia ou ferramentas especiais.

Apesar das perfuratrizes rotativas existirem desde o final do século XIX, foi apenas na década de 1920, com a descoberta e o patenteamento da widia ("wie diamante" = como o diamante) que se registrou um significativo avanço tecnológico no desenvolvimento da perfuração rotativa. A alta dureza e grande resistência ao desgaste desse material e seu preço inferior ao diamante vêm permitindo sua utilização na perfuração de materiais menos resistentes (CAMBEFORT, 1968).

\subsubsection{Equipamentos básicos}

As sondagens rotativas são utilizadas em trabalhos de prospecção, para as áreas de geologia de engenharia/geotecnia e pesquisa mineral. De uma maneira menos intensa, esse tipo de investigação direta é aplicada também a trabalhos nas áreas de meio ambiente e hidrogeologia. A instalação típica dessa sonda rotativa é composta pelos seguintes equipamentos: (a) tripé de perfuração, (b) sonda propriamente dita, (c) coluna de perfuração, (d) revestimentos e (e) bomba hidráulica. A coluna de perfuração é composta pelo alimentador d'água, hastes, barriletes, calibrador e coroa (SERRA Jr., 1991).

A sonda é o componente respousável pela geração e transmissão da energia motora à coluna de perfuração, possuindo geralmente um motor à combustão e, em alguns, casos elétrico. O cabeçote aciona o fuso ou mandril, imprimindo o movimento rotativo do motor a toda a coluna de perfuração. Nesse tipo de equipamento, o avanço da perfuração é acionado 
por um sistema hidráulico (SERRA Jr., 1991). Os sistemas hidráulico e de transmissão da sonda são representados na Figura 3.23. Durante a perfuração, é estabelecido um equilíbrio entre as variáveis: (a) torque, (b) velocidade de rotação da coluna e (c) força normal, estabelecida pelo sistema hidráulico.
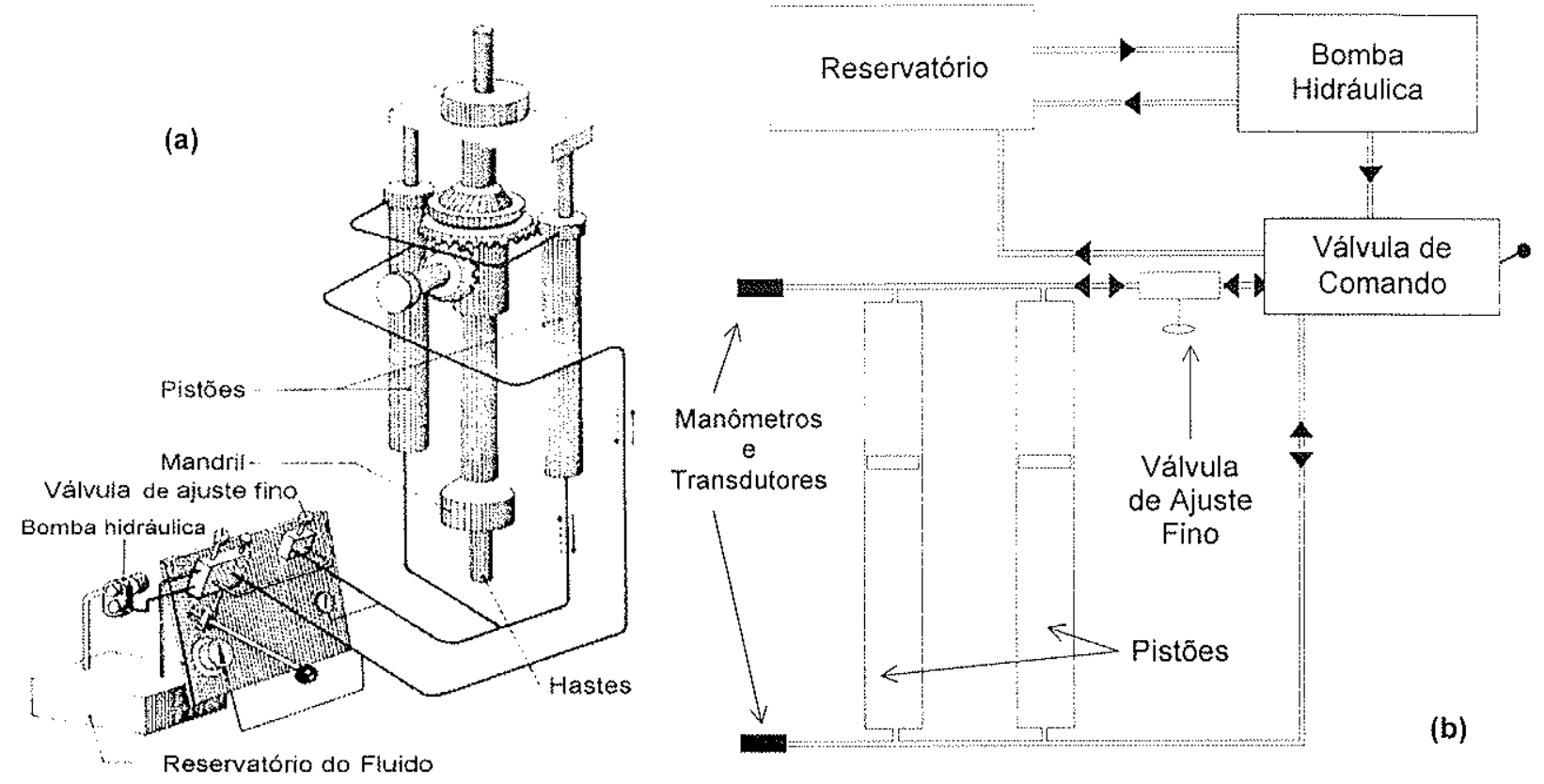

Figura 3.23 - Sistema de avanço hidráulico em sonda rotativa: (a) ilustração tridimensional (PEREDA, 1998) e (b) esquema ilustrativo com os sensores instalados (b).

A coluna de perfuração é o conjunto de peças, presas por roscas, que transmite a torção do motor à ferramenta cortante (coroa), na extremidade da coluna, onde efetivamente ocorre o desgaste da rocha. Através das hastes, que compõem a coluna, é bombeado o fluido (água ou lama) que refrigera a operação de corte, carreando os resíduos produzidos pela perfuração (SERRA Jr., op.cit.). As hastes representam a maior parte da coluna de perfuração, em termos de peso e de comprimento.

A bomba d'água (ou bomba de circulação) é acionada também por motor a explosão ou elétrico. Esse equipamento fornece pressão ao fluido de refrigeração, para sua circulação descendente, através da coluna de perfuração (SERRA Jr., op.cit.). A eliminação dos resíduos produzidos pelo corte é função da velocidade de subida da água, agora por fora das hastes, no espaço entre a coluna e o furo (ou ainda, entre a coluna e o revestimento). Quanto menor o espaço, maiores serão a velocidade do fluido e a capacidade de arraste de detritos. A prática mostra que esta velocidade deve situar-se entre 0,40 e 0,60 metros por segundo. Velocidades inferiores podem provocar a precipitação das partículas e a prisão da coluna. Valores superiores provocam lavagem e erosão do testemunho, e desprendimento prematuro dos diamantes (MAQUESONDA, s.d.). 
O barrilete é a peça destinada ao armazenamento do testemunho de sondagem, à medida que ele é cortado (SERRA Jr., 1991). Existem vários tipos de barrilete, cujos avanços tecnológicos têm procurado diminuir a rotação e o atrito da amostra com a camisa interna, evitando ainda seu contato direto com o fluido de perfuração. Todos esses cuidados são realizados na tentativa de aumentar a porcentagem de recuperação das amostras, principalmente em rochas menos resistentes. A retirada de "amostras íntegras" é importante para a caracterização dos materiais, tanto nas áreas de geologia de engenharia, como em mineração.

A ferramenta cortante, que no caso da sondagem rotativa geralmente é uma coroa, é rosqueada na extremidade do barrilete. Via de regra, o material cortante utilizado nas coroas é carboreto de tungstênio ("widia") ou diamante industrial (SERRA Jr., op.cit.). A especificação das coroas é de fundamental importância numa campanha de sondagens, podendo determinar tanto a qualidade dos testemunhos, quanto o rendimento da perfuração (BERBERIAN, 1986).

As coroas de widia possuem formato de pastilhas (retangular, hexagonal ou piramidal) e são embutidas no corpo da coroa. Sua utilização está mais associada a materiais inconsolidados, que fornecem menor resistência à perfuração (SERRA Jr., op.cit.). Coroas diamantadas são bastante difundidas na perfuração para fins de prospecção e seus principais elementos constituintes são:

a) estruturais - corpo e matriz

b) funcionais - rosca, batente, lateral externa, lateral interna ou garganta, face, saídas d'água e diamantes (Figura 3.24).
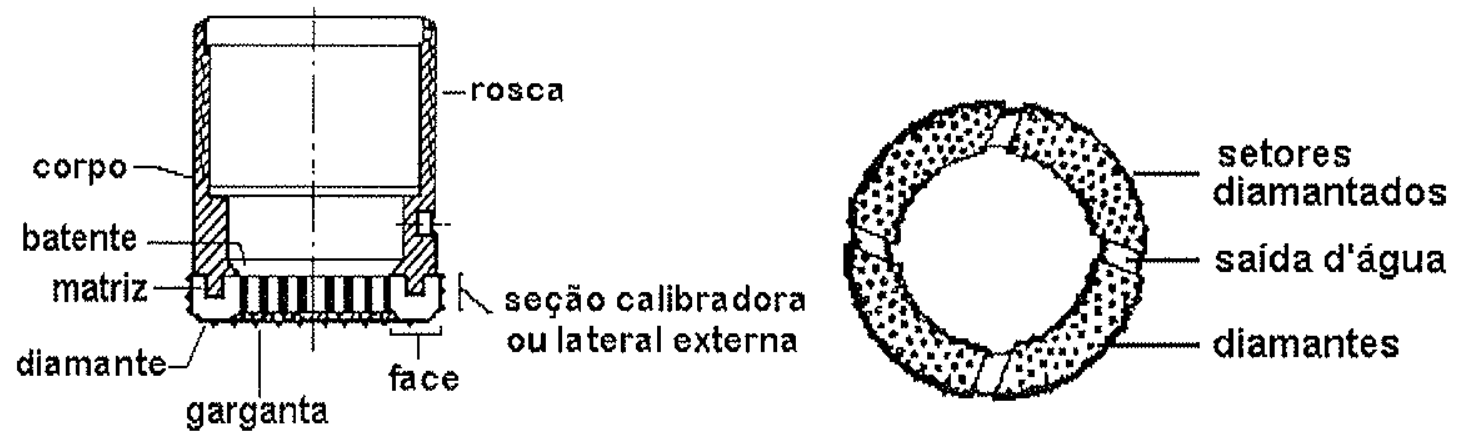

Figura 3.24 - Elementos estruturais e funcionais das coroas diamantadas (MARX, $1967^{2}$ apud SERRA Jr. 1991).

\footnotetext{
${ }^{2}$ MARX, C. (1967) Diamonds bits and their use in shallow holes. Publicação da Christensen Diamonds Products Co. Mining Division, 30 p..
} 
O corpo da coroa contém os elementos funcionais rosca e batente, saliência interna que torna mais robusta a região diamantada (matriz). O corte do corpo da coroa e seus detalhes construtivos estão relacionados ao tipo e série do barrilete (SERRA Jr., 1991). O elemento estrutural matriz contém os demais elementos estruturais: diamantes, garganta, lateral externa, face e saídas d'água.

A matriz realiza a fixação dos diamantes ao corpo da coroa, sendo também composta por um material duro e resistente à abrasão. A dureza da matriz é especificada de acordo com a dureza dos materiais perfurados, sendo classificada em três categorias (SERRA Jr., op.cit.): (a) matriz normal - rochas pouco abrasivas, (b) matriz dura - rochas medianamente abrasivas e (c) matriz extradura - rochas muito abrasivas.

O diamante é considerado um dos elementos funcionais de maior importância nas coroas. Apesar da sua extrema dureza, os diamantes são relativamente frágeis, o que determina que as operações de perfuração realizem-se sem impactos ou vibrações excessivas, evitando fraturas pelos seus planos de clivagem. O aquecimento dos diamantes é controlado com a circulação de fluido no local de corte, evitando sua grafitização (entre 450 e $850^{\circ} \mathrm{C}$ em ambiente oxidante) (SERRA Jr., op.cit.).

O diamante "drilling" é o tipo selecionado e de boa qualidade, utilizado na indústria de perfuração. São classificados em categorias, denominadas "extra", "primeira qualidade", "segunda qualidade", etc., ou com codificações equivalentes, conforme o país de origem ou processo de industrialização (IPT, $1977^{3}$, ABGE, $1980^{4}$ apud SERRA Jr., op.cit.). Essa classificação relaciona-se ao grau de pureza do diamante, referindo-se a eventuais inclusões de outros elementos, tais como, silicatos, óxidos de ferro, etc. (MAQUESONDA, s.d.). O tamanho do diamante é expresso em número de pedras por sua unidade de peso (quilate), ou seja, pedras por quilate (PPQ) (um quilate $\cong 0,2 \mathrm{~g}$ ).

A face da coroa desempenha importante papel durante a perfuração, já que contém os diamantes responsáveis pelo corte. A face pode ter diferentes contornos, denominados perfis de face. Os diversos perfis de face são determinados pelas diferenças de resistência dos materiais perfurados e pelas particularidades das coroas, definidas pela série do

\footnotetext{
${ }^{3}$ INSTITUTO DE PESQUISAS TECNOLÓGICAS DO ESTADO DE SÃO PAULO (1977) Pesquisa e acompanhamento técnico sobre equipamentos de sondagens rotativas. Relatório n⒒813.

${ }^{4}$ ASSOCIAÇÃO BRASILEIRA DE GEOLOGIA DE ENGENHARIA (1980) Glossário de termos técnicos de geologia de engenharia. Equipamentos de sondagem. São Paulo, 65 p.il..
} 
equipamento (SERRA Jr., 1991). Existem quatro perfis padronizados ("DCDMA"): (a) plano, (b) semiplano, (c) arredondado e (d) semi-arredondado. Os perfis semiplano e semiarredondado são os mais usados para condições gerais de perfuração. Existem outros perfis, como os escalonados, com um ou mais degraus. Os perfis padronizados e um exemplo de um perfil escalonado com quatro degraus são apresentados na Figura 3.25.

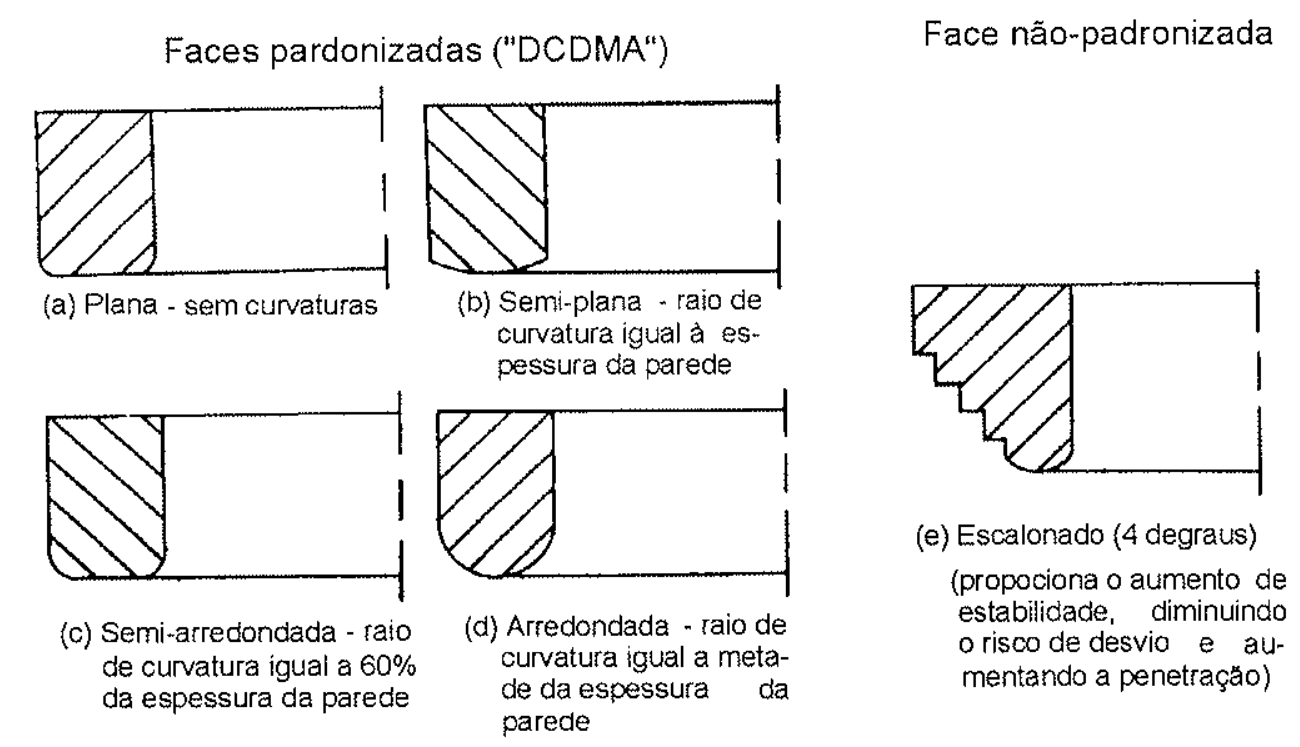

Figura 3.25 - Perfis da face de corte - coroas diamantadas (DIAMANGEO, s.d. e MAQUESONDA, s.d.).

As saídas d'água na coroa têm a função de permitir a passagem do fluido de perfuração do interior da coluna, o qual realiza a refrigeração da coroa e o carreamento dos detritos originados pela perfuração. Normalmente as saídas d'água são formadas por cortes na superfície da própria face da coroa (Figuras 3.24 e 3.26). As saídas d'água podem ser construídas por meio de furos longitudinais no próprio corpo da coroa. Nesse caso elas são chamadas de saídas frontais. Esse tipo de saída procura diminuir o contato da água com o testemunho e aumentar a recuperação.

De acordo com a forma de distribuição dos diamantes, as coroas são agrupadas em duas categorias: (a) coroa com diamantes cravados e (b) coroa com diamantes impregnados.

a) coroas cravadas

Esse tipo de coroa é bastante utilizado e possui uma única camada de diamantes, distribuídos na superfície da face da coroa e incrustados até certa profundidade na matriz. Normalmente são empregadas de 10 a $80 \mathrm{PPQ}$, sendo que após perderem seu poder de corte, uma grande porcentagem dos diamantes é recuperada pelo processo de descravação. A escolha da matriz em função do tipo de rocha a ser perfurada é um fator de grande importância para a obtenção de uma perfuração eficiente. 
A quantidade em peso de diamantes de uma coroa é denominada quilatagem. Os principais fatores que influenciam a quilatagem são o diâmetro da coroa e o tamanho das pedras ("PPQ" ou "número de pedras por quilate"). Um exemplo do tamanho das pedras em função do valor em PPQ é apresentado na Figura 3.26.
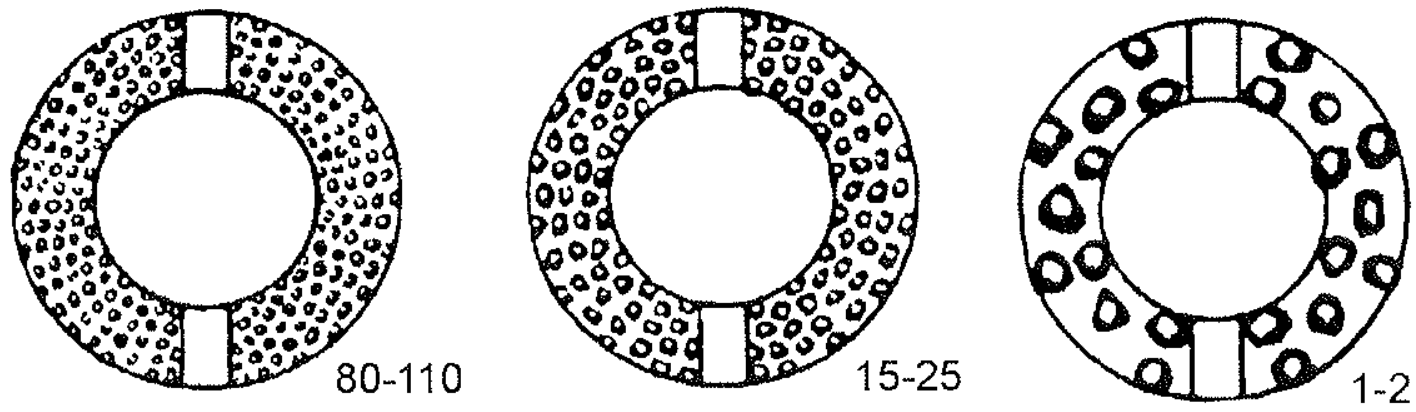

Figura 3.26 - Tamanho relativo das pedras em função do PPQ (pedras por quilate) (MAQUESONDA, s.d.).

A escolha do tamanho dos diamantes também é função do tipo de rocha a ser perfurada. Via de regra as pedras maiores são recomendadas para rochas de baixa resistência, e as pequenas para rochas mais resistentes.

Os diamantes podem estar mais ou menos enrustidos na massa da matriz, sendo que apenas $1 / 3$ a $1 / 8$ do tamanho do diamante fica projetado para fora da mesma. Essa projeção é chamada exposição do diamante. Há recomendações para que em rochas de baixa resistência utilizem-se maiores exposições, e a situação inversa para rochas resistentes. Contudo, AQUINO (1976) ${ }^{5}$ apud SERRA, Jr. (1991) ressalta que cada fabricante adota um critério próprio, dentro dos limites acima citados, e fornece as coroas, quando não solicitados em contrário, dentro de suas próprias especificações.

b) coroas impregnadas

As coroas com diamantes impregnados possuem pequenas partículas de diamantes uniformemente distribuídos dentro da matriz. À medida que desgasta a matriz, novos diamantes são expostos até o limite da profundidade impregnada, de tal forma que a coroa é consumida até o desgaste total. São empregados diamantes de 80 a 1000 PPQ. Essa coroa é

${ }^{5}$ AQUINO, J. B. (1976) O uso do diamante na perfuração de rochas. Publicação da SONDAP Sondas e Equipamentos de Prospeç̧ão, 52 p. 
recomendada para rochas homogêneas e resistentes (HUART, $1977^{6}$ apud SERRA Jr., 1991).

Para o presente trabalho, a coroa utilizada e suas características possuem relevância, uma vez que influenciam diretamente a perfuração. No entanto, o trabalho não avançou no sentido de discutir a influência desse fator, devido ao fato de praticamente não se ter variado a ferramenta de corte ao longo de todos os testes em rocha.

\section{Revestimento do furo}

Em muitas situações, em especial quando a prospecção realiza-se a partir do terreno natural, é comum que as sondagens rotativas (mistas) para a prospecção possuam os seus trechos iniciais revestidos para proteção contra o fechamento do furo. Exceção aos furos iniciados diretamente na rocha (afloramentos naturais, pedreiras ou áreas previamente cortadas), as sondagens empregam sempre esse recurso. $O$ revestimento evita 0 desmoronamento do furo e diminui a perda da água de circulação. O fechamento do furo ocorre tanto nos níveis superficiais, devido à baixa resistência e coesão dos solos, como nas porções mais profundas, pela ocorrência de intercalações de rocha fraturada.

O revestimento avança após a perfuração, "recortando" (aumentando o diâmetro do furo) para a instalação sucessiva de suas peças rosqueáveis. A coluna de revestimento é adaptada na boca do furo ao hasteamento. Como o restante do equipamento de perfuração, o revestimento é um equipamento padronizado para os diversos diâmetros existentes.

A evolução do equipamento de perfuração rotativa criou uma padronização e normas de nomenclatura. $O$ balanceamento da coluna, numa seqüência integrada de diâmetros, segundo o princípio telescópico, permite a diminuição progressiva do diâmetro e o conseqüente avanço do furo. Existem dois sistemas que normalizam internacionalmente a nomeclatura e as dimensões dos equipamentos de sondagem rotativa diamantada: (a) o sistema americano, desenvolvido em conjunto pela "Diamond Core Drill Manufactures Association" (DCDMA), "Canadian Diamond Drilling Association", (CDDA), "British Standard Institute" (BSI), "Australian Diamond Drilling Association" (ADDA) e "South African Diamond Association" (SADA), e o sistema europeu ou métrico Craélius, 
desenvolvido pela Companhia Craélius, mais utilizado na Europa (IPT, $1977^{7}$ apud SERRA Jr., 1991).

O resumo da nomenclatura utilizada pelo sistema americano ou "DCDMA" é apresentado no Quadro 3.5.

Quadro 3.5 - Nomenclatura do sistema americano ou "DCDMA" para equipamentos de sondagem rotativa diamantada (SERRA Jr., 1991).

\begin{tabular}{|l|l|l|}
\hline Designação & Nomenclatura de duas letras & Nomeclatura de três letras \\
\hline Equipamentos & $\begin{array}{l}\text { Primeira: diâmetro do furo } \\
\text { Segunda: grupo e série }\end{array}$ & $\begin{array}{l}\text { Primeira: diâmetro do furo } \\
\text { Segunda: grupo de furos } \\
\text { telescopáveis e hastes } \\
\text { Terceira: série }\end{array}$ \\
\hline $\begin{array}{l}\text { Hastes de perfuração e } \\
\text { conectores }\end{array}$ & Ew, Aw, Bw, Mw & - \\
\hline $\begin{array}{l}\text { Barrilete, calibrador e coroa } \\
\text { diamantada }\end{array}$ & $\begin{array}{l}\text { Grupo } x-\text { junção lisa com conector: } \\
\mathrm{Rx}, \mathrm{Ex}, \mathrm{Ax}, \mathrm{Bx}, \mathrm{Nx}, \mathrm{Hx} ; \\
\begin{array}{l}\text { Grupo } w-\mathrm{wunção} \mathrm{lisa} \mathrm{sem} \mathrm{conector} \\
\text { (direta): Rw, Ew, Aw, Bw, Nw, Hw, } \\
\text { Pw, Sw, Uw, Zw }\end{array}\end{array}$ \\
\hline $\begin{array}{l}\text { Tubo de revestimento } \\
\text { (calibrador, conectores } \\
\text { coroa e sapata) }\end{array}$ & $\begin{array}{l}\text { EwT, AwT, BwT, NwT, HwT } \\
\text { EwM, AwM, BwM, NwM, HwM }\end{array}$ \\
\hline
\end{tabular}

A série "T" não é muito conhecida no Brasil, enquanto que as séries " $D$ " e " $L$ ", equivalentes à série " $\mathrm{M}$ ", são muito utilizadas; o sistema "wire-line" tem nomenclatura com duas e três letras: a primeira designa o diåmetro, a segunda " $Q$ " o grupo e série "wire-line". Há também uma terceira letra " $U$ " que designa uma série especial desse equipamento. As hastes de perfuração possuem nomenclatura com duas ou três letras (p.e. "NQ" e "NCQ").

O protótipo para o monitoramento de perfuração foi adaptado em uma sonda fabricada pela Indústria Nacional de Sondas e Equipamentos "SONDEQ" Ltda., modelo SS21. As principais caracteristicas técnicas da sonda Sondeq SS-21 estão apresentadas no Quadro 3.6.

O motor da sonda aciona o sistema de transmissão, que estabelece a rotação da coluna de perfuração. Esse motor aciona ainda (a) uma bomba que alimenta um sistema hidráulico e determina o avanço e recuo da coluna, por meio de dois pistões $(\varnothing=60 \mathrm{~mm}) \mathrm{e}$ (b) o guincho que retira a coluna de perfuração durante as manobras ${ }^{8}$.

\footnotetext{
${ }^{7}$ INSTITUTO DE PESQUISAS TECNOLÓGICAS DO ESTADO DE SÄO PAULO (1977) Escolha de equipamento de sondagens rotativas para investigaçöes geológicas em locais de barragens. Relatório $n^{\circ} 10.194$.

${ }^{8}$ intervalos na perfuração, quando o barrilete é içado para a retirada das amostras perfuradas no trecho.
} 
Quadro 3.6 - Características técnicas da Sonda SS-21 (SONDEQ. s.d. ${ }^{a}$ ).

\begin{tabular}{|c|c|c|}
\hline UNIDADE DA SONDA & \multicolumn{2}{|c|}{ CARACTERISTICAS } \\
\hline Motor & \multicolumn{2}{|c|}{$\begin{array}{l}\text { Agrale } M-790 \text { dois cilindros e potência de } 20-27 \mathrm{cv} / \mathrm{DIN} \text { (a } 2.000 \text { e } \\
3.000 \mathrm{rpm} \text {, respectivamente) }\end{array}$} \\
\hline Transmissão & \multicolumn{2}{|c|}{ Três velocidades com relações $(6.6: 1),(4.3: 1)$ e $(2.2: 1)^{9}$} \\
\hline Sistema Hidráulico & \multicolumn{2}{|c|}{$\begin{array}{l}\text { Dois cilindros com avanço de } 500 \mathrm{~mm} \text { e ângulo de giro de } 360 \text { graus. } \\
\text { Acionamento do sistema através de uma bomba de palhetas (vazão } \\
\text { constante em torno de até } 23 \text { litros/minuto) }\end{array}$} \\
\hline \multicolumn{3}{|c|}{ CAPACIDADE DE PERFURAÇÃO } \\
\hline Furo & Diâmetro (mm) & Profundidade $(\mathrm{m})$ \\
\hline Ex & 38.1 & 280 \\
\hline Ax & 49.2 & 210 \\
\hline $\mathrm{Bx}$ & 60.3 & 160 \\
\hline $\mathrm{Nx}$ & 76.2 & 120 \\
\hline $\mathrm{Hx}$ & 99.9 & 100 \\
\hline
\end{tabular}

A bomba para a limpeza e refrigeração da perfuração também é fabricada pela "SONDEQ", modelo SB-75 C. Suas principais características estão resumidas no Quadro 3.7. O equipamento utilizado está apresentado na Figura 3.27.

Quadro 3.7 - Características técnicas da bomba para o fluido de circulação (SONDEQ, s.d. ${ }^{\text {b) }}$.

\begin{tabular}{|l|l|l|l|}
\hline \multicolumn{3}{|c|}{ BOMBA SONDEQ SB-75 } \\
\hline Vazão máxima & $75 \mathrm{l} / \mathrm{min}$ & Motor & $M 85-$ Agrale $2.300 \mathrm{~cm}^{3}$ \\
\hline Pressáo máxima & $35 \mathrm{~kg} / \mathrm{cm}^{2}$ & Potência & $7,5 \mathrm{HP}$ \\
\hline
\end{tabular}

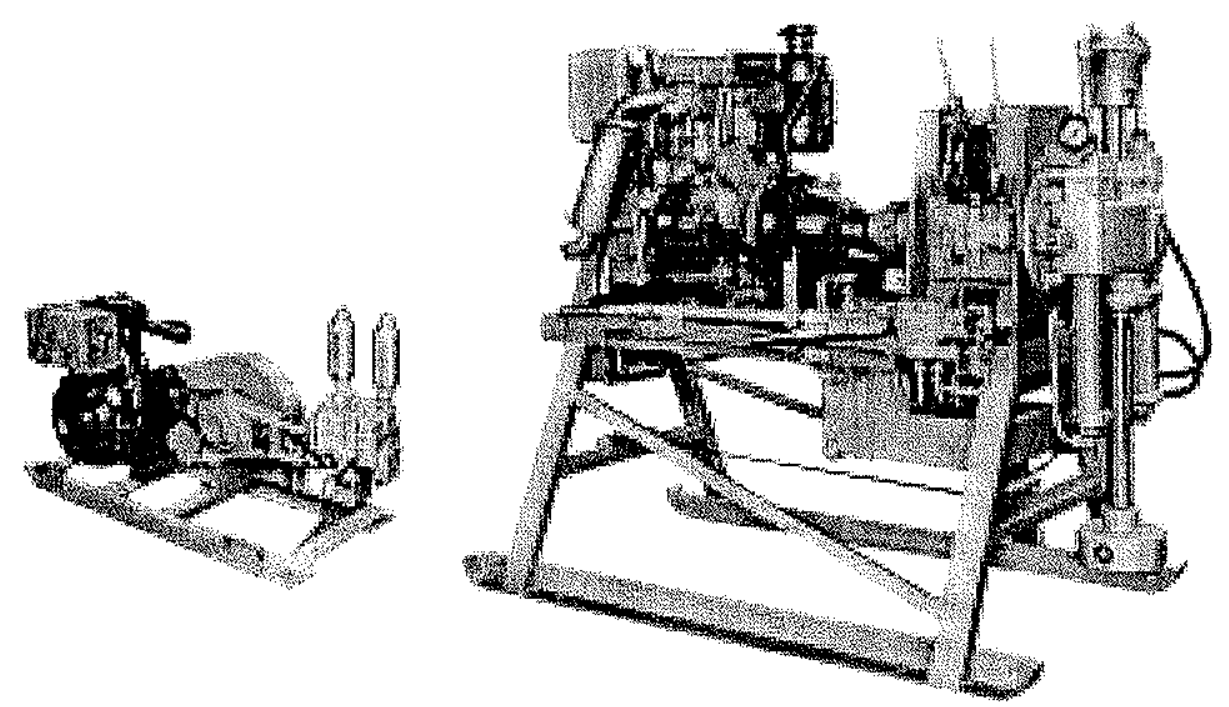

Figura 3.27 - Bomba SB-75 e sonda para prospecção geológica SS-21 (SONDEQ, s.d. ${ }^{a}$ e SONDEQ, s.d. $\left.{ }^{b}\right)$.

${ }^{9}$ Esses valores referem-se ao catálogo do equipamento. As reais relações adotadas foram medidas diretamente no equipamento. 


\subsubsection{Perfuração abrasiva}

Os estudos sobre perfurabilidade de rocha são numerosos, principalmente considerando a perfurabilidade por métodos percussivo e rotopercussivo. Existem trabalhos desenvolvidos especificamente para a perfuração abrasiva, porém em quantidade menor. $\mathrm{Na}$ sua maioria, os trabalhos sobre perfurabilidade têm por objetivo a previsão de produção e rendimento das ferramentas cortantes, não existindo preocupação específica com a classificação do material. Geralmente, a classificação das rochas perfuradas baseia-se no tipo litológico, constituição mineralógica ou apenas na porcentagem total de quartzo, sendo realizada apenas como um meio para a obtenção do objetivo principal.

No entanto, alguns trabalhos avançam no sentido de correlacionar a perfurabilidade com índices físicos e parâmetros geotécnicos: resistência à compressão (TSOUTRELIS, 1969); porosidade e densidade aparentes, e resistência à compressão e tensão, coeficiente de Poison e módulo de Young (estático e dinâmico) (CLARK, 1979).

PROTODYAKONOV (1963) relaciona a dureza (resistência ao corte), a deformabilidade e a abrasividade como as três principais propriedades que influenciam a perfuração. $O$ autor afirma que o método de perfuração estabelece a importância relativa de cada uma das propriedades envolvidas. Para as sondagens rotativas, a dureza e a abrasividade determinam preponderantemente o grau de perfurabilidade da rocha. $O$ autor apresenta ainda um equipamento para a medida de dureza e abrasividade para avaliação da perfurabilidade rotativa. $O$ aparelho é constituído por três unidades: (a) de perfuração, (b) de avanço e (c) de medida da força axial. Por meio de testes de perfuração é determinada a resistência da rocha à perfuração abrasiva.

CLARK (op.cit.) reserva um capítulo especialmente para discussão da perfuração diamantada. O trabalho apresenta também resultados de diversos estudos sobre esse tipo de perfuração. $O$ autor afirma que os estudos experimentais para a avaliação da perfurabilidade de rocha com ferramentas diamantadas baseiam-se: (a) na dureza e na tenacidade das rochas, (b) na potência aplicada por volume perfurado de rocha e (c) na taxa de penetração relacionada às forças resistivas da rocha e às penetrativas aplicadas. Sondagem diamantada é o principal item de custo nas atividades de prospecção geotécnica, determinando a importância da previsão da perfurabilidade da rocha para uma adequada estimativa de custos. 
A força de rotação atuante na coroa diamantada provoca ruptura e cominuição na superfície da rocha, devido à pressão exercida e à remoção da rocha pela ação de corte dos diamantes. A resistência da rocha à perfuração pode ser entendida como a reação à pressão sobre a ferramenta de corte e a resistência ao corte que se opõe ao torque da sondagem (CLARK, 1979).

3.3. Técnica do monitoramento da perfuração (diagrafia instantânea)

O controle, registro e interpretação dos fatores que intervêm na perfuração de solos e rochas é uma técnica utilizada há algumas décadas nas áreas de petróleo, geotecnia e hidrogeologia.

A utilização do monitoramento da perfuração em geotecnia inicia-se na França em meados dos anos 70 do século passado (COELHO \& SANTOS, 1985). CASSAN (1988) afirma que o surgimento do primeiro aparelho comercial aconteceu após 1974, com a empresa Jean Lutz. Posteriormente, outros dispositivos vieram como o "ENPASOL numerique" da empresa Soletanche (em 1981), o aparelho L.I.M. (em 1985) e o aparelho FONDASOL (em 1986).

No início da década de 1980, dois importantes eventos deram destaque à utilização da técnica de diagrafia instantânea. Em 1982, o $14^{\circ}$ CONGRESSO INTERNACIONAL DE GRANDES BARRAGENS apresenta um relato do Comitê Francês sobre Novas Técnicas de Prospecção. Em 1983, o SYMPOSIUM INTERNATIONAL RECONNAISSANCE DES SOLS ET DES ROCHES PAR ESSAIS EN PLACE, promovido pela I.A.E.G. (International Association of Engineering Geology and Environment), reserva um tema especialmente para o assunto diagrafia.

Uma forma de monitoramento não automatizado é descrita por CETESB (1978). O autor refere-se à realização em sondagem-teste (rotativa) de perfis cronológicos, perfilandose dados de tempo médio de perfuração para intervalos de $0,5 \mathrm{~m}$. Esse procedimento realizado para a pesquisa de água subterrânea equivale ao monitoramento da velocidade de avanço na diagrafia instantânea.

No Brasil, não se tem registro de trabalhos publicados relatando coleta sistemática e análise de parâmetros de sondagem. Em eventos de caráter nacional, destaca-se o painel apresentado no $5^{\circ}$ CONGRESSO BRASILEIRO DE GEOLOGIA DE ENGENHARIA, referente ao trabalho de SCARMÍNIO (1988) e as discussões ocorridas no $7^{\circ}$ CONGRESSO BRASILEIRO DE GEOLOGIA DE ENGENHARIA por ocasião dos trabalhos de TAIOLI 
et al. (1993) e DOBEREINER et al. (1993). SILVA (1995) faz uma revisão bibliográfica sobre o tema e apresenta resultados de testes manuais (não automatizados) da técnica do monitoramento da perfuração em investigações para túneis e barragens.

Embora na área de hidrogeologia a aplicação da técnica seja muito mais restrita, os equipamentos de perfuração e de monitoramento são idênticos. Mesmo com objetivos finais distintos, as campanhas de investigação nessas duas áreas destinam-se a localizar e classificar feições geológicas de interesse.

Os equipamentos utilizados para o monitoramento de sondagens destrutivas possuem diversos fabricantes. Os principais equipamentos comercialmente utilizados são: (a) Enpasol (b) Solétanche, (c) Diagrofar Lutz, (d) Mazier-Renoult e (e) Dactest. Os princípios básicos de funcionamento desses equipamentos são bastante semelhantes (SILVA, op.cit.).

Considerando as perfurações realizadas para geotecnia, cujas condições são bastante próximas às do equipamento e dos furos do presente trabalho, os objetivos do monitoramento seriam resumidos em: (a) controle da perfuração, visando a obtenção de informações para a melhor classificação dos maciços perfurados; (b) mapeamento das condições das descontinuidades (geralmente não identificáveis no procedimento tradicional de investigação: condições de alteração e preenchimento de fraturas e falhas, zonas fraturadas); (c) controle de qualidade de serviços geotécnicos (injeção para a impermeabilização e consolidação de maciços), (d) utilização da maior quantidade possível de furos sem amostragem, objetivando diminuição de custos e prazos das campanhas e (e) realização de furos em condições que provoquem o menor desgaste possivel nas ferramentas cortantes.

Uma abordagem semelhante à do presente trabalho foi apresentada por d'ÁVILA et al. (1994), onde foi realizado o monitoramento experimental de sondagens rotativas com amostragem. O sistema denominado SISPER ("Sistema de instrumentação de sonda rotativa") foi desenvolvido a partir de uma sonda de pequeno porte: MACH 920 da Maquesonda (potência de $11 \mathrm{CV}$ ). Esse tipo de perfuratriz é mais utilizado para serviços geotécnicos, tais como execução de tirantes, do que propriamente para prospecção geológica. O protótipo monitorava os seguintes parâmetros: (a) pressão do fluido de perfuração, (b) carga no sistema de avanço do furo (manual) e (c) deslocamento da ferramenta.

Para sondagem rotativas em geotecnia e mineração, destaca-se que as impressões do sondador, obtidas durante a execução do furo, são bastante precisas em algumas situações. 
Durante a perfuração, o operador da sonda "sente" os diferentes materiais perfurados, por meio do comportamento da velocidade de avanço da perfuração, porcentagem da aceleração total do motor (potência) necessária à manutenção da velocidade de rotação, vibração da coluna de perfuração, etc. Essas observações do sondador permitem a inferência de algumas características do material perfurado, mesmo antes da retirada e abertura do barrilete. Essas características referem-se principalmente a: (a) tipos litológicos num determinado contexto geológico, (b) alteração e intercalações alteradas no maciço rochoso, (c) graus de fraturamento diversos, (d) fraturas isoladas, (e) ausência e tipo de preenchimento de fraturas.

No entanto, essas informações raramente são aproveitadas na confecção do Perfil Individual de Sondagem ${ }^{10}$, em muitas ocasiões nem mesmo são registradas no Boletim de Sondagem (ou Boletim do Sondador) ${ }^{11}$

PEREDA (1998) afirma que nem sempre é possível conciliar a produção dos furos com a obtenção de dados para a análise dos parâmetros da perfuração, pois esse último, muitas vezes requer que a sonda seja manobrada de forma específica, prejudicando a produtividade. Em perfurações rotativas, por exemplo, parâmetros como pressão sobre a coroa e velocidade de rotação podem ser alterados pelo sondador, a fim de prolongar a vida útil da ferramenta e manter uma condição satisfatória de produção. PEREDA (op.cit.) comenta a terminologia específica, onde o termo "furação" estaria mais associado à operação de perfurar, destruindo o material, sem a preocupação de amostragem. Já o termo "sondagem" relacionar-se-ia à perfuração com a intenção de auscultação e retirada de testemunhos para sua amostragem sistemática.

A técnica do monitoramento dos parâmetros de perfuração, também é conhecida como "diagrafia instantânea", difere-se da diagrafia diferida (retardada) pelo fato dessa segunda realizar-se nos testemunhos coletados ou nas paredes internas (métodos geofísicos: elétricos, térmicos, acústicos ou radioativos), após a execução do furo.

Todos os fatores que influenciam a perfuração ou são determinados pelas condições

${ }^{10}$ Perfil Individual de Sondagem é o documento oficial da empresa responsável pela execução da sondagem, o qual descreve os materiais amostrados, suas caracteristicas (alteração, fraturamento, etc.), os métodos executivos da perfuração e ainda outras informações de interesse (niveis d'água verificados, profundidade dos revestimentos, etc.). Todas essas informações são apresentadas em formulário padronizado.

${ }^{11}$ Boletim de sondagem è o documento onde o operador da sonda descreve as atividades relativas principalmente à execução do furo. Esse documento serve de subsídio à confecção do Perfil Individual de Sondagem. 
dos maciços perfurados, denominam-se parâmetros de perfuração. Esses parâmetros são divididos em dois grupos, segundo BROWN \& BARR (1978): variáveis independentes e variáveis dependentes. BAPTISTA (1986) e SCARMÍNIO (1988) para essa mesma divisão denominam os grupos de parâmetros de funcionamento da sonda e parâmetros do terreno, respectivamente.

\subsubsection{Variáveis independentes ou parâmetros de funcionamento}

As variáveis independentes são aquelas controladas diretamente pelo operador da sonda:

a) Pressão sobre a ferramenta de corte

A pressão sobre a ferramenta de corte é o principal parâmetro de funcionamento, representado pela força axial exercida pelo sistema hidráulico da sonda sobre a ferramenta de corte, no sentido de avanço do furo. Essa força é determinada principalmente pela vazão e pela pressão de óleo do sistema hidráulico (controlada pelo operador e regulada na bomba hidráulica). Ressalta-se que essa pressão é convertida em força pelo sistema hidráulico. Assim, o parâmetro mais significativo é a força no sentido da perfuração, ou ainda, a pressão da superfície de corte da ferramenta sobre o material perfurado (solo ou rocha), considerando a superfície de corte.

Em furos verticais ou com altos mergulhos, quando essa força tem sentido oposto ao avanço, denomina-se força de frenagem o esforço exercido pelo equipamento para aliviar o peso da composição sobre a ferramenta de corte. A pressão efetiva (ou peso efetivo) sobre a ferramenta de corte é dada pela soma dos efeitos determinados pelo equipamento (carregamento ou frenagem), pelo próprio peso da ferramenta de corte e do hasteamento, e pelo empuxo exercido pelo fluido de perfuração.

No tipo de sonda utilizado nos testes do protótipo, foi necessário o controle de pressão em dois pontos do sistema hidráulico, para determinar o sentido da força e o seu valor absoluto. Na parte experimental do trabalho, esses valores são referidos como pressões descendente (PDesc) e ascendente (PAsc), respectivamente.

Diversos autores, apresentam dados sobre as correlações da pressão ou força sobre a ferramenta de corte (BROWN \& BARR, 1978; CLARK, 1979; HOWARTH \& ADAMSON, 1988). As melhores correlações da pressão ocorrem com a velocidade de avanço e com o torque. 
b) Velocidade de rotação

Esse parâmetro, controlado parcialmente pelo operador, representa a velocidade angular que o sistema de transmissão do equipamento de perfuração imprime à ferramenta de corte em furos rotativos e rotopercussivos. Para pressão de corte constante, o aumento da velocidade de rotação tende a aumentar a velocidade de avanço da sondagem, resguardadas as condições apropriadas de refrigeração da coroa e de limpeza da frente perfurada.

A velocidade de rotação da coluna, de maneira inversa ao torque, varia com as diversas marchas do sistema de transmissão. Para um nível de potência constante, o aumento da pressão diminui a velocidade de rotação e aumenta o torque aplicado ao processo de perfuração.

c) Vazão de saída da bomba do fluido de circulação

O fluido de circulação, normalmente água ou lama, é utilizado para refrigeração da ferramenta de corte, remoção dos detritos da perfuração e estabilização das paredes do furo. A vazão do fluido é determinada pela capacidade da bomba e pela forma de sua operação (porcentagem da aceleração total do motor que a aciona). O registro desse parâmetro é realizado com a instalação de um medidor de vazão na linha. A influência da vazão do fluido de circulação no processo de perfuração aumenta em materiais com menores valores de resistência. As altas velocidades de avanço aumentam a importância da remoção eficiente dos detritos.

\subsubsection{Variáveis dependentes ou parâmetros do terreno}

São aquelas que respondem mais diretamente às condições do terreno perfurado.

a) Velocidade de avanço

Embora a velocidade de avanço seja influenciada por uma série de outros parâmetros de funcionamento, ainda assim ela reflete diretamente a resistência dos materiais perfurados, sendo relacionada diretamente à perfurabilidade.

Devido à facilidade na sua obtenção e à possibilidade de precisão nos seus registros, esse parâmetro é considerado, nesta técnica, o mais importante parâmetro do terreno.

b) Percussão refletida

Parâmetro característico de sondagens percussivas ou rotopercussivas ("wagondrill"), onde a energia para a perfuração é aplicada por meio de choques periódicos, 
transmitidos para o maciço pelo conjunto de hastes. A energia transmitida pelo equipamento é parcialmente consumida na cominuição da rocha, sendo parte refletida. O monitoramento da percussão refletida consiste no registro da amplitude da onda refletida pelo maciço (COELHO \& SANTOS, 1985). O parâmetro percussão refletida está diretamente relacionado à resistência e dureza da rocha, e ao seu grau de fragmentação.

c) Torque (momento ou binário de rotação)

Nos equipamentos para o monitoramento de sondagem ou diagrafia instantânea (sem amostragem), o torque é medido por intermédio da instalação de um transdutor de pressão no circuito hidráulico ou pneumático de alimentação do motor de rotação (sondagens rotopercussivas) (SCARMÍNIO, 1988).

Nas sondagens rotativas, o parâmetro torque traduz o esforço que o motor da sonda exerce sobre a ferramenta, vencendo a reação criada pelo atrito entre a ferramenta de corte e o terreno. Esse esforço de torção é transmitido do motor à ferramenta de corte, pelo sistema de transmissão, através do conjunto de hastes de perfuração. Deve-se destacar que o torque é bastante influenciado pela pressão sobre a ferramenta cortante, pelo atrito das hastes com as paredes do furo (furos profundos) e pela redução do fluido de circulação (BAPTISTA, 1986).

Ensaios em laboratório mostram a relação do torque com outros parâmetros ou índices do processo de perfuração. As relações do torque com a penetração por rotação e com a força exercida sobre a ferramenta estão apresentadas nas figuras 3.28 e 3.29 , respectivamente.

d) Pressão do Fluido de Circulação

A pressão do fluido de circulação é um parâmetro associado ao grau de estanqueidade (permeabilidade) das unidades atravessadas pela ferramenta de sondagem. A pressão do fluido é um parâmetro bastante sensível em algumas litologias. A ferramenta de corte, ao atravessar materiais argilosos, especialmente plásticos e pouco rígidos, tende a sofrer um afundamento no fundo do furo, dificultando a circulação pelo fechamento das saídas de água e, consequentemente, aumentando a pressão do fluido de circulação. Da mesma maneira, terrenos arenosos, maciços fissurados ou outros níveis de materiais de alta permeabilidade tendem a produzir uma diminuição na pressão do fluido de circulação, devido à facilidade da percolação nesses meios (SCARMíNIO, 1988). 


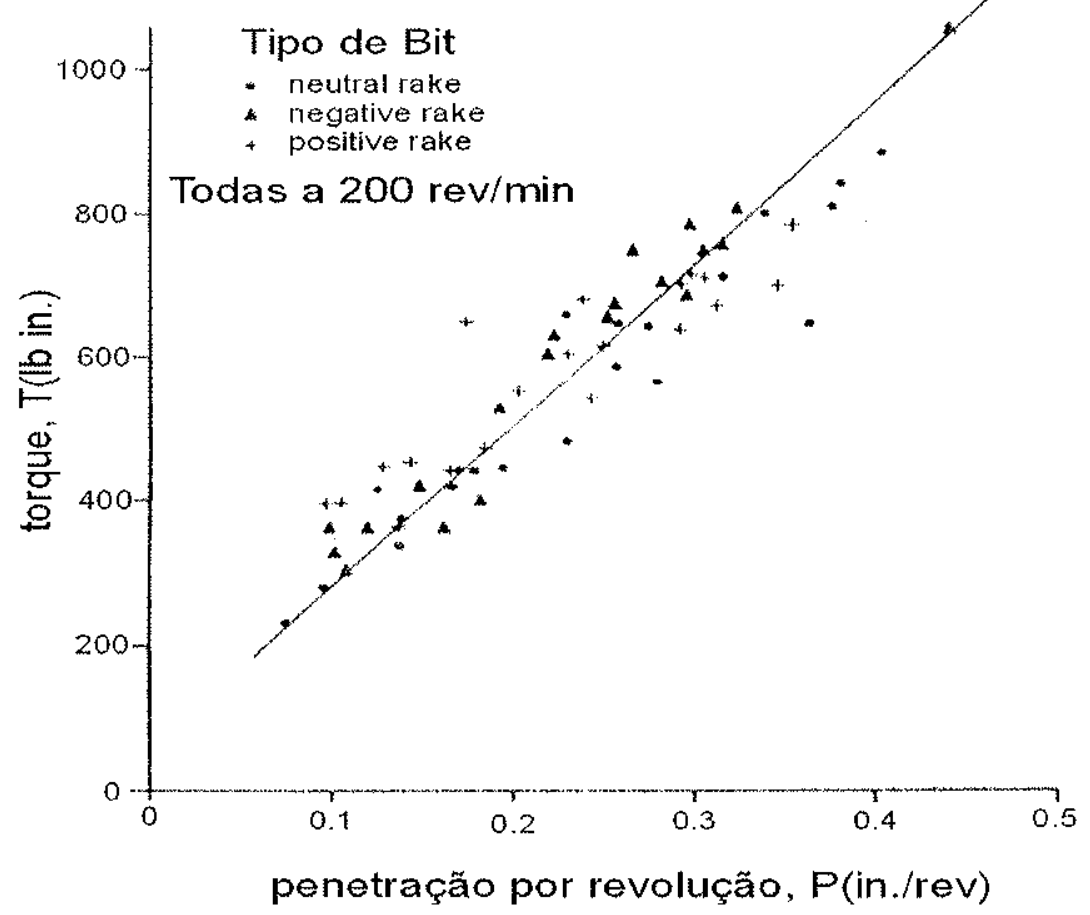

Figura 3.28- Torque e penetração por revolução para sondagens rotativas em folhelho (TEALE, 1965).

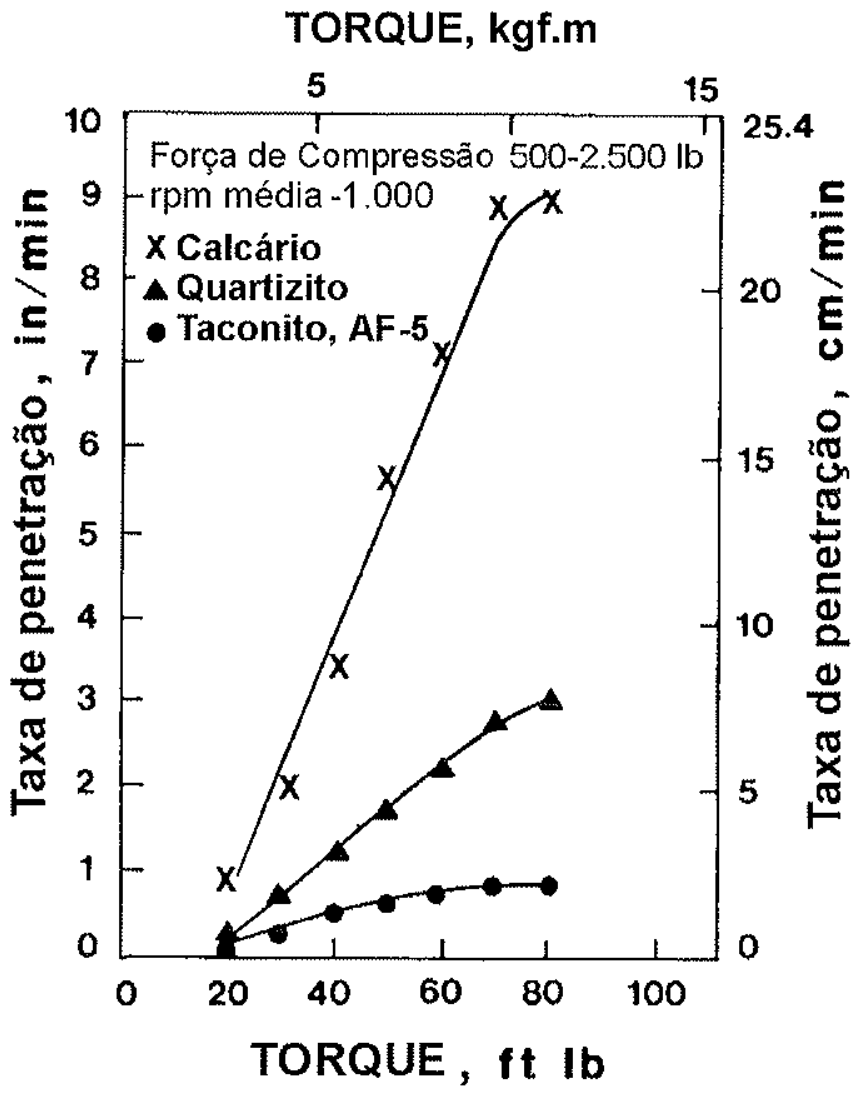

Figura 3.29 - Torque e velocidade de avanço para sondagens rotativas (CLARK, 1979). 
e) Ganho / Perda do Fluido de Circulação

O controle da quantidade de fluido de circulação é realizado com o balanço entre o volumes injetado e restituído pelo furo. Seu controle também fornece informações sobre as condições hidrogeológicas/ hidrogeotécnicas dos maciços: presença de descontinuidades, zonas fraturadas, condições de artesianismo, etc. O controle desses parâmetros possui interesse especial em materiais mais frágeis (solos ou rochas brandas), devido ao papel desagregador que a água sob pressão assume nessas condições.

3.3.3. Modelos teóricos e empíricos para a interpretação dos parâmetros de perfuração

Diversos autores desenvolveram estudos onde as variáveis envolvidas na perfuração são analisadas e correlacionadas, englobando exemplos em condições de obra e de laboratório, abrangendo os diversos métodos de perfuração. GIRARD (1985) faz um resumo abrangente desses trabalhos. Esses estudos foram motivados por várias finalidades, entre elas: (a) desenvolvimento de equipamentos, (b) otimização das condições de perfuração (maior rendimento de equipamentos) e (c) suporte para utilização da técnica do monitoramento da perfuração.

Outros autores também propuseram modelos para a previsão da perfurabilidade de rocha. Um trabalho dos mais citados é o de TEALE (1965), que trata do conceito de energia específica em perfurações rotativas não percussivas. Essa energia é definida como sendo a energia necessária à perfuração de uma unidade volumétrica de rocha,

$$
E_{v}^{\prime}=\frac{F_{v}}{A}+\frac{W \cdot T}{A \cdot V_{a}}
$$

onde, a primeira parcela refere-se à componente da força de compressão e a segunda ao torque. $F_{v}, T, W, A$ e $V_{a}$ são, respectivamente, a força de compressão sobre a ferramenta, o torque, a velocidade de rotação, a área de corte e a velocidade de avanço do furo.

O próprio autor (op.cit.) sugere que o valor da componente da força de compressão $\left(E_{v}\right)\left(1^{a}\right.$ parcela) é desprezível, quando comparada à componente do torque $\left(E_{t}\right)$ (2 $2^{\mathrm{a}}$ parcela). O presente trabalho considerou apenas a parcela correspondente ao torque para a estimativa da energia envolvida na perfuração.

Outra importante referência é o trabalho de CLARK (1979), que embora não seja específico para perfurações abrasivas, discute detalhadamente o assunto. $O$ autor afirma que as forças sobre a coroa diamantada causam (a) a ruptura superficial ou esmagamento devido ao carregamento e (b) a remoção da rocha pela ação de raspagem dos diamantes. O 
mecanismo de raspagem pelos diamantes seria similar ao atrito desenvolvido entre superfícies de metal (usinagem mecânica). A abrasão da superfície da rocha produz uma resistência variável, devido ao cisalhamento intermitente, causado pela estrutura granular da rocha. Essa resistência intermitente foi também observada por DEKETH (1995) e na parte experimental do presente trabalho (Capítulo 5).

HOWARTH \& ADAMSON (1988) confirmam os valores despreziveis de $E_{v}$, comparados a $E_{t}$ (Quadro 3.8), referentes ao trabalho de TEALE (1965). O trabalho apresenta correlações entre os resultados de testes de perfurabilidade, obtidos através de sondagens e "Tunnel Boring Machines" (TBM em pequena escala), com outros parâmetros e índices físicos: (a) resistência à compressão simples (RCU), (b) densidade aparente e (c) saturada, (d) porosidade aparente, (e) velocidade de ondas de compressão (P) e (f) "Schmidt hammer".

Alguns trabalhos mais recentes apresentam métodos empíricos para a determinação da perfurabilidade das rochas (TAMROCK, 1988 e TAMROCK, 1986). Esses trabalhos tratam a perfurabilidade como a taxa de penetração de uma ferramenta cortante na rocha. TAMROCK (1988) afirma que essa propriedade da rocha não pode ser precisamente definida por qualquer propriedade mecânica da rocha (p.e. resistência à compressão ou tensão), sendo determinada pela composição mineral, textura, tamanho dos grãos (granulação para rochas ígneas ou granulometria para rochas sedimentares), grau de alteração, etc.

Quadro 3.8 - Taxas de energia especifica obtidas do torque e da força de compressão (HOWARTH \& ADAMSON 1988).

\begin{tabular}{|l|c|l|}
\hline Tipo de Ferramenta & Relação $E_{v}: E_{\mathrm{t}}$ & Referência \\
\hline Ferramenta diamantada $\left(\phi_{\mathrm{e}}=37 \mathrm{~mm}\right)$ & $1: 500$ & HOWARTH \& ADAMSON (1988) \\
\hline Drag bits $\left(6 \mathrm{~m}\right.$ dia TBM $\left.{ }^{12}\right)$ & $1: 560$ & $\begin{array}{l}\text { ROWLANDS }(1973)^{13} \text { apud HOWARTH } \\
\text { \& ADAMSON (1988) }\end{array}$ \\
\hline $\begin{array}{l}\text { Drag bits (máquina de perfuração } \\
\text { rotativa) }\end{array}$ & $1: 650$ & $\begin{array}{l}\text { ROXBOROUGH et al.(1972) }{ }^{14} \text { apud } \\
\text { HOWARTH \& ADAMSON (1988) }\end{array}$ \\
\hline
\end{tabular}

\footnotetext{
${ }^{12}$ Equipamento de perfuração de túnel ("tunnell boring machine")

${ }^{13}$ ROWLANDS, D. (1973) Rock frature by diamond drilling. Tese de doutorado, Universidade Queensland, Australia, $157 \mathrm{p}$.

${ }^{14}$ ROXBOROUGH, F.F.; RISPIN, A. (1972) The mechanical cutting characteristics of the Lower Chalk. Relatório para TRRL, p.241. Universidade de Newcastle.
} 
Os índices propostos para a avaliação da perfurabilidade são: (a) índice da taxa de perfuração (DRI) e (b) classificação dos tipos litológicos, baseados na perfurabilidade de uma rocha padrão (Granito Barre).

Apesar desses testes terem sido desenvolvidos para a perfuração percussiva e rotopercussiva, a abordagem do problema é também de interesse para a avaliação da perfurabilidade pelo processo rotativo abrasivo.

O índice de perfuração (DRI) é determinado com base em dois parâmetros: (a) valor de friabilidade $S_{20}$ e (b) valor Siewers J (valor $S J$ ). O valor de friabilidade $S_{20}$ é avaliado no teste de britagem, no qual se obtém a resistência da rocha ao esmagamento, devido ao repetido impacto da queda de um peso $(14 \mathrm{~kg} / 25 \mathrm{~cm}$ de altura). A rocha em teste é britada e uma amostra $(0,5 \mathrm{~kg})$ na fração $11,2-16,0 \mathrm{~mm}$ é submetida a 20 golpes. O índice $\mathrm{S}_{20}$ corresponde à porcentagem do material reduzido a uma granulometria inferior a $11,2 \mathrm{~mm}$.

$\mathrm{O}$ valor SJ, dado pelo teste de perfuração em uma miniatura (Figura 3.30), é uma medida da profundidade do furo, expresso em décimos de milímetro, após 200 revoluções.

(a)

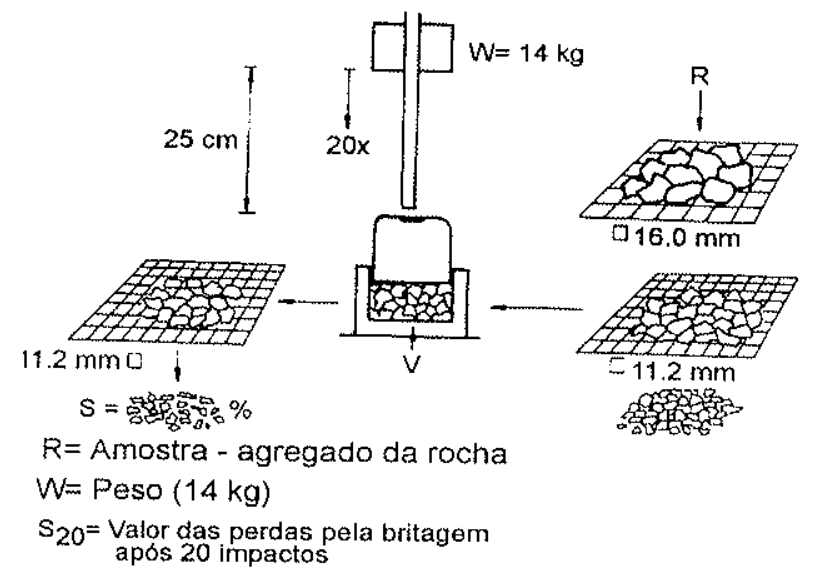

(b)

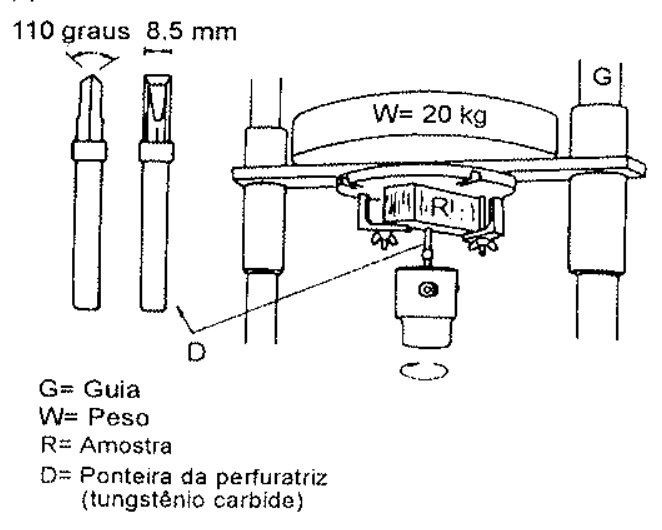

Figura 3.30 - (a) Perdas por britagem para determinação do valor de friabilidade $S_{20}$ e (b) teste em perfuratriz miniaturizada para determinação do Valor SJ (TAMROCK, 1986).

O ábaco apresentado na Figura 3.31 ilustra a obtenção do valor empírico do índice de perfuração. A classificação a partir desse índice e as faixas de valores para alguns tipos litológicos são apresentados na Figura 3.32.

A classificação baseada na perfurabilidade do Granito Barre utiliza esse tipo litológico bastante homogêneo, cujo fator de perfurabilidade é igual a 1,00, para o estabelecimento dos fatores relativos das demais litologias. Essa padronização tem um caráter inteiramente empírico, inclusive relacionando a potência cinética das perfuratrizes, com o diâmetro do furo, para a previsão da velocidade de avanço. 


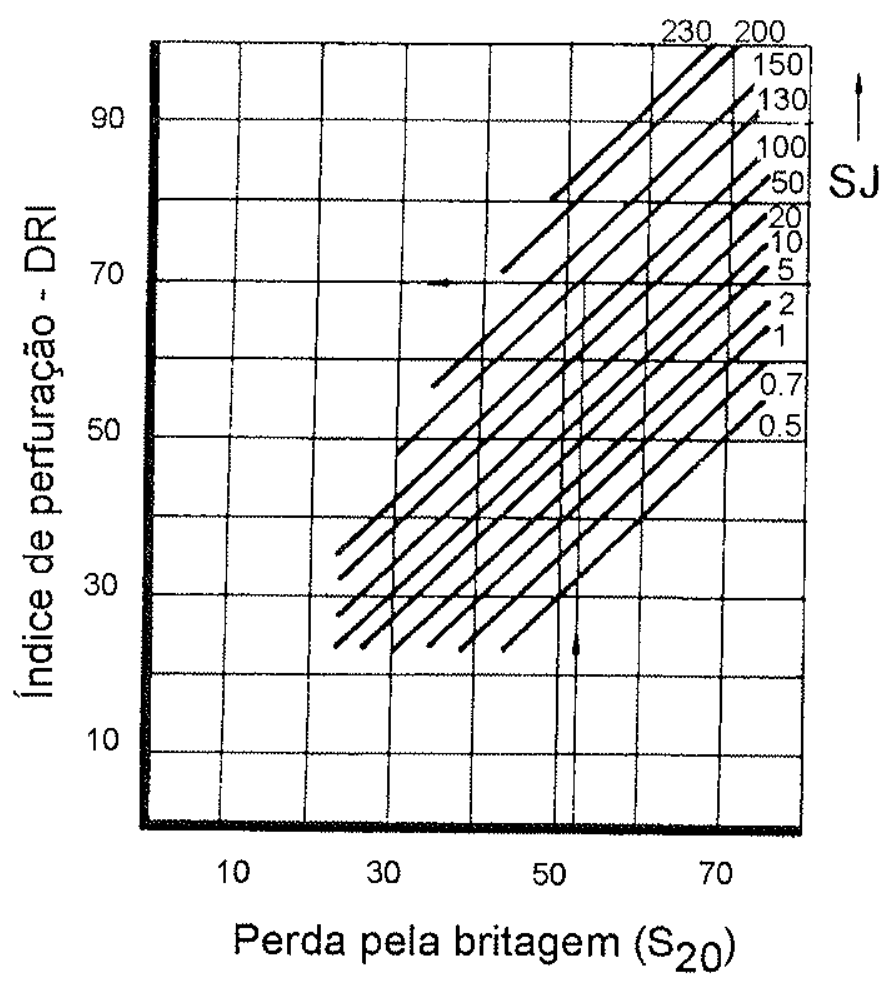

Figura 3.31 - Ábaco para determinação do Indice Perfuração (DRI), a partir dos valores de $S_{20}$ e SJ (TAMROCK, 1986).

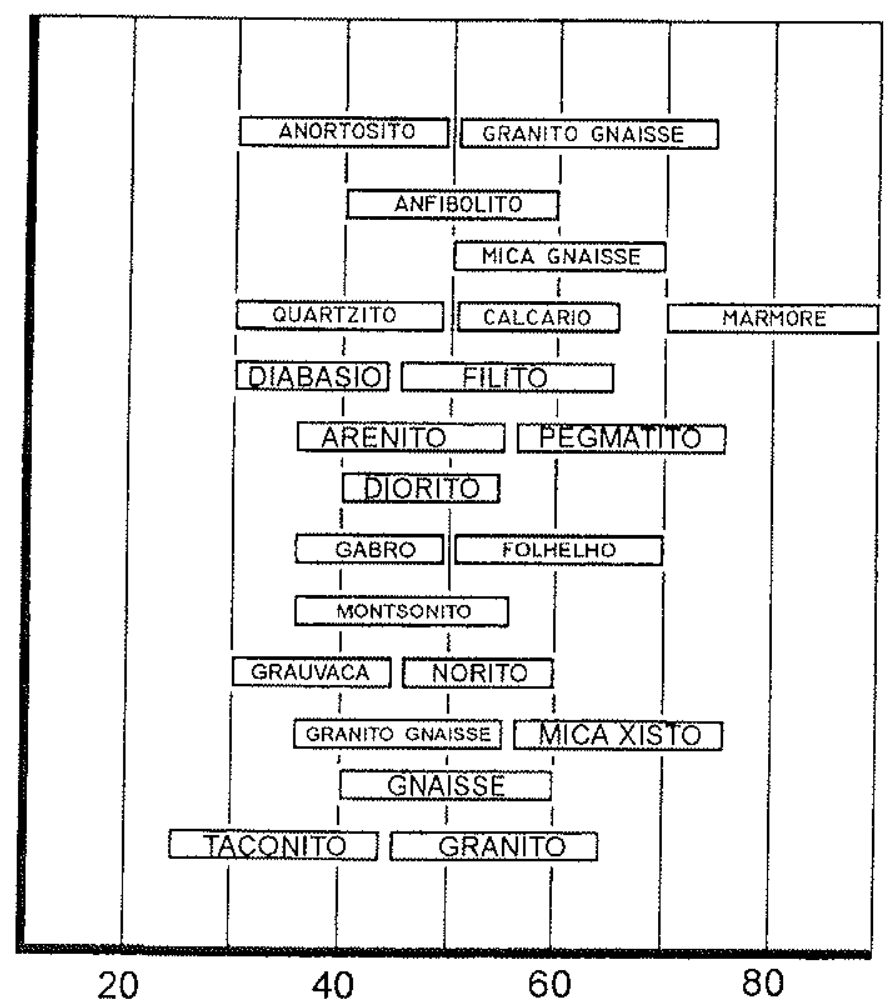

\begin{tabular}{lr} 
Índice de Penetração & DRI \\
\hline Extremamente baixo & 21 \\
Muito baixo & 28 \\
Baixo & 37 \\
Médio & 49 \\
Alto & 65 \\
Muito alto & 86 \\
Extremamente alto & 114 \\
\hline
\end{tabular}

Figura 3.32 - Classificação da rocha segundo o valor do DRI e faixas de valor de DRI para alguns tipos litológicos (TAMROCK, 1986).

O trabalho de DEKETH (1995) estuda os mecanismos básicos de desgaste que ocorrem durante o corte da rocha, baseando-se nos resultados de experimentos em escala de 
laboratório. Embora o trabalho não se relacione diretamente à perfurabilidade, apresenta um tratamento empírico de interesse à pesquisa. Seus objetivos também são distintos, a saber: (a) desenvolvimento de ferramentas de corte; (b) melhora na previsão do seu desgaste em projetos de corte de rocha. A parte experimental desse trabalhos utilizou um torno, onde foram desgastadas rochas sedimentares. Um esquema ilustrando o princípio desses testes é apresentado na Figura 3.33.

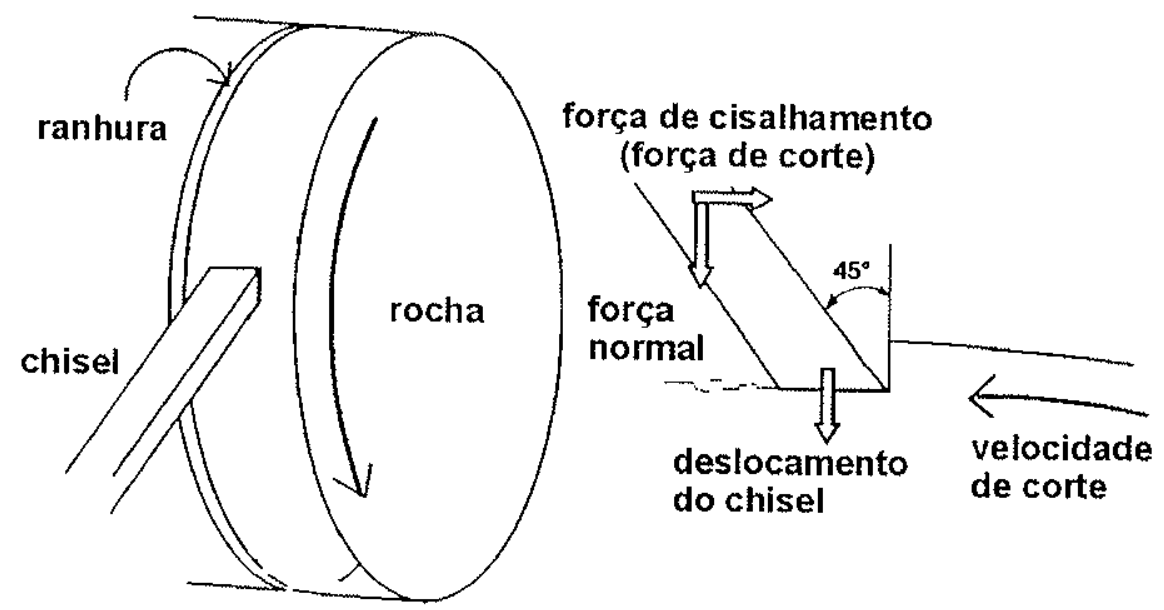

Figura 3.33 - Princípio dos testes de raspagem realizados em DEKETH (1995).

$\mathrm{O}$ autor refere-se a três modos de desgaste: $I, I I$ e $I I I$, respectivamente. A diferença entre os três refere-se à relação entre a velocidade de deslocamento tangencial relativa entre a rocha e a ferramenta de corte e a velocidade de avanço axial, dada pelo passo do torno (Figura 3.34). Essa relação condiciona a pressão sobre a rocha e, consequentemente, a forma como ocorre o desgaste com a rocha. 


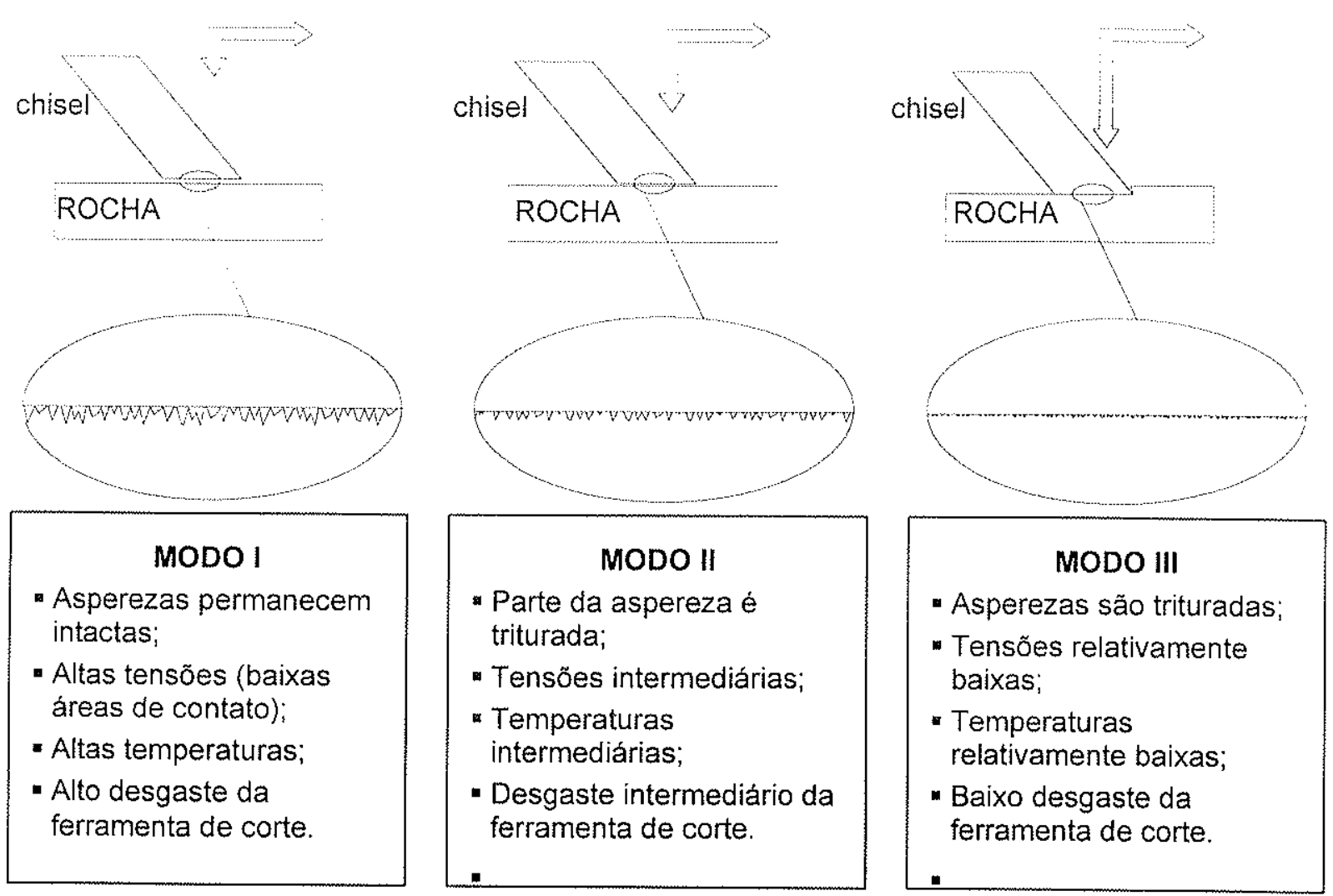

Figura 3.34 - Modos de desgaste (DEKETH, 1995).

DEKETH (1995) apresenta ainda o comportamento das forças instantâneas de corte, componentes correlacionáveis às forças que compõem ao torque na perfuração de rocha. Foi utilizada uma freqüência de amostragem de alguns Hertz, e é possível notar-se a grande variabilidade desses parâmetros (Figura 3.35). O comportamento do torque nesse ensaio ilustra a resistência variável citada por CLARK (1979).
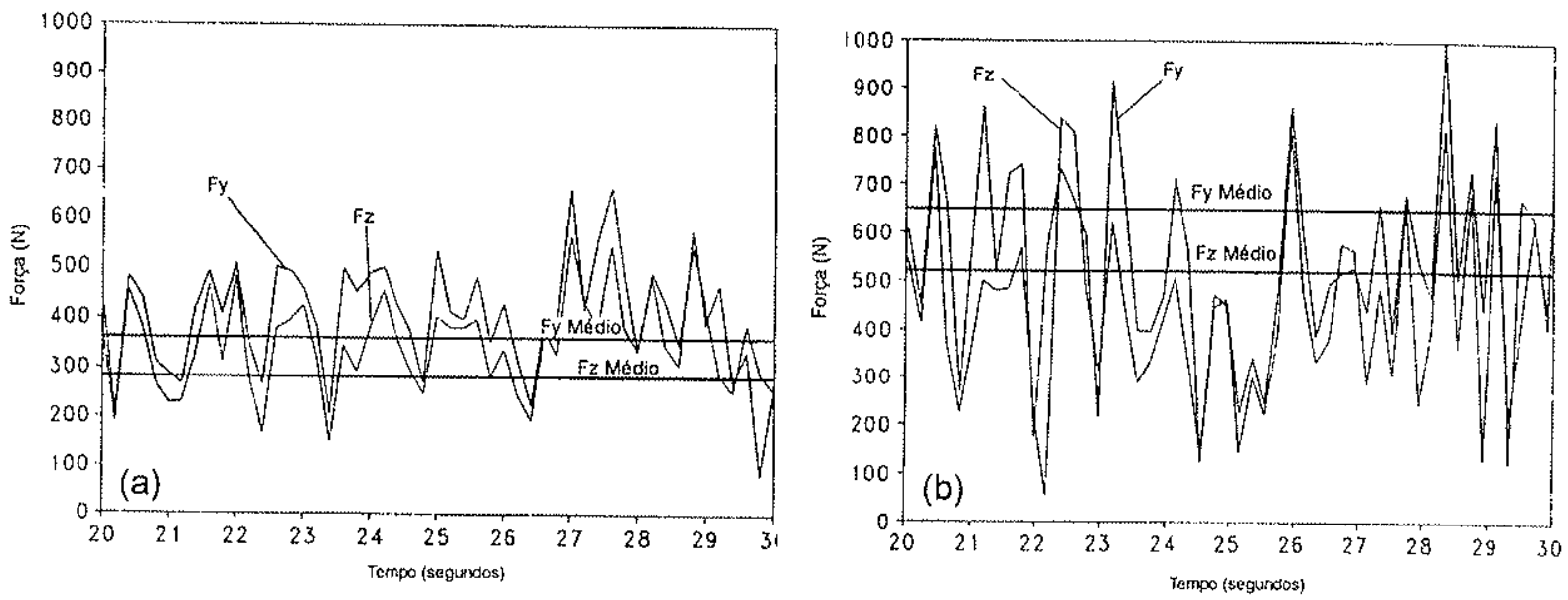

Figura 3.35 - Forças instantâneas de corte em função do tempo. Velocidade de corte $-0.4 \mathrm{~m} / \mathrm{s}$. (a) Avanço 0,07 mm/rev (MODO 1); (b) 0,57 mm/rev (MODO III) (DERETH, 1995). 


\subsubsection{Utilização de diagrafias instantâneas na campanha de investigação}

A técnica do monitoramento da perfuração ou diagrafia instantânea, da maneira como vem sendo aplicada desde a década de 1970, especialmente em geotecnia, pode ser dividida em dois grupos, de acordo com a finalidade de sua aplicação: (a) prospecção: caracterização e classificação de maciços naturais; (b) controle da qualidade de tratamentos executados em maciços (injeção para consolidação de maciços). Embora não existam registros bibliográficos de monitoramento sistemático de sondagens rotativo-abrasivas, um terceiro grupo poderia ser considerado, quando se refere a sondagens com testemunhos: (c) controle da qualidade da execução da perfuração.

Essa preocupação com os equipamentos utilizados e com a forma de execução da sondagem rotativa aumenta nos maciços constituídos por rochas brandas, onde a menor resistência dificulta a recuperação de amostras.

Dentro das campanhas de investigação em geotecnia, os altos custos relativos da sondagem rotativa com amostragem e a relevância das condições de sua realização conferem ao monitoramento da perfuração um campo de aplicação no controle da qualidade da execução da perfuração. Em certos contextos geológicos (p.e. rochas sedimentares ou com o perfil de intemperismo muito desenvolvido), o conhecimento das condições de perfuração constitui-se num importante subsidio para classificação. Apesar dessa possibilidade, na prospecção geológico-geotécnica, a diagrafia instantânea é quase que exclusivamente aplicada: (a) como complemento/detalhamento da campanha de investigações diretas tradicionais (furos rotativos com retirada de testemunhos e sem monitoramento); (b) exclusivamente em furos percussivos ou rotopercussivos. Assim, os furos destrutivos monitorados tornaram-se uma opção para o adensamento da malha de sondagem, num sítio geológico adequadamente conhecido, permitindo custos e prazos menores.

Segundo GIRARD (1985), a relação de custos entre a sondagem destrutiva não monitorada, a destrutiva monitorada (diagrafia instantânea) e a rotativa seria da ordem de 1 : $1,25: 4$.

Via de regra, esse tipo de rocha menos resistente (rocha branda) não é adequadamente caracterizado utilizando-se sondagens a percussão (lavagem e ensaio de resistência SPT). Ao mesmo tempo, são frágeis ao processo abrasivo do método de perfuração rotativo, tornando sua amostragem difícil e em algumas situações não acrescentando objetivamente parâmetros à caracterização. 
Apesar de existir há algumas décadas e de suas "vantagens", a técnica do monitoramento não é muito difundida, em especial no Brasil. Um conjunto de fatores pode ter contribuído para a não disseminação da técnica nas atividades geotécnicas ligadas à prospeç̧ão. Entre eles citam-se: (a) a inexistência de padrões objetivos determinando as condições executivas da sondagem e (b) existência de fatores de difícil controle e que podem ter considerável influência no processo de perfuração entre os quais citam-se o estado de desgaste das ferramentas de corte e os tipos dessas ferramentas (forma, diâmetro, quilatagem, resistência da matriz).

Apesar dos valores numéricos, sempre obtidos no monitoramento, predomina uma análise qualitativa dos resultados, tanto nos parâmetros diretamente lidos, como nos índices compostos ou paramétricos.

A utilização sistemática dos resultados da diagrafia instantânea, de maneira mais quantitativa, depende necessariamente do equacionamento e/ou controle dessas "variáveis".

\subsection{Geologia regional da área dos testes de perfuração}

Os testes de perfuração foram realizados na área do Instituto de Geociências, Zona Oeste do Município de São Paulo, numa região caracterizada por estar no limite entre a calha do Rio Pinheiros e as encostas da sua margem esquerda. Os materiais perfurados compreendem quatro unidades geológicas distintas: aterros, sedimentos quaternários, Bacia Sedimentar de São Paulo e Embasamento Pré-Cambriano.

O Embasamento Pré-Cambriano é formado por terrenos policíclicos, referíveis ao Cinturão de Dobramentos Ribeira (HASUI et al., 1975), composto por rochas metamórficas, migmatíticas e granitóides. Essa unidade é seccionada por inúmeras zonas de cisalhamento, de caráter dextral, orientadas segundo direções ENE a EW. JULIANI (1992) descreve as zonas de falha como "o característico geológico mais espetacular da região de São Paulo". Segundo o autor (op.cit.) essas zonas são difíceis de serem representadas em mapas geológicos, devido à grande heterogeneidade da deformação. As faixas tectonizadas atingem até $5 \mathrm{~km}$ de espessura, com núcleos relativamente poupados. É comum a ocorrência de cristalização metamórfica de minerais em condições compatíveis com a zona dos xistos verdes.

$\mathrm{Na}$ área de teste do protótipo, a seqüência estratigráfica é constituída pelo embasamento cristalino (Pré-Cambriano), sedimentos da Bacia Sedimentar de São Paulo e sedimentos quaternários. A Bacia Sedimentar de São Paulo é entendida como uma das 
integrantes do denominado Rift Continental do Sudeste do Brasil (RCSB), juntamente com outros nove embaciamentos alojados em uma estreita faixa, alongada e deprimida, de orientação ENE, entre as cidades de Curitiba (PR) e Barra de São João (RJ) (RICCOMINI \& COIMBRA, 1992). A borda norte da estrutura é retilínea e controlada pela zona de cisalhamento Taxaquara-Jaguari, enquanto no sul os contatos com o embasamento cristalino são irregulares. Os eixos menor e maior da bacia possuem 25 e $75 \mathrm{~km}$ de extensão, respectivamente.

Os depósitos sedimentares continentais compreendem a unidade basal, a qual é constituída pelas formações Resende, Tremembé e São Paulo (Grupo Taubaté). Recobrindo essa unidade, de forma presumivelmente discordante, ocorre ainda a Formação Itaquaquecetuba (RICCOMINI, 1989). Os sedimentos terciários perfurados nos testes do equipamento, provavelmente pertencem à Formação Resende. Duas litofácies principais caracterizam essa unidade: (a) depósitos de leques aluviais proximais, incluindo diamictitos e conglomerados com seixos, matacões e blocos, dispersos em matriz essencialmente lamítica a arenosa e (b) lamitos, predominantemente arenosos.

O material quaternário, de origem aluvial, é bem característico dessa unidade litoestratigráfica, com sedimentos argilosos com matéria orgânica sotopostos a camadas arenosas. Os aterros, originados de intervenção antrópica, variam bastante de espessura, e são determinados pelas intervenções relativas à implantação do Instituto de Geociências. 


\section{SISTEMA DE MONITORAMENTO DA PERFURAÇÃO}

O protótipo do sistema de monitoramento da perfuração para sondas de prospecção geológica foi desenvolvido procurando causar a menor interferência possivel com as atividades e procedimentos estabelecidos para a execução do furo. Seja em geotecnia, mineração, meio ambiente ou hidrogeologia, a finalidade da perfuração determina algumas diferenças nos procedimentos e nos equipamentos utilizados: porte e capacidade da sonda, tipo do equipamento - sistemas de hastes, revestimentos ou barriletes.

Os furos para prospecção executados em solo e rocha procuram atender, ou pelo menos estabelecer um equilíbrio, entre os principais objetivos desse tipo de trabalho: (a) amostragem dos materiais em subsuperfície (recuperação); (b) acesso direto aos maciços, possibilitando a realização de ensaios "in situ"; (c) produtividade da perfuração e (d) rendimento dos equipamentos, especialmente de coroas e calibradores. O monitoramento da perfuração é uma atividade que pode ser realizada atendendo a diversos objetivos. Qualquer que seja o objetivo, a atividade deverá inserir-se nessa situação estabelecida e, portanto, compatibilizar-se com os objetivos existentes.

4.1. Parâmetros monitorados, seleção dos sensores e instalação no equipamento de perfuração

O protótipo do sistema de monitoramento desenvolvido é composto pelo (a) conjunto de sensores, (b) caixa de alimentação e reunião dos sinais, (c) sistema de conversão $\mathrm{AD}$, e (d) sistema de armazenagem e tratamento dos dados (Notebook). A instalação dos sensores no sistema de perfuração está esquematizada na Figura 4.1. Fotografias são apresentadas nas figuras 4.2 e 4.3 .

Para a especificação dos sensores, consideraram-se os parâmetros a serem registrados e suas faixas de variação esperadas, de acordo com o equipamento. Dessa forma, os sensores foram escolhidos a partir do sistema de perfuração (sonda/bomba) e do sistema de conversão (AD) disponíveis. As faixas de variação desses parâmetros esperadas inicialmente nos testes de campo são apresentadas no Quadro 4.1.

A especificação dos sensores foi realizada considerando-se: (a) compatibilidade com o conversor utilizado (ADS-2000 - Lynx); (b) precisão de pelo menos $2 \%$ nas faixas de trabalho; (c) níveis de proteção compatíveis às intempéries (sol, chuva, variações de 
temperatura entre 10 e $50^{\circ} \mathrm{C}$ ); (d) alimentação através de baterias convencionais ( $\mathrm{Pb}$ ácido 12 VDC carregáveis pela sonda) ou baterias tipo $\mathrm{Pb} \operatorname{seco}(12 \mathrm{VDC}-2,2 \mathrm{Ah})$;

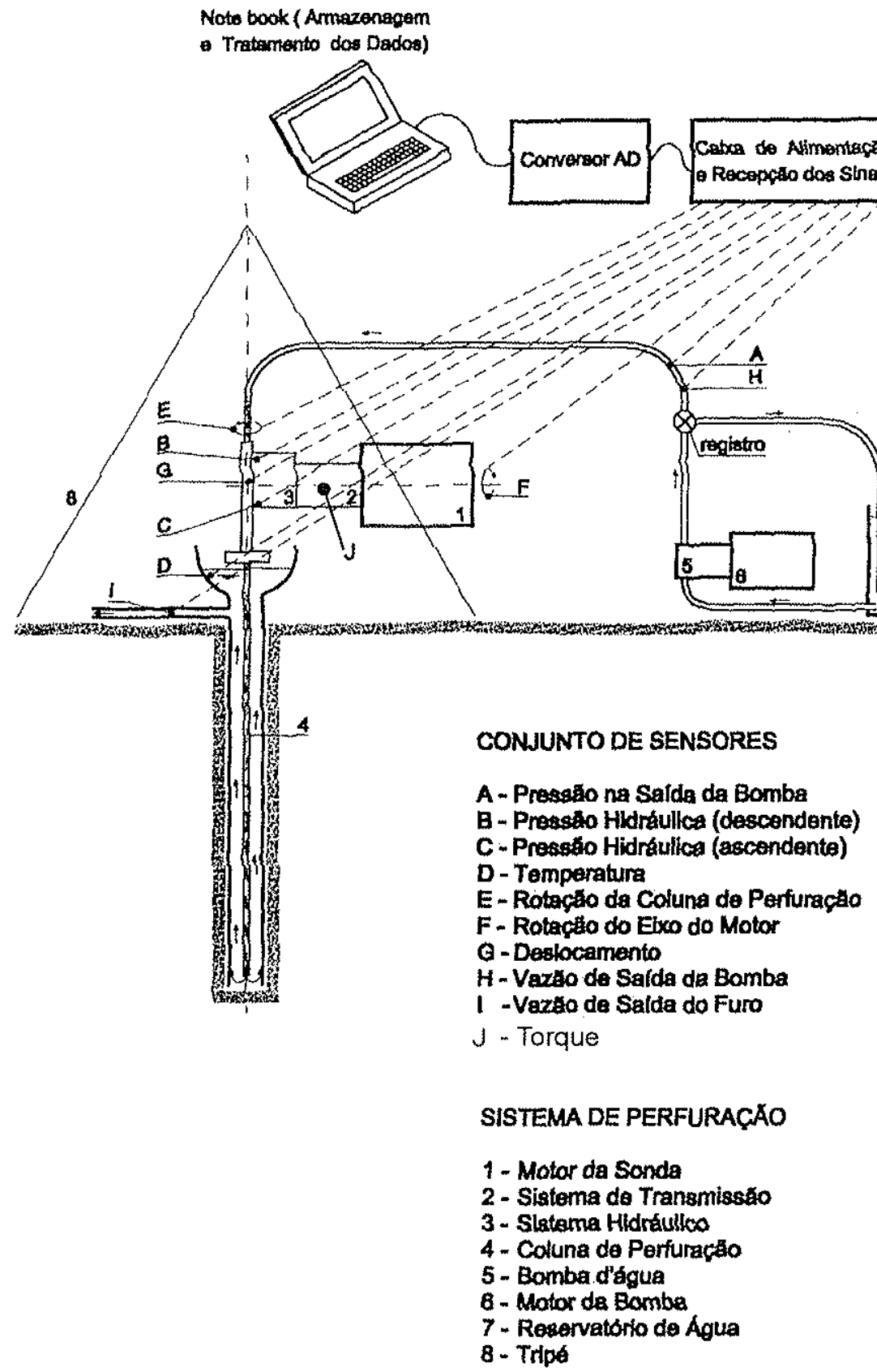

Figura 4.1 - Esquema de instalação do conjunto de sensores/ sistema de conversão no sistema de perfuração (sonda/bomba).

As faixas reais observadas em alguns parâmetros mostraram valores diferentes dos especificados nos respectivos catálogos. De maneira geral, os valores máximos observados foram menores do que os especificados para os sensores. Em nenhum parâmetro monitorado esse fato comprometeu a utilização do respectivo sensor. 

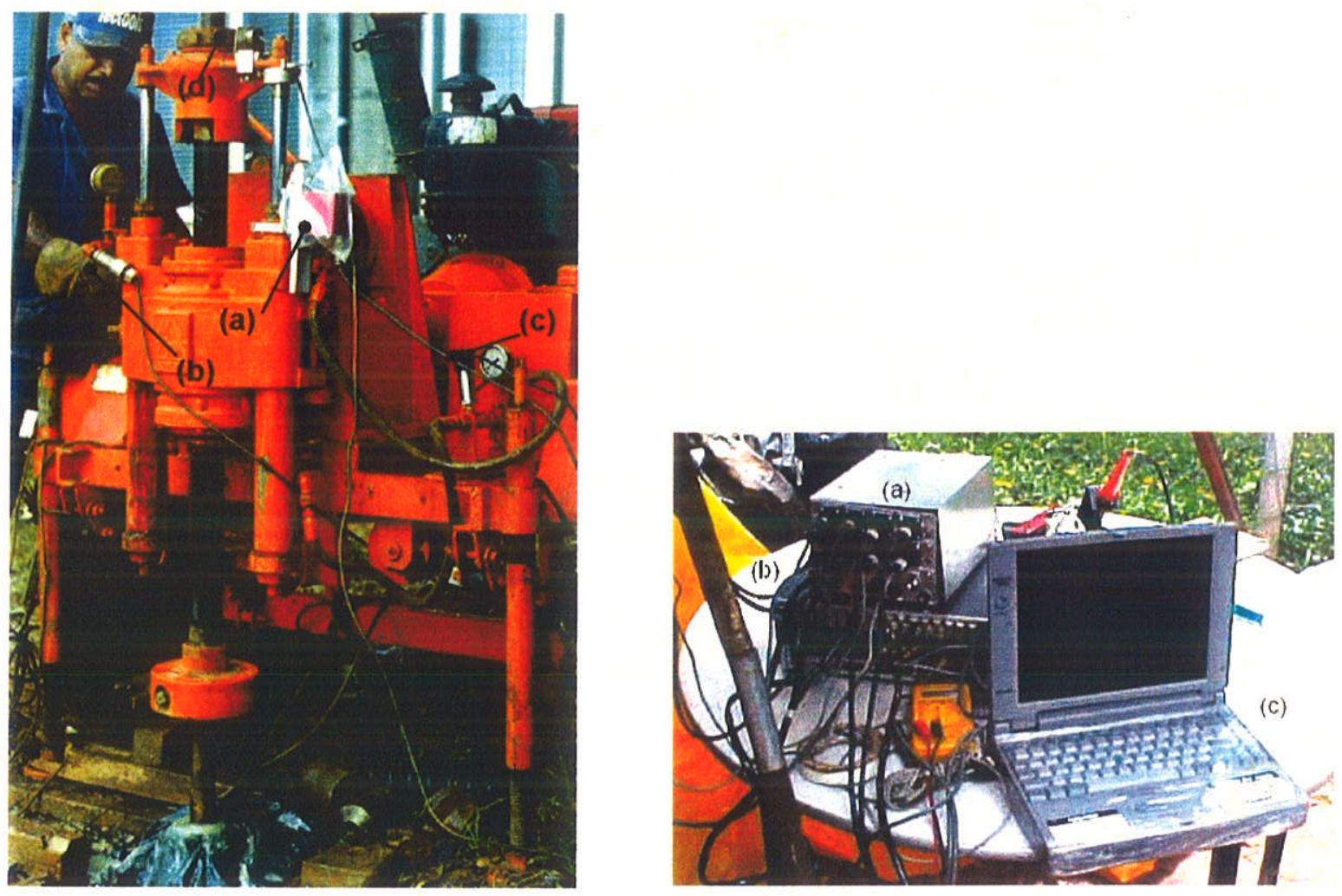

Figura 4.2- Fotografia de sensores instalados Figura 4.3- Fotografia do sistema de aquisição (a) na sonda: (a) deslocamento, pressões (b) descendente e (c) ascendente do caixa de alimentação e recepção dos sinais, hidráulico, e proximidade (d).

(b) conversor AD e (c) Notebook.

Quadro 4.1 - Faixa de variação dos parâmetros a serem medidos na SONDEQ SS-21/ SB-75C.

\begin{tabular}{|c|c|c|c|}
\hline Parâmetro de Interesse & Parâmetro Monitorado* & Tipo de Sensor & Faixa de Variação \\
\hline $\begin{array}{l}\text { Velocidade instantânea } \\
\text { de avanço }\end{array}$ & $\begin{array}{l}\text { Posição dos pistões no } \\
\text { sistema hidráulico, } \\
\text { considerando a taxa de } \\
\text { amostragem }\end{array}$ & $\begin{array}{l}\text { Medidor de } \\
\text { deslocamento (tipo } \\
\text { potenciômetro rotativo) }\end{array}$ & $\begin{array}{l}\text { até } 4,0 \mathrm{~cm} / \mathrm{s} \\
(500 \mathrm{~mm})^{*}\end{array}$ \\
\hline $\begin{array}{l}\text { Força ou pressão na } \\
\text { ferramenta de corte }\end{array}$ & $\begin{array}{l}\text { Pressões no sistema } \\
\text { hidráulico da sonda } \\
\text { (ascendente e descendente) }\end{array}$ & \multirow{2}{*}{$\begin{array}{l}\text { Sensores de pressão } \\
\text { ("strain gages") }\end{array}$} & 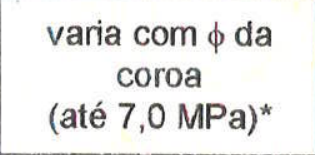 \\
\hline $\begin{array}{l}\text { Pressão do fluido de } \\
\text { circulação no local do } \\
\text { corte }\end{array}$ & $\begin{array}{l}\text { Pressão do fluido de } \\
\text { circulação na saída da } \\
\text { bormba }\end{array}$ & & 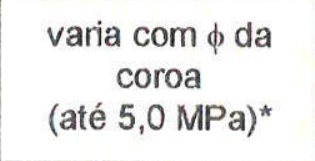 \\
\hline $\begin{array}{l}\text { Vazão da saida da bomba } \\
\text { de circulação }\end{array}$ & $\begin{array}{l}\text { Vazão da saída da bomba de } \\
\text { circulação }\end{array}$ & \multirow{2}{*}{$\begin{array}{l}\text { Medidores de Vazão } \\
\text { (tipo eletromagnético) }\end{array}$} & de 0,2 a $4,5 \mathrm{~m}^{3} / \mathrm{h}$ \\
\hline Vazão de retorno do furo & Vazão de retorno do furo & & de 0,2 a $4,5 \mathrm{~m}^{3} / \mathrm{h}$ \\
\hline $\begin{array}{l}\text { Velocidade de rotação da } \\
\text { coluna de perfuração }\end{array}$ & $\begin{array}{l}\text { Freqüência de passagem } \\
\text { dos anteparos pelo sensor }\end{array}$ & \multirow{2}{*}{$\begin{array}{l}\text { Sensores de } \\
\text { Proximidade }\end{array}$} & 1.900 a $3.000 \mathrm{rpm}$ \\
\hline $\begin{array}{l}\text { Velocidade de rotação do } \\
\text { eixo do motor }\end{array}$ & $\begin{array}{l}\text { Freqüência de passagern } \\
\text { dos anteparos pelo sensor }\end{array}$ & & 320 a 1.700 rom \\
\hline $\begin{array}{l}\text { Torçue aplicado à } \\
\text { perfuração }\end{array}$ & $\begin{array}{l}\text { Deformação angular no } \\
\text { acoplamento elástico }\end{array}$ & $\begin{array}{l}\text { Sensor desenvolvido } \\
\text { (Capítulo 5) }\end{array}$ & $\begin{array}{l}\text { até } 65 \mathrm{~N} \cdot \mathrm{m} / \\
\left(\text { até } 30^{\circ}\right)^{*}\end{array}$ \\
\hline
\end{tabular}


Todos esses sensores foram instalados na sonda ou na linha da bomba d'água (Figura 4.1), alguns diretamente, outros através de adaptações específicas.

\subsubsection{Deslocamento e velocidade de avanço}

A velocidade de avanço foi monitorada através do controle do deslocamento da coluna de perfuração, solidária ao sistema hidráulico que a conduz. O sensor utilizado para esse controle é baseado num potenciômetro rotativo, com um sistema de molas e roldanas para a linearização do movimento. As principais características desse equipamento estão apresentadas no Quadro 4.2. O sensor de deslocamento foi fixado por meio de suportes às extremidades de um dos pistões. As fotografias do sensor e de seu suporte estão apresentadas na Figura 4.4.

Quadro 4.2 - Características do transdutor de deslocamento

\begin{tabular}{|l|c||l|l|}
\hline \multicolumn{3}{|c|}{ Modelo DP-500C - Marca TML } \\
\hline Amplitude & $500 \mathrm{~mm}$ & Temperatura & \multicolumn{1}{|c|}{$0 \sim 80^{\circ} \mathrm{C}$} \\
\hline Saída & $2,5 \mathrm{mVN} \pm 0,3 \%$ & Resistência & Entrada $260 \Omega /$ saída $350 \Omega$ \\
\hline Sensibilidade & $10 \cdot 10^{-6} / \mathrm{mm}$ & $\begin{array}{l}\text { Tensão de } \\
\text { excitação }\end{array}$ & $\begin{array}{c}\text { Recomendada 1 2 V } \\
\text { (máxima permitida 5 V) }\end{array}$ \\
\hline $\begin{array}{l}\text { Força de Deslocamento } \\
\text { ("Spring force") }\end{array}$ & $220 \mathrm{gf}$ & Conexão elétrica & $\begin{array}{c}\text { CR } 9710\left(\phi 60,3 \mathrm{~mm}^{2} 4 \mathrm{core}\right. \\
\text { "Shielded Vinyl Cable" 10 m) }\end{array}$ \\
\hline Erro de Linearidade & $0,3 \%$ FRO & Dimensões & $(125 \times 75 \times 65 \mathrm{~mm})$ \\
\hline
\end{tabular}
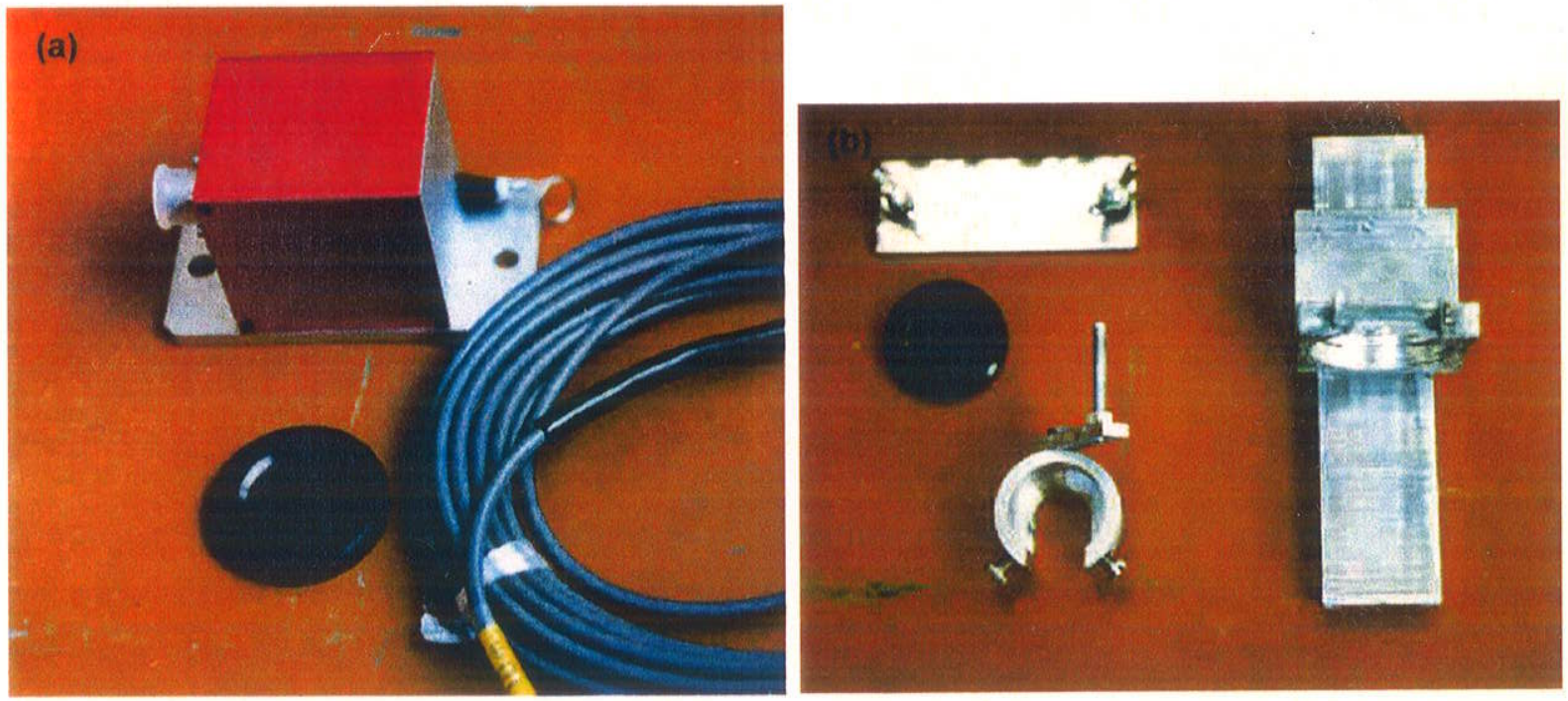

Figura 4.4 - Detalhe do (a) sensor de deslocamento e (b) das peças do seu suporte. 


\subsubsection{Pressões no sistema hidráulico e na linha d'água}

Os sensores de pressão no protótipo são em número de três: dois instalados no sistema hidráulico da sonda e um na bomba d'água. Convencionou-se chamar os sensores do sistema hidráulico de descendente e ascendente, relacionando-os às pressões nos pistões que produzem seu movimento no sentido de avanço do furo e no sentido inverso, respectivamente. As principais características desses aparelhos são apresentadas no Quadro 4.3. A posição dos três sensores no sistema de perfuração está indicada esquematicamente na Figuras 4.1. A sonda já possui locais específicos para a instalação dos manômetros usados para o ajuste da pressão da bomba do hidráulico. Os sensores de pressão foram encomendados no mesmo diâmetro e tipo de rosca desses aparelhos. Nesses locais foram instaladas conexões tipo "T", preservando os manômetros originais e permitindo a instalação dos transdutores do sistema automatizado. A fotografia do aparelho utilizado é apresentada na Figura 4.5 .

Quadro 4.3 - Transdutores de pressão (sistema hidráulico da sonda e saída da bomba d'água).

\begin{tabular}{|c|c|c|c|}
\hline & Saída da bomba d'água & $\begin{array}{l}\text { Sistema hidráulico } \\
\text { (descendente) }\end{array}$ & $\begin{array}{l}\text { Sistema hidráulico } \\
\text { (ascendente) }\end{array}$ \\
\hline Marca/modelo & \multicolumn{3}{|c|}{ Hitronic $\mathrm{H} 50$} \\
\hline Amplitude (range) & 0 a $5,0 \mathrm{MPa}$ & 0 a $7,0 \mathrm{MPa}$ & 0 a $7,0 \mathrm{MPa}$ \\
\hline Saída & \multicolumn{2}{|c|}{4 a $20 m A^{15}$} & 0 a $5 \mathrm{Vcc}$ \\
\hline $\begin{array}{c}\text { Repetibilidade + } \\
\text { Histerese + Linearidade }\end{array}$ & \multicolumn{3}{|c|}{ $\pm 0,5 \% \mathrm{FE}$} \\
\hline Temperatura do fluido & \multicolumn{3}{|c|}{0 a $70^{\circ} \mathrm{C}$} \\
\hline Temperatura ambiente & \multicolumn{3}{|c|}{0 a $50^{\circ} \mathrm{C}$} \\
\hline Conexão na linha & Rosca NPT 1" (macho) & \multicolumn{2}{|c|}{ Rosca gás $1 / 4^{n}$ (macho) } \\
\hline
\end{tabular}

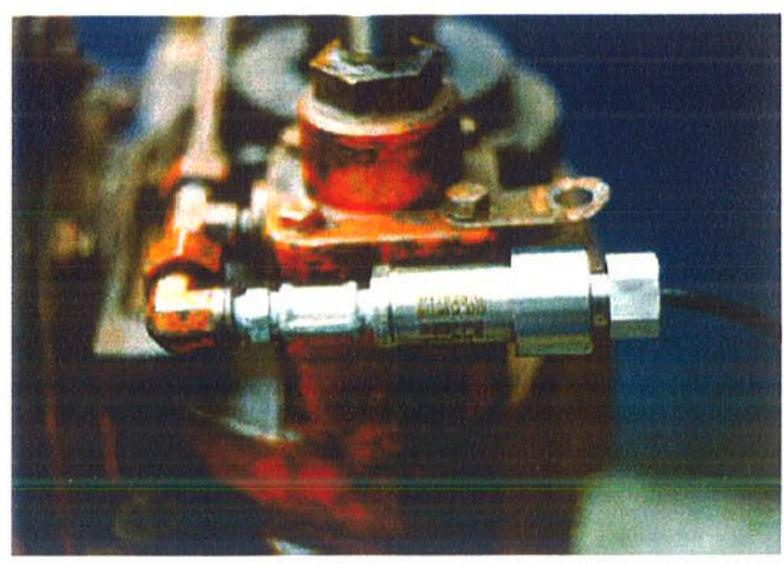

Figura 4.5 - Detalhe do sensor de pressão utilizado no monitoramento.

\footnotetext{
${ }^{15}$ Adaptado para leitura em tensão.
} 


\subsubsection{Vazões na linha d'água da bomba}

Para a medida das vazões na linha de água da bomba, foram adquiridos dois sensores eletromagnéticos. As características comuns e específicas de cada aparelho são resumidas no Quadro 4.4. Nesse tipo de equipamento, o fluido de circulação pode ser descartado ao sair do furo ou conduzido a um tanque, para sedimentação do material mais grosseiro e posterior reaproveitamento. Devido à proposta de controle da vazão que retorna do furo, foram adaptados reservatórios (bacia com capacidade de aproximadamente 15 litros) em pedaços de revestimento com $10 \mathrm{~cm}$ de comprimento, nos diâmetros $\mathrm{Nx}$ e $\mathrm{Hx}$ (Figura 4.6c), utilizados para regularizar o fluxo e permitir a medida na saída do furo (Figura 4.1). Esse recurso e, conseqüentemente, o monitoramento da vazão de saída do furo foram utilizados apenas na primeira etapa de testes. Essa mudança foi determinada pela alteração do escopo do trabalho, ou seja, mudança da interpretação hidrogeológica para a geológico-geotécnica dos parâmetros de perfuração.

Quadro 4.4 - Características dos sensores de vazão.

\begin{tabular}{|c|c||c|c|}
\hline \multicolumn{4}{|c|}{ Modeio (fabricante): MAG 600 (Nykon Dwyler) } \\
\hline Amplitude (range) & $\begin{array}{c}1,0-15,0 \mathrm{~m}^{3} / \mathrm{h} \\
(17 \text { a } 250 \mathrm{l} / \mathrm{min})\end{array}$ & $\begin{array}{c}\text { Diâmetro da } \\
\text { Tubulação }\end{array}$ & $11 / 2^{\text {“16 }}$ \\
& $\begin{array}{c}0,9-9,0 \mathrm{~m}^{3} / \mathrm{h} \\
(15 \mathrm{a} 150 \mathrm{l} / \mathrm{min})\end{array}$ & & $1 / 2{ }^{\prime \prime 17}$ \\
& $0-5 \mathrm{Vcc}$ & Temperatura & 0 a $50^{\circ} \mathrm{C}$ (ambiente) \\
\hline Saída & $\begin{array}{c} \pm 0,5 \% \text { ou } \\
1,25 \mathrm{e} 0,75 \mathrm{l} / \mathrm{min}\end{array}$ & Alimentação & 24 Vcc \\
\hline Precisão & & & \\
\hline
\end{tabular}
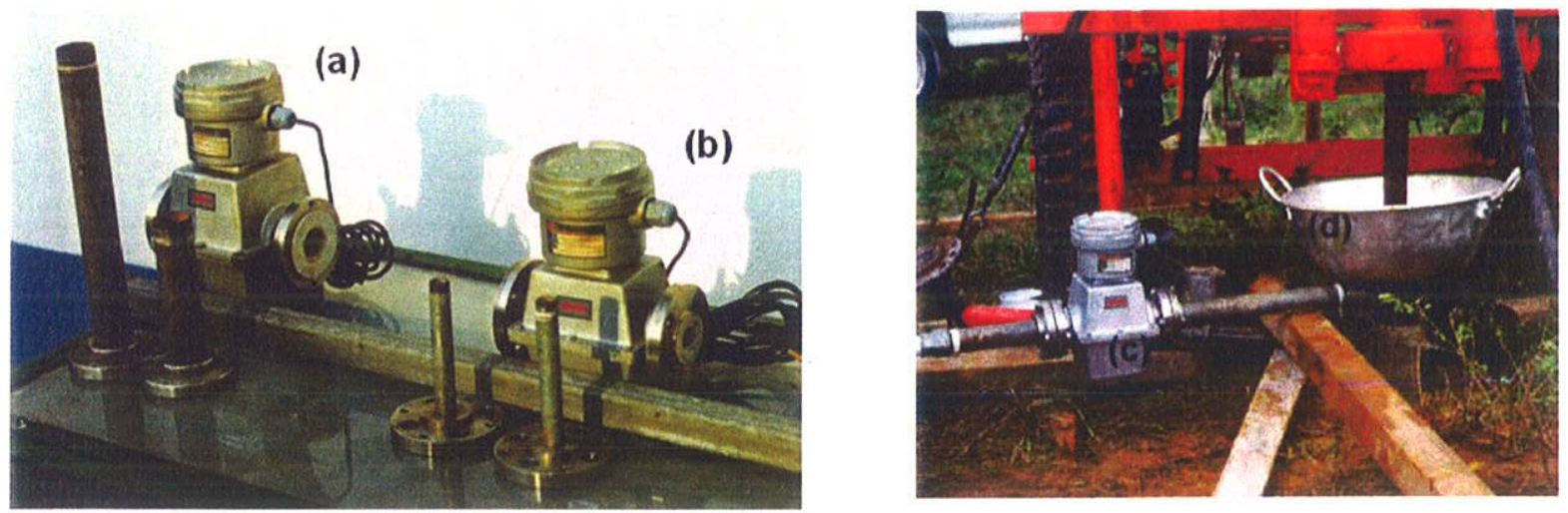

Figura 4.6 - Detalhe dos sensores de vazão e suas respectivas flanges de adaptação na linha d'água, (a) $1 \frac{1}{2} "$, (b) $1 / 2 "$, (c) $1 \frac{1}{2}$ " instalado na saída do furo e (d) reservatório para medida da vazão de saída.

\footnotetext{
${ }^{16}$ Sensor de vazão da saída da bomba d'água (11/2").

17 Sensor de vazäo do retorno do furo (1/2").
} 
O sensor de vazão da saída da bomba ( $\left(1 / 2^{c c}\right)$ (figuras $4.6 b$ e $\left.4.7 a\right)$ foi instalado na linha d'água após o registro do retorno da bomba d'água.

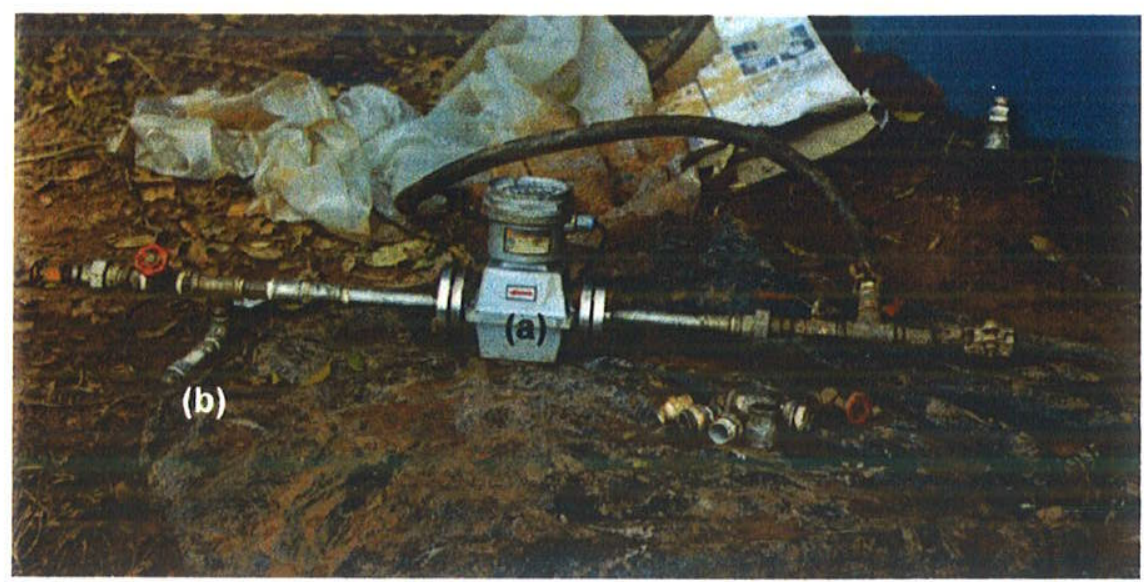

Figura 4.7 - Instalação dos sensores (a) de vazão (1/2"2) e (b) de pressão na linha d'água (entrada).

$\mathrm{Na} 2^{\mathrm{a}}$ etapa de testes foi observada a possibilidade de controle da vazão de entrada no furo por meio do controle da rotação do motor. O sistema de controle do eixo do motor da sonda foi adaptado no eixo do motor da bomba. Nos testes realizados sem a pressurização da linha, os resultados foram bastante satisfatórios.

\subsubsection{Temperatura do fluido de circulação}

Foi prevista a instalação do sensor de temperatura na saída do fluido do furo, dentro do reservatório adaptado para a instalação do sensor de vazão. O aparelho adquirido para esse controle foi um termopar, que permite leituras com resolução de $0,2{ }^{\circ} \mathrm{C}$. Nas duas etapas de testes, esse sensor não foi utilizado. A idéia inicial era observar diferenças na temperatura do fluido ao longo do avanço do furo e tentar correlacionar essas alterações graduais ou bruscas aos diferentes aqüíferos atravessados.

\subsubsection{Torque aplicado ao processo de perfuração}

$\mathrm{Na}$ primeira etapa de testes ("Testes do Equipamento em Operação"), os trabalhos foram realizados sem um controle específico de torque. Imaginava-se que com o monitoramento da porcentagem da aceleração total do motor (o) e da velocidade de rotação seria possível estimar-se com a precisão necessária, o nível de torque envolvido no processo de corte da rocha. Posteriormente, ficou esclarecido que para esse controle, seria necessária a calibração do motor, com a realização de testes dispendiosos, não previstos no projeto.

Os resultados apresentados nessa etapa de testes não possuem o controle de torque. Os valores utilizados nos cálculos da energia específica de perfuração foram admitidos a 
partir de dados adquiridos junto ao fabricante. Ficou então clara a necessidade de um sensor específico para a medida dessa grandeza.

Como opção disponível no mercado, existem equipamentos como o descrito no item 3.1.3.4. Apesar de sua alta precisão, esse tipo de sensor não é adequado ao sistema, devido ao elevado custo e à sua incompatibilidade com as condições de operação (presença de água, lama, além das condições de vibração e temperatura).

Como alternativa, foi desenvolvido um sensor específico para uma avaliação do torque. Esse equipamento deveria ter a precisão necessária para as medidas e ainda adaptarse às condições existentes junto à sonda em operação. $O$ princípio do funcionamento, suas características técnicas e os resultados de seus testes são apresentados no Capítulo 5.

\subsubsection{Sensores de proximidade (velocidades de rotação)}

As velocidades de rotação são medidas através da contagem de voltas dos eixos dentro do tempo de aquisição entre as gravações dos dados. Sensores de proximidade transversal indutivo e anteparos metálicos foram instalados em partes fixas da sonda e nos eixos monitorados, respectivamente. A freqüência do sinal produzido é diretamente proporcional à velocidade de rotação. As características desses sensores de proximidade estão resumidas no Quadro 4.5.

Quadro 4.5 - Sensores de proximidade para medição das velocidades de rotação.

\begin{tabular}{|l|l||l|l|}
\hline \multicolumn{3}{|c|}{ BALLUFF Balluff Electronic Switch (BES 516-327-E4-Y 5) } \\
\hline $\begin{array}{l}\text { Distância Sensora } \\
\text { Nominal (Sn) }\end{array}$ & $10 \mathrm{~mm}$ & Zona de Operação (Sa) & 0 a $8 \mathrm{~mm}$ \\
\hline Saida & Normalmente aberta & Tensão de alimentação & 10 a $30 \mathrm{~V} \mathrm{DC}$ \\
\hline Corrente sem carga & $\leq 25 \mathrm{~mA}$ & Corrente de carga (la) & 60 a $400 \mathrm{~mA}$ \\
\hline $\begin{array}{l}\text { Histerese de } \\
\text { Comutação }\end{array}$ & $\leq 15 \%$ de Sr & Freqüência chaveamento & $1.500 \mathrm{~Hz}$ \\
\hline Classe de proteção & IP67/IP68 (campo) & Temperatura de operação & -25 a $+70^{\circ} \mathrm{C}$ \\
\hline Dimensões & $30 \times 30 \mathrm{~mm}$ (cilindrico) & & \\
\hline
\end{tabular}

O sensor de proximidade (Figura 4.8a) foi instalado numa porção sem rotação da sonda, por meio de suporte próprio (Figura 4.8b), sendo os quatro anteparos (Figura 4.8c), que produzem os sinais, fixados numa peça (Figura 4.8d), a qual rotaciona solidária à coluna de perfuração. Mesmo antes da realização de testes em bancada, foi possível prever o erro 
associado a esse sistema de medição da velocidade de rotação, o qual está ligado diretamente ao número de anteparos instalados no eixo, conforme mostra Figura 3.11.

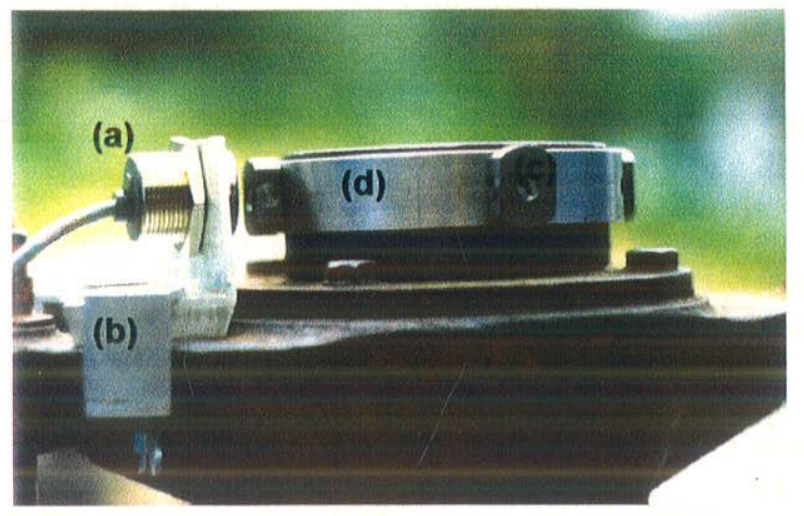

Figura 4.8 - Detalhe do sensor de proximidade (a) instalado na sonda, através de seu suporte (b). Anteparos (c) e respectivo suporte (d) instalados em peça solidária à coluna, defronte ao sensor de proximidade.

A rotação do motor foi obtida na $1^{\text {a }}$ etapa de testes de maneira semelhante, utilizando-se, devido ao menor diâmetro do eixo, apenas 2 anteparos. Na $2^{\mathrm{a}}$ etapa de testes, a velocidade de rotação do eixo do motor foi obtida diretamente do equipamento que mediu o torque. Os sensor de proximidade do eixo do motor da sonda, foi então adaptado ao motor da bomba, como um segundo sistema de estimativa da vazão de entrada no furo.

Visando centralizar a alimentação dos sensores e facilitar a montagem e o transporte do sistema de monitoramento, foi construída a "Caixa de Alimentação e Reunião dos Sinais" (Figura 4.3a). Essa caixa metálica reúne todas as baterias, fusíveis de proteção e chaves "on-off", além de conectores multipinos para os diversos sensores instalados na sonda/bomba, sendo ligada diretamente ao Conversor A/D (entrada para os sinais analógicos e para os digitais). Todos os sensores estão ligados a essa caixa, exceção ao de temperatura e ao de deslocamento, que puderam ser ligados diretamente ao sistema ADS-2000, através da placa Al 2160 (módulo para condicionamento dos sinais do ADS 2000). O sensor de torque, no protótipo foi ligado diretamente ao computador através de sua porta serial.

\subsection{Sistema de conversão analógico-digital}

O Conversor Analógico-Digital (A/D) (Figura 4.3b) é o equipamento que recebe os sinais analógicos dos sensores (tensão ou corrente elétrica proporcional ao parâmetro medido) e digitaliza essas informações, ou seja, transforma os sinais em números binários que são transmitidos e gravados no computador, no protótipo utilizando o formato ASCII. Esse aparelho também realiza as contagens para o monitoramento da velocidade de rotação. 


\subsubsection{Equipamento}

O conversor utilizado no protótipo de monitoramento pertence ao Departamento de Geologia Sedimentar e Ambiental (IG/USP). O equipamento é fabricado no Brasil e foi adquirido no mercado. Suas principais características técnicas estão resumidas no Quadro 4.6.

Quadro 4.6 - Sistema de Aquisição de Dados Lynx (série ADS-2000).

\begin{tabular}{|c|c|c|c|}
\hline \multicolumn{4}{|c|}{ CARACTERISTICASTECNICAS } \\
\hline número de canais & 16 & linguagem de programaçäo & Alto nivel \\
\hline $\begin{array}{l}\text { faixas de operaçäo (tensão ou } \\
\text { corrente) }\end{array}$ & $\begin{array}{c} \pm 1, \pm 2, \pm 5 \text { e } \pm 10 \mathrm{~V} \\
\text { (selecionadas por } \\
\text { software) }\end{array}$ & impedância da entrada $(\Omega)$ & $100 \mathrm{k} \Omega$ \\
\hline $\begin{array}{l}\text { tipos de entrada (unipolar ou } \\
\text { bipolar) }\end{array}$ & Ambas & tipo de sincronismo & $\begin{array}{l}6 \text { contadores } \\
\text { temporizadores }\end{array}$ \\
\hline número de bits (resolução) & 16 bits & $\begin{array}{l}\text { comunicaçāo como } \\
\text { computador }\end{array}$ & $\begin{array}{l}\text { interface } \\
\text { paralela }\end{array}$ \\
\hline freqüência de amostragem & $\begin{array}{l}\text { Até } 100 \mathrm{k} \\
\mathrm{amostras} / \mathrm{s}\end{array}$ & fonte & $\begin{array}{l}110 / 220 \vee A C \\
\text { ou } 12 \vee D C\end{array}$ \\
\hline
\end{tabular}

$O$ conversor $A / D$ funciona ligado a um microcomputador, no caso do protótipo em trabalho no campo, um notebook (Pentium 100) (Figura 4.3c). No teste de laboratório e na $1^{\text {a }}$ etapa de testes, o monitoramento foi realizado com um computador de mesa (desktop).

\subsubsection{Software para aquisição e tratamento dos dados}

O software de aquisição (Turbo Pascal versão 5.0 Borland) foi especialmente desenvolvido para o protótipo, instalado no microcomputador e permitindo a configuração do sistema de monitoramento, especificamente: (a) configuração dos canais digitais (rotação) e analógicos (velocidade linear, pressões, vazões e temperatura) do conversor A/D (Lynx AD 2120); (b) configuração dos Parâmetros Globais; (c) caminho (disco e diretório) da gravação dos resultados; (d) nome do arquivo; (e) dimensões do buffer de aquisição; (f) freqüência base de aquisição; ( $g$ ) freqüência de aquisição (gravação) e (h) trecho perfurado.

\section{Módulo de tratamento dos dados aquisitados}

Pelo menos na fase inicial de testes, optou-se pela transferência dos dados aquisitados para uma planilha eletrônica (MS EXCEL 97), realizando nesse ambiente o seu tratamento. Os dados foram aquisitados na forma dos valores de saída dos sensores. Através das calibragens realizadas (item 4.3), esses sinais são convertidos nas respectivas grandezas físicas. 


\subsection{Testes e calibração dos sensores em laboratório}

Todos os sensores adquiridos foram testados preliminarmente em laboratório. $\mathrm{O}$ objetivo dessa etapa do trabalho foi a análise dos sinais obtidos e a calibração dos aparelhos.

Os gráficos com a calibração dos sensores de: (a) deslocamento, (b) pressão hidráulica descendente, (c) pressão hidráulica ascendente, (d) pressão na linha d'água, (e) vazão de entrada no furo e (f) vazão de saída do furo são apresentados nas figuras 4.9 a 4.14 , respectivamente.

\section{Deslocamento (Ganho 600)}

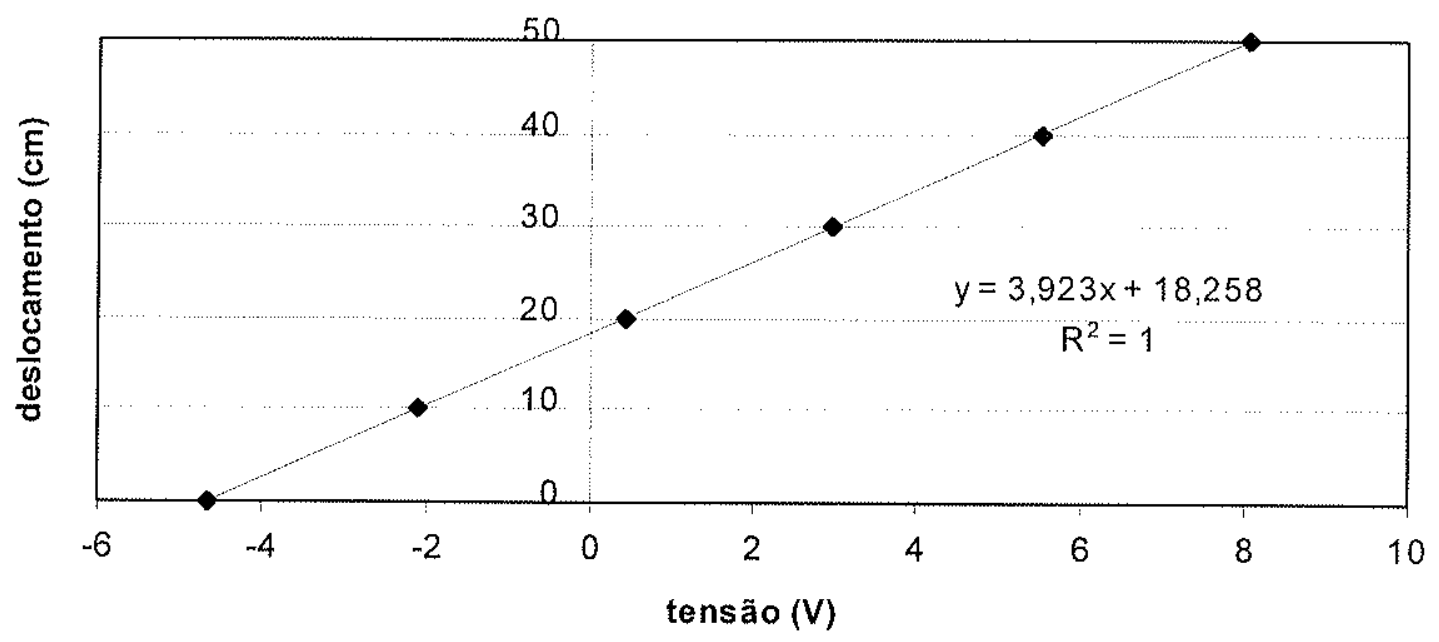

Figura 4.9 - Calibração do sensor de deslocamento.

\section{Pressão Descendente}

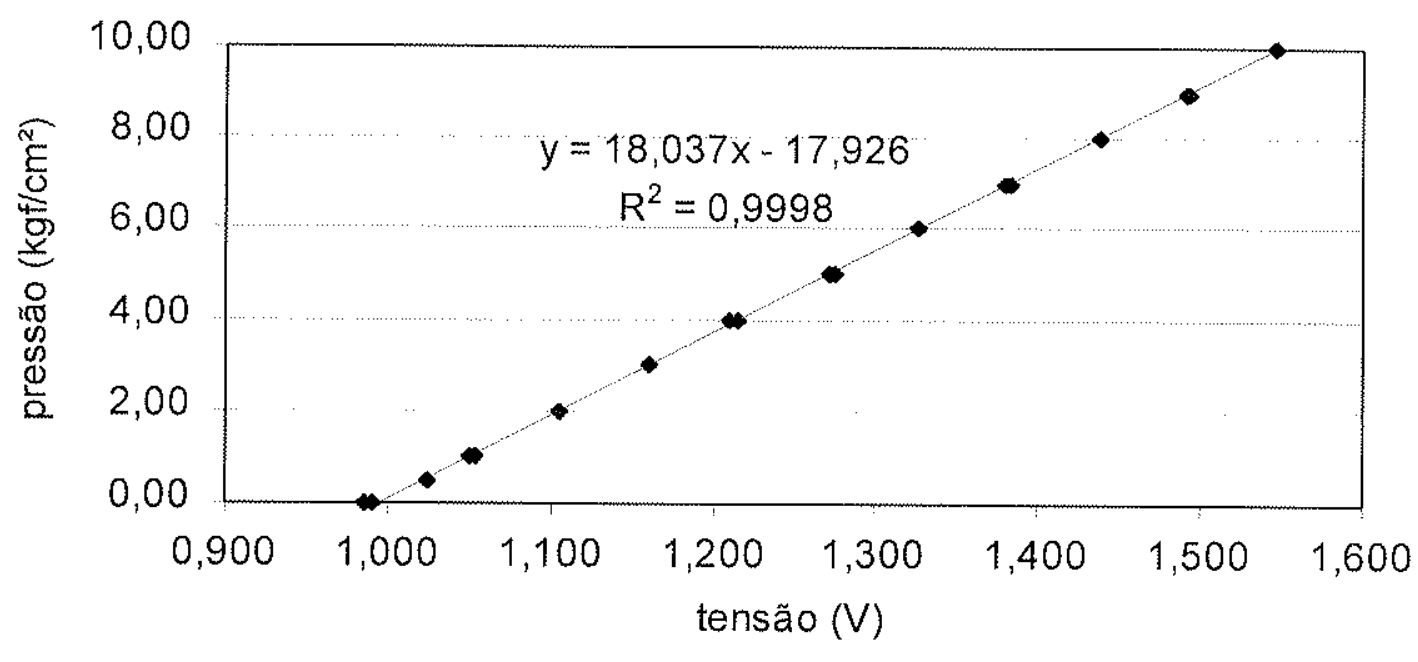

Figura 4.10 - Calibração do sensor de pressão do sistema hidráulico (descendente). 


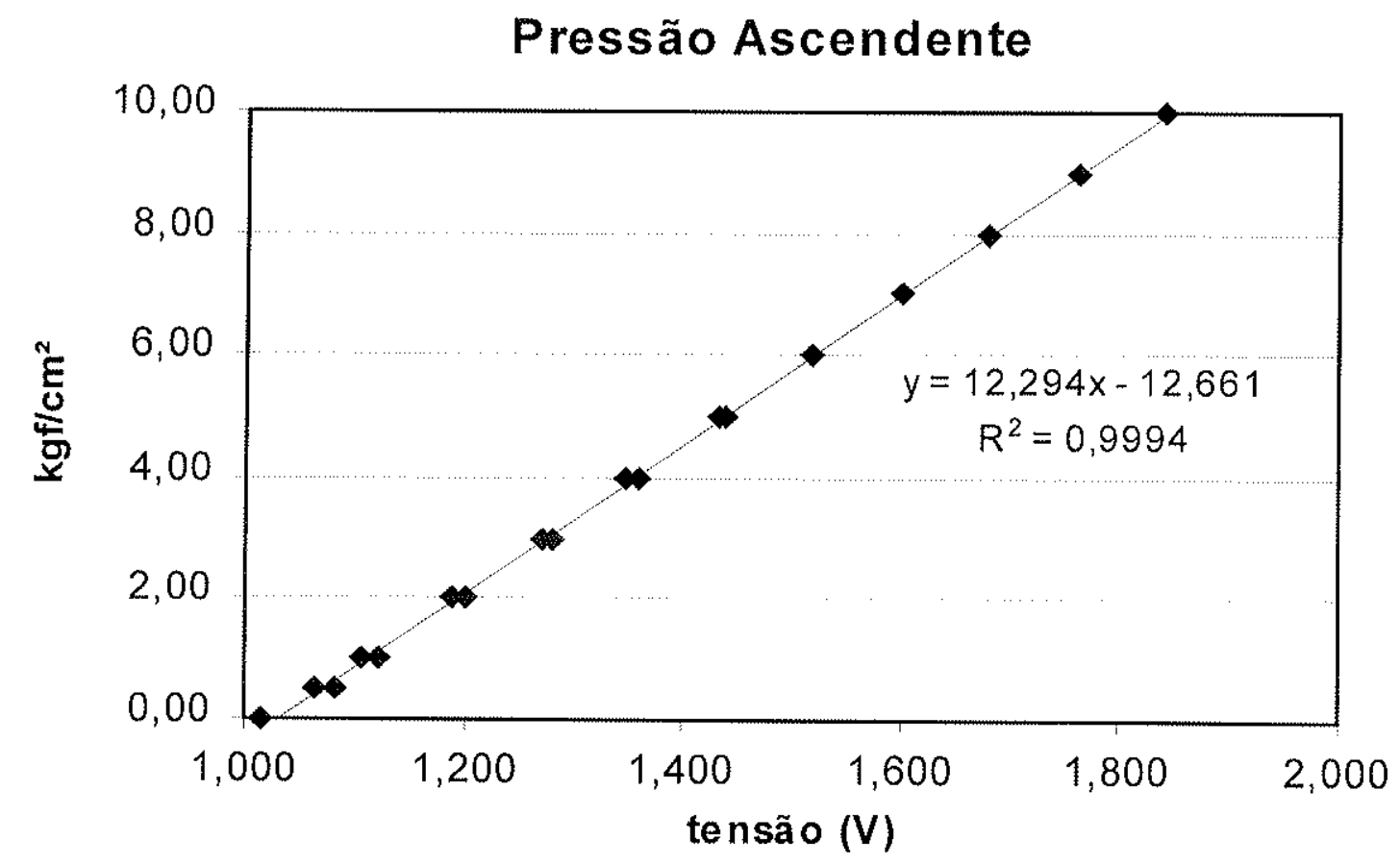

Figura 4.11 - Calibração do sensor de pressão do sistema hidráulico (ascendente).

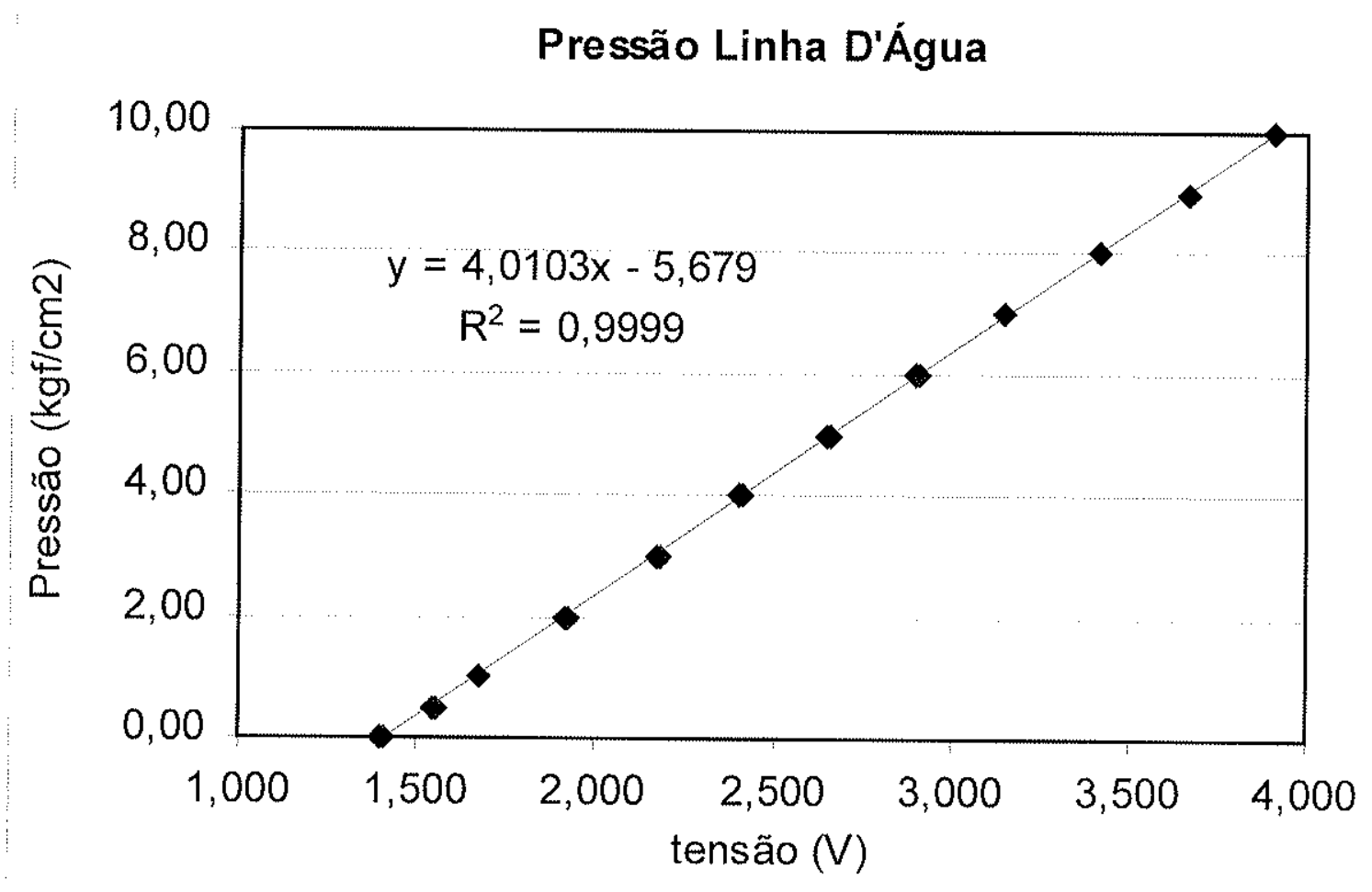

Figura 4.12 - Calibração do sensor de pressão da linha d'água. 
Sensor 1/2" (VazaoE)

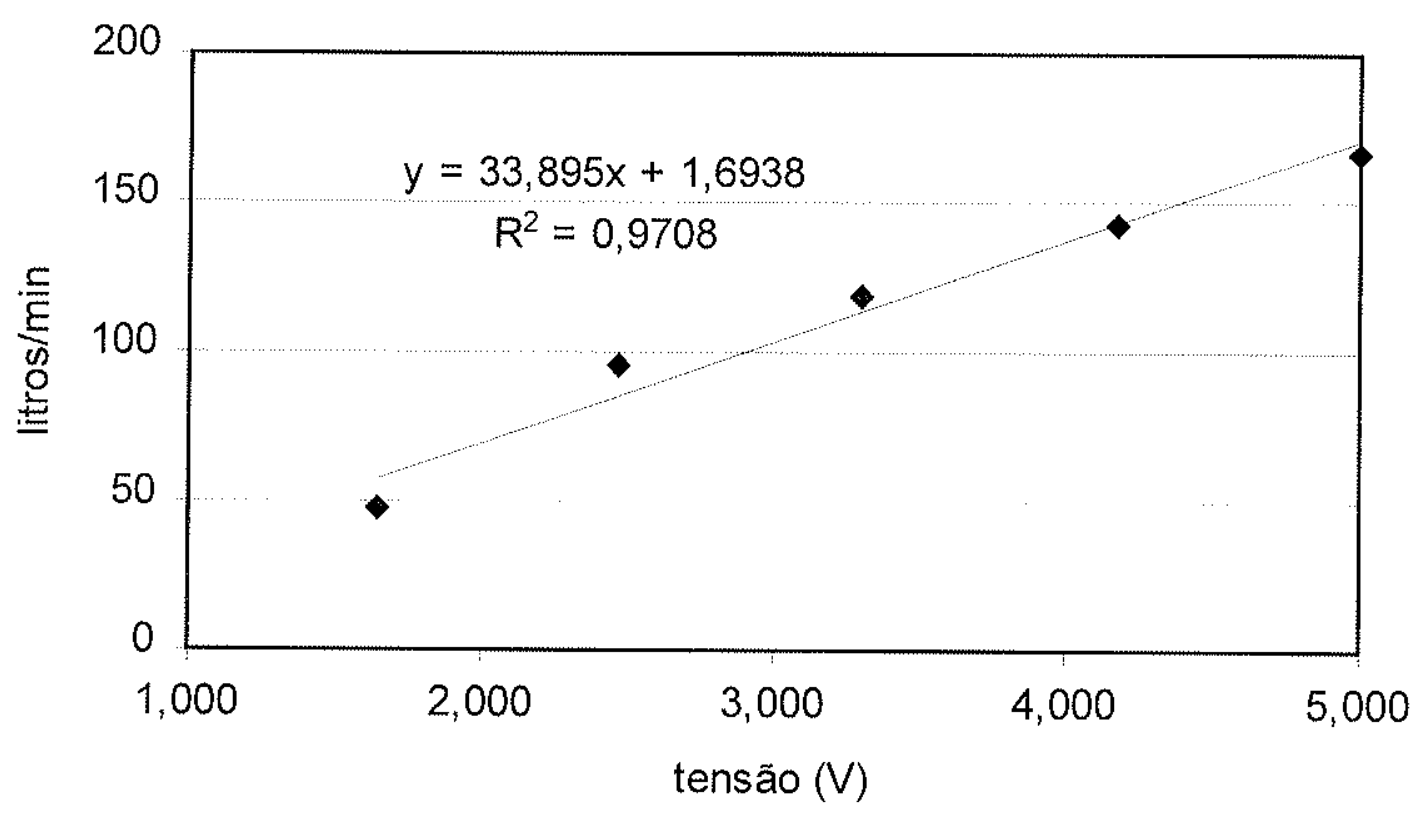

Figura 4.13 - Calibração do sensor de vazão de entrada no furo (VazaoE) (1/2").

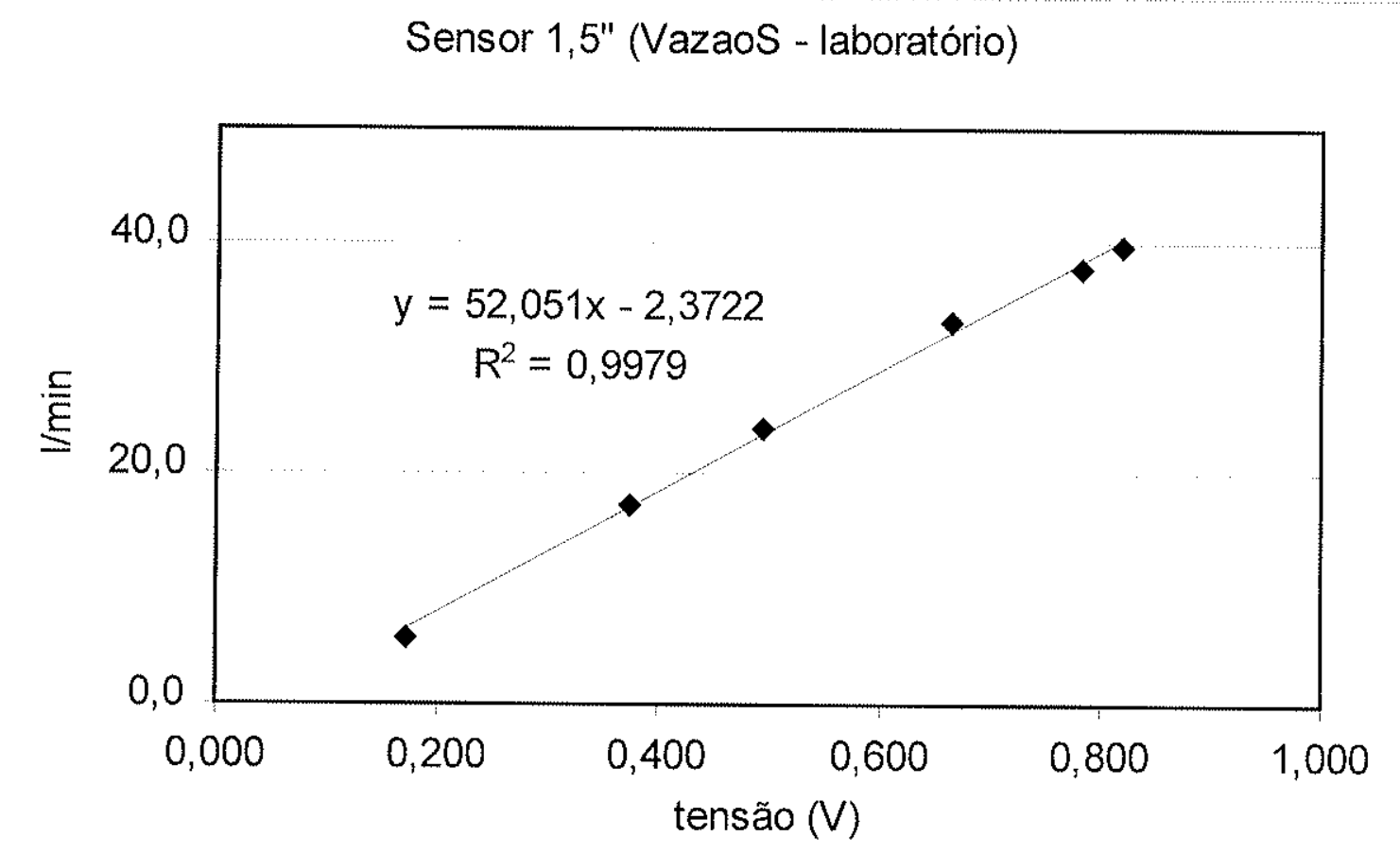

Figura 4.14 - Calibração do sensor de vazão da saida (VazaoS) (1 1/2"). 


\section{PROTÓTIPO DO SENSOR DE TORQUE}

Além dos testes dos sensores em bancada, os testes com o protótipo do sistema de monitoramento foram realizados em duas etapas: (a) $1^{\text {a }}$ etapa - testes com a sonda em operação e (b) $2^{a}$ etapa - testes de operação em campo. Na primeira, a estimativa do torque aplicado pelo motor foi proposta por meio da velocidade de rotação e da porcentagem da aceleração total. O desenvolvimento do trabalho mostrou a necessidade de um instrumento específico para a avaliação do torque consumido durante a perfuração da rocha. Para essa finalidade desenvolveu-se um equipamento composto por: (a) um acoplamento elástico e (b) um sistema eletrônico para medir as deformações impostas pelo torque no acoplamento.

\subsection{Dificuldades para a obtenção direta do parâmetro torque}

A ação de um torque em regime permanente sobre um elemento elástico produz uma deformação específica, diretamente proporcional ao módulo do torque. No caso de um sistema em movimento de rotação, as principais dificuldades para o uso desse princípio são: (a) como medir essa deformação, e (b) como transmitir o valor medido ao sistema de aquisição.

Outra solução foi ainda cogitada: instalação de "strain-gages" no eixo do motor e utilização de um sistema de teletransmissão para o envio dos dados ao computador. Essa solução foi abandonada devido aos seguintes fatores: (a) a instalação dos "strain-gages" necessitaria de um comprimento livre de eixo, que o equipamento utilizado não possui; (b) os custos dessa solução eram altos para o projeto e (c) essa forma de aquisição somente havia sido aplicada a baixas velocidades de rotação.

Uma vez que os instrumentos disponíveis no mercado são de custos elevados e aplicação incompatível com as condições de funcionamento da sonda (água, alta temperatura, possibilidade de choques mecânicos), optou-se pelo desenvolvimento de um aparelho específico para essa finalidade.

\subsection{O sensor de torque proposto}

A sonda utilizada na pesquisa mostrou-se adequada à adaptação do sensor de torque proposto. Na maioria dos modelos de sonda rotativa, a caixa de câmbio e o motor são acoplados, não existindo eixo livre, nem mesmo espaço aberto entre o motor e a caixa de câmbio, que permitisse a instalação do instrumento da forma como foi concebido. As 
fotografias com o acoplamento original (a) e com o sensor instalado (b) são apresentadas na Figura 5.1.
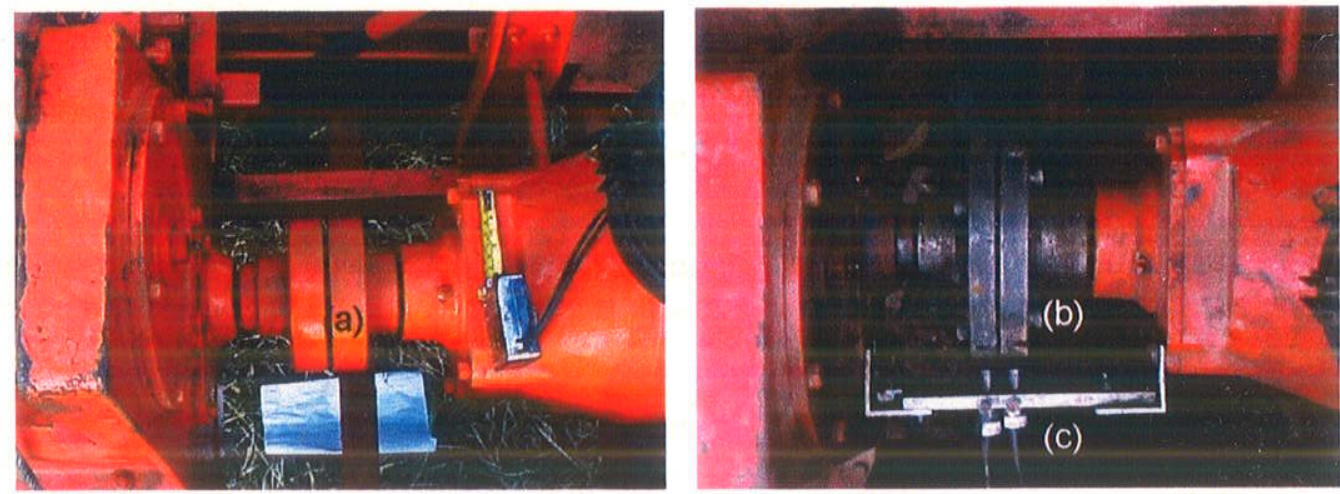

Figura 5.1 - Acoplamento original da sonda (a) e acoplamento elástico do sensor de torque desenvolvido (b). Sensores de proximidade e respectivo suporte (c).

O acoplamento elástico substituiu o existente na sonda (Figura 5.1a), transferindo a rotação do motor (à direita) para a caixa de câmbio (à esquerda). O acoplamento desenvolvido possui um conjunto de quatro molas, dimensionadas para o nível de tensões produzidas, função do torque máximo do motor. A peça está representada esquematicamente na Figura 5.2.

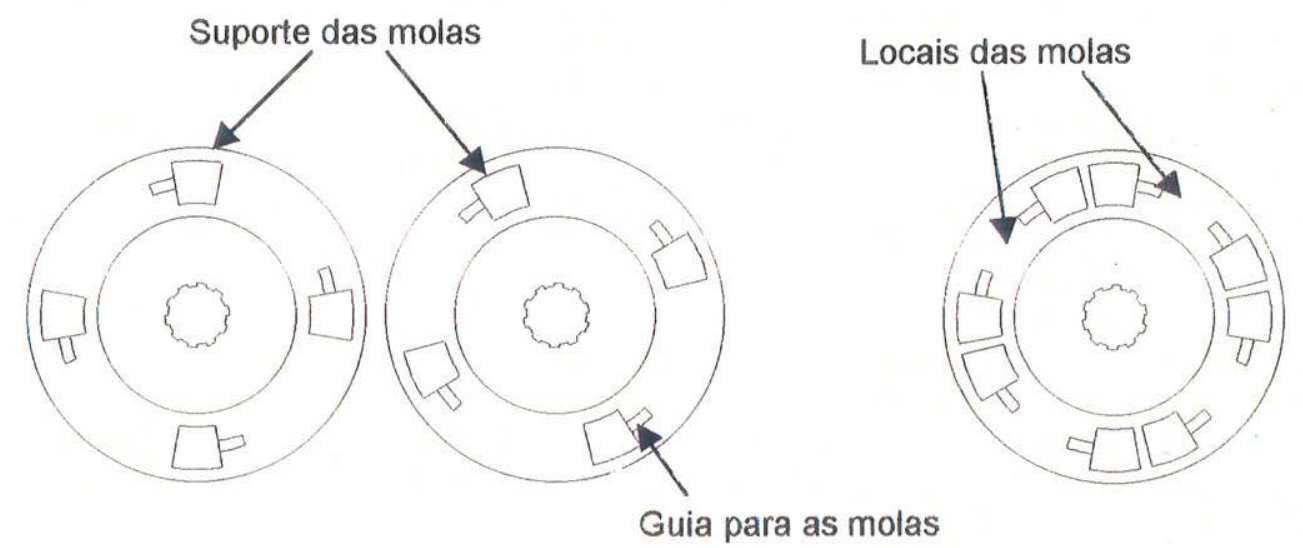

(a) Acoplamento elástico "aberto" com suas duas peças separadas (b) Posição dos suportes das molas com do acoplamento elástico montado ou "fechado"

Figura 5.2 - Esquema do acoplamento elástico.

$\mathrm{O}$ torque fornecido pelo motor é transferido à caixa de câmbio pelo acoplamento elástico, que se deforma em função das condições em que está sendo realizada a perfuração, ou seja, em função do torque aplicado.

Através da calibração estática (Figura 5.3), realizada com um torquímetro "T" (incerteza de $2,5 \mathrm{~N} . \mathrm{m}$ ), obteve-se a taxa de deformação do acoplamento elástico em função do torque aplicado (Figura 5.4). 


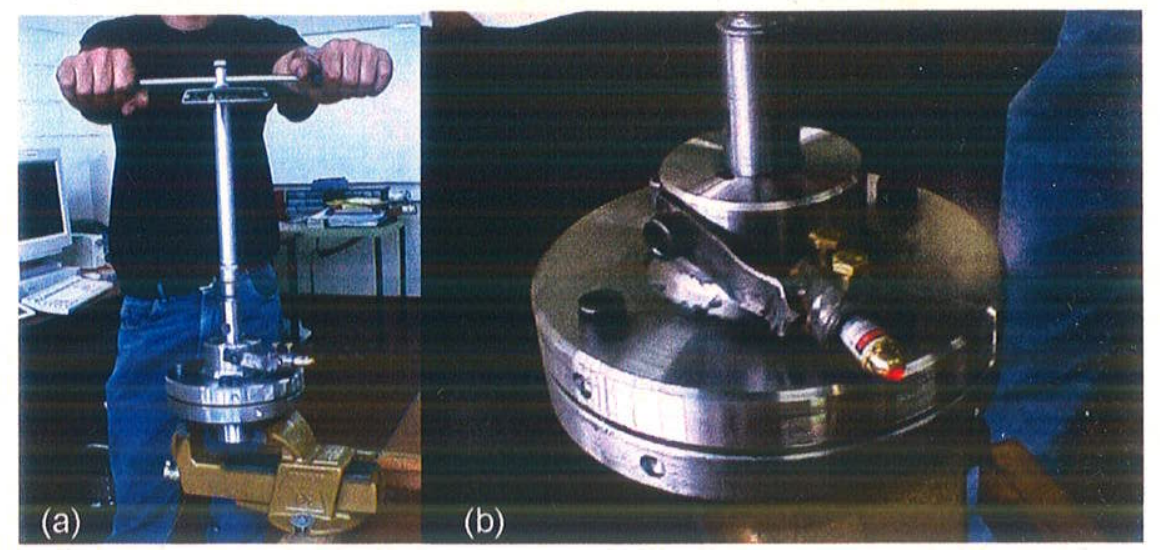

Figura 5.3 - (a) Fotografias com a calibração estática do acoplamento elástico. (b) Detalhe do laser utilizado para medida do deslocamento angular.

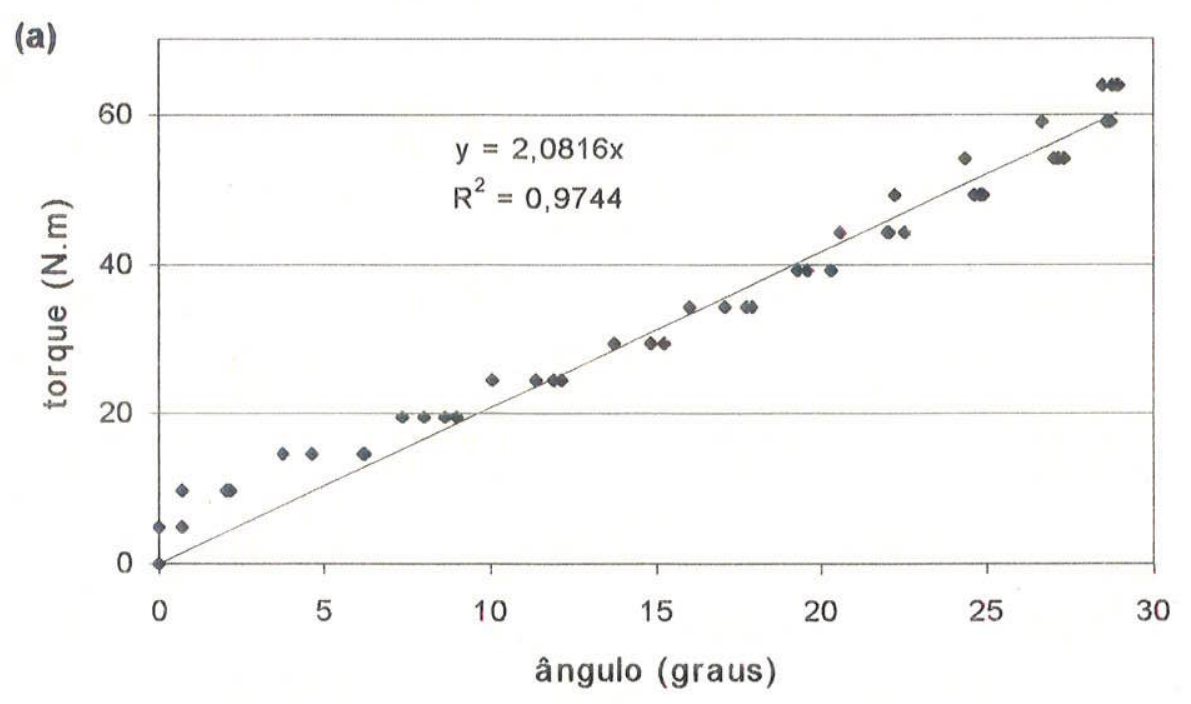

(b)

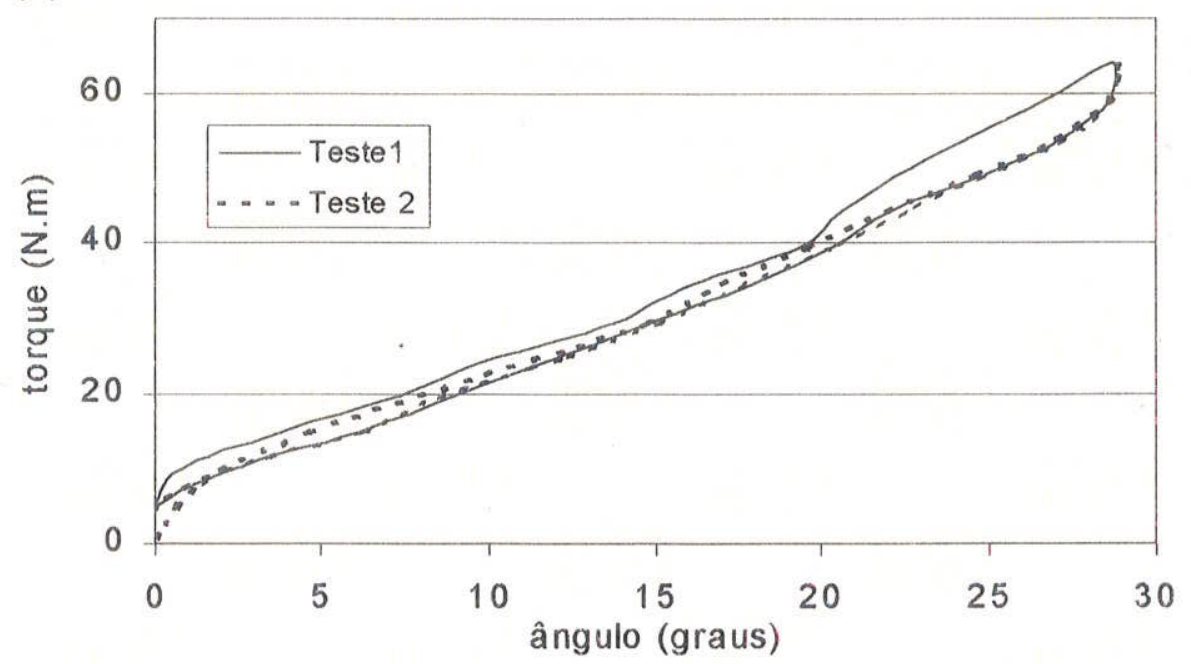

Figura 5.4 - (a) Taxa de deformação do acoplamento com o torque aplicado e (b) trajetórias de carregamento e descarregamento dos mesmos pontos.

O sensor de torque é composto ainda por um sistema eletrônico, cuja função é detectar o movimento rotativo do conjunto e o movimento relativo na peça, função da 
deformação imposta pelo torque aplicado. Através da instalação de imãs, dois a dois em cada flange do acoplamento, em posição diametralmente oposta; e da utilização de sensores de proximidade (tipo "Hall"), foi possível detectar o movimento rotativo do conjunto e a deformação das molas dentro da peça, determinado pelo torque imposto.

Os sinais produzidos pelos sensores são retificados por um circuito eletrônico, gerando sinais de pulso (onda quadrada). Como existem dois imãs em cada lado da conexão elástica, a freqüência dos sinais representa o dobro da velocidade de rotação do eixo do motor. A defasagem entre a entrada dos pulsos e/ou o início das ondas, expressa em milisegundos, é proporcional à deformação da peça e, conseqüentemente, ao torque aplicado (Figura 5.5).

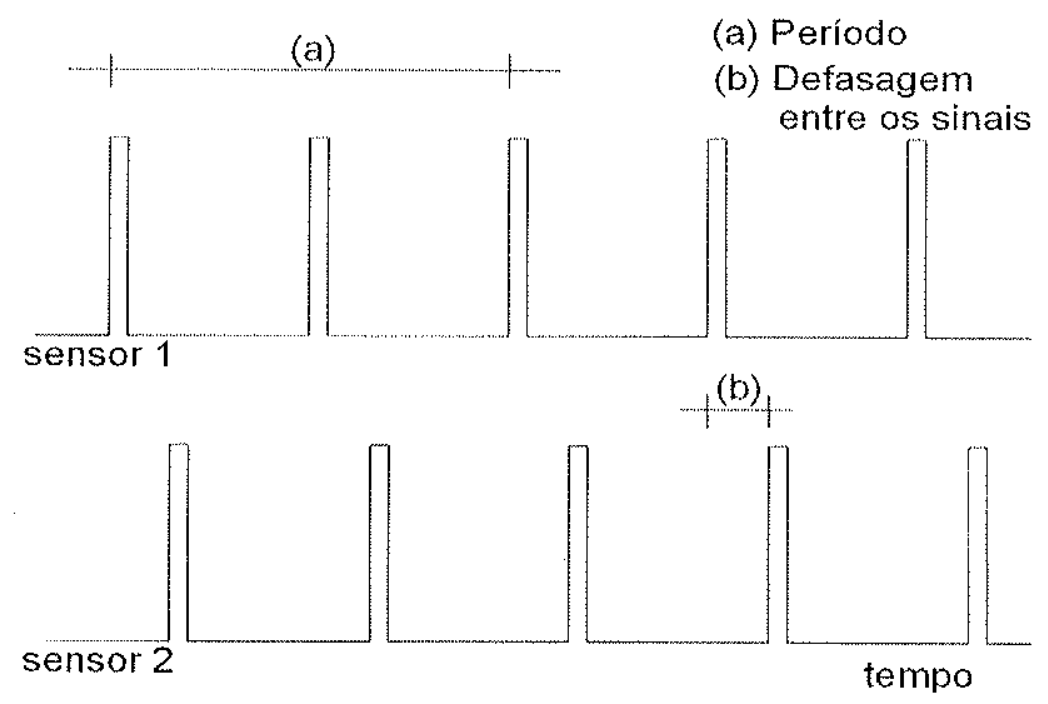

Figura 5.5 - Sinais dos sensores instalados no acoplamento da sonda. Periodo de rotação do motor (a) e defasagem proporcional ao torque aplicado (b).

Um microprocessador programável (a) recebe os sinais dos sensores, identifica esses tempos: o período de um dos sinais e a defasagem entre os dois (clock de $2 \mathrm{MHz}$, ou seja, precisão de $0,5 \mu \mathrm{s}$ ); (b) processa esses valores e (c) envia diretamente para o computador, através de sua porta serial, o valor da rotação e o ângulo de deformação do acoplamento. A precisão do sistema eletrônico para a medida da deformação angular foi avaliada por meio de testes dinâmicos, onde a defasagem dos ímãs foi simulada com anteparos fixos (Figura 5.6). O valor obtido mostrou que o sistema eletrônico é bastante sensível, gerando uma correlação bastante satisfatória para a medida de torque. 


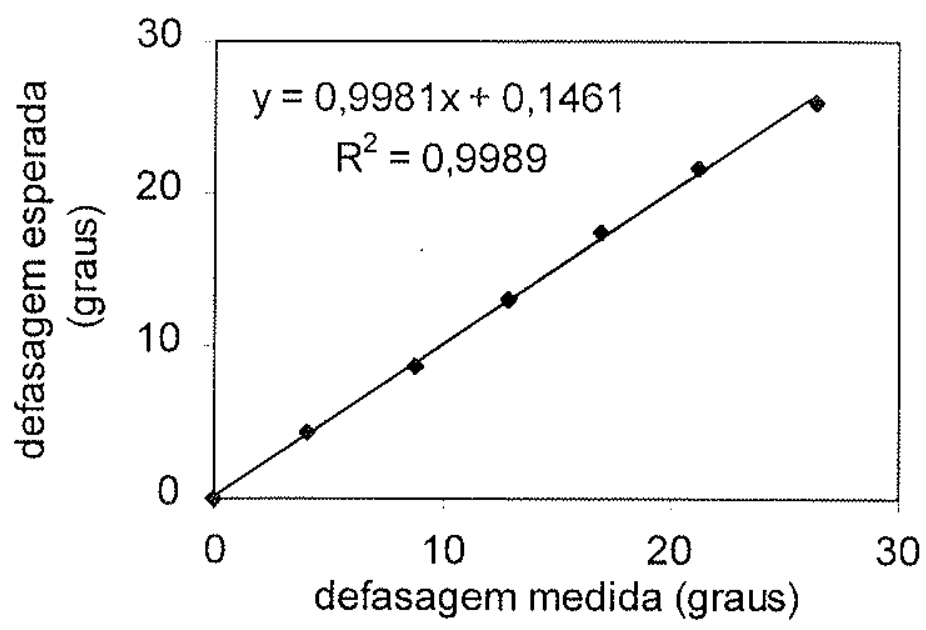

Figura 5.6 - Teste do sistema eletrônico para medida da defasagem (anteparos fixos).

A inclinação da curva de "torque x deformação angular do acoplamento elástico" (Figura 5.3a) possibilita, portanto, a correspondência direta da defasagem angular medida com um valor de torque correspondente.

Caso os imãs estivessem precisamente alinhados, o ângulo medido pelo sistema eletrônico poderia ser diretamente associado ao valor do torque. No acoplamento utilizado não houve essa preocupação e o ângulo obtido não poderia ter essa associação. Além dessa questão, durante a realização dos testes foram detectadas deformações permanentes nas molas do acoplamento. Essa dificuldade poderia ser contornada com o uso de molas fabricadas com materiais com maior valor de tensão de trabalho dentro do regime elástico. $\mathrm{O}$ valor do módulo de elasticidade não pode mudar significativamente, sob pena de alterar a resolução das medidas de deformação para um mesmo torque. Esse fato também inviabilizaria a calibração do torquímetro para a obtenção do valor absoluto de torque. No presente trabalho, a informação utilizada foi a diferença entre a condição de rotação de pré e pós-perfuração (livre de atrito na face da coroa) e a condição de furação (com atrito na face da coroa). O conjunto de molas foi trocado seis vezes durante os testes, na intenção de minimizar a interferência das deformações permanentes.

\subsection{Procedimentos para a medida de torque}

Mesmo sem a realização da perfuração, ou seja, com a coluna de perfuração girando livre, numa determinada profundidade e porcentagem de aceleração total, o motor imprime um determinado torque à caixa de câmbio. Estando o conjunto em regime, o torque aplicado é consumido pelas forças dissipativas que se opõem à rotação da coluna: atrito lateral do 
barrilete (principalmente no alargador), viscosidadade do fluido de circulação, rendimento mecânico da transmissão.

O início da perfuração é marcado pela aplicação de uma força resultante, através da coluna de perfuração, sobre a ferramenta de corte, composta pelo peso da composição e pela atuação do sistema hidráulico. Surge um atrito dinâmico entre a face da ferramenta de corte e a rocha. Nesse momento, a tendência é de diminuição da velocidade de rotação e de aumento do torque aplicado. Essas alterações equilibram-se, de acordo com a posição do acelerador e a marcha estabelecidas na sonda. A diferença entre a condição de não-perfuração e a de perfuração representa o acréscimo do atrito frontal da ferramenta de corte.

Observou-se uma grande variação do torque ao longo do tempo. Alguns fatores podem ser associados a esse comportamento: (a) trepidação devido à base do motor não encontrar-se bem lastreada e (b) resistência variável devido à heterogeneidade da rocha (item 3.3.3). Mesmo que não haja alteração nas condições de aceleração do motor ou da pressão sobre a ferramenta de corte, essas variações não são desprezíveis e exigem que o valor representativo de um trecho perfurado seja admitido, considerando-se a média aritmética dos valores lidos ao longo do trecho.

Na tentativa de se obter valores mais representativos das condições de perfuração, foram estabelecidos os seguintes procedimentos para a execução da manobras de sondagem:

a) No início e término da perfuração da manobra do pistão ${ }^{18}$, a sonda funciona por trinta segundos, nas condições de aceleração impostas durante a perfuração, sem o avanço do hidráulico, portanto, sem o atrito frontal e sem perfuração.

b) Antes do início e término do avanço do hidráulico, é acionada a embreagem, interrompendo a transferência de rotação no eixo do motor para o eixo da sonda. Esse procedimento identifica nos registro o momento exato do início e término da perfuração.

c) Dentro das possibilidades do equipamento, a perfuração é realizada na maior velocidade possivel. Para isso, a pressão sobre a ferramenta de corte deve ser alta, produzindo maior atrito frontal e, conseqüentemente, maior demanda de torque. Dessa maneira, tem-se também uma maior deformação angular, facilitando a obtenção do parâmetro torque na faixa de medição de maior nível de confiabilidade do torsiômetro.

\footnotetext{
${ }^{18}$ Perfuração do trecho de $50 \mathrm{~cm}$ correspondente ao curso do pistão do sistema hidráulico.
} 
Com o estabelecimento desses procedimentos, é possível avaliar o ângulo de deformação da peça em rotação, antes do início da perfuração e durante a perfuração. A diferença angular resultante é associada diretamente, a partir da taxa de deformação obtida na calibração estática, com o torque efetivamente envolvido com a perfuração. Os três níveis de torque obtidos com esses procedimentos são ilustrados na Figura 5.7.

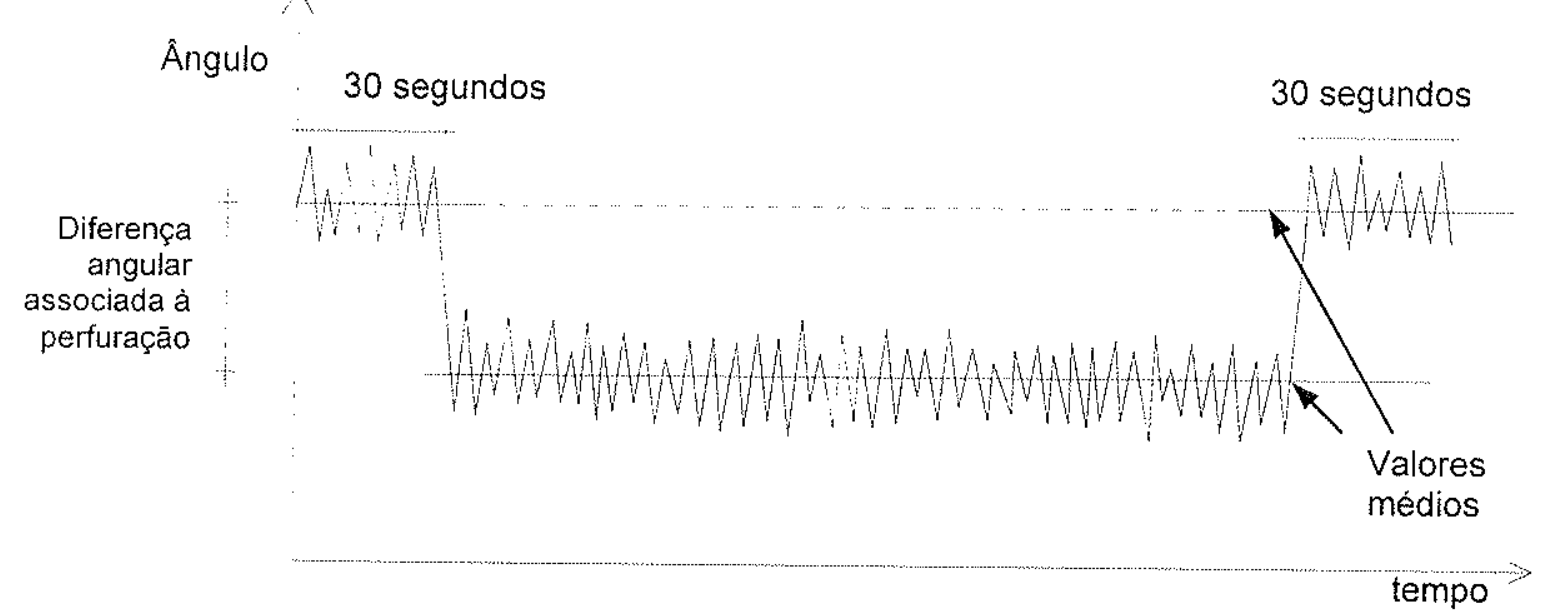

Figura 5.7 - Comportamento típico dos parâmetros associados à estimativa do torque durante a
perfuraçăo.

Os testes de perfuração realizados com o sensor mostraram um problema não previsto. Durante a execução do furo, a sonda realiza outras operações, além da perfuração. A principal delas refere-se a instalação do revestimento no trecho em solo. É comum que a sonda necessite "rodar" dezenas de metros de revestimento para essa preparação do furo. Considerando solos muito arenosos, como são os da região dos testes, essa operação requer muita energia da sonda. Apesar do acoplamento elástico ter sido projetado para absorver o torque máximo do equipamento, foi observada uma progressiva diminuição no curso das molas e o aparecimento de folgas no acoplamento. Houve um caso durante os testes de perfuração na rocha, onde um único "travamento" da coluna de perfuração inutilizou completamente ("folga" maior que $10^{\circ}$ ) todo um conjunto de molas.

$O$ conjunto de molas foi trocado quatro vezes durante a realização dos testes, no entanto, a calibração foi realizada apenas uma vez. Considerou-se que, como todas as molas possuíam a mesma especificação, a curva de calibração esperada não deveria ser significativamente diferente. 


\section{ANÁLISE E DISCUSSÃO DOS DADOS}

Nas diversas áreas de aplicação das sondagens rotativas com amostragem (geotecnia, mineração, meio ambiente, hidrogeologia, etc.), entre outras finalidades, elas são usadas para caracterização e classificação rochas. Em situações especiais, a sonda rotativa pode ser utilizada em solo, porém esse procedimento é evitado devido aos altos custos envolvidos. Em casos específicos, ensaios realizados no furo remanescente da sondagem rotativa permitem a avaliação das condições hidrogeotécnicas e, em situações mais raras, hidrogeológicas.

O protótipo em desenvolvimento permite monitorar até nove grandezas físicas junto à sonda e à bomba (linha de água). Considerando o controle do tempo, realizado através da freqüência de amostragem estabelecida, e a profundidade do furo, obtém-se ainda outras oito grandezas. A relação entre essas grandezas, medidas direta ou indiretamente, utilizadas na classificação dos maciços ou no controle da perfuração é apresentada no Quadro 6.1.

Quadro 6.1 - Relação entre grandezas medidas e parâmetros de classificação/controle.

\begin{tabular}{|c|c|}
\hline Grandeza Medida & Parâmetro de classificação/controle \\
\hline - Posição da coluna de perfuração (m) & \multirow{3}{*}{$\begin{array}{l}\text { - Velocidade de avanço da perfuração }(\mathrm{m} / \mathrm{s}) \\
\text { - Taxa de penetração }(\mathrm{m} / \mathrm{rev}) \\
\text { - Freqüência de rotação da coluna }(\mathrm{Hz}) \\
\text { - Relação do câmbio para correção do } \\
\text { torque (adimensional) }\end{array}$} \\
\hline - Freqüência de rotação do motor $(\mathrm{Hz})$ & \\
\hline - Frequeência de rotação da coluna $(\mathrm{Hz})$ & \\
\hline - Pressão no hidráulico (descendente) (MPa) & \multirow{2}{*}{$\begin{array}{l}\text { - Pressão ou força efetiva sobre a } \\
\text { ferramenta de corte }{ }^{19}(\mathrm{MPa})\end{array}$} \\
\hline - Pressão no hidráulico (ascendente) (MPa) & \\
\hline - Deformação no acoplamento elástico (graus) & - Torque aplicado à perfuração (N.m) \\
\hline - Vazão de entrada (fluido de perfuração) $\left(\mathrm{m}^{3} / \mathrm{s}\right.$ ) & \multirow{2}{*}{$\begin{array}{l}\text { - Volume de fluido introduzido no furo }\left(\mathrm{m}^{3}\right) \\
\text { - Volume de fluido retornado do furo }\left(\mathrm{m}^{3}\right) \\
\text { - Taxa de retorno }\left(\mathrm{m}^{-1}\right)\end{array}$} \\
\hline - Vazão de saída (fluido de perfuração) $\left(\mathrm{m}^{3} / \mathrm{s}\right)$ & \\
\hline - Temperatura $\left({ }^{\circ} \mathrm{C}\right)$ & "Temperatura $\left({ }^{\circ} \mathrm{C}\right)$ \\
\hline
\end{tabular}

\footnotetext{
${ }^{19}$ A pressão efetiva de corte considera fatores relacionados à profundidade (peso da coluna e empuxo do trecho
imerso)
} 
As características e os parâmetros de interesse (geotécnicos, hidrogeotécnicos ou hidrogeológicos) às unidades geológico-geotécnicas também podem ser numerosas numa campanha de investigação: permeabilidade ou condutividade hidráulica, coeficiente de armazenamento, nível d'água, presença de aqüíferos suspensos, coesão, ângulo de atrito, entre outras.

A grande quantidade e diversidade dos dados monitorados dificultam sua representação e interpretação. Isso pode ser notado nas descrições dos parâmetros de sondagem realizadas por BAPTISTA (1986) e SCARMÍNIO (1988). Apesar do monitoramento ser um contínuo e detalhado registro das condições de execução do furo e das respostas do terreno, em muitas situações é difícil o aproveitamento prático dessas informações.

Segundo a bibliografia específica sobre diagrafia de sondagem em furos destrutivos, a análise dos dados é realizada essencialmente de maneira qualitativa. Os valores obtidos na bibliografia raramente têm caráter absoluto, sendo sempre considerados de maneira comparativa, dentro da obra ou de uma campanha específica. No casos dos furos com amostragem, apesar dos procedimentos e do equipamento serem padronizados em termos de diâmetros e tipos de rosca, acredita-se que uma análise quantitativa seria prejudicada, entre outros fatores, pela influência da variedade de ferramentas de corte (granulação e qualidade dos diamantes, tipos de matriz, etc.).

O aproveitamento sistemático e efetivo dos parâmetros de perfuração na caracterização e classificação de maciços demanda uma abordagem que permita que essas informações possam ser extrapoladas para fora da campanha de investigação específica, ou seja, que eles possam ser associados a características intrínsecas das rochas e maciços, através de critérios mais "absolutos".

No presente trabalho, considerou-se perfurabilidade como a resistência do material à desagregação provocada pelo processo rotativo-abrasivo de perfuração. Portanto, é natural que ela seja relacionada a outras formas de resistência, como é apresentado por TSOUTRELIS (1969) com relação à resistência à compressão uniaxial (RCU). Outros autores também realizaram correlações com a perfurabilidade de rochas (CLARK, 1979; HOWARTH \& ADAMSON, 1988). 
O fluido de limpeza e refrigeração e as condições de sua utilização (densidade, vazão, pressão) possuem ainda um potencial de aproveitamento na inferência de características relativas à hidrogeotecnia dos maciços. A principal dificuldade para a utilização desse parâmetro está relacionada à tendência de aumento de trechos não revestidos à medida que o furo avança. Esses trechos podem colaborar, tanto para a absorção do fluido, quanto para o aumento do seu retorno (em condições de artesianismo), mascarando e tirando significado dos resultados e das interpretações obtidas.

Em algumas situações geológicas, o monitoramento da perfuração apresenta maior potencial de aproveitamento. Os métodos diretos de investigação, em especial as sondagens mistas, perdem qualidade de informação na caracterização de materiais com resistência intermediária, p.e. rochas sedimentares (rochas brandas) ou materiais de transição solo-rocha. Características como graus de alteração ou coesão, heterogeneidades e anisotropias ou resistência mecânica, inerentes às condições geológicas, poderiam ser associadas à perfurabilidade, de modo contínuo ao longo do furo, com uso das técnicas do monitoramento da perfuração.

\subsection{Perfuração rotativo-abrasiva na sonda}

Considerando o tipo de equipamento utilizado, os parâmetros ou condicionantes que se inter-relacionam, controlando a perfuração rotativa, estão representados na Figura 6.1. Existem outros fatores, não representados, que também determinam o avanço do furo. Mais difíceis de serem avaliados, esses fatores podem ter grande influência no processo de perfuração. Entre eles, os principais estão relacionados às características da ferramenta de corte: geometria, tipo (cravada ou impregnada), quilatagem total, granulometria (PPQ) e qualidade dos diamantes, dureza da matriz, geometria da face, número e forma das saídas d'água, grau de desgaste ou uso, etc.

$\mathrm{O}$ avanço da perfuração é representado diretamente pela velocidade de avanço do furo $\left(V_{a}=l / \Delta t\right)$, ou ainda pela taxa de penetração $(\delta)(\mathrm{cm} / \mathrm{rev})$. Esses dois parâmetros relacionam-se através da velocidade angular de rotação:

$$
V a=\delta . W
$$


Destaca-se que esses parâmetros, apesar de representativos da qualidade e características dos materiais, dependem do equipamento e de sua forma de operação.

A perfurabilidade associa-se às características intrínsecas dos materiais, possuindo um caráter menos "relativo", quando ela é representada através de parâmetros específicos, por exemplo, através do valor da energia ou do trabalho gastos por unidade de volume de material perfurado ("cortado").

TEALE (1965) considera a energia necessária para a perfuração de um volume unitário de rocha como um valor teórico mínimo. Em condições reais, esse valor é difícil de ser avaliado, devido às numerosas perdas mecânicas existentes entre o motor e o local da perfuração. No caso da perfuração rotativo-abrasiva, justifica-se a superação desse valor teórico mínimo, devido às interações entre a ferramenta de corte e a rocha, que resultam na perfuração fora das condições de máxima eficiência. As perdas mecânicas no sistema de transmissão, o atrito da ferramenta fora da face cortante, a resistência à rotação da coluna pela viscosidade do fluido de perfuração, as perdas térmicas pelo atrito envolvido são outras parcelas da "energia perdida", ou seja, a energia não utilizada especificamente para o avanço do furo.

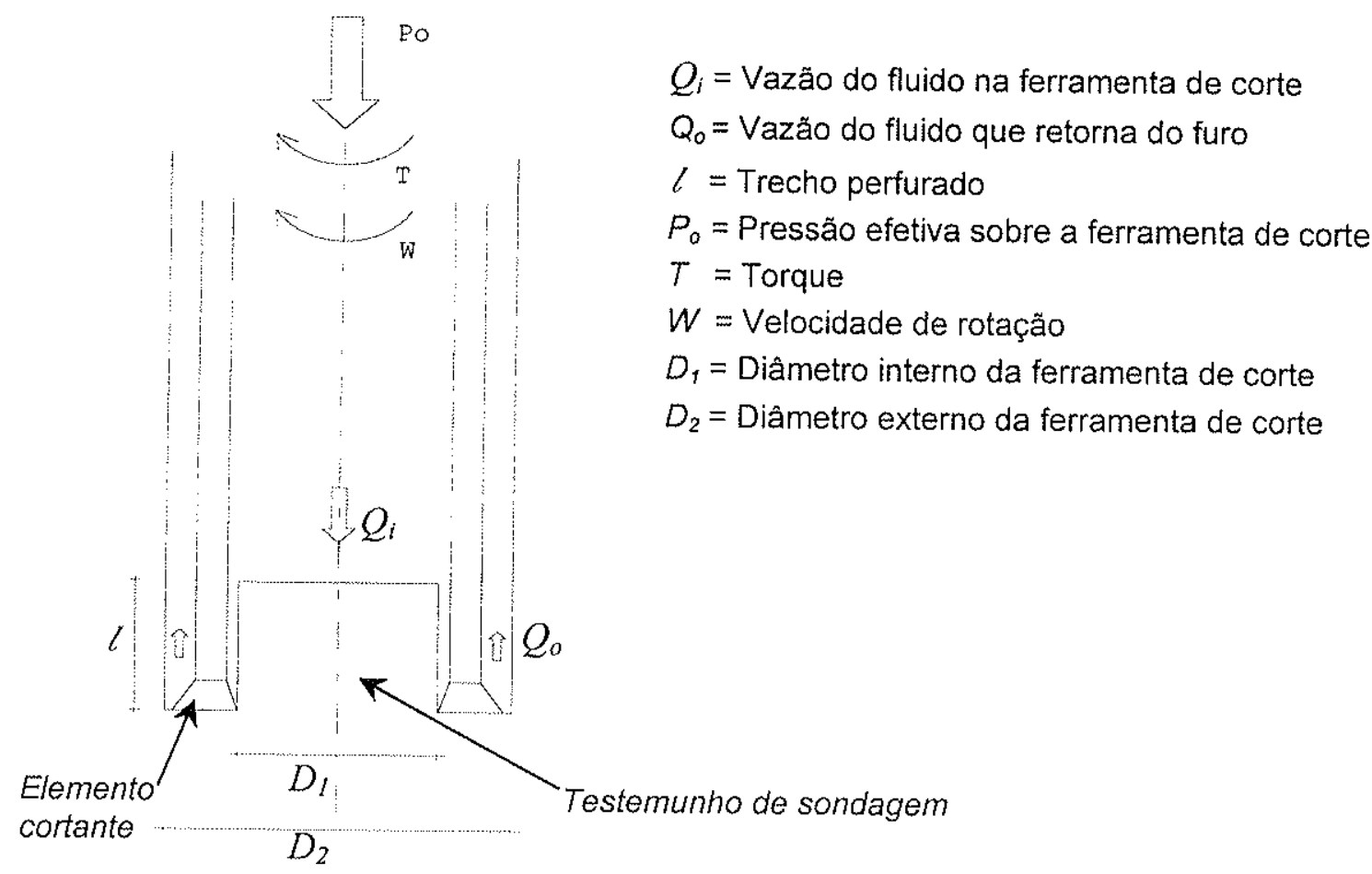

Figura 6.1 - Elementos envolvidos na perfuraçăo. 
A energia para a rotação da ferramenta de corte é gerada por um motor a explosão ou elétrico; portanto, a energia total despendida pode ser avaliada pelo combustivel (diesel ou gasciina) ou energia elétrica consumidos (corrente elétrica). Em termos físicos, a potência produzida pelo motor (Pot Total (Watt) é expressa apenas pelos parâmetros velocidade de rotação $(W)(\mathrm{rad} / \mathrm{s})$ e torque $(T)(N . \mathrm{m})$, através da fórmula:

$$
\text { Pot }_{\text {Total }}=W \cdot T
$$

A expressão é válida para qualquer condição da sonda em funcionamento, mesmo quando essa não estiver perfurando. Nesse caso, a energia gasta em um determinado intervalo de tempo (Pot Total . $\Delta t$ ) será integralmente utilizada para a manutenção da rotação da coluna, na condição de rotação máxima para o nível específico de potência.

A partir do momento em que as superfícies da rocha e da ferramenta de corte passam a ter contato, pressionadas pela ação de uma força de compressão normal $\left(F_{v}\right)$, é gerada uma pressão na superfície de corte $\left(P_{o}\right)$. Por essa definição, $F v$ é a resultante de todas as forças que agem sobre a coluna de perfuração. Nessas condições, uma parcela da energia total começa a ser transferida para o processo de perfuração rotativoabrasivo. A velocidade de rotação tende a diminuir, mas pode permanecer constante, dependendo da potência do motor e de suas condições de funcionamento. Uma parcela do torque produzido pelo motor passa a ser "consumida" pela perfuração. Apesar do equilíbrio na relação rotação/torque (expressão 6.1), a alteração do nível de rotação determinada por um novo estado de carregamento da ferramenta de corte, altera a potência fornecida pelo motor a explosão, de acordo com suas características técnicas (Curva de torque - Figura 3.14).

A força ou pressão efetiva sobre a ferramenta de corte determina, provavelmente dentro de certos limites, a parcela dessa potência total do motor transferida para o processo de perfuração. O valor dessa parcela é o que de fato relaciona-se à resistência da rocha à perfuração. A potência transferida para a perfuração ( Pot $_{\text {erff }}$ ) seria assim determinada pela pressão efetiva sobre a ferramenta de corte e pela interação das superfícies da rocha e da ferramenta cortante. Essa interação determina um acréscimo de torque e pode inclusive englobar outros fatores inerentes à ferramenta de corte, tais como seu nivel de desgaste ou sua geometria. 
A relação da Figura 6.2 refere-se à transferência de energia sonda-rocha, e é um modelo clássico em sistemas físicos. Um determinado parâmetro estabelece uma "condição ótima", fora da qual o sistema ou a transferência de energia é menos eficiente. Diversos trabalhos, embora não tratem do assunto especificamente sob esse enfoque, sugerem mesmo assim essa relação da pressão ou força de compressão na ferramenta de corte com a velocidade de avanço perfurações rotativas (BIELSTEIN \& CANNON, 1950; CLARK, 1979). Em perfurações percussivas, essa mesma relação entre a força de compressão sobre a ferramenta de corte e a sua velocidade de avanço pode ser observada (SCHMIDT, 1972; CLARK, 1979).

$$
\text { Pot }_{\text {Perf }}=k . \text { Pot } \text { Total } \quad \text { (6.3), } \quad \text { onde } 0 \leq \mathrm{k}<1 \text {, estando o }
$$
valor de k relacionado à $P o$. (Figura $6.2)$

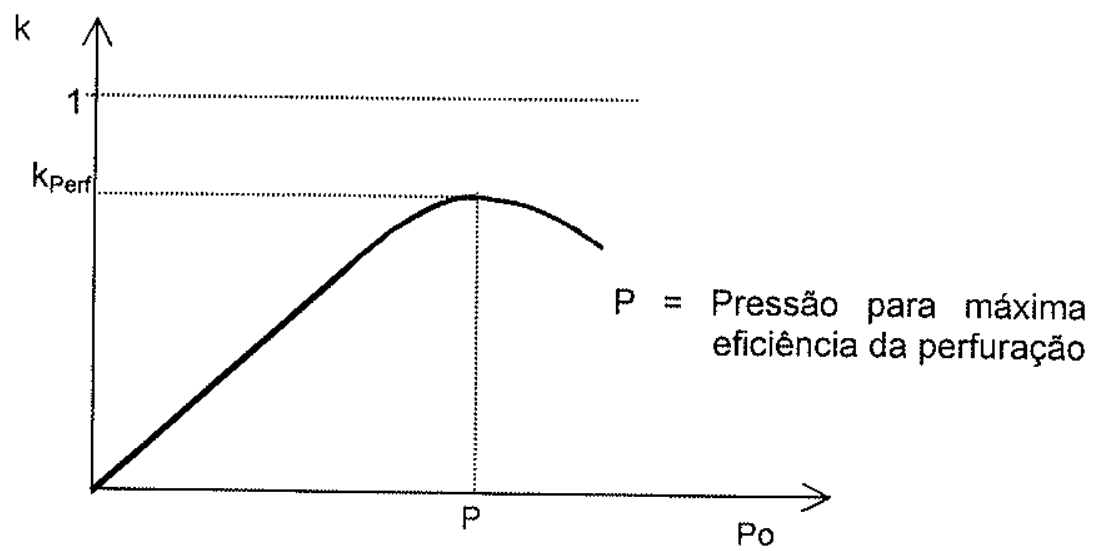

Figura 6.2 - Influência da pressão efetiva na ferramenta de corte $\left(P_{0}\right)$, considerando a transferência da energia da sonda para o processo de perfuração.

Não é esperada grande influência da vazão do fluido de limpeza diretamente na perfuração, especialmente em rochas mais resistentes. O fluxo de água ou lama apenas retira o material cominuido, garantindo uma interação eficiente entre as superfícies da ferramenta de corte e da rocha.

A utilização do processo rotativo-abrasivo não é indicada para a perfuração de solos. A perfuração desse material com a sonda rotativa justifica-se devido à facilidade operacional. $\mathrm{Na}$ verdade, a perfuração em solos ou em rochas menos resistentes dar-seia por um processo de escarificação ou "raspagem", e não por um processo de desgaste abrasivo. Quando há perfuração de solo com a sonda, esse tipo de investigação é denominada de sondagem mista. É comum a intercalação de ensaios de penetração SPT a cada metro, para a amostragem e caracterização do solo. 
A avaliação da energia de perfuração específica, considerando os equipamentos e o método rotativo-abrasivo, é mais difícil em solo. Isso ocorre porque os níveis de energia são significativamente menores e, portanto, mais difíceis de serem medidos em uma sonda projetada para perfurar até rocha sã.

Esse fato pode ser observado na etapa de testes. A cobertura de solos sedimentares foi perfurada com diversas ferramentas: brocas de arraste ( $\mathrm{Hx}$ e $\mathrm{Nx}$ ) e uma ferramenta sem especificação (Figura 6.3 a, b e c, respectivamente).
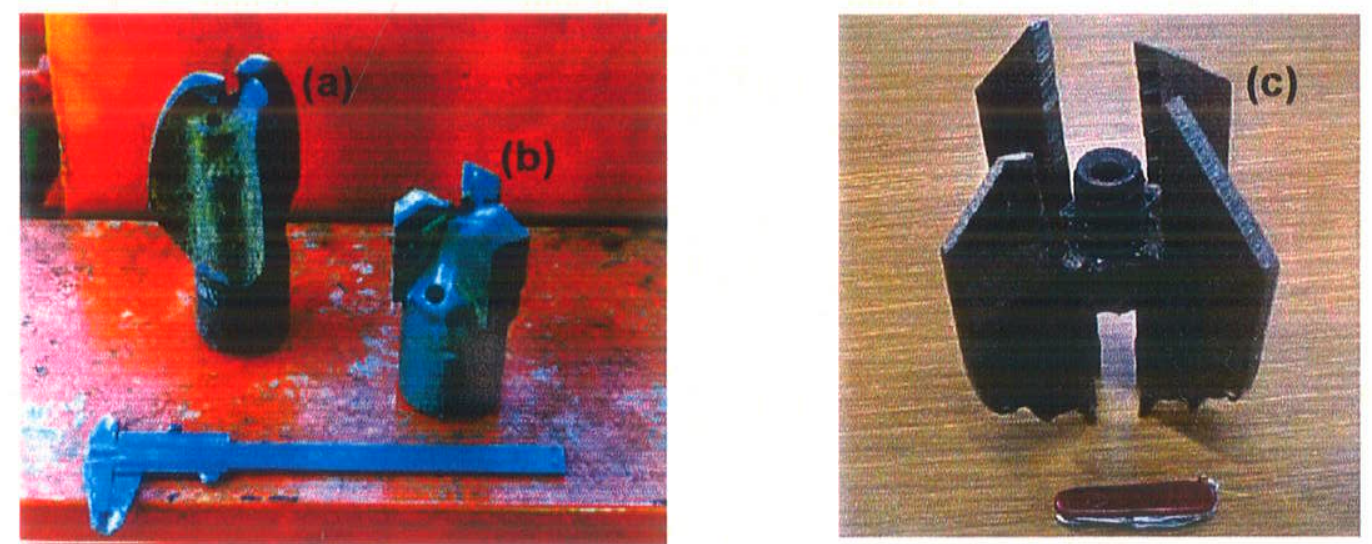

Figura 6.3 - Ferramentas de corte utilizadas na perfuração em solo: brocas de arraste diâmetros $\mathrm{Hx}(\mathrm{a}), \mathrm{Bx}(\mathrm{b})$ e a broca sem especificação $(\phi=20 \mathrm{~cm})$ (c).

Outro fator que pode ser previsto no monitoramento em solo é o aumento significativo da importância da vazão do fluido de perfuração na entrada do furo. Enquanto esse parâmetro possui apenas uma função de refrigeração e limpeza do material cortado em rochas resistentes, em solos, especialmente nos arenosos, a vazão do fluido desempenha uma função de desagregação do material na saída da ferramenta de corte.

Observa-se ainda que a velocidade máxima de avanço nos solos é limitada pela capacidade de limpeza e carreamento do material "cortado". Por esse motivo, o torque transferido para o processo de perfuração tende a ser muito mais baixo. Mesmo baixas pressões exercidas sobre a ferramenta de corte provocam o entupimento das saídas de água frontal e a imediata interrupção da perfuração.

Da mesma forma que nos solos, esse fenômeno pode ocorrer também nas chamadas rochas brandas. BIELSTEIN \& CANNON (1950) tratam especificamente dos fatores que afetam a velocidade de penetração da ferramenta de corte nesse tipo de material. A ferramenta de corte utilizada é do tipo "rotary" e os autores referem-se a esse condicionante como "fator hidráulico". 
Nos trechos em rocha, quase toda a perfuração foi realizada com coroas $\mathrm{Nw}$ impregnadas. Apenas a primeira manobra (rocha alterada) do furo da $1^{\text {a }}$ etapa de testes foi realizada com a coroa cravada. A fotografia com as ferramentas de corte utilizadas está apresentada na Figura 6.4.

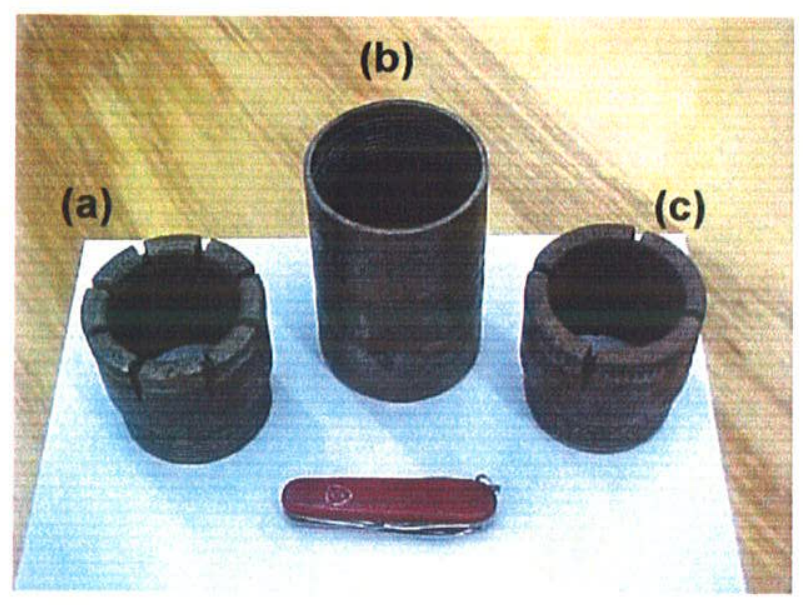

Figura 6.4- Ferramentas de corte utilizadas na perfuração em rocha: coroa impregnada Nw (10 quilates) (a), calibrador (b) e coroa cravada Nw (70-80 ppq) (c).

\subsection{Análise dimensional da perfurabilidade}

Considerando a proposta de TEALE (1965), que define a energia especifica como o valor mínimo gasto para a perfuração de um volume unitário de rocha, considera-se o trecho perfurado nas condições de máxima transferência de energia para o processo de perfuração ( $\mathrm{k}_{\max }$ - Figura 6.2). A análise dimensional dessa variável $(\mathrm{M}=$ massa, $\mathrm{T}=$ tempo e $\mathrm{L}=$ comprimento) apresenta a unidade em que ela é esperada:

- Perfurabilidade $(\mathrm{Pf}) \Leftrightarrow \quad$ Energia despendida / Volume cortado = Energia específica de perfuração (EEP)

$$
\left[\frac{M L^{2}}{T^{2}} / L^{3}\right] \Rightarrow\left[\frac{M}{L T^{2}}\right]
$$

6.3 Estimativa da energia transferida utilizando o acréscimo de torque

Para as variáveis apresentadas nas Figuras 6.1 e 6.2, a energia específica ou perfurabilidade $(P f)$ seria expressa por: 


$$
E E P=\frac{k \cdot W \cdot T \cdot \Delta t}{\pi \cdot\left(D_{2}^{2}-D_{1}^{2}\right)} \frac{1}{4}
$$

A implementação do sensor de torque, na segunda etapa de testes, permitiu a estimativa do torque através da deflexão do acoplamento elástico, determinada pelas condições de perfuração. Essa deflexão relaciona-se às seguintes condições de operação da sonda: (a) nível de aceleração do motor e (b) pressão efetiva sobre a ferramenta de corte.

Dessa forma, não seria mais necessária a avaliação da transferência de energia do motor para a perfuração $(\mathrm{k})$, discutida no item 6.1. O acréscimo de torque $(\Delta T)$ ou torque da perfuração (T) é a parcela envolvida no processo de perfuração. Sendo assim, a energia de perfuração no presente trabalho foi estimada através da expressão:

$$
E E P=\frac{8 . W \cdot \Delta T \cdot \Delta t}{\left(D_{2}^{2}-D_{1}^{2}\right) l}
$$

\subsection{Condições reais dos parâmetros medidos}

Comparando-se os parâmetros monitorados no protótipo e os fatores que determinam a perfuração (Figura 6.1), observa-se que todo o monitoramento é realizado junto à sonda, na superfície, enquanto a perfuração efetivamente ocorre no fundo do furo. Esse fato pode significar pelo menos algumas dezenas de metros de distância para sondagens geotécnicas ou até algumas centenas de metros em furos para mineração. A influência desse fator é maior ou menor para cada um dos parâmetros.

\subsubsection{Posição do furo e velocidade de avanço}

Dentro de cada manobra do pistão do hidráulico, a posição é controlada pelo sensor de deslocamento. O controle do tempo é realizado através da freqüência de amostragem na aquisição. Derivando-se a variável posição em relação ao tempo, obtém-se o parâmetro velocidade de avanço do furo $\left(V_{a}\right)$. O aumento da profundidade representa um maior comprimento da coluna de perfuração, o que aumenta o valor absoluto da deformação específica no carregamento e descarregamento provocado pelo sistema hidráulico durante a perfuração. Ainda assim, acredita-se que a velocidade de avanço média não seja significativamente influenciada por esse fator. Esse efeito fica 
visível nos perfís de velocidade de avanço (anexo A.1), onde essas deformações centimétricas provocam grandes anomalias positivas e negativas, ressaltadas pela baixa velocidade de avanço nos materiais rochosos (ordem de centímetros $/ \mathrm{min}$ ).

\subsubsection{Pressão efetiva sobre a ferramenta de corte (Po)}

Além da geometria da própria ferramenta (diâmetros interno e extemo), a pressão efetiva sobre a ferramenta de corte depende de dois fatores:

- contribuição da sonda;

Contribuição estabelecida pelo diferencial de pressão no sistema hidráulico $(d P=P D e s c-P A s c)$. Os dois pistões transformam a pressão da bomba em força, cujo valor e sentido depende desse diferencial e da área interna de suas seções. No caso da Sonda SS-21 (Sondeq), cada pistão possui $60 \mathrm{~mm}$ de diâmetro interno. Considerando-se que as pressões máximas do sistema hidráulico atingem aproximadamente 4,9 $\mathrm{MPa}$, a contribuição da sonda representa valores até $27,5 \mathrm{kN}$, ou seja, um acréscimo de $8,2 \mathrm{MPa}$ numa coroa $\mathrm{Nx}$.

Para a válvula de comando da sonda existem três "estados": (a) sem movimento, quando toda vazão da bomba retorna para o reservatório, (b) avanço da coluna, quando toda vazão é desviada para a parte superior do pistão ("PDesc"), onde a pressão tornase máxima, estando próxima a zero na parte inferior e (c) recuo da coluna, a situação inversa à anterior.

- peso imerso da coluna de perfuração (Pi)

$$
P i=P_{c o l}-E i, \quad(6.6), \quad \text { onde } P_{c o l} \text { é o peso da }
$$
coluna e Ei é o empuxo da porção imersa.

A "Estimativa da Contribuição da Coluna de Perfuração" foi realizada apenas nos testes da $1^{\text {a }}$ etapa. Foi calculada a contribuição do peso da coluna de perfuração, considerando todos seus componentes: hastes, niples, barrilete, alargador e coroa. Para fins práticos, outra forma de considerar essa parcela da pressão seria através do peso $($ Peso $/ \mathrm{m})$ e volume $(\mathrm{Vol} / \mathrm{m})$ médios deslocados por metro da coluna de perfuração: 


$$
\begin{aligned}
P i=l_{c \cdot} \cdot \frac{P e s o}{m}-l_{c i} \cdot \frac{V o l}{m} \cdot \gamma_{\text {fludo }} \quad(6.7), \text { onde: } \\
\qquad \begin{aligned}
l_{c} & =\text { comprimento total da coluna; } \\
l_{c i} & =\text { comprimento imerso da coluna; } \\
\gamma_{\text {fluido }} & =\text { densidade do fluido de perfuração }
\end{aligned}
\end{aligned}
$$

\section{- geometria da ferramenta cortante}

A geometria da ferramenta cortante (diâmetros interno e externo, forma da face, etc.) determina a área sobre a qual incide a resultante das forças sobre a coluna de perfuração.

\subsubsection{Velocidade de rotação da coluna e torque}

Teoricamente, esses parâmetros não deveriam ser muito influenciados pela profundidade. No entanto, as perdas mecânicas ocorridas devido ao atrito da coluna nas paredes do furo e a resistência viscosa do fluido de perfuração tendem a aumentar com a profundidade. Esse tipo de perda mecânica diminui a velocidade de rotação, "consumindo" parte do torque que seria aproveitado no processo de perfuração. A influência da profundidade no torque é de difícil avaliação. Além da profundidade do furo, o consumo do torque em processos não diretamente relacionados à perfuração é determinado pelo: (a) diâmetro do furo e do revestimento, (b) profundidade do revestimento e (c) características do fluido de circulação (densidade, viscosidade).

As velocidades de rotação da coluna de perfuração são menores devido às reduções na caixa de câmbio. Para cada marcha, a mesma proporção de redução do câmbio, representa um respectivo aumento do torque fornecido. A determinação dessa relação, através do monitoramento da velocidade do eixo do motor, permite o controle da qualidade da aquisição, já que os valores calculados devem estar próximos aos valores correspondentes às três marchas do equipamento $(5,6,3,4$ e 1,8 , respectivamente, primeira, segunda e terceira marcha).

Registra-se ainda o "consumo" do torque na deformação elástica das hastes que compõem a coluna de perfuração. Em geotecnia, é comum a utilização de hastes com diâmetro menor que o da coroa e que os barriletes. Associada a furos executados a grandes profundidades, essa prática pode determinar grandes deformações angulares. 


\subsubsection{Pressão da água}

Devido à incompressibilidade do fluido de circulação e à relativa rigidez da linha d'água, as condições de operação no fundo do furo transmitem de modo eficiente para o sensor em superfície, as alterações de pressão da linha d'água. Portanto, a princípio, esse parâmetro poderia ser considerado pouco influenciado pela profundidade.

\subsubsection{Vazão de entrada no furo}

A vazão de entrada no furo é pouco influenciada pela profundidade. A menos de pequenos vazamentos na linha após o sensor, a vazão que atingiu o material cortado pela sonda foi sempre a mesma injetada pela bomba. No entanto, destaca-se que os acoplamentos das hastes podem apresentar vazamentos significativos, mais difíceis de serem detectados, dificultando a interpretação dos resultados. $\mathrm{Na}$ verdade, a estanqueidade de toda a linha precisaria ser garantida para a representatividade desse parâmetro.

\subsubsection{Vazão de retorno do furo}

A vazão de retorno pode ser influenciada por todo o trecho sem revestimento do furo. Com o aumento da profundidade, os furos tendem a ser não-revestidos, a vazão de retorno e seus respectivos ganhos ou débitos com relação à vazão de entrada, não teriam relação direta com o material efetivamente cortado na extremidade da coluna, mas sim, com todo o trecho sem revestimento.

A análise desse parâmetro deve procurar reconhecer "variações bruscas", as quais poderiam ser associadas a alguma nova condição hidrogeológica. Na verdade, as anotações no Boletim de Sondagem registram os casos mais extremos desse tipo de evento (por exemplo, perda total da água de lavagem) e algumas vezes, passam até para o Perfil Individual de Sondagem. Com o monitoramento desse parâmetro, eventos menos extremos seriam também registrados e interpretados, de acordo com o interesse da investigação.

Dessa forma, a influência do fator profundidade é mais significativa, em ordem crescente, para as seguintes áreas: petróleo, mineração (geral), hidrogeologia, geotecnia 
e meio ambiente, devido à profundidade média decrescente nos furos realizados para cada uma dessas áreas.

\subsection{Tratamento dos dados coletados pelo protótipo}

O protótipo do sistema de monitoramento forneceu na tela do computador, durante a aquisição, os valores dos parâmetros monitorados, em intervalos de tempo determinados (na $1^{\text {a }}$ etapa de testes, $1,00 \mathrm{~Hz}$ com freqüência base de $100 \mathrm{~Hz}$ e na $2^{\mathrm{a}}$, $0,33 \mathrm{~Hz}$ com freqüência base de $50 \mathrm{~Hz}$ ).

Os arquivos-texto, salvos em disco, passaram por uma "seleção manual", na qual foram extraídos os intervalos onde a sonda não realizava efetivamente a perfuração. Esses trechos foram selecionados através de: (a) velocidade de rotação da coluna, (b) posição e (c) pressão do hidráulico. Esse procedimento determinou que os valores médios estimados durante a perfuração fossem mais significativos das condições reais impostas para a perfuração do material.

$\mathrm{O}$ arquivo gerado com os valores dos sinais produzidos pelos sensores é processado numa planilha de dados (p.e. EXCEL 97). Com a planilha realiza-se: (a) conversão das leituras dos sensores nos parâmetros físicos de interesse; (b) configuração dos índices da conversão (obtidos através da calibração de cada sensor); (c) correção do efeito da profundidade nas pressões efetivas sobre a ferramenta de corte; e (d) representação gráfica dos resultados (perfil dos trechos perfurados).

\subsection{Resultados experimentais}

$\mathrm{Na}$ parte experimental do projeto, foram realizadas sondagens rotativas monitoradas para obtenção dos parâmetros de perfuração (solo/sedimento e rocha). Foram executados seis furos, dos quais dois avançaram no maciço rochoso.

Devido à grande quantidade dos dados (nove parâmetros diretos), a interpretação poderia ser realizada de diversas formas, com objetivos distintos. A pesquisa bibliográfica mostrou que em sondagem destrutivas, onde a técnica é usualmente aplicada, a coleta dos dados é geralmente realizada tomando como base intervalos de perfuração, e não intervalos de tempo (freqüência de amostragem constante). Nesses casos, os intervalos de perfuração para a amostragem situam-se entre centimétricos e 
decimétricos. Os resultados diretamente coletados ou posteriormente interpretados são perfilados pela profundidade, ou seja, são apresentados em gráficos cartesianos de linha, onde a abscissa é o parâmetro relacionado à perfuração e a ordenada, a profundidade invertida. Esse modo de análise é considerado "macroscópico", pois se refere a uma análise, geralmente qualitativa, de espessuras, no mínimo, decamétricas do maciço. Para a interpretação dos resultados foram analisadas lâminas petrográficas das amostras rompidas nos ensaios de resistência à compressão uniaxial (RCU). O objetivo específico dessa atividade foi tanto determinar as variações mineralógicas dos tipos petrográficos como observar feições microscópicas, que pudessem condicionar a resistência da rocha (alteração dos minerais, microfraturas).

A bibliografia refere-se ainda a ensaios de perfurabilidade em laboratório, onde são estudados os fatores envolvidos, ou seja, os parâmetros de perfuração considerados na diagrafia de sondagem, e suas correlações com alguns dos parâmetros das rochas. Pela própria escala desse tipo de análise, pode-se considerá-la de detalhe ou "pontual", quando comparada com a perfilagem dos parâmetros de sondagem.

Na tentativa de obter-se parâmetros para correlações com os resultados obtidos no monitoramento dos furos, foram realizadas investigações adicionais. Foram elas: (a) sondagens a percussão para a caracterização das camadas de solo (descrição geológica e ensaios SPT); (b) ensaios de mecânica das rochas, especificamente, índices físicos, resistência à compressão simples $(\mathrm{RCU})$ e à compressão puntiforme $\left(\operatorname{Is}_{(50)}\right)$ e (c) perfilagem geofísica.

\subsubsection{Sondagens a percussão e furos rotativos monitorados}

A localização regional e a locação específica de cada furo realizado no projeto são apresentadas na Figura 6.5. Os resultados obtidos permitiram a apresentação de uma seção geológica esquemática da área (Figura 6.6). 


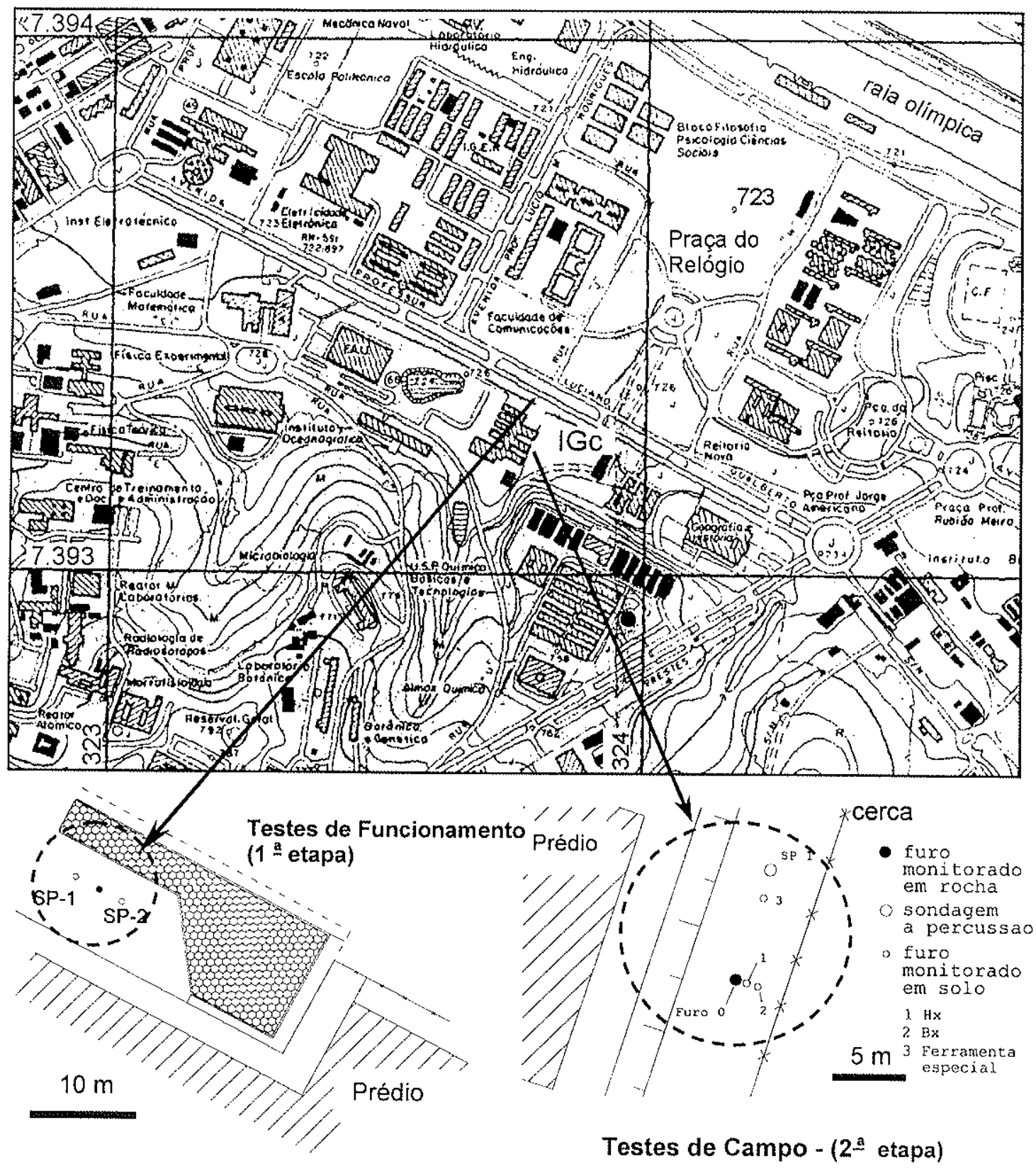

Figura 6.5 - Localização e locação das sondagens monitoradas e das sondagens a percussão 


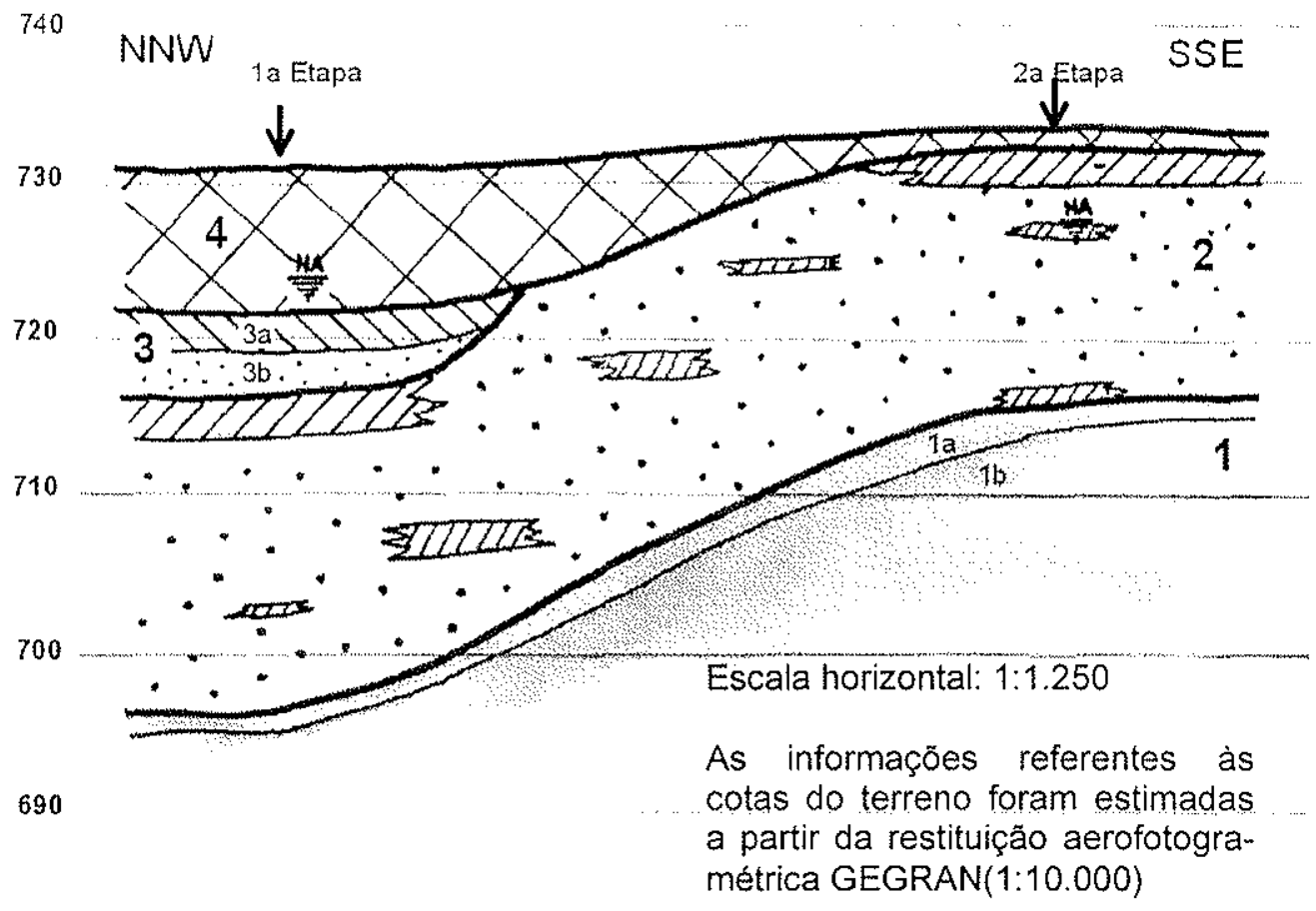

4 Solo superficial/aterro solos siltosos a argilo-siltosos. Cores marrom avermelhado/ amarelado

3 Aluvião Quaternário $\quad$ (3a) Argila orgânica cinza-escuro

(3b) Areia fina cinza

2 Formação Resende - sedimentos francamente arenosos (areia fina a grossa), cor predominantemente cinza-claro, com fragmentos de rocha ou quartzo. Intercalações de camadas métricas de argila

1 Embasamento Pré-Cambriano Gnaisse milonítico

(1a) Solo de alteração/saprolito de gnaisse

(1b) Gnaisse são a pouco alterado, diversos graus de fraturamento

Figura 6.6. - Seção geológica esquemática da área de estudo. Região dos furos rotativos monitorados e das sondagens a percussão.

A unidades apresentadas na Figura 6.6 são caracterizadas:

a) Solo superficial/aterro, com espessuras variando entre 9 e 10 metros a menos de 1 metro, para as regiões da $1^{a}$ e $2^{a}$ etapas de testes, respectivamente. Granulometria argilo-siltosa a siltosa, cores variadas e valores de resistência à penetração SPT $4<$ $\mathrm{N}<10$.

b) Formação aluvial quaternária: 2 a 3 metros de argila orgânica cinza-escuro, com valores de resistência à penetração SPT $0<\mathrm{N}<2$, sotopostos a 3 metros de areia fina pouco argilosa cinza e valores de SPT $2<N<13$. É identificável apenas nos furos da $1^{\text {a }}$ etapa de testes. 
c) Formação Resende: Sedimentos predominantemente arenosos (areia fina a grossa) amarelo e cinza, com a maioria dos valores de resistência SPT entre 20 e 40. Intercalação de níveis com fragmentos de rocha ou quartzo. Ocorrência de nível superior com espessura de 2 metros de argila cinza-esverdeado a cinza-claro $(12<\mathrm{SPT}<15)$. Intercalações de camadas argilo-siltosas métricas, cor cinza $(10<\mathrm{SPT}<15)$.

d) Embasamento Pré-Cambriano: Profundidades variando entre 18 e 35 metros; ocorrem no topo dessa unidade solos residuais. A espessura dos solos varia de decimétrica, na área da $1^{\underline{a}}$ etapa de testes (região da calha do rio), até algo em torno de, 1 metro (área da $2^{a}$ etapa). Os materiais de transição (rocha alterada) também ocorrem com baixas espessuras em toda a região estudada. Essa unidade é representada, em termos de litologia por um ortognaisse porfiroclástico com feições miloníticas. Os pórfiro-cristais são centimétricos, constituídos por feldspato potássico. As principais estruturas da rocha são o bandamento composicional, faixas félsicas (quartzo-feldspáticas) e máficas (biotita e anfibólio), e a xistosidade. O comportamento espacial dessas estruturas é vertical a subvertical. Considerando-se informações secundárias regionais (JULIANI, 1992), sua direção varia em torno de N50-55W. Macroscopicamente, as feições que denotam a deformação a qual o maciço foi submetido são: (a) estiramento dos cristais de plagioclásio, eventualmente associados a feições indicativas de rotação; (b) pórfiros cristais fraturados, principalmente ao longo de suas clivagens.

O nível freático encontra-se em torno de 7 metros de profundidade. Provavelmente esse nível esteja "suspenso" ("nível empoleirado") devido à presença da camada argilosa no topo do aluvião, na área da $1^{a}$ etapa de testes. O nível d'água medido com o furo revestido até o aluvião atingiu mais de 10 metros. Na área da $2^{\text {a }}$ etapa de testes não foi observada variação no nível tão pronunciada.

\subsubsection{Testes de funcionamento ( 1 a etapa)}

O teste da sonda em operação forneceu os primeiros parâmetros da perfuração de solos e rochas, obtidos através do protótipo. Os resultados foram tratados através das médias dos trechos monitorados, no caso, as subdivisões (manobras de pistão) estabelecidas dentro das manobras de sondagem, trecho perfurado necessário para 
encher o barrilete com testemunho da rocha. Dessa forma, o valor máximo discriminado foi $50 \mathrm{~cm}$, que corresponde ao curso do hidráulico. Dentro desses trechos foram calculadas as condições médias de operação da sonda, as respostas do terreno e ainda a energia específica de perfuração. Todos os resultados estão apresentados na forma de tabelas no anexo A.1- Resultados dos testes de perfuração. Informações sobre a qualidade do material rochoso perfurado nessa etapa estão resumidas no Quadro 6.2.

Quadro 6.2 - Qualidade do material perfurado.

\begin{tabular}{|c|c|c|c|c|}
\hline Manobra $(\mathrm{m})$ & Litologia & Recuperação (\%) & Alteração $^{20}$ & RQD (\%) \\
\hline 34.40 a 35.21 & \multirow{2}{*}{\begin{tabular}{c} 
Biotita-Gnaisse \\
\cline { 3 - 5 } Milonítico
\end{tabular}} & 63 & $\mathrm{~A} 4 / \mathrm{A} 3$ & 20 \\
\cline { 4 - 5 } & & 28 & $\mathrm{~A} 3$ & 0 \\
\hline 35.21 a 36.09 & 45 & $\mathrm{~A} 2$ & 0 \\
\hline
\end{tabular}

Foram perfilados para esse furo: (a) a energia específica de perfuração, (b) velocidade de avanço, (c) taxa de penetração ( $\mathrm{cm} /$ revolução); (d) pressão sobre a ferramenta de corte; (e) velocidade de rotação da coluna; velocidade de rotação do motor. Esses valores médios para os trechos perfurados foram plotados num perfil, ao longo da profundidade do furo (Figuras 6.7 a 6.12).

Os valores de torque não foram efetivamente medidos nessa etapa de testes. Inicialmente, eles foram arbitrados, com base na tabela fornecida pelo fabricante do motor (Figura 3.15). Com os resultados da etapa posterior, considerando as médias dos resultados do monitoramento de torque, foi possível recalcular as energias envolvidas na perfuração da $1^{\mathrm{a}}$ etapa, chegando-se a valores que podiam ser comparados entre as duas etapas.

\footnotetext{
${ }^{20}$ Diferentemente do que é realizado no perfil individual de sondagem, representou-se na tabela a quafidade apenas do material recuperado.
} 


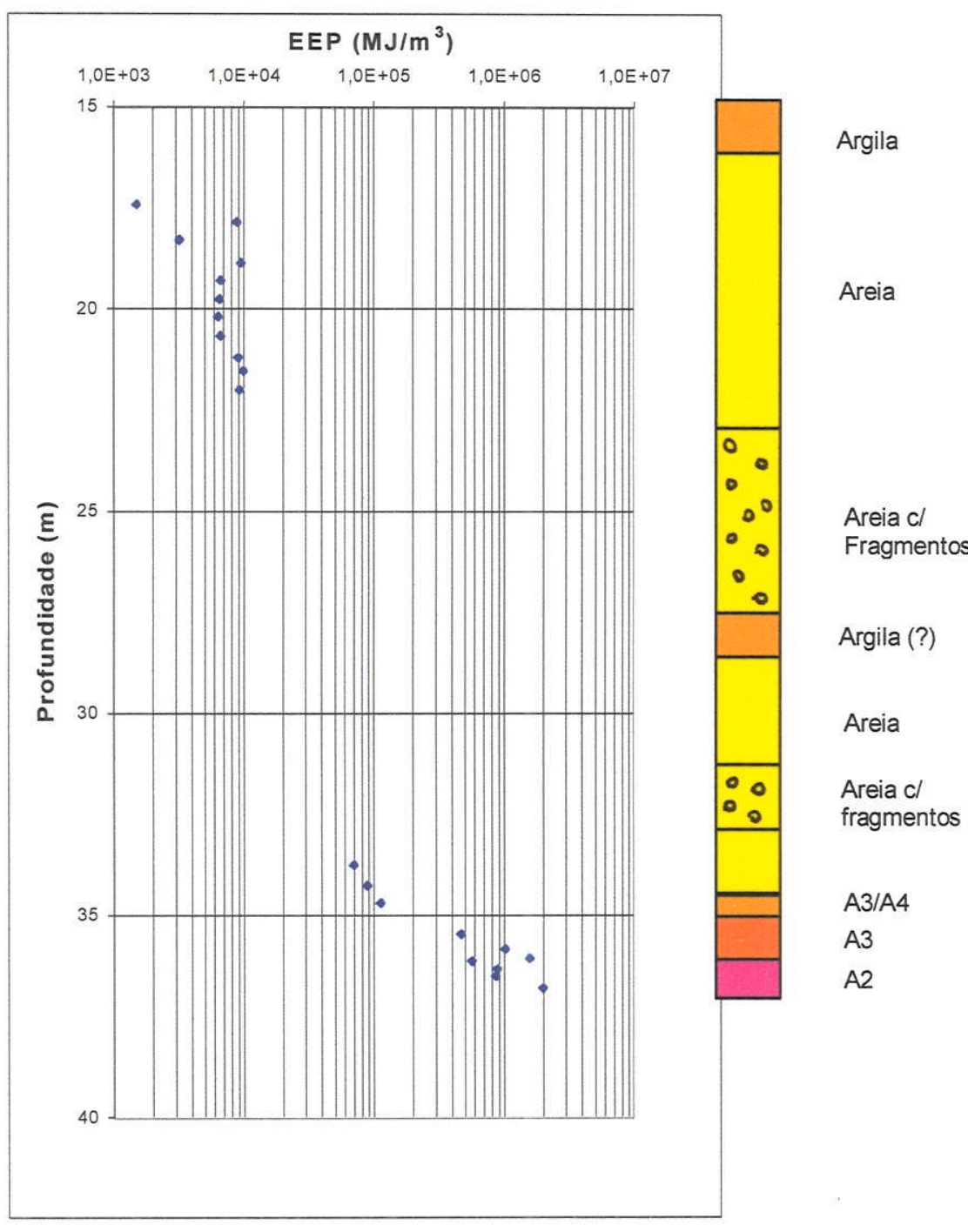

$\vec{N}$

Figura 6.7 - Valores médios da energia específica de perfuração (EEP).

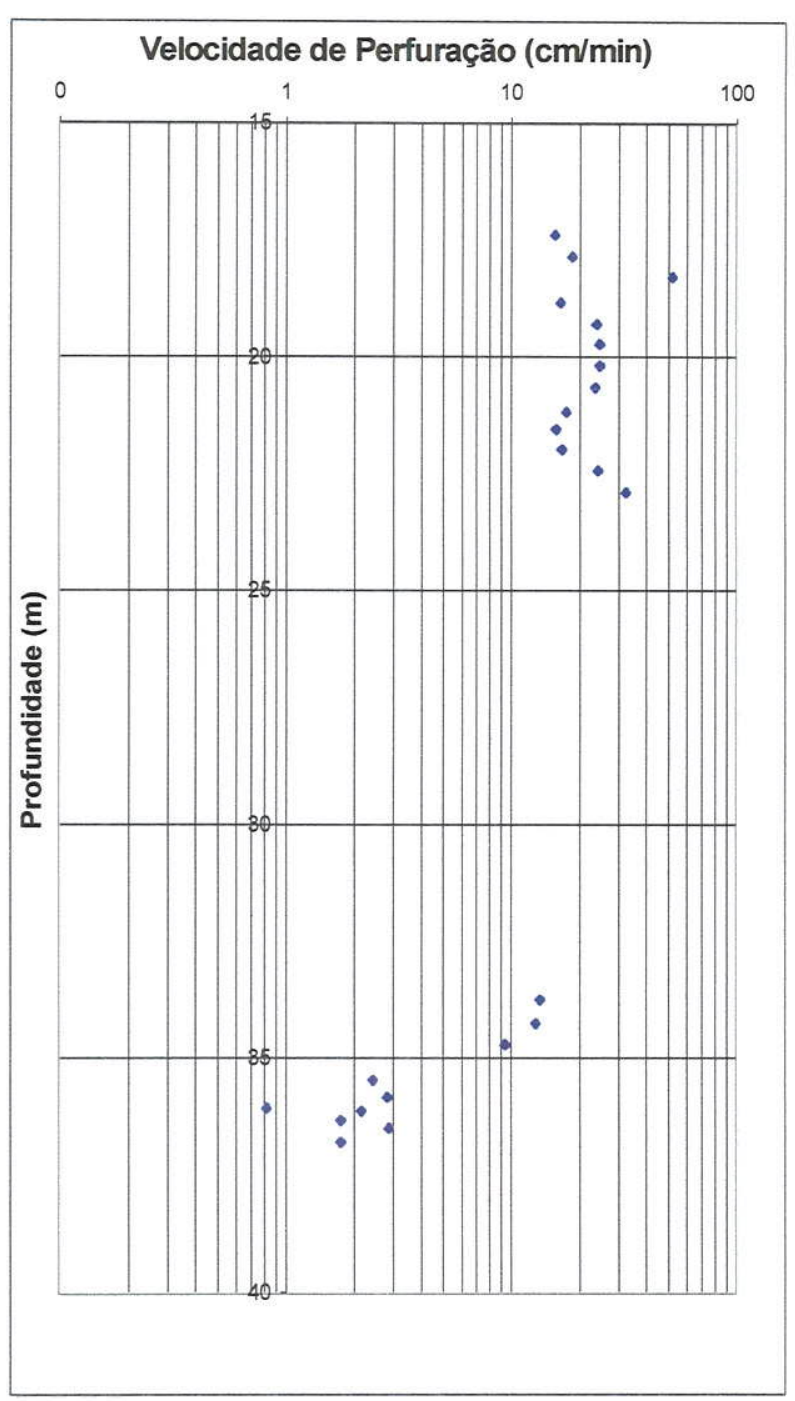

Formação

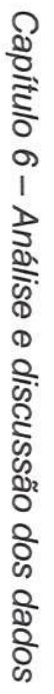

Embasamento Pré-Cambriano (Gnaisse)

Figura 6.8 - Valores médios da velocidade de perfuração. 


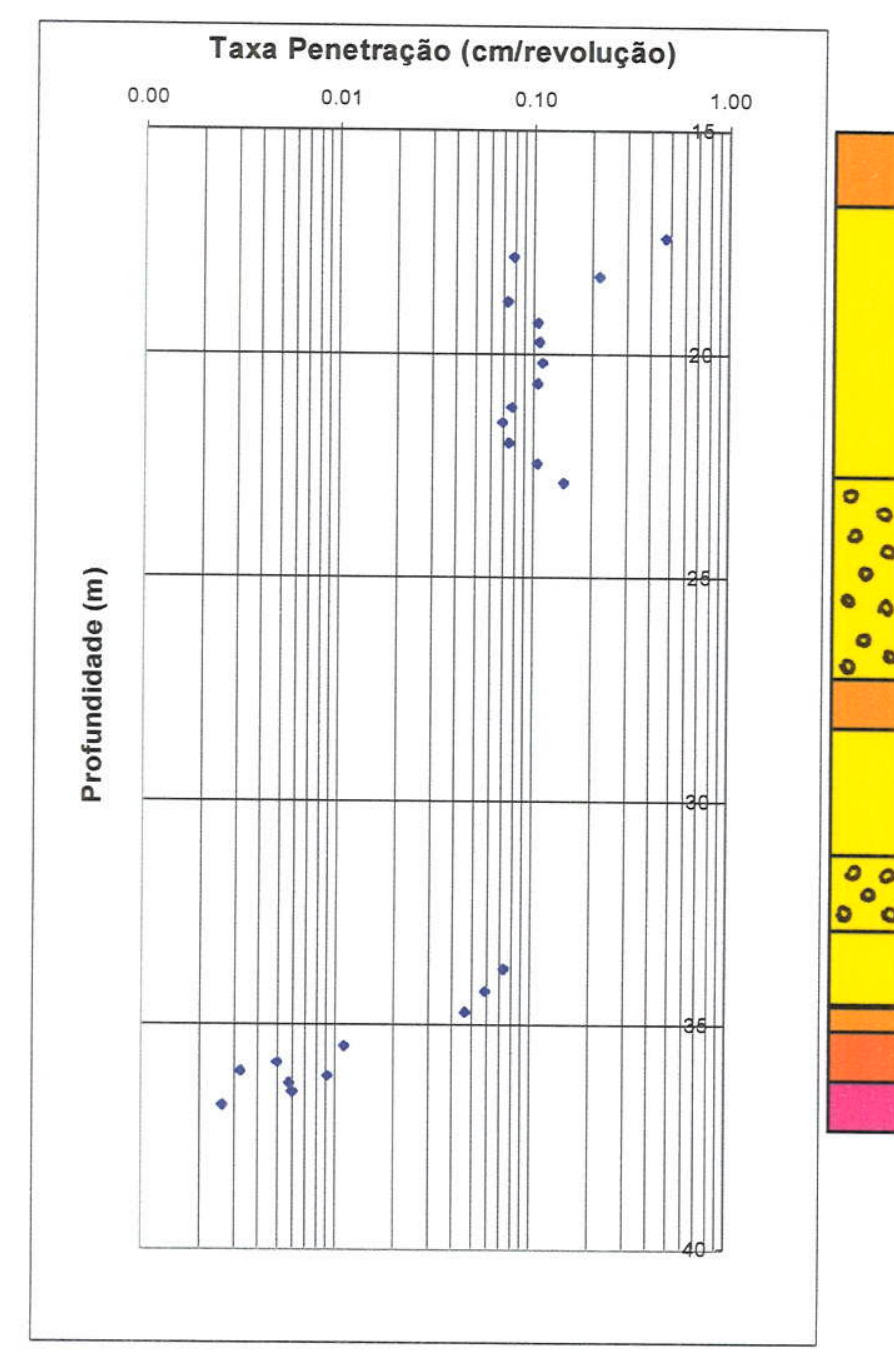

$\overrightarrow{\mathrm{\omega}}$

Figura 6.9 - Valores médios da taxa de penetração.

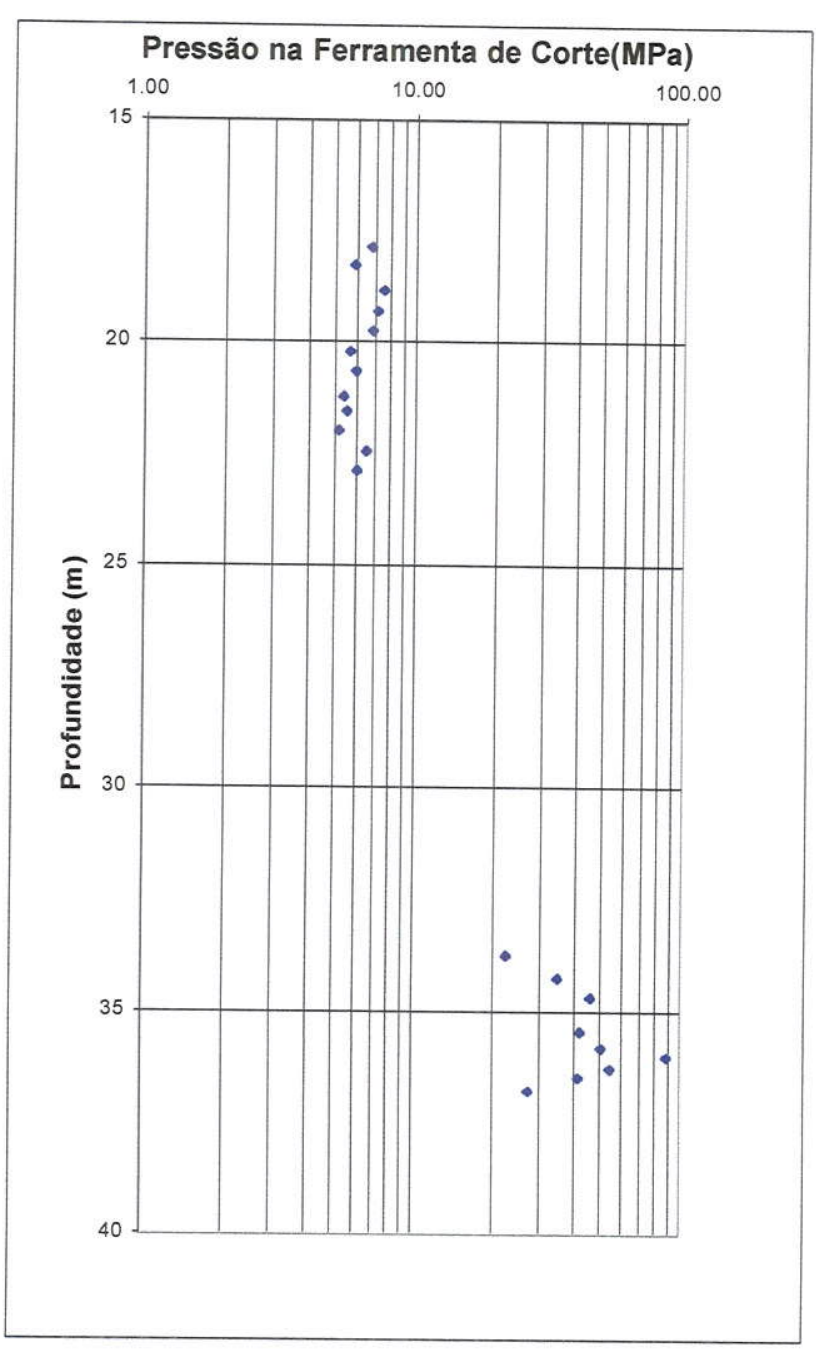

Formação Resende

Areia cl

fragmentos

Argila (?)

Areia

Areia cl

fragmentos

A3/A4

A3

A2

Figura 6.10 - Valores da pressão na ferramenta de corte.
Embasamento Pré-Cambriano (Gnaisse) 


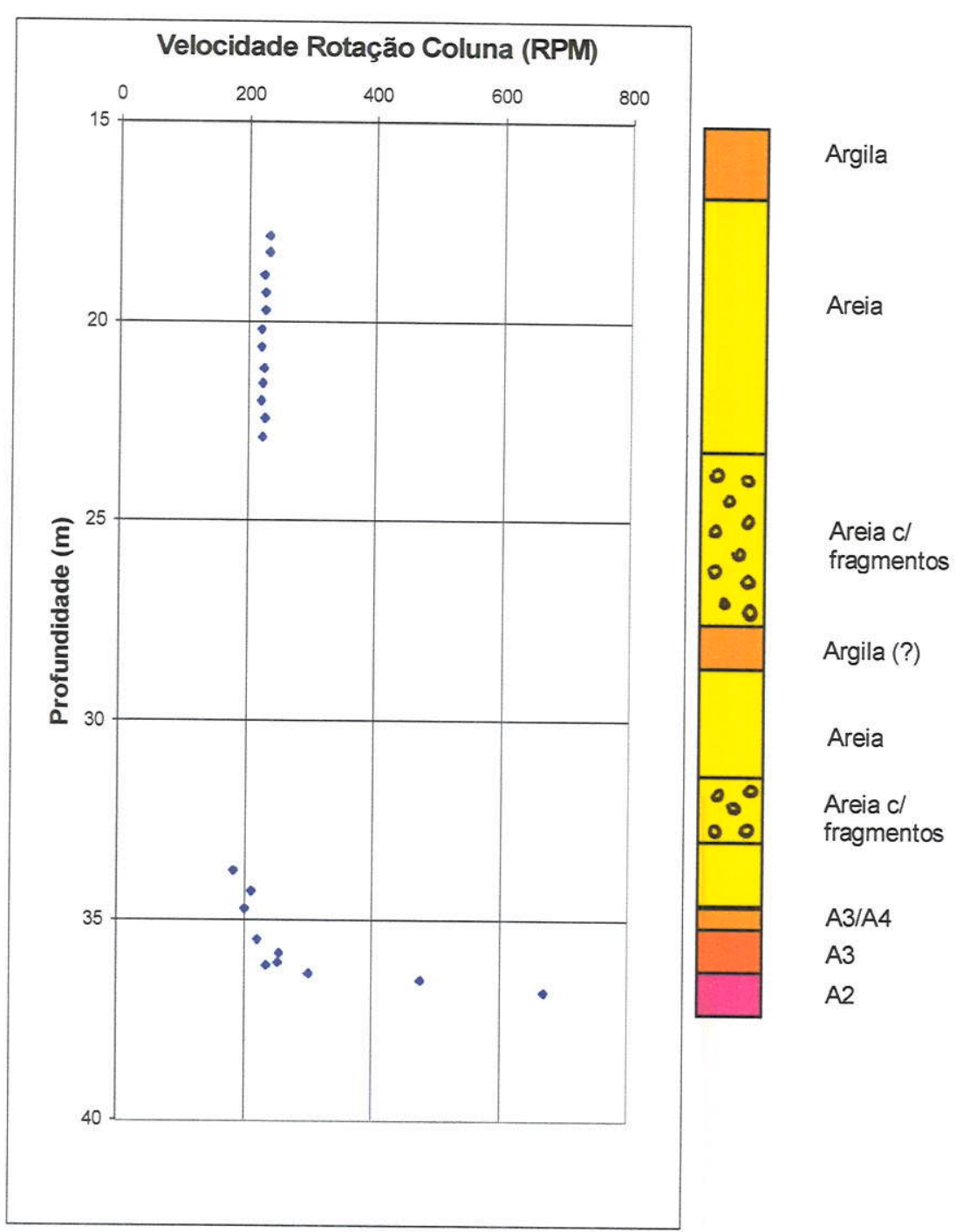

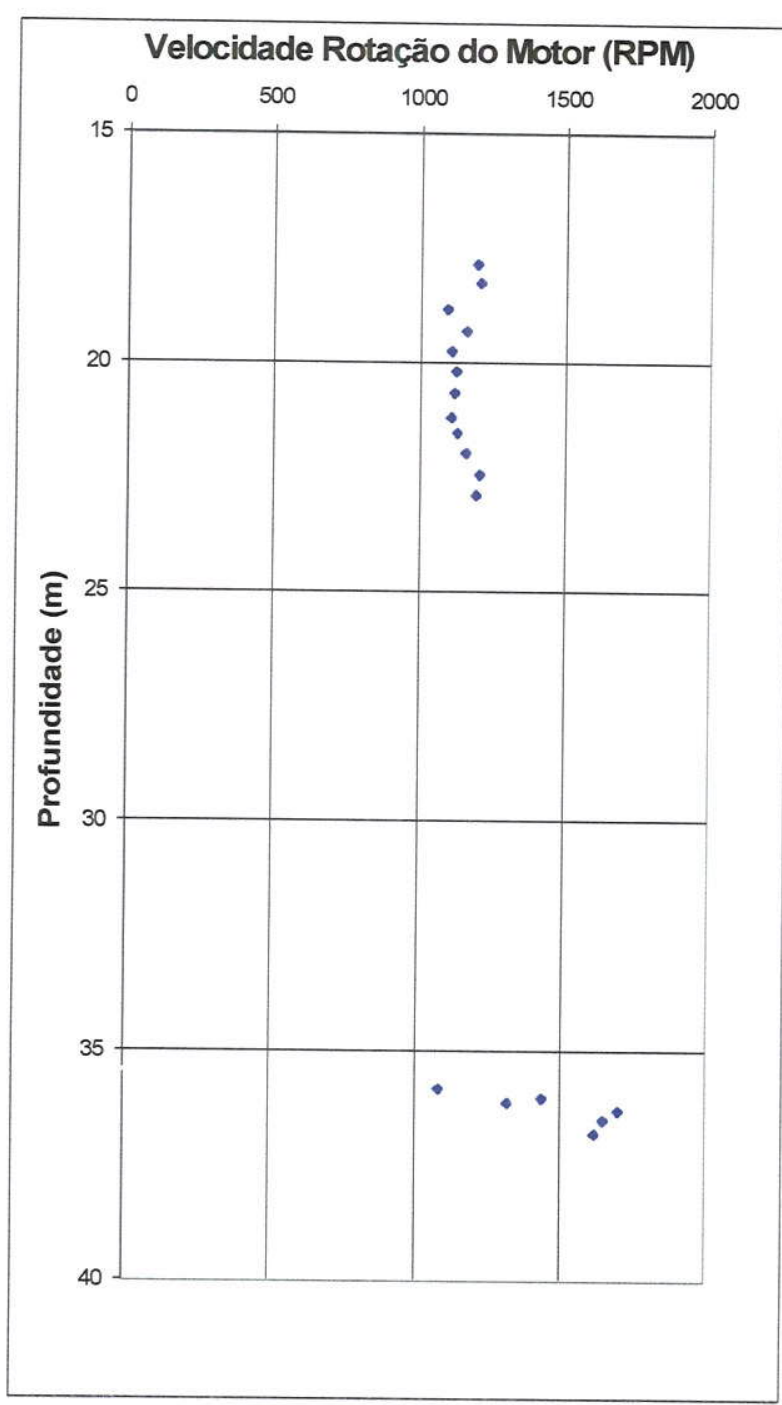

Formação

Resende

Embasamento Pré-Cambrian (Gnaisse)

Figura 6.12 - Valores médios da rotação do motor. 
A energia de perfuração é o parâmetro do qual se espera a maior independência da forma de execução da sondagem. Mesmo assim, ela não pode ser considerada independente. DEKETH (1995) apresenta resultados que sugerem essa influência, definindo pelo menos três "modos" de execução do corte da rocha. Esses "modos" estariam relacionados à velocidade de avanço/pressão da ferramenta de corte sobre a rocha, no caso desse trabalho, o passo do torno. O autor (op.cit.) trabalhou basicamente com rochas brandas, que deve facilita a variação do comportamento do material frente às solicitações da perfuração. Provavelmente, em rochas mais resistentes, não deva existir variações tão pronunciadas, porém não se pode descartar a existência de mais de um "modo" de corte.

Os demais parâmetros, velocidade de avanço, taxa de penetração e pressão sobre a ferramenta de corte são interdependentes. Os gráficos com as velocidades de rotação são ilustrativos das condições da perfuração.

Para a classificação da resistência dos maciços naturais à perfuração, os parâmetros pressão na linha d'água e as vazões do fluido de perfuração não possuem significado expressivo. Exceção poderia ser feita à vazão de saída da bomba (VazaoE vazão de entrada no furo), quando a perfuração é realizada em rochas brandas ou solos.

Inicialmente, imaginava-se que a perfuração em solo não poderia fornecer resultados significativos com a sonda rotativa, uma vez que a energia envolvida na perfuração do solo é pequena, quando comparada com a potência do equipamento. Porém, o resultado do teste mostrou variações significativas nos valores obtidos. Esses resultados devem ser encarados com restrições. Sem a medida de torque precisa e com a limitação da velocidade de avanço do furo determinada pela capacidade de limpeza do sistema de circulação, os resultados ficam comprometidos, em termos de significado geotécnico.

Nos testes posteriores, com o auxílio do torquímetro, verificou-se que esse parâmetro também varia e que a estimativa da energia especifica de perfuração, admitindo o torque constante, equivaleria simplesmente ao controle da velocidade de avanço. A velocidade é diretamente associada à energia de perfuração, se as condições de execução forem constantes. Essa condição não foi garantida para essa etapa de testes. 
O detalhe do perfil apresentado na Figura 6.13 mostra a energia em valores bem abaixo daqueles observados no maciço rochoso e uma grande variação na resistência. Da mesma forma, o valor da resistência à penetração SPT também varia nos furos próximos.

Tanto na perfuração em solo como em rocha, não se pode afirmar em que condições de transferência de energia a perfuração foi realizada, ou seja, qual a eficiência do processo de perfuração (Figura 6.2).

Como ao longo de praticamente todo o furo não foi utilizada a válvula de ajuste fino, os valores das pressões medidas no hidráulico representaram realmente a contribuição do hidráulico na pressão sobre a ferramenta de corte. Analisando o gráfico da Figura 6.10, pode-se afirmar que a pressão sobre a ferramenta de corte foi semelhante (5 a $8 \mathrm{MPa}$ ) nos trechos monitorados em solo. Essa afirmativa não é válida para o trecho em rocha, cujos valores variam entre 20 a $100 \mathrm{MPa}$. O valor da energia estimada no teste necessitaria ser "corrigido" em função do valor da pressão empregada. Dessa forma, a energia obtida iria aproximar-se da energia específica de perfuração, parâmetro mais representativo da qualidade geotécnica dos solos e rochas. 

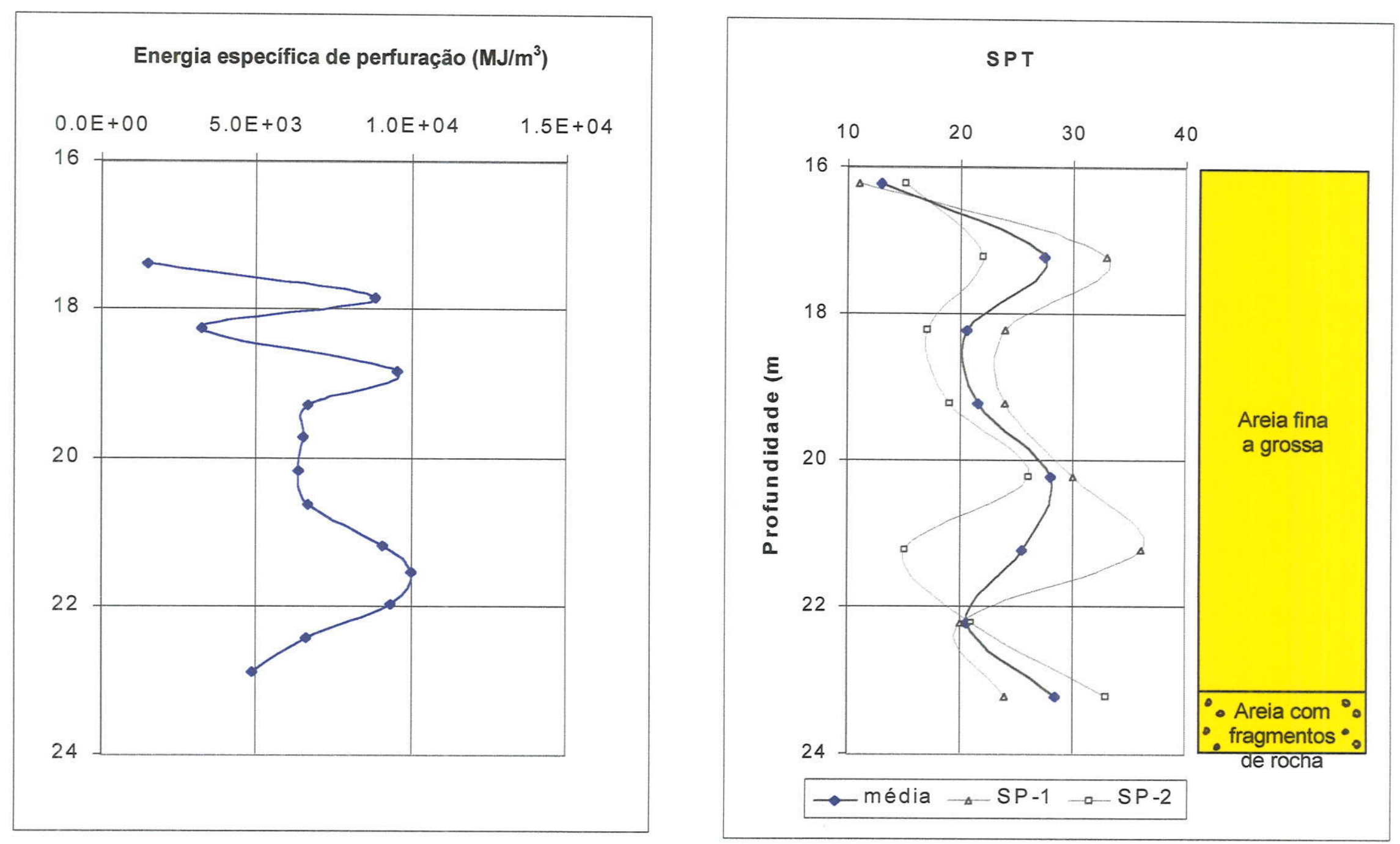


\subsubsection{Testes de Campo (segunda etapa)}

Os testes de campo foram realizados após o desenvolvimento do sensor de torque para a sonda. A energia de perfuração pôde então ser estimada, considerando-se todos os principais parâmetros envolvidos.

Apesar de pouco usual, nessa etapa, foram realizados de forma experimental três furos monitorados em solo, com as seguintes ferramentas de corte: brocas de arraste (a) $\mathrm{Nx}$, (b) Hx e (c) ferramenta de corte sem especificação.

Os furos com a broca de arraste não apresentaram bons resultados, uma vez que as deflexões observadas foram pequenas ou mesmo "negativas". Isso significa que o torque envolvido na perfuração, considerando essas ferramentas, foi pequeno e, conseqüentemente, os erros envolvidos, mais significativos.

Na tentativa de obtenção de parâmetros de perfuração em solo, foi utilizada uma ferramenta disponibilizada com o equipamento, porém sem especificação. Essa peça, com um diâmetro quase três vezes maior $(20 \mathrm{~cm})$ e superfície de corte mais de sete vezes superior à da broca $\mathrm{Nx}$, cortou um volume maior de solo, envolvendo energias maiores e, conseqüentemente, deflexões que puderam ser medidas com maior precisão. A comparação da deflexão angular dos furos realizados, respectivamente com broca $\mathrm{Hx}$ e com a ferramenta sem especificação, está apresentada na Figura 6.14. 


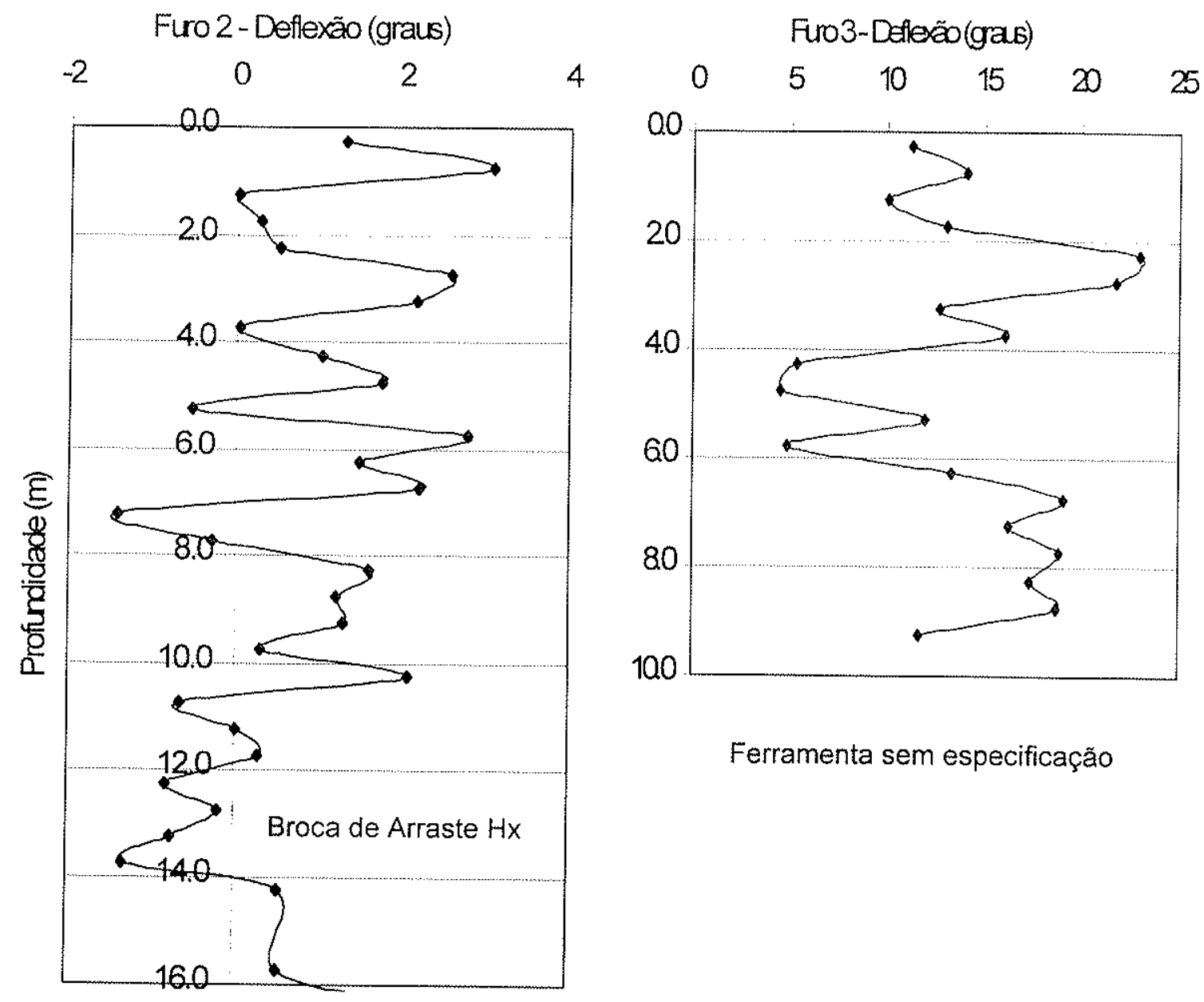

Figura 6.14 - Valores de deflexão medidos nas perfurações em solo.

A comparação entre a perfilagem da Energia Específica de Perfuração (EPP) e os valores de resistência à penetração SPT, e ainda uma coluna com a classificação geológica e textural dos solos/sedimentos são apresentados na Figura 6.15 . Considerando os dados disponiveis, não parece haver correlação direta entre a energia específica de perfuração e a resistência SPT dos materiais inconsolidados. Apesar desse resultado, os dados não parecem suficientes para descartar um "significado geotécnico" para o parâmetro, considerando a perfuração em solos e sedimentos inconsolidados. 

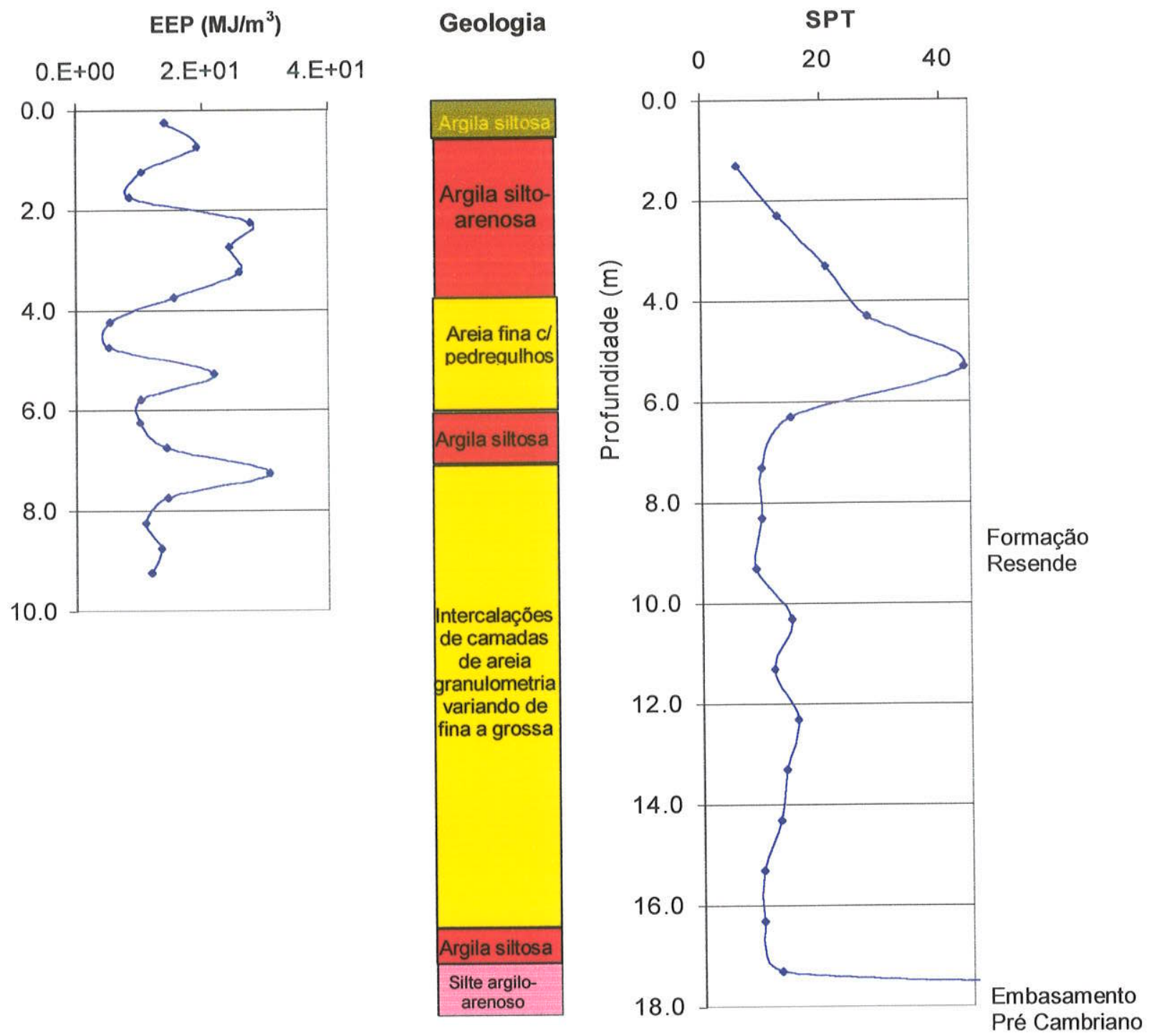

Figura 6.15 - Comparação entre os perfis de EEP, textura e resistência SPT.

\subsubsection{Monitoramento da perfuração e a perfilagem geofísica}

Embora um dos principais objetivos da pesquisa fosse a obtenção de dados que permitissem a perfilagem das informações do monitoramento das perfurações em rocha, isso não foi possível para o Furo Zero ( $2^{\underline{a}}$ etapa de testes). A descontinuidade nos registros, originada por problemas na sonda e na execução do furo, impossibilitou a realização desse objetivo.

Os trechos onde foi possível o monitoramento, dentro das manobras de sondagem realizadas, estão apresentados no Quadro 6.3. Os registros das manobras de pistão são identificados pela profundidade do início do trecho. O perfil individual de 
sondagem do Furo Zero é apresentado em anexo e distingue os trechos monitorados. Uma montagem com fotografias de todas as amostras é ainda apresentada no anexo A.2.

Quadro 6.3- Testes de Campo - Arquivos de aquisição (Furo Zero)

\begin{tabular}{|c|c|c|c|c|c|}
\hline \multicolumn{2}{|c|}{ Manobra da Sondagem } & \multirow{2}{*}{\multicolumn{4}{|c|}{$\begin{array}{c}\text { Manobras de Pistão } \\
\text { (identificação dos arquivos de aquisição) }\end{array}$}} \\
\hline $\operatorname{De}(m)$ & $a(m)$ & & & & \\
\hline 18,35 & 18,50 & \multicolumn{4}{|c|}{-} \\
\hline 18,50 & 20,00 & \multicolumn{4}{|l|}{ FO_1850 } \\
\hline 20,00 & 20,62 & \multicolumn{4}{|l|}{ FO_2050 } \\
\hline 20,62 & 22,12 & FO_2062 & F0_211: & $2 \quad F O \_21$ & 62 \\
\hline 22,12 & 22,74 & \multicolumn{4}{|l|}{ FO_2212 } \\
\hline 22,74 & 23,85 & \multicolumn{4}{|c|}{ FO_ 2374} \\
\hline 23,85 & 24,02 & \multicolumn{4}{|c|}{-} \\
\hline 24,02 & 25,15 & \multicolumn{4}{|l|}{ F0_2415 } \\
\hline 25,15 & 26,25 & \multicolumn{4}{|c|}{-} \\
\hline 26,25 & 27,75 & \multicolumn{4}{|c|}{-} \\
\hline 27,89 & 29,54 & FO_2804 & FO_2855 & FO_2885 & FO_2905 \\
\hline 29,54 & 30,05 & \multicolumn{4}{|l|}{ Fo_2954 } \\
\hline 30,05 & 31,54 & $\begin{array}{l}\text { Fo_3004 } \\
\text { Fo_3104 }\end{array}$ & $\begin{array}{l}\text { FO_3029 } \\
\text { Fo_3129 }\end{array}$ & FO_ 3054 & FO_3079 \\
\hline
\end{tabular}

Apesar desse fato, a perfilagem geofísica foi realizada no Furo Zero ( $2^{\mathrm{a}}$ etapa de testes). As sondas utilizadas referem-se aos métodos: (a) caliper, (b) eletrorresistividade (espaçamentos de 25, 50 e $100 \mathrm{~cm}$ ), (c) microrresistividade $(2,5$ e 5,0 cm) e (d) gama natural. As figuras 6.16 a 6.18 mostram os equipamentos utilizados.
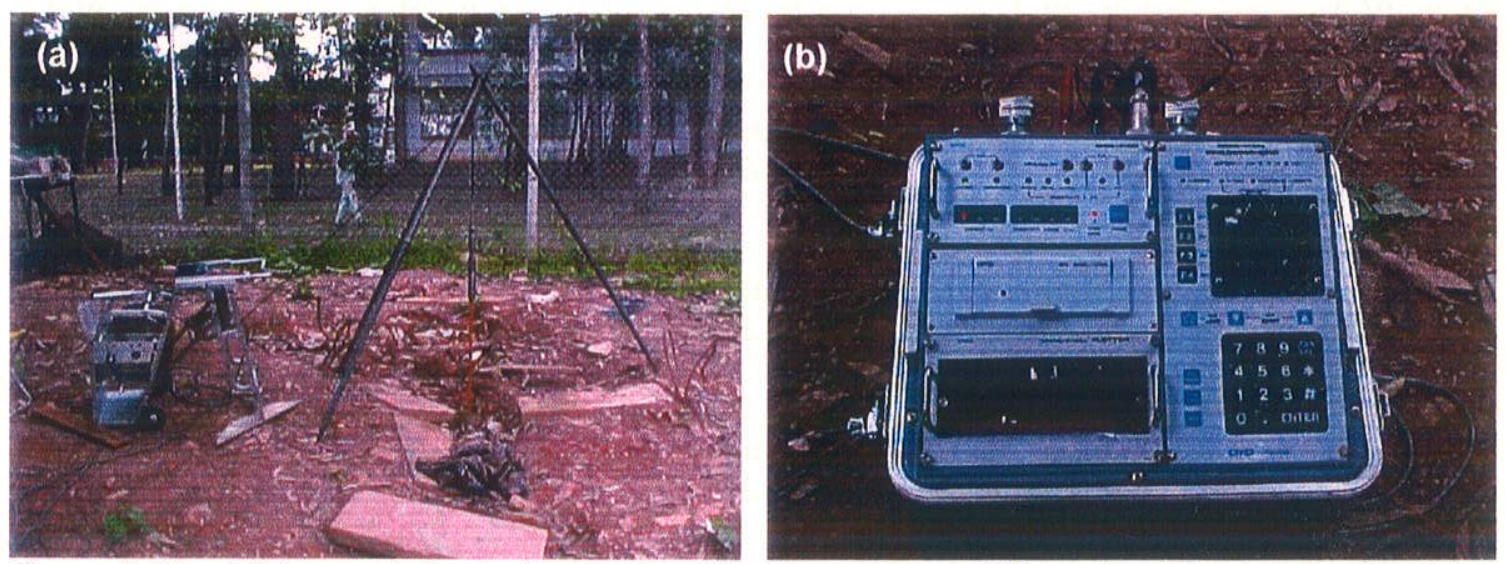

Figura 6.16 -.Vista geral do equipamento utilizado para a subida e descida das sondas (a) e detalhe do "Geologger" (b). 

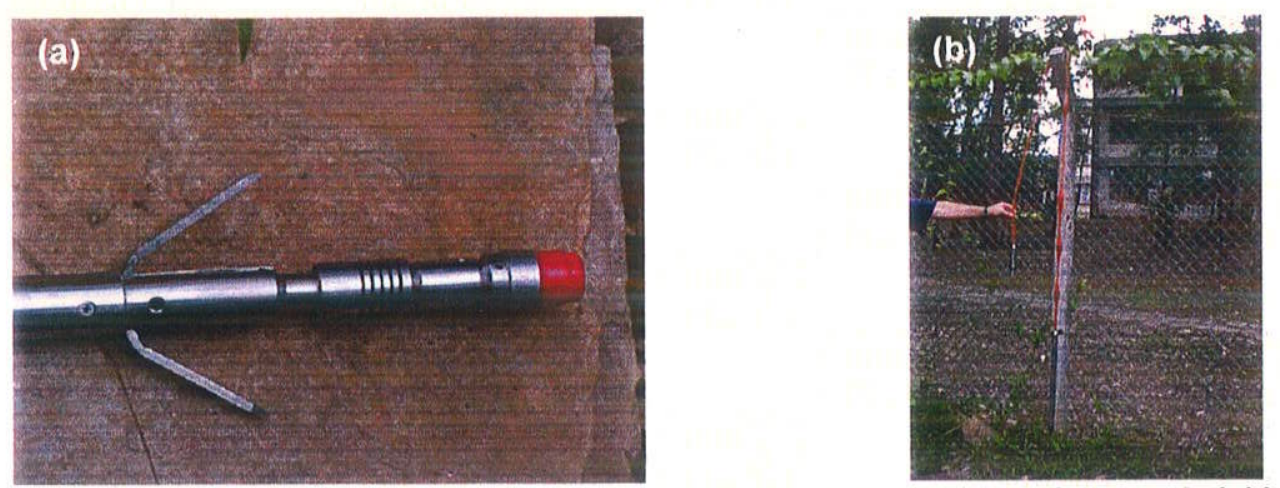

Figura 6.17 -.Detalhe das sondas para a perfilagem caliper (a) e eletrorresistividade (b).
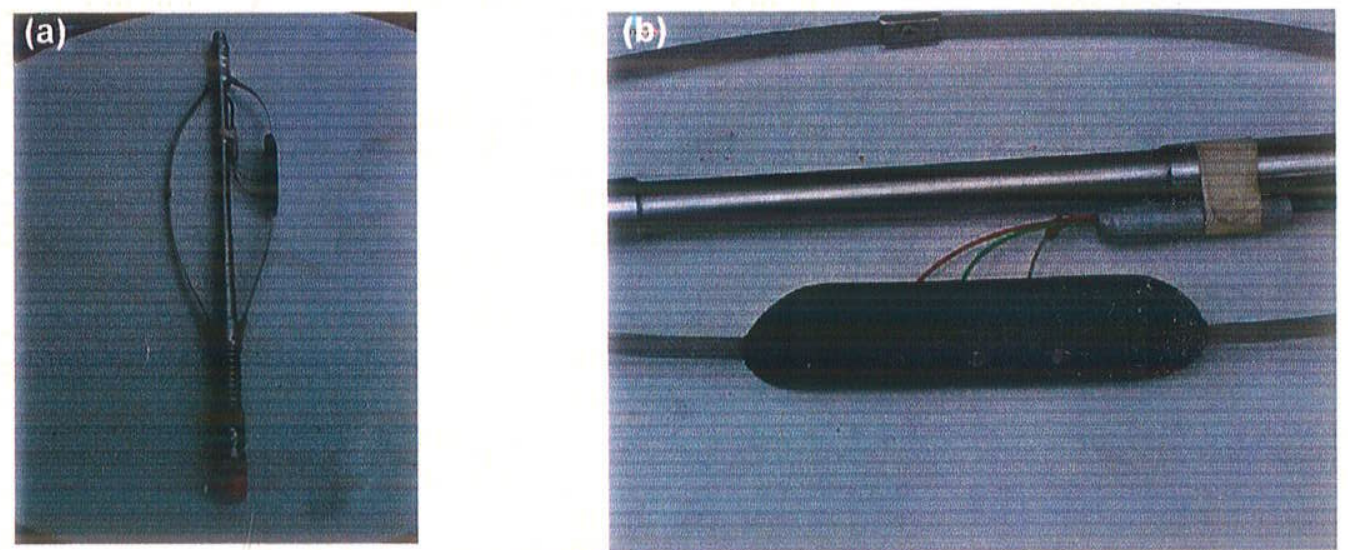

Figura 6.18 - Sonda da perfilagem de microrresistividade (a) e detalhe dos sensores(b).

Todos perfis geofísicos realizados no Furo Zero (caliper, eletrorresistividade, microrresistividade e gama natural) estão apresentados no seu respectivo perfil individual de sondagem (anexo A.2).

As correlações desses dados com a perfilagem do monitoramento foram impossibilitadas pela descontinuidade do registro dos parâmetros de sondagem. Mesmo assim, algumas considerações puderam ser realizadas a respeito dos resultados:

a) no perfil de gama natural, existe clara relação entre os "picos" (valores acima de 20 cps) e as intercalações argilosas da Formação Resende. O padrão dos solos de alteração de gnaisse é bem marcante, no perfil. No maciço rochoso, o comportamento desse parâmetro é mais uniforme, destacando-se picos associados a fraturas localizadas (caliper);

b) os perfis de microrresistividade realizados com os dois espaçamentos entre eletrodos (5 e $10 \mathrm{~cm}$ ) são bastante coerentes entre si, ou seja, o comportamento das duas curvas é similar em termos de variações e inflexões. Esses resultados apresentam ainda uma boa correlação com fraturas isoladas ou zonas fraturadas observadas no perfil de 
sondagem. As fraturas ou zonas fraturadas são identificadas por fortes inflexões para valores relativamente baixos nas curvas;

c) os perfis de resistividade $(25$ a $100 \mathrm{~cm}$ ) possuem um comportamento homogêneo. Exceção é feita aos arranjos de 25 e $50 \mathrm{~cm}$, onde são observados "picos" com valores mais altos de resistividade $(21,0$ e $21,5 \mathrm{~m})$. Esses locais estariam associados a porções mais íntegras do maciço, menos alteradas ou fraturadas. No perfil de microrresistividade, esse padrão repete-se, porém não se mantém ao longo de todo o perfil. Considera-se como justificativa para essa situação, as estruturas mais superficiais estarem mais aliviadas no topo do maciço rochoso e, portanto, terem o fraturamento mais destacado, sendo inclusive identificado pelo macroarranjo; e

d) o perfil caliper mapeia as fraturas ao longo do furo, onde se destaca uma zona fraturada existente a $26,30 \mathrm{~m}$, na qual deve ter ocorrido queda de material para o interior do furo, devido ao diâmetro atingido pela sondagem $(105 \mathrm{~mm})$.

\subsubsection{Ensaios de mecânica das rochas}

Considerando os trechos rocha monitorados em rocha do Furo Zero e as dimensões necessárias dos testemunhos para a preparação, foram selecionadas vinte e seis amostras para os ensaios de resistência puntiforme e sete para os de resistência à compressão simples. Foi estimada a energia de perfuração específica (EEP) para cada um desses trechos, utilizando-se os dados coletados no monitoramento.

Os locais de onde foram retiradas as amostras estão mapeados no perfil individual de sondagem - Furo Zero (Anexo A .2). Os índices físicos das amostras selecionadas foram determinados: (a) massa específica aparente seca, (b) massa específica aparente saturada, (c) absorção de água e (d) porosidade aparente (ABNT, 1992a), e estão apresentados na forma de tabelas no anexo A.3.

\subsubsection{Ensaios de resistência à compressão puntiforme}

A correlação entre os resultados de massa específica aparente seca e absorção aparente das amostras dos ensaios de resistência puntiforme é apresentada na Figura 6.19 , ilustrando a faixa de variação desses índices. 


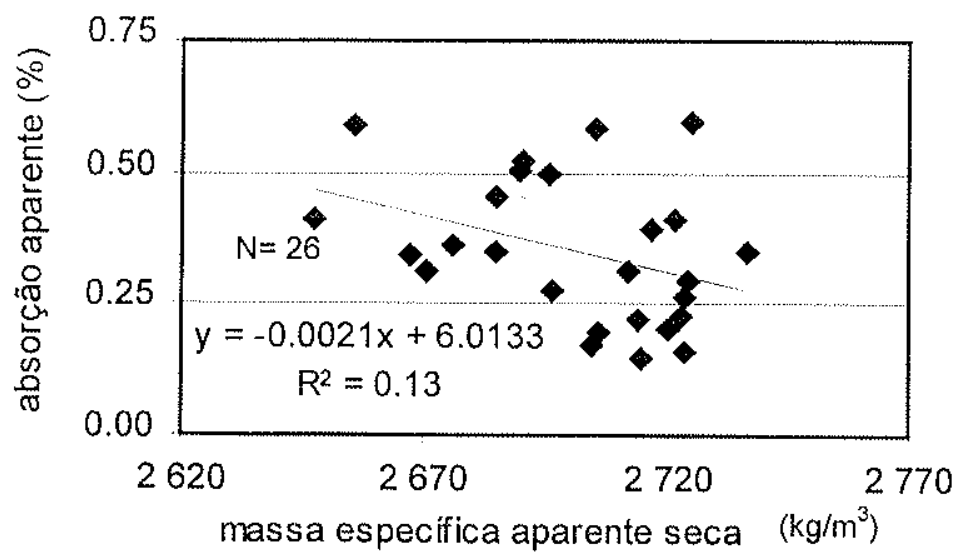

Figura 6.19 - Faixa de variação dos índices físicos. Amostras dos ensaios de resistência à compressão puntiforme.

Os primeiro ensaios foram realizados em testemunhos de rocha (amostras cilíndricas). Os valores máximos de resistência eram esperados nos ensaios com a direção do carregamento perpendicular ao plano do bandamento/xistosidade da rocha. No entanto, numa primeira etapa, devido o conjunto de amostras não possuir em sua totalidade dimensões que permitissem o ensaio nessas condições, as amostras foram ensaiadas com carregamento subparalelo ao bandamento/xistosidade, ou seja, na direção do eixo de perfuração.

Para essa forma de ensaio, já eram esperados valores anômalos, influenciados pelas descontinuidades (fraturas, microfraturas) associadas ao bandamento/xistosidades. O ensaio puntiforme solicita a resistência à tração das amostras. Segundo a geometria imposta, essa solicitação ocorreu subperpendicularmente aos planos do bandamento/xistosidade. Esses resultados são apresentada na Figura 6.20.

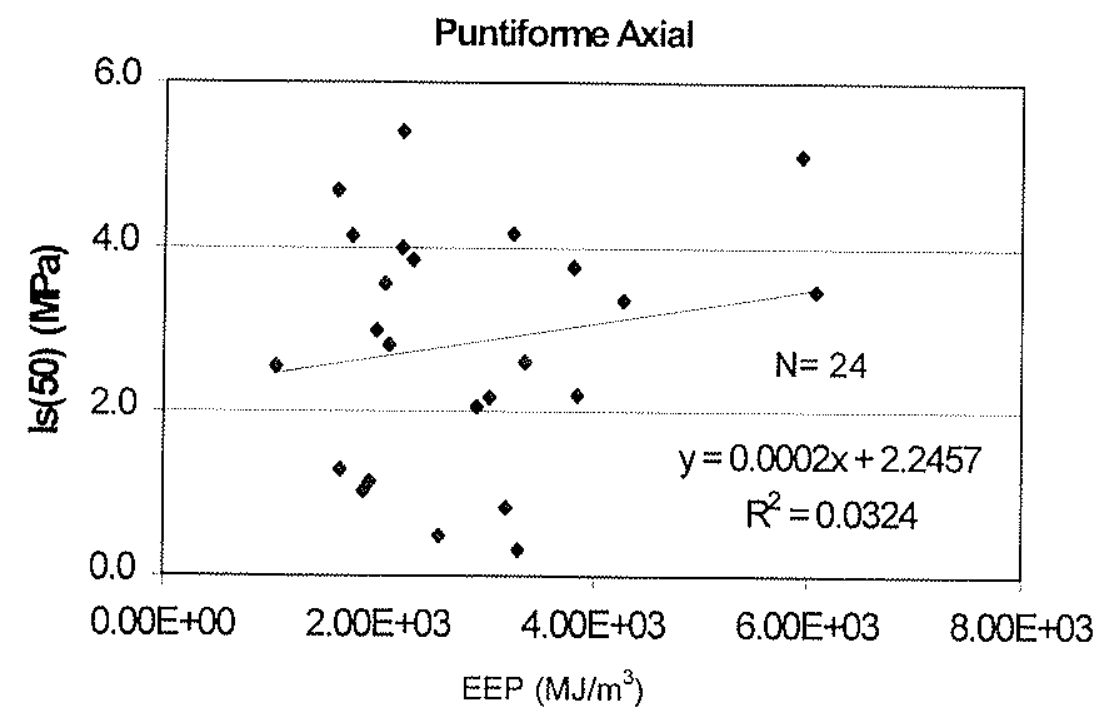

Figura 6.20 - Correlação entre energia especifica de perfuração (EEP) e resistência à compressão puntiforme $\left(\mathrm{IS}_{(50)}\right)$. Compressão paralela à xistosidade. 
A baixa correlação com a energia específica de perfuração (EEP) observada foi inicialmente justificada pela geometria dos ensaios, com o carregamento tendo sido realizado paralelo à xistosidade.

Considerando a pouca disponibilidade de amostra e tentando esgotar as possibilidades de ensaio do material, foi realizada nova etapa de ensaios de resistência puntiforme. Foram aproveitados os corpos de prova rompidos na etapa anterior e preparadas novas amostras. Apesar desse procedimento não ser recomendado, ele foi realizado por se acreditar que a forma como as amostras romperam no ensaio anterior, teria mobilizado uma baixa porcentagem da resistência máxima da amostra.

As amostras foram preparadas para ensaio de fragmentos, agora orientadas para que a compressão ocorresse perpendicular ao bandamento/xistosidade da rocha. De maneira geral, os valores obtidos foram extremamente baixos, considerando o tipo litológico ensaiado. Os valores de resistência obtidos também não foram significativamente superiores, quando comparados com a etapa anterior.

Apesar da nova geometria do ensaio e da menor dispersão dos resultados, a correlação obtida com a energia específica de perfuração (EEP) ainda foi considerada baixa. Esses resultados estão apresentados na Figura 6.21 .

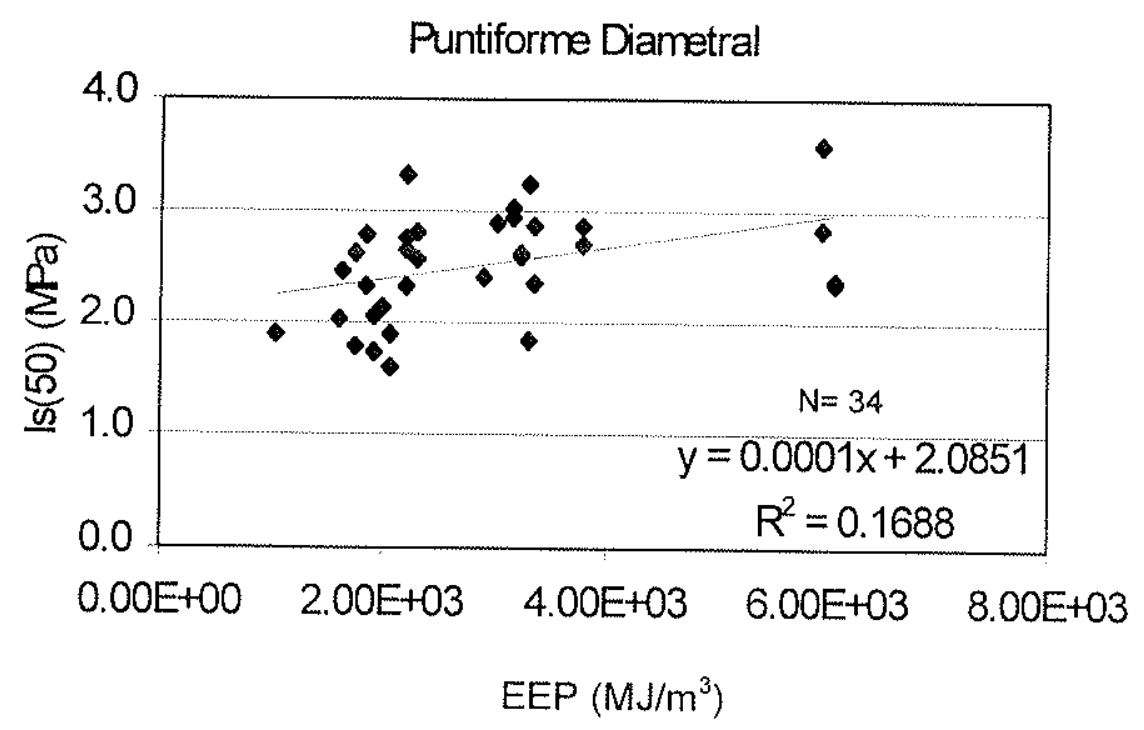

Figura 6.21 - Correlação entre energia específica de perfuração (EEP) e resistência à compressão puntiforme $\left(\mathrm{IS}_{(50)}\right)$. Compressão perpendicular à xistosidade. 


\subsubsection{Ensaios de resistência à compressão uniaxial}

Os locais da sondagem onde foram retiradas amostras para os ensaios de resistência à compressão uniaxial estão mapeados no perfil individual de sondagem Furo Zero (anexo A.2).

Os ensaios de compressão uniaxial foram realizados em 7 amostras de rocha sã, caracterizadas através dos seus índices físicos (ABNT, 1992a) e da velocidade de propagação de ondas ultra-sônicas (figuras 6.22 e 6.23, respectivamente).

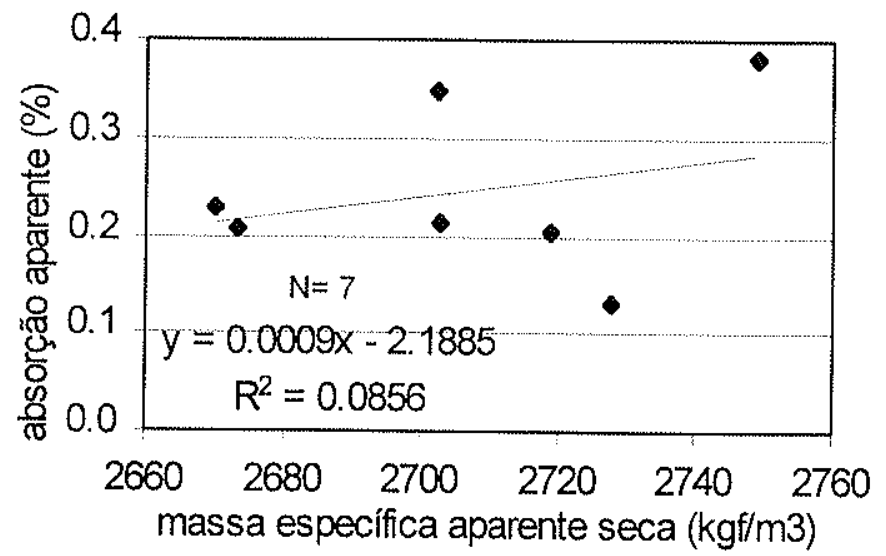

Figura 6.22 - Variação dos indices físicos (Ensaios RCU).

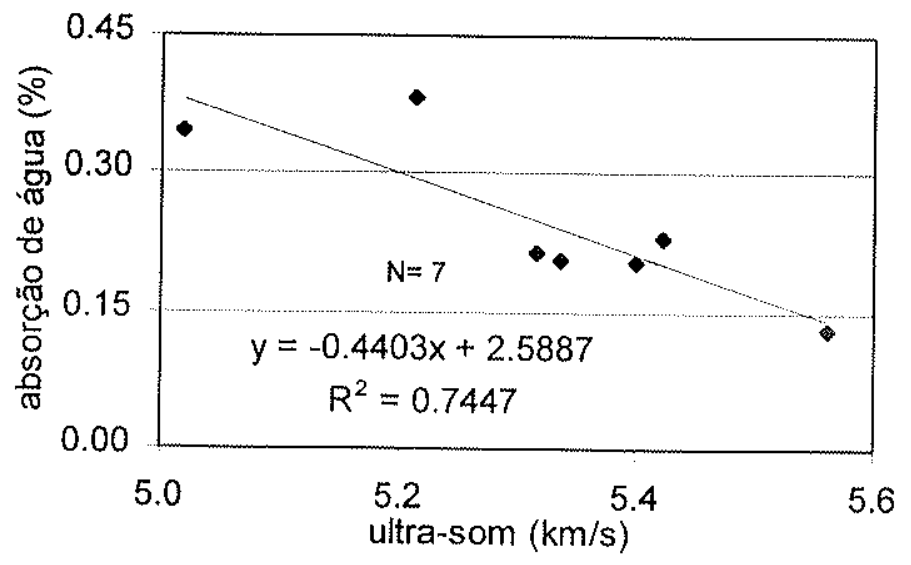

Figura 6.23 - Correlação entre a velocidade de ultra-som e a absorção de água (Ensaio RCU).

Normalmente utilizada em estudos de perfurabilidade, outra forma de caracterização das amostras é a estimativa da porcentagem volumétrica de quartzo. Considerando a avaliação realizada a partir da descrição macro e microscópica das amostras, apresenta-se a correlação da energia especifica de perfuração (EEP) com esse índice para as sete amostras analisadas (Figura 6.24). 


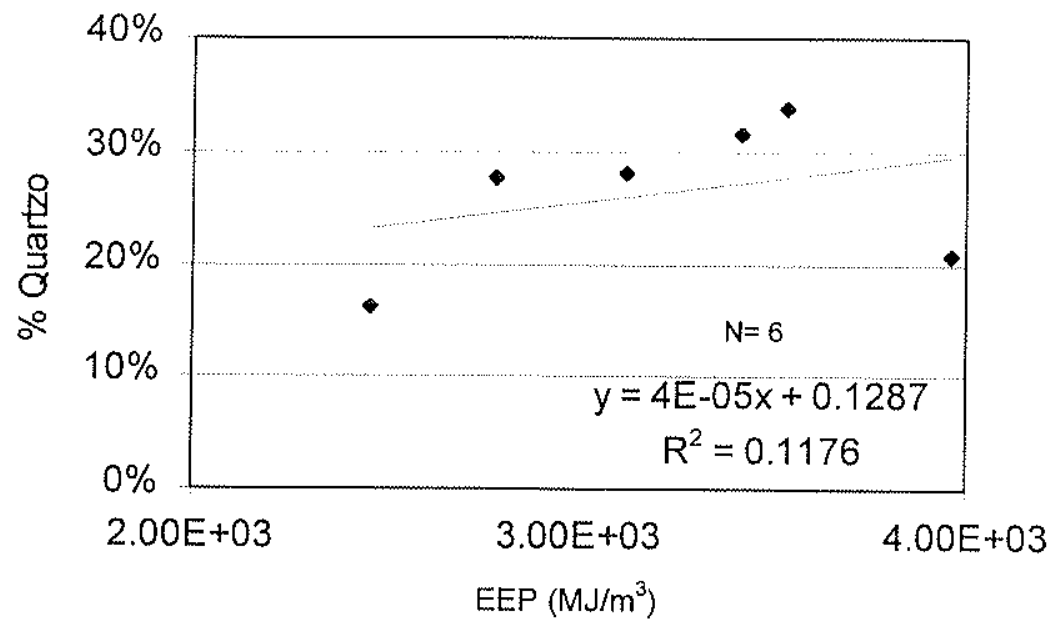

Figura 6.24 - Correlação entre a energia especifica de perfuração e o volume estimado de quartzo nas amostras.

Apesar da porcentagem de quartzo não determinar diretamente a energia de perfuração específica da rocha, provavelmente ela deva ser um dos fatores que a determina. Apesar de baixa, existe uma correlação diretamente proporcional, devido à resistência à abrasão desse mineral.

Apesar de maior, a correlação entre o volume estimado de quartzo e a resistência à compressão uniaxial das amostras também é baixa (Figura 6.25).

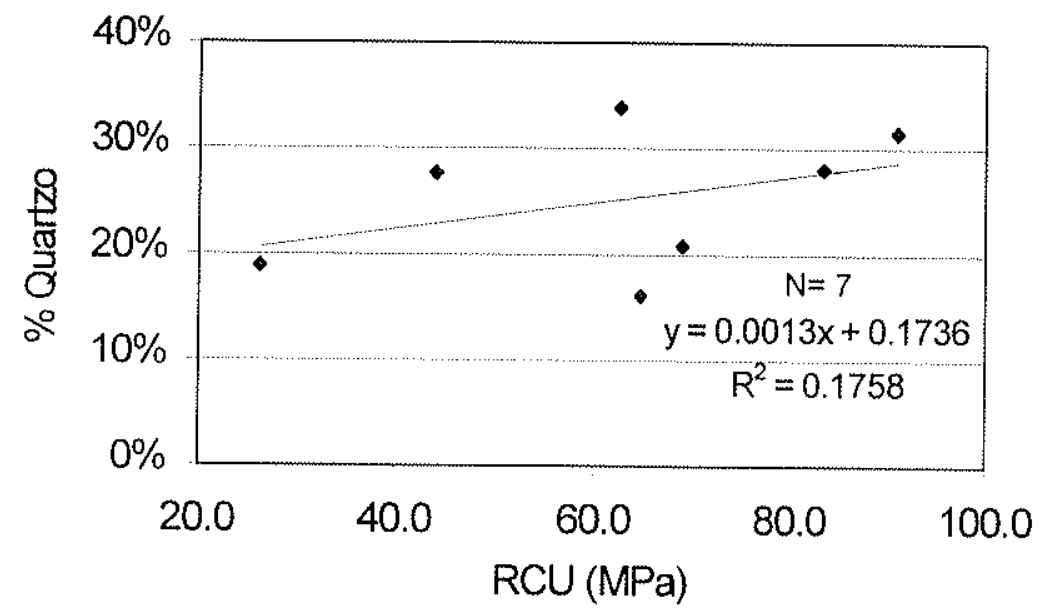

Figura 6.25 - Correlação entre a resistência à compressão simples e o volume estimado de quartzo nas amostras.

Finalmente, analisou-se a correlação entre a energia especifica de perfuração (EEP) e a resistência à compressão unixial (RCU). Para esse tipo de ensaio e considerando o fato da direção do cisalhamento esperado no corpo-de-prova não ser paralelo ao mergulho do bandamento/xistosidade, esperava-se menor influência das descontinuidades na resistência. As rupturas ocorrendo pela matriz da rocha deveriam 
dar uma melhor correlação da energia especifica de perfuração (EEP) com a resistência (RCU).

Apesar das expectativas, foi observada alta dispersão nesses resultados (Figura 6.26). Provavelmente o baixo número de amostras e a homogeneidade relativa devem ter contribuído para esse resultado.

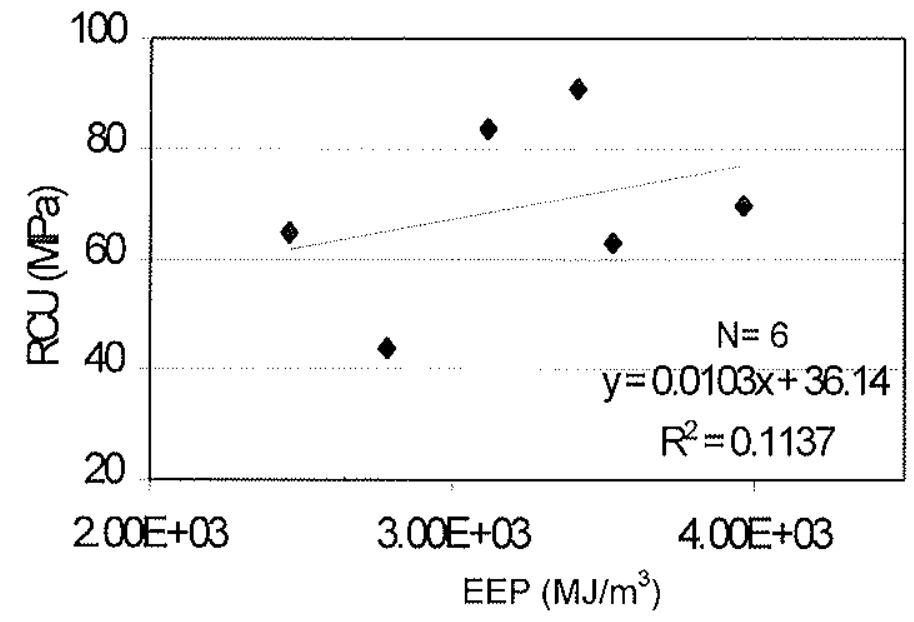

Figura 6.26 - Correlação entre energia especifica de perfuração (EEP) e resistência à compressão uniaxial (RCU). Compressão paralela à xistosidade. ${ }^{21}$

Apesar de poucas amostras, os resultados da figura sugerem dois conjuntos distintos. Analisando a "qualidade das rupturas" e a respectiva influência das descontinuidades, foi possível separar as seis amostras nos dois grupos lineares. Destaca-se que a correlação entre os dois subconjuntos é muito alta: 1,00 e 0,99 , respectivamente. Os critérios utilizados para essa classificação estão apresentados no anexo A.3.

Foi observada a presença de feições estruturais, especificamente, fraturas ou outros planos de fraqueza, subparalelos ao bandamento/xistosidade da rocha, com suas superfícies mais ou menos alteradas. Essas feições e a quantidade de material alterado associado (óxidos/hidróxidos de ferro) são condicionantes do quanto a ruptura aproxima-se do modelo esperado para materiais isotrópicos. Esse modelo é definido por dois planos de cisalhamento que definem os dois cones de ruptura, associados à base e ao topo do corpo-de-prova.

\footnotetext{
${ }^{21}$ A amostra RCU.6 foi desconsiderada devido à sua ruptura ter sido totalmente condicionada por uma descontinuidade paralela ao bandamento/xistosidade da rocha (anexo A.3).
} 
As amostras foram classificadas segundo esses dois critérios: "qualidade da ruptura" e "alteração na superfície de ruptura" (anexo A.3), sendo observado:

(a) a alteração está diretamente relacionada à "qualidade da ruptura". As amostras com superfícies menos alteradas possuem melhor "qualidade de ruptura";

(b) o conjunto das seis amostras, se separado em dois grupos, segundo a qualidade de ruptura/alteração na superfície de ruptura, representa os dois conjuntos de amostras alinhadas na Figura 6.26 (EPP x RCU).

(c) As amostras com dificuldade para ajuste no modelo estão sempre situadas nos extremos dos conjuntos (mínima ou máxima EEP e resistência RCU).

Considerando-se as hipóteses adotadas e os resultados observados nos ensaios, poder-se-ia imaginar as amostras distribuídas em dois grupos discretos: (a) as amostras com "ruptura típica", menos influenciada pelas descontinuidades e anisotropia da rocha e (b) amostras com a ruptura menos caracterizada, mais influenciada pelas descontinuidade e anisotropia da rocha.

Apesar dos dois grupos na Figura 6.26 serem muito distintos, era esperado que essa influência ocorresse de modo mais contínuo, como a própria classificação da ruptura e da alteração das fraturas sugeriria. Por outro lado, não se pode excluir a possibilidade das características das feições alteradas e a sua geometria com relação ao ensaio, separarem os resultados em dois grupos distintos: "influenciados" e "nãoinfluenciados", conforme mostram os próprios resultados.

O modelo para a interpretação dos resultados foi confirmado pela análise petrográfica das amostras. Considerando a mineralogia, as 7 lâminas analisadas são bastante semelhantes, sendo constituídas basicamente por: feldspatos (alcalino e plagioclásio) (42 a 53\% em volume), quartzo (16 a 34\%), anfibólio (hornblenda) (6 a $11 \%$ ), biotita (13 a 29\%), óxidos/hidróxidos de ferro, titanita e opacos ${ }^{22}$. A alteração intempérica é incipiente nas 7 amostras, sendo reconhecida através da argilização de alguns cristais de plagioclásio (Figura 6.27) e pela presença de fraturas mais ou menos contínuas, preenchidas por óxido de ferro, geralmente paralelas à foliação da rocha.

\footnotetext{
${ }^{22}$ Não foi considerada a amostra RCU-6, a qual que possui a mesma mineralogia, porém em porcentagens volumétricas bastante diferenciadas.
} 

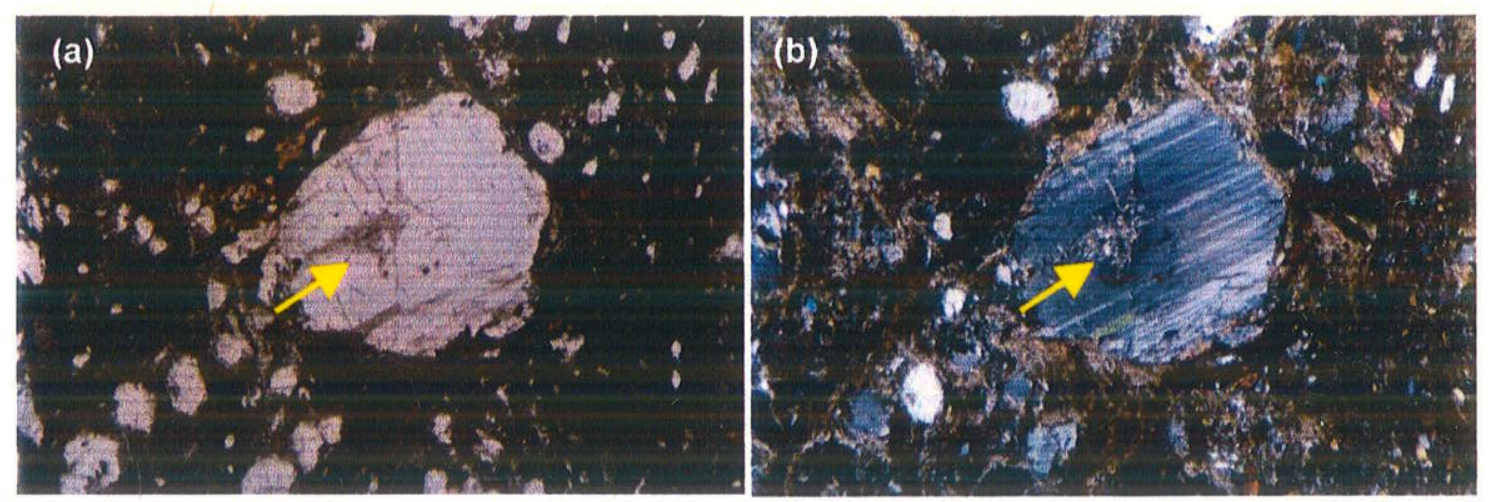

Figura 6.27 - Detalhe do processo incipiente de alteração das amostras: argilização dos feldspatos. Amostra RCU-7. Aumento 20x (a) polarizadores descruzados e (b) polarizadores cruzados.

Em termos microscópicos, a única feição reconhecida que justificaria a variação nos valores da resistência a compressão simples (RCU) é a quantidade das fraturas, avaliável na seção das lâminas (perpendicular ao bandamento/xistosidade), e sua persistência. No plano em que as lâminas foram cortadas (perpendicular às estruturas), a avaliação da persistência é apenas parcial. Essas feições podem apresentar desenvolvimento diferenciado em direções distintas no plano de foliação da rocha. Esses planos preenchidos com óxidos/hidróxidos de ferro são ilustrados na figuras 6.28.
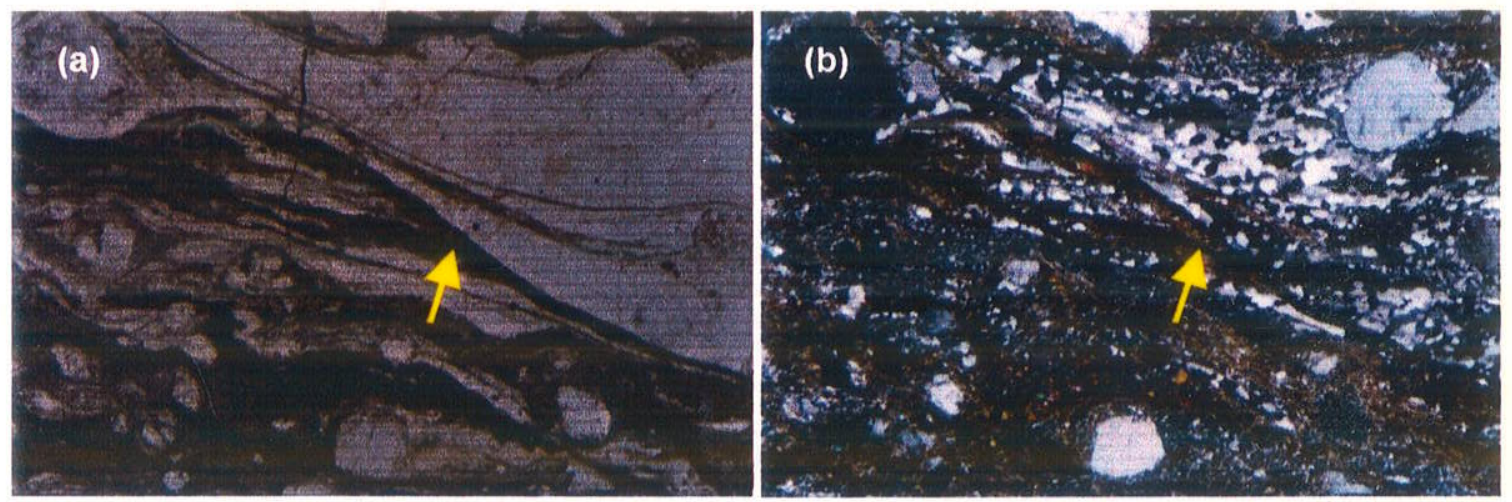

Figura 6.28 - Detalhe das fratura preenchidas por óxidos/hidróxidos de ferro. Amostra RCU-3. Aumento 20x (a) polarizadores descruzados e (b) polarizadores cruzados.

\subsection{Análise dos resultados obtidos e do comportamento da sonda}

O protótipo do sistema de aquisição registra automaticamente diversos parâmetros associados à perfuração. Esse conjunto de dados pode ser utilizado tanto para a classificação dos materiais perfurados como para o controle das condições de perfuração. Os registros da velocidade de rotação da coluna e do acréscimo de torque devido ao processo de perfuração (deflexão do acoplamento elástico corrigido pela relação da marcha utilizada) estabelecem a potência fornecida pelo motor ao processo de perfuração. Essa potência aplicada por um período de tempo, produz energia ou 
trabalho, gerando o desgaste ou corte de um volume de rocha. A razão entre a energia fornecida e o volume de rocha cortado representa a energia específica de perfuração (EEP).

Os demais parâmetros de controle referem-se a: posição ou avanço da perfuração; pressões associadas ao sistema hidráulico da sonda, ou seja, pressões descendente e ascendente, representando, respectivamente, as componentes no sentido do avanço do furo e no sentido oposto; vazão e pressão do fluido introduzido no furo, além da velocidade de rotação do motor. As velocidades de rotação do motor e da coluna estabelecem a relação utilizada na caixa de câmbio, ou seja, a marcha na qual o equipamento realiza a perfuração.

Apesar da automação ser inerente ao processo de aquisição, o tratamento dos dados é ainda realizado de maneira "manual" no protótipo. O sistema possui "instabilidades" que precisam ser sanadas. Outro fator que dificultou a obtenção desses dados para a correlação foi a condição de manutenção da sonda.

Apesar da dificuldade de obtenção dos dados, nota-se que com o devido monitoramento da profundidade, o protótipo realiza um preciso acompanhamento das condições de perfuração. Para monitorar a profundidade da ferramenta de corte é essencial a ancoragem da sonda, pois sua elevação, devido à ação do sistema hidráulico, fornece informações falsas para o sistema, que poderiam ser erroneamente interpretados. A ancoragem da sonda deve também diminuir a variação do parâmetro torque, observada nos testes de perfuração.

Dentro dos modelos existentes no mercado, a sonda utilizada foi considerada adequada à realização do trabalho, uma vez que permitiu que o eixo do motor fosse monitorado, por meio da instalação do acoplamento elástico. A maioria dos modelos não permite essa instalação de maneira tão fácil, em função do exíguo espaço entre a caixa de câmbio e o motor. Os projetos das sondas rotativas disponíveis no mercado não prevêem o monitoramento, especialmente aquele destinado à determinação da energia de perfuração. Chegou a ser cogitado o aproveitamento das deformações do disco de friç̧ão para a instalação do sensor de torque, existente em todos os modelos. $O$ monitoramento de torque realizado dessa maneira viabilizaria o controle desse parâmetro na maioria dos modelos de sonda existentes no mercado. Essa alternativa foi 
abandonada devido à dificuldade de instalação dessas peças, praticamente no interior do motor (capa seca). As demais adaptações físicas para a instalação dos sensores são relativamente simples.

A maneira como a estimativa do torque foi proposta inicialmente ( $1^{\text {a }}$ etapa de testes), utilizando-se curvas de potência do motor, mostrou-se inadequada, tanto pela dispendiosa calibração que ela pressupõe, como também pela imprecisão, causada por diversos fatores que influenciam o desempenho do motor (regulagem do motor, qualidade do combustível).

O sensor desenvolvido e os procedimentos implantados foram a maneira mais fácil disponível para a obtenção desse parâmetro.

Com a medida do implemento de torque, a partir da $2^{\text {a }}$ etapa de testes, as considerações realizadas no item 6.1 , sobre a transferência de energia do motor para o processo de perfuração, tornam-se menos relevantes, já que esse novo parâmetro deve englobar algumas variáveis já discutidas, por exemplo, pressão efetiva sobre a ferramenta de corte. Talvez outras variáveis também talvez possam ser englobadas pela estimativa do acréscimo no valor de torque. É o caso, por exemplo, do tipo de ferramenta e o seu grau de desgaste. Essas variáveis estariam associadas às condições da interação ferramenta-rocha e, portanto, é intuitivo imaginar que possuam reflexos no acréscimo de torque.

Uma dificuldade do monitoramento está relacionada à forma de funcionamento da sonda e aos objetivos da prospecção. Para a determinação mais representativa da energia específica de perfuração (EEP), o acréscimo de torque deve ser o mais alto possível. Essa condição é obtida através do estabelecimento de uma alta pressão efetiva entre a ferramenta cortante e a superfície da rocha, produzindo a máxima velocidade de avanço. Provavelmente essa condição deve corresponder às condições definidas por DEKETH (1995) onde a força normal é maior (MODO II ou III).

A velocidade de avanço da sonda é estabelecida pelo operador, por meio da vazão regulada na válvula de ajuste fino. A perfuração em solo realizada com brocas de arraste, diâmetros $\mathrm{N}$ e $\mathrm{W}$, exemplificam uma situação onde essa condição ideal para o estabelecimento da energia específica de perfuração não pode ser atingida. A velocidade de avanço do furo é limitada pela capacidade de limpeza do sistema de circulação do 
fluido. A ultrapassagem da capacidade do equipamento provoca o entupimento da saida d'água e a imediata paralisação do avanço. Como resultado, obtêm-se baixos ângulos de deflexão, em alguns casos negativos, caracterizando uma limitação de leitura do aparelho.

Em maciços rochosos, essa limitação ocorre de modo diferente. A perfuração da rocha pode ser realizada com diversas pressões sobre a ferramenta de corte. Para cada ferramenta, o atrito dinâmico com a rocha é diretamente determinado pelo valor dessa pressão. Pressões excessivas provocam sobrecarga na coluna de perfuração (hastes Aw), trepidação, sobrecarga no sistema de ancoragem da sonda e até o comprometimento da ferramenta de corte ("queima" dos diamantes).

$\mathrm{Na}$ verdade, para se considerar a energia específica de perfuração como parâmetro de classificação do maciço, seria necessário: (a) determinar se para a perfuração de rochas mais resistentes existiriam também os "modos" definidos por DEKETH (1995), que alteram a energia de perfuração para um mesmo material; (b) confirmando a existência dessas condições diferenciadas ("modos"), seria necessário garantir que todo o furo fosse realizado nas mesmas condições, ou seja, sempre no mesmo "modo", para que as variações registradas representassem com certeza variações nas características dos materiais, e não apenas alteração no "modo" de execução.

A deformação no acoplamento elástico é calculada pela da relação entre a defasagem dos sinais e o período de rotação. A parte eletrônica do sensor de torque é muito precisa. No entanto, observa-se grande oscilação nos valores medidos, devido à parte mecânica (acoplamento elástico). Esse ruído está ligado intimamente ao funcionamento da sonda: (a) pelo motor a diesel utilizado, e (b) pela forma de interação entre a ferramenta de corte e a rocha. A aquisição eletrônica dos dados permitiria que essa variação fosse "filtrada", por meio da aquisição em freqüências mais altas e do estabelecimento de valores médios. Esse recurso não foi aplicado, por dificultar a detecção de erros nos valores medidos e, porque, matematicamente, os resultados são equivalentes, uma vez que as deflexões utilizadas são sempre consideradas em termos das médias dos trechos perfurados.

A proposta inicial do trabalho procurou desenvolver um sistema que não interferisse nos procedimentos e na operação das sondagens rotativas. No final, ficou 
claro que, dependendo do objetivo do monitoramento, essa proposta é conflitante com os objetivos da prospecção, devido à questão da amostragem (recuperação). O sistema hidráulico é movido por uma bomba de palhetas. A válvula do comando hidráulico direciona o óleo bombeado para a parte superior ou inferior dos pistões, determinando o sentido do seu deslocamento, descendente ou ascendente, respectivamente. No entanto, o controle da máquina não é realizado apenas por meio dessa válvula. A operação da sonda prevê ainda a utilização da "Válvula de Ajuste Fino", a qual realiza o controle da vazão de óleo para os pistões, e, conseqüentemente, a velocidade de avanço da perfuração.

A válvula de ajuste fino permite ao operador estabelecer uma velocidade de avanço compatível com a capacidade de corte e limpeza do equipamento, considerando a resistência do material perfurado. Esse procedimento impede que a reação ao avanço levante a sonda ou force demasiadamente a sua ancoragem. Ocorrendo a sobrecarga, compromete-se a qualidade da amostragem e a integridade do próprio equipamento.

A operação utilizando a válvula de ajuste fino descaracteriza a pressão do hidráulico e mesmo a velocidade de avanço como parâmetros da perfuração. Nessa forma de operação, o que determina a pressão no hidráulico é o grau de estrangulamento estabelecido pela válvula de ajuste. Os testes realizados mostraram que essa forma de operação tem como resultado o estabelecimento de uma diferença de pressão $(d P)$ alta no hidráulico, sem que isso reflita necessariamente em pressões proporcionais na ferramenta de corte. A passagem para o pistão é "estrangulada" pela válvula de ajuste fino. Como a vazão da bomba é constante, o volume de óleo que não vai para o pistão, retorna novamente ao reservatório.

Quase todos os testes de funcionamento ( $1^{\text {a }}$ etapa) foram realizados sem a utilização da válvula de ajuste fino, devido à baixa resistência dos solos ou alteração das rochas. Todos os demais testes foram realizados utilizando-se a válvula. A diferença entre essas duas situações está ilustrada nos gráficos de diferencial de pressão apresentados no anexo A.1 (Resultados dos testes de perfuração), onde é possível visualizar a forma irregular de aplicação da pressão e o desaparecimento das variações e estabilização nos valores máximos, quando a válvula é utilizada $\left(1^{a}\right.$ Etapa de Testes arquivo rock3609.xls). No caso da utilização da válvula, os valores elevados de pressão não são integralmente transferidos para o contato ferramenta de corte - rocha. 
Em parte, as dificuldades encontradas devem-se ao fato das sondas existentes para perfuração rotativo-abrasiva serem projetadas para a perfuração e obtenção de amostras, não para a realização de sondagens monitoradas.

Apesar das dificuldades na obtenção dos parâmetros, os resultados indicam correlações com parâmetros de resistência, principalmente com a resistência à compressão uniaxial (RCU) das amostras de rocha.

Finalmente, acredita-se que os parâmetros de perfuração poderiam ser introduzidos como dados de entrada para classificações geomecânicas de maciços. Montadas inicialmente para atender grandes obras de engenharia, a partir da década de 1940, esses modelos estão associados principalmente a obras que envolvam escavação subterrânea e corte de taludes (barragens, túneis viários e mineração). Para que o seu objetivo final seja atendido, o que significa, para se obtenha uma previsão confiável de comportamento frente à execução e operação da obra, algumas etapas fazem-se necessárias: (a) proposição dos parâmetros geológico-geotécnicos de interesse e de classes representativas e identificáveis na prospecção (métodos de investigação direto e indireto, ensaios de laboratório, descrição táctil-visual de amostras); (b) proposição de uma forma de articulação dessas diversas classes de parâmetros geológico-geotécnicos, resultando nas classes de maciço do modelo, com comportamento similar e passíveis de tratamento uniforme na obra e (d) descrição das possibilidades de tratamento dessas classes de maciço na execução da obra. 


\section{CONCLUSÕES}

Este projeto teve como objetivo (a) desenvolver e (b) testar um protótipo para monitoramento de sondas rotativas, além de (c) procurar estabelecer correlações dos parâmetros obtidos com resultados de ensaios geotécnicos de campo e laboratório, visando a aplicação prática do método.

O primeiro e segundo objetivos foram integralmente atingidos. $\mathrm{O}$ desenvolvimento do protótipo iniciou-se por uma etapa de especificação e aquisição dos principais sensores: (a) um de deslocamento, (b) dois de proximidade, (c) três de pressão e (d) dois de vazão; que teve como finalidade o monitoramento da (a) posição e velocidade da perfuração; (b) velocidades de rotação da coluna de perfuração e do eixo do motor; (c) pressões no sistema hidráulico e na linha de água da bomba e (d) vazões de entrada e saída do fluido de circulação no furo, respectivamente. Foram confeccionadas adaptações físicas para a instalação dos sensores na sonda e na bomba disponíveis. Para a aquisição propriamente, dita foi utilizado um conversor $\mathrm{AD}$ e um microcomputador. Um software foi especialmente desenvolvido para o gerenciamento do sistema, o que permitiu a sua configuração e operação.

Da mesma forma, o segundo objetivo também foi atingido, uma vez que cada sensor foi testado em bancada, com o sistema de aquisição em operação. Posteriormente, realizaram-se testes de perfuração com o protótipo instalado na sonda, em duas etapas consecutivas. Embora não fosse um objetivo inicial, a evolução do trabalho indicou a necessidade de um sensor de torque específico para o monitoramento da sonda. Esse sensor foi concebido, desenvolvido, testado e incorporado ao sistema de monitoramento. $O$ processo utilizado de medida de torque em eixo giratório sem contato mecânico é inédito.

A $1^{\text {a }}$ e $2^{\text {a }}$ etapas corresponderam aos testes sem e com o sensor de torque desenvolvido, respectivamente. A parte experimental do trabalho identificou e procurou exemplificar algumas possibilidades do monitoramento da perfuração rotativa com amostragem de rocha:

(a) análise "macroscópica", obtida por meio da perfilagem dos parâmetros mais significativos, especialmente, velocidade de avanço, taxa de penetração e energia de específica de perfuração. Os parâmetros do monitoramento obtidos em solo foram perfilados e comparados com os resultados obtidos de resistência à penetração SPT. Apesar da discrepância entre esses dois parâmetros nos perfis, os dados disponíveis não 
são suficientes para afirmar que os parâmetros da perfuração em solo não possam ter uma interpretação geológica ou geotécnica. A análise "macroscópica" ficou prejudicada nas perfurações em rocha, devido à descontinuidade dos registros.

(b) análise de detalhe, de caráter mais pontual, onde foram buscadas correlações com índices físicos e resistência à compressão das amostras. As correlações estabelecidas com os parâmetros de resistência mostraram altas dispersões. Esse resultado pode ser justificado pela influência das descontinuidades, principalmente, nos resultados da resistência à compressão puntiforme, e pela dimensão inadequada da população de amostras.

Apesar dessa limitação, as relações entre a energia específica de perfuração e os parâmetros de mecânica das rochas apresentaram tendências semelhantes: uma relação crescente e com baixo coeficiente angular entre energia específica de perfuração (EEP) e resistências à compressão.

No caso da resistência à compressão uniaxial foi proposto um modelo de classificação baseado na análise da ruptura e na descrição das condições de alteração de suas superfícies. Essa classificação permitiu a divisão dos resultados em dois grupos com excelentes correlações com a energia específica de perfuração. Essa interpretação dos resultados baseou-se ainda em análise petrográfica das amostras.

Com relação ao terceiro objetivo do trabalho, ou seja, aquele relacionado às possibilidade de aplicação do monitoramento na caracterização de maciços, afirma-se que os resultados obtidos, apesar da quantidade restrita de amostras, indicam para um potencial de aplicação prática do método em campanhas de investigação geológico-geotécnicas.

A implantação efetiva do monitoramento de sondagens rotativas com amostragem e o aproveitamento dessas informações de maneira sistemática dependem de:

a) desenvolvimento do sistema de aquisição

O protótipo necessita de aperfeiçoamentos, no sentido de tornar mais prática a sua utilização, diminuindo a influência dos procedimentos do monitoramento nos processos executivos da sondagem. Apesar desse fato, a operação do sistema é simples, uma vez que praticamente todos os testes de perfuração na $2^{\mathrm{a}}$ etapa foram realizados apenas com a presença do sondador e de seus ajudantes, com um mínimo de treinamento específico;

b) adaptação da sonda ao monitoramento visando a caracterização geológico-geotécnica

As sondas e os equipamentos de sondagem são projetados para realizar a perfuração e recuperar amostras. Entende-se não só o protótipo deve ser adaptado à sonda, que também a 
sonda deve adaptar-se ao monitoramento. Esse ajuste geral dos equipamentos iria procurar estabelecer um equilíbrio do monitoramento com os demais objetivos já estabelecidos para a sondagem, ou seja, obtenção de amostras preservadas do maciço e uma produtividade razoável do equipamento.

O sistema de aquisição já utiliza um conversor $\mathrm{A} / \mathrm{D}$, equipamento que além de monitorar o processo, tem capacidade de controlar a perfuração, por meio de "atuadores" ou acionadores que seriam instalados na sonda. Essa idéia é apresentada na Figura 3.21. Utilizando-se esse recurso já disponível no conversor, a perfuração poderia ser programada, utilizando-se um processo interativo, onde os sensores indicariam as condições impostas e, o sistema de monitoramento e controle, realizaria continuamente os ajustes necessários para garantir produzir condições homogêneas de perfuração.

c) testes em laboratório

É fundamental para o desenvolvimento da técnica de monitoramento de sondagens rotativas com amostragem, que sejam realizados testes em laboratório para avaliar a influência das variáveis que influenciam a perfuração. Essas variáveis referem-se (a) influência do tipo de ferramenta cortante (geometria da coroa, tipo e granulometria dos diamantes); (b) influência do tipo litológico e de suas variações mineralógicas e (c) influência do nível de desgaste da ferramenta de corte, entre outros.

A realização dos testes em laboratório forneceria uma maior quantidade de dados a custos muito inferiores aos dos testes de perfuração executados. O desenvolvimento do sistema de monitoramento, subsidiado pelos resultados dos testes em laboratório, trará maior representatividade aos resultados, uma vez que os fatores envolvidos poderiam ser isoladamente avaliados.

O monitoramento da perfuração, utilizado para a classificação geológico-geotécnica de maciços, será uma técnica promissora, complementar às informações já disponibilizadas pelo método tradicional de sondagem, se forem confirmadas correlações consistentes e generalizadas entre os parâmetros de perfuração e o comportamento dos maciços.

A resistência mecânica dos materiais é um parâmetro presente na maioria dessas classificações. A possibilidade de correlações entre parâmetros de resistência e de perfuração, dá ao monitoramento da sondagem a possibilidade de aplicação como parâmetro de entrada para a utilização nesses modelos. 


\section{REFERÊNCIAS BIBLIOGRÁFICAS}

ASSOCIAÇÃO BRASILEIRA DE GEOLOGIA DE ENGENHARIA (ABGE) (1990) Diretrizes para a execução de sondagens: $2^{\mathrm{a}}$ tentativa. São Paulo. 45 p. (Boletim Especial).

ASSOCIAÇÃO BRASILEIRA DE GEOLOGIA DE ENGENHARIA (ABGE) (1990) Diretrizes para a execução de sondagens: $2^{\mathrm{a}}$ tentativa. São Paulo. 45 p. (Boletim Especial).

ASSOCIAÇÃO BRASILEIRA DE NORMAS TÉCNICAS (ABNT) (1992a) Rochas ornamentais - Determinação da massa específica aparente, porosidade aparente e absorção de água aparente (NBR 12.766). 2p.

ASSOCIAÇÃO BRASILEIRA DE NORMAS TÉCNICAS (ABNT) (1992b) Rochas para revestimento - Determinação da resistência à compressão uniaxial (NBR 12.767). $2 p$.

d'ÁVILA, C.J.R., ORTIGÃO, J.A. R., SARDELLA, I.M.B., KAUATI, A (1994) SISPER- Sistema de instrumentação de sonda rotativa. In: INFOGEO - São Paulo, 1994. Anais...São Paulo, Associação Brasileira de Mecânica de Solos.

BALLUFF (s.d.) Sensores de proximidade: indutivos, capacitivos, de campo magnético, optoeletrônicos, ultrasônicos. 59 p. (catálogos de equipamentos)

BAPTISTA, R.J.F. (1986) Diagrafias instantâneas e diferidas como método de prospecção em geologia de engenharia. Lisboa, 199 p. Dissertação (mestrado). Universidade de Nova Lisboa.

BASILE, A.C.S. \& SANTOS, B.C. (1989) Medidor eletromagnético de vazão. In... Simpósio Brasileiro de Medição de Vazão, Anais..., 1. São Paulo out/1998 IPT p.2459-2469.

BERBERIAN, D. (1986) Sondagem do subsolo para fins de engenharia. Brasília. Infrasolo, il..

BERTACHINI, A.C. (1987) Estudo das características hidrogeológicas dos terrenos cristalinos sob clima úmido na Região de Jundiaí, em São Paulo. 110 p.. Dissertação (mestrado). Universidade de São Paulo.

BIELSTEIN, W.J.; CANNON, G.E. (1950) Factors affecting the rate of penetration of rock bits. Central Committee on drilling and production practice. Division of production. American Petroleum Institute. p.61-78.

BOLOGNA, M.S. (1996) Correlação poço-a-poço usando perfis geofísicos: aplicações no Subgrupo Itararé e na Formação Serra Geral da Bacia do Paraná. Dissertação de Mestrado. Instituto Astronômico e Geofísico - Universidade de São Paulo, 73 p..

BROWN, E.T. \& BARR, M.V. (1978) Instrumented drilling as an aid to site investigations. In: INTER. CONG. INTER. ASSOC. ENG. GEOL., 1978, Madrid. Proceedings of... Madrid: INTER. ASSOC. ENG. GEOL., v.1, sec.4, 172 p., p.21-28.

CAMBEFORT, H. (1968) Perforaciones y Sondeos: su empleo enlos trabajos de 
reconocimiento y en las obras publicas. Ed. Omega, Barcelona, il..

CASSAN, M. (1988) Les essais in situ en mecanique des sols. Paris, Eyrolles, Cap. 10 , p. $437-$ 451: Diagraphies instantanées.

CETESB - CIA DE TECNOLOGIA DE SANEAMENTO AMBIENTAL (1978) Água subterrânea e poços tubulares. São Paulo, Cetesb, 1978.482 p.il..

CLARK, G. B. (1979) Principles of rock fragmentation. John Wiley and Sons, 610 p.

COELHO, A.G.; SANTOS J.L.T.(1985) Novas técnicas de prospecção geotécnica. Diagrafias instantâneas em sondagens destrutivas. Revista Geotecnia, Lisboa, $n^{\circ} 43$, p. 21-40.

CONGRESSO BRASILEIRO DE GEOLOGIA DE ENGENHARIA, 5., São Paulo, 1987. Anais. Săo Paulo, ABGE, 1987.2v.

CONGRESSO BRASILEIRO DE GEOl OGIA DE ENGENHARIA, 7., Poços de Caldas. 1993. Anais. São Paulo, ABGE, 1993. 2v.

CONGRESSO INTERNACIONAL DE GRANDES BARRAGENS, 14., Rio de Janeiro, 1982. Anais. Rio de Janeiro, 1982.

DEKETH, H.J.R.(1995) Wear of rock cutting tools - Laboratory experiments on the abrasivity of rock. Balkema. Roterdam. 144 p. il.

DIAMANGEO (s.d.) Coroas Diamantadas 12 p (catálogo de equipamentos).

DOBEREINER, L. et al. (1993) Geologia de engenharia na Europa e no Brasil - Situação atual e perspectivas para o ano 2000. In: CONGRESSO BRASILEIRO DE GEOLOGIA DE ENGENHARIA, VII, 1993, Poços de Caldas. Anais..., São Paulo.

DUNNICLIFF, J.(1988) Geotechnical instrumentation for monitoring field performance. John Wiley \& sons, New York 577 p.

FERREIRA, A.B.H. (1986) Novo dicionário da língua portuguesa. Rio de Janeiro. $2^{a}$ edição. $36^{\mathrm{a}}$ impressão. Nova Fronteira, 1838 p.

FRADEN, J.(1993) AIP handbook of modern sensors. Physics, designs and applications. AIP Press American Institute of Physics. New York, 522 p.

GIRARD, H. (1985) Contribution a l'exploitation des paramètres de forage en génie civil. Bordeaux. $161 \mathrm{p}$. Tese (doutorado). Universidade de Bordeaux.

GULDICINI, G. et. al. (1972) Um método de classificação geotécnica preliminar de maciços rochosos. In: SEMANA PAULISTA DE GEOLOGIA APLICADA, 4, 1972, São Paulo. Anais... São Paulo: ABGE. V.3, p. 258-331.

HARTLEY, J.S. (1994) Drilling tools and programme management. Rotterdam, AA Balkema, $150 \mathrm{p}$. 
HASUI, Y,; CARNEIRO, C.D.R.; COIMBRA, A.M. (1975) The Ribeira Folded Belt. Revista Brasileiro de Geociências, 5:256-266.

HBM - HOTTINGER BALDWIN MESSTECHNIK (s.d.) Product Summary. 177 p. (Catálogo de Equipamentos).

HOWARTH, D.F. \& ADAMSON, W.R. (1988) Performance characteristics of small scale rotary boring machine instrumented with large drag picks. Int. J. Rock Mech. Min. Sci \& Geomech.Abstr.. Vol 25, n.1, pp.25-33.

INSTITUTO DE PESQUISAS TECNOLÓGICAS DO ESTADO DE SÃO PAULO (1984) Estudos geológico-geotécnicos para caracterização e classificação de maciços rochosos para projetos de engenharia (túneis, lavra a céu aberto e barragens). São Paulo. (IP'T - Relatório nº 19.569).

INSTITUTO NACIONAL DE METROLOGIA (INMETRO) (1995) Vocabulário internacional de termos fundamentais e gerais de metrologia. Rio de Janeiro. INMETRO.

INSTITUTO NACIONAL DE METROLOGIA (INMETRO) (1998) Guia para a expressão da incerteza de medição. $2^{\mathrm{a}}$ edição. Rio de Janeiro. INMETRO. 121p.

INTERNATIONAL SOCIETY OF ROCK MECHANICS (ISRM) - COMMISSION ON TESTING METHODS (1985) Working group on revision of the Point Load Test Method. Il. 20 p.

ISMAIL, K.A.R.; GONÇALVES, M.M.; BENEVENUTO, F.J. (1998) Instrumentação básica para engenharia. Ed.do autor. Campinas. 470p. il.

JULIANI, C. (1992) O embasamento pré-cambriano da Bacia de São Paulo. In: PROBLEMAS GEOLÓGICOS E GEOTÉCNICOS NA REGIÃO METROPOLITANA DE SÃO PAULO. Anais.... São Paulo: ABAS/ABGE/SBG-SP, p.3-45.

LE MAITREE, R.W. (ed.) (1989) A classification of igneous rock and glossary of terms: Recommendations of the International Union of Geological Sciences - Subcommission on the systematics of igneous rocks. Oxford. Blackwell Scientific Publications. 193 p.

LYNX (s.d.) Sistema ADS-2000. AI-2160: Módulo condicionador de 16 entradas. Manual do usuário. $52 \mathrm{p}$.

MAQUESONDA, (s.d.) Maquesonda - tecnologia, mineração, prospecção). 92 p. (catálogo de equipamento)

NUSSENZVEIG, H.M. (1981) Curso de física básica. São Paulo. Edgard Blücher. vol.1. 519 p.

NYKON DWYLER (s.d.) Soluções em medição de vazão e nível. 4 p.(catálogo de equipamentos).

PEREDA, J.E. (1998) Parâmetros de furação, índices paramétricos e diagrafias instantânteas na prospecção geotécnica. São Paulo. 234 p. Dissertação (mestrado). Escola Politécnica, Universidade de São Paulo. 
PROTODYAKONOV, M.M. (1963) Mechanical properties and drillability of rocks. In: SIMP. ROCK MECH., 5th, 1962, Minessota. Proceedings of..., ed. C. Fairhurst, The MacMillan Co. , New York, p.103-118.

RICCOMINI, C. (1989) O Rift Continental do Sudeste do Brasil. Tese (doutoramento). Universidade de São Paulo. São Paulo, 256p.

RICCOMINI, C.; COIMBRA, A.M. (1992) Geologia da Bacia de São Paulo. In: MESA REDONDA SOBRE ASPECTOS GEOLÓGICOS E GEOTÉCNICOS DA BACIA SEDIMENTAR DE SÃO PAULO, São Paulo. Anais... São Paulo, AABMS.

SCARMÍNIO, M. (1988) Diagrafias na investigação geotécnica. Lisboa. Dissertação (mestrado). Universidade de Nova Lisboa. $186 \mathrm{p}$.

SCHMIDT, R. L. (1972) Drillability studies. Percussive drilling in the field. Bureau of Mines Report of Investigations - 7684, $31 \mathrm{p}$.

SERRA Jr., E. (1991) Equipamentos de sondagens rotativas para amostragem de rochas brandas em investigações geológicomgeotécnicas. São Carlos, 102 p. Dissertação (mestrado). Escola de Engenharia de São Carlos, Universidade de São Paulo.

SILVA, F. A. (1995) Os parâmetros e o monitoramento da perfuração: possibilidades de utilização na pesquisa geológico-geotécnica. São Carlos, 126 p. Dissertação (mestrado). Escola de Engenharia de São Carlos, Universidade de São Paulo.

SONDEQ (s.d.) ${ }^{1}$ Equipamentos para sondagem. 56 p., ilust.(Catálogo de Equipamento).

SONDEQ (s.d.) Manual de Instrução - Sonda SS 21 e 31., 20 p., ilust..

STACK, B. (1982) Handbook of mining and tunnelling machinery. Chichester; New York : J. Wiley, 742 p. il.

TAIOLI, F. (1992) Desenvolvimento e testes de sistema sismográfico de alta resolução. São Paulo, 119 p. (Tese de doutoramento, Instituto de Geociências - Universidade de São Paulo).

TAIOLI, F. (1999) Avaliação de propriedades elásticas dinâmicas de materiais geológicos da Região Metropolitana de São Paulo. São Paulo, 87 p. (Tese de livre docência, Instituto de Geociências - Universidade de São Paulo).

TAIOLI, F. et al. (1993) Considerações sobre a utilização de técnicas de investigações indiretas em geologia de engenharia. In: CONG. BRASILEIRO DE GEOL. DE ENGENHARIA, 7, Poços de Caldas, 1993. Anais... São Paulo, Associação Brasileira de Geologia de Engenharia, volume 1, p. 1- 5 .

TAMROCK (1986) Handbook of underground drilling. Jukka Naapuri.(ed.) 327p.

TAMROCK (1988) Surface drilling and blasting. $474 \mathrm{p}$.

TEALE, R. (1965) The concept of specific energy in rock drilling. Int. J.Rock Mech. Min. Sci. \& Geomech. Abstr., v.2, p.57 73. 
TML (s.d.) Civil engineering transducers. Tokyo Sokki Kenkyujo Co. Ltd. (TML Pam E-720) 13 p.(catálogo de equipamentos).

TML (s.d.) ${ }^{2}$ Instruments. Tokyo Sokki Kenkyujo Co. Ltd. (TML Pam E-301) 6 p.(catálogo de equipamentos).

TML (s.d.) Strain Gages. Tokyo Sokki Kenkyujo Co. Ltd.(TML Pam - 101 G) 25 p.(catálogo de equipamentos).

TML (s.d.) $)^{4}$ Transducers. Tokyo Sokki Kenkyujo Co. Ltd. (TML Pam E-701 U) 24p.(catálogo de equipamentos).

TSOUTRELIS, C.E. (1969) Determination of the compressive strength of rock in situ or in test blocks using a diamond drill. Int. J. Rock Mec. Min,. Sci.;Geomech, Abstr. 6:31 1-321.

WEBSTER, J.G.(ed.)(1999) The measurement, instrumentation and sensors handbook, CRC Press/Springer/IEEE Press.

WINKLER, H.G. (1976) Petrogenesis of metamorphic rocks. $4^{\mathrm{a}}$ ed. New York: Springer-Verlag. $334 \mathrm{p}$.

WOLFF, E.A. \& MERCANTI, E.P. (1974) Geoscience instrumentation. John Wiley \& Sons. New York. 819 p. ilustr. 
ANEXO A.1

RESULTADOS DOS TESTES DE PERFURAÇÃO 


\section{LEIA-ME.DOC}

O presente $C D$ apresenta os resultados relativos à tese de doutoramento do aluno Flávio Almeida da Silva, intitulada "PROTÓTIPO PARA O MONITORAMENTO DE SONDAS ROTATIVAS E APLICAÇÃO NA PROSPECÇÃO GEOLÓGICO-GEOTÉCNICA". Os dados referem-se a arquivos gravados pelo protótipo do sistema de aquisição (dados brutos) (arquivos com extensão .txt), planilhas com o tratamento dos dados (arquivos com extensão .xls) e seus respectivos gráficos. O projeto de pesquisa esteve diretamente associado ao Projeto FAPESP - no 96/10005-2, sob a responsabilidade do Prof. Dr. Fábio Taioli.

O dados no CD estão separados inicialmente em duas planilhas, referentes às duas fases de testes do equipamento: $1^{\mathrm{a}}$ Etapa (Testes de Funcionamento) e $2^{\mathrm{a}}$ Etapa (Testes de Campo).

Outra divisão dos dados refere-se ao seu nível de tratamento:

(a) Os dados brutos, ou seja, os arquivos gravados diretamente pelo protótipo do sistema de aquisição não possuem extensão ou possuem extensão .txt.

(b) Os dados tratados, ou seja, os sinais interpretados pelos aparelhos e a respectiva estimativa da energia específica de perfuração (EEP) da manobra, do trecho com ensaio de resistência puntiforme ou do trecho com ensaio de resistência à compressão uniaxial (RCU) estão apresentados nos arquivos com extensão $. x / s$.

O número existente nos arquivos possui a seguinte codificação: (a) os dois primeiros algarismos referem-se à profundidade do topo do trecho perfurado; (b) os dois segundos, os centímetros complementares (p.e. 2145 . - topo do trecho perfurado, iniciado a $21,45 \mathrm{~m}$ ).

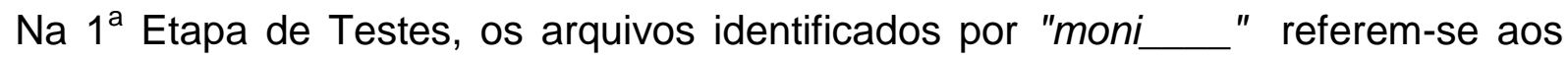
trechos perfurados em solo ou sedimento. Da mesma forma, os identificados por "rock ", referem-se aos trechos perfurados em rocha. 
$\mathrm{Na} 2^{\mathrm{a}}$ Etapa de Testes, os dados são divididos nos quatro furos realizados: Furo Zero, Furo 1, Furo 2 e Furo 3.

O "Furo Zero" refere-se ao furo realizado em rocha, de onde foram retiradas as amostras para os ensaios de resistência à compressão uniaxial (RCU) e respectivas lâminas petrográficas, e ensaios de resistência à compressão puntiforme (Is $(50))$, e onde foram realizadas as perfilagens geofísicas.

O "Furo 1", o "Furo 2" e o "Furo 3" referem-se aos furos em solo/sedimento realizados com as brocas de arraste $\mathrm{Nx}, \mathrm{Hx}$ e ferramenta sem especificação, respectivamente. 
ANEXO A.2

PERFIS INDIVIDUAIS DE SONDAGEM - FUROS

REALIZADOS NAS ÁREAS DOS TESTES DE PERFURAÇÃO 

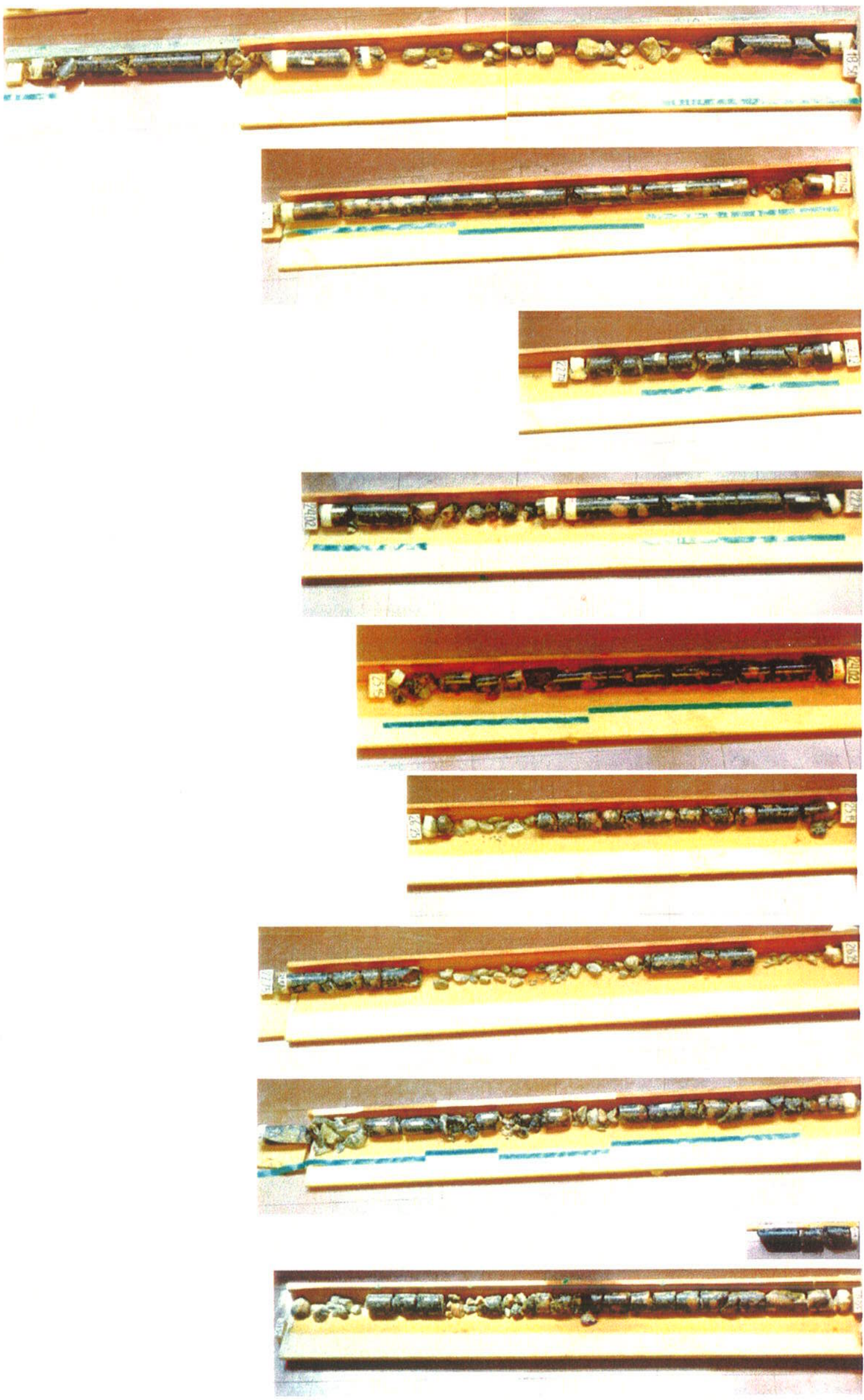

Montagem fotográfica do Furo Zero ( $1^{\mathrm{a}}$ etapa). As faixas verdes representam os trechos monitorados. 
Anexo A2 - Sondagens realizadas nas áreas dos testes de perfuração

\begin{tabular}{|c|c|c|c|}
\hline \multirow{2}{*}{ 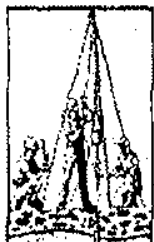 } & \multicolumn{3}{|c|}{ Sondagem a Percussão } \\
\hline & $\begin{array}{l}\text { CLIENTE } \\
\text { OBRA: } \\
\text { LOCNL: }\end{array}$ & $\begin{array}{l}\text { INSTITUTO DE GEOCIENCIAS - USP } \\
\text { RECONHECIMENTO DE SOLO } \\
\text { CIOUDE UNIVERSTTRR SKO PAULO / SP }\end{array}$ & $\begin{array}{l}\text { SP. } 0 \text { I } \\
\text { Inicio: } 13 / 12 / 2000 \\
\text { Fim: } 13 / 12 / 2000 \\
\text { Coto: }\end{array}$ \\
\hline
\end{tabular}

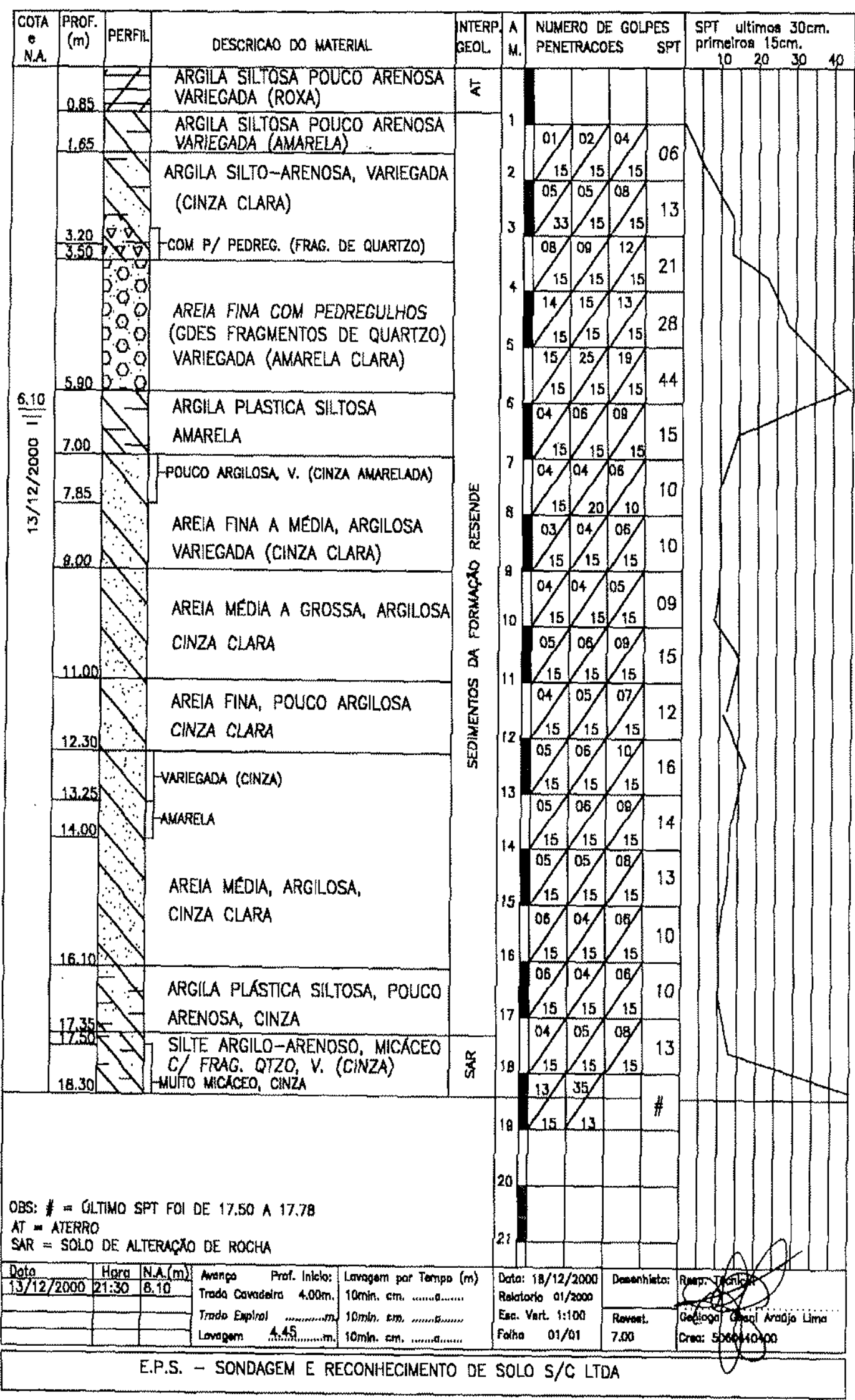


PARÂMETROS DE CLASSIFICAÇÃO

QUADRO A.2.1- Graus de coerência (modificado de GUIDICINI et. al., 1972)

\begin{tabular}{|c|l|l|}
\hline SIGLA & \multicolumn{1}{|c|}{ ROCHA } & \multicolumn{1}{c|}{ CARACTERÍSTICA } \\
\hline C1 & Rocha coerente & $\begin{array}{l}\text { Quebra com dificuldade ao golpe do martelo, produzindo } \\
\text { fragmentos de bordas cortantes. Superfície dificilmente } \\
\text { riscável por lâmina de aço. Somente escavável a fogo. }\end{array}$ \\
\hline C2 & $\begin{array}{l}\text { Rocha medianamente } \\
\text { coerente }\end{array}$ & $\begin{array}{l}\text { Quebra com dificuldade ao golpe do martelo. Superfície } \\
\text { riscável com lâmina de aço. Escavável a fogo. }\end{array}$ \\
\hline C3 & Rocha pouco coerente & $\begin{array}{l}\text { Quebra com facilidade ao golpe do martelo, produzindo } \\
\text { fragmentos que podem ser partidos manualmente. } \\
\text { Superfície facilmente riscável com lâmina de aço. } \\
\text { Escarificável. }\end{array}$ \\
\hline Rocha incoerente & $\begin{array}{l}\text { Quebra com a pressão dos dedos, desagregando-se. } \\
\text { Pode ser cortada com lâmina de aço. Friável e escavável } \\
\text { com lâmina. }\end{array}$ \\
\hline
\end{tabular}

QUADRO A.2.2 - Graus de alteração (IPT, 1984)

\begin{tabular}{|l|c|l|}
\hline \multicolumn{1}{|c|}{ GRAU DE ALTERAÇÃo } & SIGLA & \multicolumn{1}{|c|}{ CARACTERISTICAS DA ROCHA } \\
\hline Rocha são ou praticamente sã & A1 & $\begin{array}{l}\text { Apresenta minerais primários sem vestígio de alteração ou } \\
\text { com alterações física químicas incipientes. Nesse caso, a } \\
\text { rocha é ligeiramente descolorida. }\end{array}$ \\
\hline Rocha medianamente alterada & A2 & $\begin{array}{l}\text { Apresenta minerais medianamente alterados e a rocha é } \\
\text { bastante descolorida }\end{array}$ \\
\hline Rocha muito alterada & A3 & $\begin{array}{l}\text { Apresenta minerais muito alterados, por vezes } \\
\text { pulverulentos e friáveis. }\end{array}$ \\
\hline Rocha extremamente alterada & A4 & $\begin{array}{l}\text { Apresenta minerais totalmente alterados e a rocha é } \\
\text { intensamente descolorida, gradando para as cores do solo }\end{array}$ \\
\hline
\end{tabular}

QUADRO A.2.1 - Grau de fraturamento (IPT, 1984).

\begin{tabular}{|c|c|c|}
\hline GRAU DE FRATURAMENTO & SímBOLO & $\begin{array}{c}\text { No DE FRATURAS POR } \\
\text { METRO }\end{array}$ \\
\hline Ocasionalmente Fraturado & F1 & $<1$ \\
\hline Pouco Fraturado & F2 & $1-5$ \\
\hline Medianamente Fraturado & F3 & $6-10$ \\
\hline Muito Fraturado & F4 & $11-20$ \\
\hline Extremamente Fraturado & F5 & .20 \\
\hline
\end{tabular}




\section{ANEXO A.3}

ENSAIOS DE MECÂNICA DAS ROCHAS 
O anexo "Ensaios de Mecânica das Rochas" apresenta na forma de tabelas os resultados obtidos nos ensaios de mecânica das rochas (Quadros A.3.1 a A.3.4). Os ensaios laboratoriais referem-se a: (a) determinação dos índices físicos (massa específica, porosidade e absorção de água aparentes, segundo a NBR 12.766 (ABNT, 1992a), (b) resistência puntiforme $\left(\operatorname{Is}_{(50)}\right)$ axial ao testemunho de sondagem (compressão subparalela à xistosidade/bandamento do gnaisse) e resistência à compressão puntiforme em fragmentos (compressão perpendicular à xistosidade/acamamento da rocha, segundo orientações de ISRM, 1985) e (c) resistência à compressão uniaxial (RCU) nos testemunhos de sondagem (compressão subparalela à xistosidade/bandamento do gnaisse, segundo a NBR-12.767 (ABNT, 1992b).

Esses ensaios foram executados na tentativa de obter correlações significativas com os resultados do monitoramento da perfuração, especificamente com a Energia Específica de Perfuração (EEP).

Apesar dos resultados apresentarem as tendências esperadas (Capítulo 6), ou seja, crescente para "EEP $x$ Resistência à Compressão" e decrescente para as correlações "EPP $x$ Porosidade/Absorção de Água Aparentes", as correlações observadas foram muito baixas ( ${ }^{2}$ de 0.15 a 0.17 para a resistência puntiforme e 0.11 para compressão uniaxial).

Observou-se que o grau de alteração das descontinuidades influenciava os resultados dos ensaios. Para a interpretação dos resultados dos ensaios de resistência à compressão uniaxial (RCU), propôs-se um modelo de classificação baseado na "qualidade da ruptura" e nas feições de alteração observadas nas amostras após o ensaio (Figura A.3.1). Na descrição macroscópica anterior à ruptura, não foram observadas diferenças nas feições de alteração das amostras.

\begin{tabular}{|c|c|c|c|c|}
\hline $\begin{array}{l}\text { Geometria e alteração } \\
\text { nas descontinuidades }\end{array}$ & $\Rightarrow$ & $\begin{array}{l}\text { Qualidade đa } \\
\text { ruptura }\end{array}$ & $\Rightarrow$ & $\begin{array}{l}\text { Relação dos resultados } \\
\text { com o valor máximo de } \\
\text { resistência da matriz }\end{array}$ \\
\hline
\end{tabular}

Figura A.3.1 - Relação entre as condições das descontinuidade e a resistência da rocha nos ensaios.

Para as classificações da "qualidade da ruptura" e da "alteração nas descontinuidades (AD) dos corpos-de-prova" consideram-se as descrições apresentadas nas figuras A.3.2 e A.3.3, respectivamente.

Esse modelo permitiu a separação das amostras em dois grupos (Figura A.3.4):

- Grupo A - amostras com melhor qualidade de ruptura (descontinuidades menos alteradas)

- Grupo B - amostras com menor qualidade de ruptura (descontinuidades mais alteradas)

As correlações EEP x RCU aumentaram de maneira significativa, analisando-se os resultados separadamente em cada grupo: $R^{2}=1,00$ e $R^{2}=0,99$, respectivamente. 
Anexo A3 - Ensaios de Mecânica de Rochas

Quadro A.3.1 - Indices físicos das amostras dos Ensaios de Resistência Puntiforme - $\left.\right|_{(50)}$

\begin{tabular}{|c|c|c|c|c|c|c|}
\hline \multirow[t]{2}{*}{ Amostra } & \multicolumn{2}{|c|}{ Posição no furo } & \multirow{2}{*}{$\begin{array}{c}\text { M. Esp. Ap. } \\
\text { Seca }\left(\mathrm{kg} / \mathrm{m}^{3}\right)\end{array}$} & \multirow{2}{*}{$\begin{array}{c}\text { M. Esp. Ap. } \\
\text { Satur. }\left(\mathrm{kg} / \mathrm{m}^{3}\right)\end{array}$} & \multirow{2}{*}{$\begin{array}{l}\text { Porosidade } \\
\text { Aparente (\%) }\end{array}$} & \multirow{2}{*}{$\begin{array}{l}\text { Absorção } \\
\text { Água (\%) }\end{array}$} \\
\hline & Trecho & $(m)$ & & & & \\
\hline P1A & 18,66 & 18,71 & 2647 & 2658 & 1,09 & 0,41 \\
\hline $\mathrm{P} 2 \mathrm{~A}$ & 20,89 & 20,94 & 2706 & 2721 & 1,59 & 0,59 \\
\hline P3A & 21,54 & 21,60 & 2714 & 2720 & 0,60 & 0,22 \\
\hline P4A & 21,60 & 21,66 & 2720 & 2726 & 0,55 & 0,20 \\
\hline P5A & 21,87 & 21,92 & 2690 & 2704 & 1,40 & 0,52 \\
\hline P6A & 22,14 & 22,19 & 2723 & 2729 & 0,62 & 0,23 \\
\hline P7A & 22,35 & 22,41 & 2712 & 2721 & 0,86 & 0,32 \\
\hline P8A & 22,83 & 22,88 & 2704 & 2709 & 0,46 & 0,17 \\
\hline P9A & 22,94 & 22,99 & 2736 & 2746 & 0,96 & 0,35 \\
\hline P10A & 23,85 & 23,90 & 2690 & 2703 & 1,35 & 0,50 \\
\hline P11A & 24,14 & 24,19 & 2667 & 2676 & 0,92 & 0,35 \\
\hline P12A & 24,22 & 24,27 & 2676 & 2686 & 0,96 & 0,36 \\
\hline P13A & 24,37 & 24,42 & 2725 & 2741 & 1,62 & 0,60 \\
\hline $\mathrm{P} 14 \mathrm{~A}$ & 24,49 & 24,54 & 2717 & 2728 & 1,07 & 0,39 \\
\hline P15A & 24,56 & 24,61 & 2724 & 2731 & 0,72 & 0,26 \\
\hline $\mathrm{P} 16 \mathrm{~A}$ & 24,61 & 24,66 & 2696 & 2704 & 0,74 & 0,28 \\
\hline P17A & 24,78 & 24,83 & 2656 & 2671 & 1,57 & 0,59 \\
\hline P18A & 24,91 & 24,96 & 2671 & 2679 & 0,84 & 0,31 \\
\hline P19A & 28,14 & 28,20 & 2685 & 2697 & 1,21 & 0,45 \\
\hline P20A & 28,37 & 28,42 & 2724 & 2732 & 0,80 & 0,29 \\
\hline P21A & 28,87 & 28,92 & 2696 & 2709 & 1,34 & 0,50 \\
\hline$P 22 A$ & 30,24 & 30,29 & 2706 & 2711 & 0,54 & 0,20 \\
\hline P23A & 30,40 & 30,46 & 2724 & 2728 & 0,44 & 0,16 \\
\hline P24A & 30,58 & 30,64 & 2715 & 2719 & 0,40 & 0,15 \\
\hline P25A & 31,10 & 31,15 & 2722 & 2733 & 1,12 & 0,41 \\
\hline \multirow[t]{4}{*}{ P26A } & 31,27 & 31,32 & 2685 & 2694 & 0,95 & 0,35 \\
\hline & & Média: & 2701 & 2711 & 0,95 & 0,35 \\
\hline & \multicolumn{2}{|c|}{ Desvio Padrão: } & 24 & 23 & 0,37 & 0,14 \\
\hline & \multicolumn{2}{|c|}{ Coeficiente Variação (\%): } & 0,88 & 0,84 & 38,82 & 39,05 \\
\hline
\end{tabular}


Anexo A3 - Ensaios de Mecanica de Rochas

Quadro A .3.2 - Cálculo dos valores de Resistência à Compressão Puntiforme Axial - $\mid \mathbf{s}_{(50)}$.

\begin{tabular}{|c|c|c|c|c|c|c|c|c|}
\hline Amostra & $\begin{array}{c}D \\
(\mathrm{~cm})\end{array}$ & $\begin{array}{c}W \\
(\mathrm{~cm})\end{array}$ & $\begin{array}{l}\text { Área } \\
\left(\mathrm{cm}^{2}\right)\end{array}$ & $\begin{array}{c}\mathrm{De} \\
(\mathrm{mm})\end{array}$ & $\begin{array}{c}\text { Carga } \\
\text { (kgf) }\end{array}$ & $\begin{array}{c}\text { Is } \\
(\mathrm{MPa})\end{array}$ & F & $\begin{array}{c}\mid \mathbf{s}_{(50)} \\
(\mathrm{MPa})\end{array}$ \\
\hline$P 1 A$ & 4,8 & 5,4 & 25,9 & 57,45 & 650 & 1,93 & 1,06 & 2,06 \\
\hline$P 2 A$ & 5,0 & 5,4 & 27,0 & 58,63 & 495 & 1,41 & 1,07 & - \\
\hline P3A & 5,1 & 5,4 & 27,5 & 59,22 & 730 & 2,04 & 1,08 & 2,20 \\
\hline $\mathrm{P} 4 \mathrm{~A}$ & 4,8 & 5,4 & 25,9 & 57,45 & 890 & 2,64 & 1,06 & 2,81 \\
\hline P5A & 5,2 & 5,4 & 28,1 & 59,79 & 160 & 0,44 & 1,08 & 0,48 \\
\hline P6A & 4,7 & 5,4 & 25,4 & 56,85 & 1460 & 4,43 & 1,06 & 4,69 \\
\hline P7A & 5,0 & 5,4 & 27,0 & 58,63 & 340 & 0,97 & 1,07 & 1,04 \\
\hline P8A & 5,0 & 5,4 & 27,0 & 58,63 & 1670 & 4,76 & 1,07 & 5,12 \\
\hline P9A & 4,8 & 5,4 & 25,9 & 57,45 & 1100 & 3,27 & 1,06 & 3,48 \\
\hline P10A & 3,6 & 5,4 & 19,4 & 49,75 & 850 & 3,37 & 1,00 & 3,36 \\
\hline P11A & 5,0 & 5,4 & 27,0 & 58,63 & 720 & 2,05 & 1,07 & - \\
\hline$P 12 A$ & 4,7 & 5,4 & 25,4 & 56,85 & 260 & 0,79 & 1,06 & 0,84 \\
\hline P13A & 4,8 & 5,4 & 25,9 & 57,45 & 100 & 0,30 & 1,06 & 0,32 \\
\hline P14A & 4,8 & 5,4 & 25,9 & 57,45 & 1220 & 3,62 & 1,06 & 3,86 \\
\hline P15A & 4,6 & 5,4 & 24,8 & 56,24 & 1655 & 5,13 & 1,05 & 5,41 \\
\hline $\mathrm{P} 16 \mathrm{~A}$ & 4,8 & 5,4 & 25,9 & 57,45 & 1260 & 3,74 & 1,06 & 3,98 \\
\hline P17A & 4,1 & 5,4 & 22,1 & 53,09 & 835 & 2,90 & 1,03 & 2,98 \\
\hline P18A & 4,9 & 5,4 & 26,5 & 58,04 & 1330 & 3,87 & 1,07 & 4,14 \\
\hline P19A & 4,5 & 5,4 & 24,30 & 55,62 & 660 & 2,09 & 1,05 & 2,19 \\
\hline $\mathrm{P} 20 \mathrm{~A}$ & 4,7 & 5,4 & 25,38 & 56,85 & 815 & 2,47 & 1,06 & 2,62 \\
\hline$P 21 A$ & 4,1 & 5,4 & 22,14 & 53,09 & 360 & 1,25 & 1,03 & 1,29 \\
\hline$P 22 A$ & 4,3 & 5,4 & 23,22 & 54,37 & 1090 & 3,61 & 1,04 & 3,75 \\
\hline P23A & 4,4 & 5,4 & 23,76 & 55,00 & 1230 & 3,99 & 1,04 & 4,16 \\
\hline $\mathrm{P} 24 \mathrm{~A}$ & 4,3 & 5,4 & 23,22 & 54,37 & 1030 & 3,42 & 1,04 & 3,55 \\
\hline $\mathrm{P} 25 \mathrm{~A}$ & 4,3 & 5,4 & 23,22 & 54,37 & 330 & 1,09 & 1,04 & 1,14 \\
\hline P26A & 4,0 & 5,4 & 21,60 & 52,44 & 700 & 2,50 & 1,02 & 2,55 \\
\hline
\end{tabular}


Quadro A.3.3 - Cálculo dos valores de Resistência à Compressão Puntiforme em fragmentos (perpendicular à xistosidade/bandamento do gnaisse) - Is (50).

\begin{tabular}{|c|c|c|c|c|c|c|c|c|c|c|}
\hline Amostra & $\begin{array}{c}D \\
(\mathrm{~mm}) \\
\end{array}$ & $\begin{array}{c}\mathrm{W1} \\
(\mathrm{mm})\end{array}$ & $\begin{array}{c}\begin{array}{c}\mathrm{W} 2 \\
(\mathrm{~mm})\end{array} \\
\end{array}$ & $\begin{array}{c}\mathrm{W} \\
(\mathrm{mm})\end{array}$ & $\begin{array}{c}\text { Área } \\
\left(\mathrm{mm}^{2}\right) \\
\end{array}$ & $\begin{array}{c}\mathrm{De} \\
(\mathrm{cm})\end{array}$ & $\begin{array}{c}\text { Carga } \\
\text { (kgf) }\end{array}$ & $\begin{array}{c}\text { Is } \\
(\mathrm{MPa})\end{array}$ & $\bar{F}$ & $\begin{array}{l}\text { Is(50) } \\
\text { (MPa) }\end{array}$ \\
\hline $\mathrm{P} 1 \mathrm{D} / 1$ & 15,75 & 21,20 & 21,60 & 21,40 & 337,05 & 2,07 & 220 & 5,03 & 0,24 & 1,20 \\
\hline $\mathrm{P} 1 \mathrm{D} / 2$ & 16,35 & 23,75 & 23,60 & 23,68 & 387,09 & 2,22 & 490 & 9,75 & 0,25 & 2,40 \\
\hline $\mathrm{P} 2 \mathrm{D} / 1$ & 20,95 & 25,60 & 27,60 & 26,60 & 557,27 & 2,66 & 250 & 3,45 & 0,27 & 0,92 \\
\hline $\mathrm{P} 6 \mathrm{D} / 1$ & 18,75 & 20,95 & 22,40 & 21,68 & 406,41 & 2,27 & 430 & 8,15 & 0,25 & 2,03 \\
\hline $\mathrm{P} 6 \mathrm{D} / 2$ & 17,35 & 21,30 & 20,45 & 20,88 & 362,18 & 2,15 & 730 & 15,52 & 0,24 & 3,76 \\
\hline P7D/1 & 18,50 & 22,90 & 23,10 & 23,00 & 425,50 & 2,33 & 610 & 11,04 & 0,25 & 2,78 \\
\hline $\mathrm{P} 7 \mathrm{D} / 2$ & 17,50 & 22,30 & 22,60 & 22,45 & 392,88 & 2,24 & 480 & 9,41 & 0,25 & 2,32 \\
\hline P8D/1 & 18,60 & 22,45 & 24,00 & 23,23 & 431,99 & 2,35 & 630 & 11,23 & 0,25 & 2,83 \\
\hline P8D/2 & 18,00 & 23,30 & 23,45 & 23,38 & 420,75 & 2,31 & 780 & 14,27 & 0,25 & 3,58 \\
\hline PQD/1 & 23,00 & 23,80 & 23,00 & 23,40 & 538,20 & 2,62 & 620 & 8,87 & 0,27 & 2,35 \\
\hline $\mathrm{P9D} / 2$ & 18,60 & 21,10 & 20,75 & 20,93 & 389,21 & 2,23 & 490 & 9,69 & 0,25 & 2,39 \\
\hline $\mathrm{P} 10 \mathrm{D} / 1$ & 18,20 & - & - & - & - & - & - & - & - & - \\
\hline $\mathrm{P} 12 \mathrm{D} / 1$ & 18,85 & 21,75 & 21,95 & 21,85 & 411,87 & 2,29 & 650 & 12,15 & 0,25 & 3,03 \\
\hline $\mathrm{P} 12 \mathrm{D} / 2$ & 17,10 & 21,60 & 21,35 & 21,48 & 367,22 & 2,16 & 580 & 12,15 & 0,24 & 2,96 \\
\hline $\mathrm{P13D} / 1$ & 19,00 & 22,40 & 21,90 & 22,15 & 420,85 & 2,31 & 400 & 7,32 & 0,25 & 1,84 \\
\hline $\mathrm{P} 13 \mathrm{D} / 2$ & 20,00 & 22,15 & 22,30 & 22,23 & 444,50 & 2,38 & 740 & 12,82 & 0,25 & 3,26 \\
\hline $\mathrm{P} 14 \mathrm{D} / 1$ & 15,00 & 22,20 & 21,80 & 22,00 & 330,00 & 2,05 & 505 & 11,78 & 0,24 & 2,80 \\
\hline $\mathrm{P} 14 \mathrm{D} / 2$ & 16,95 & 21,20 & 22,95 & 22,08 & 374,17 & 2,18 & 510 & 10,50 & 0,24 & 2,56 \\
\hline $\mathrm{P} 15 \mathrm{D} / 1$ & 18,40 & 21,60 & 20,00 & 20,80 & 382,72 & 2,21 & 560 & 11,27 & 0,25 & 2,77 \\
\hline $\mathrm{P} 15 \mathrm{D} / 2$ & 19,15 & 20,25 & 21,10 & 20,68 & 395,93 & 2,25 & 690 & 13,42 & 0,25 & 3,32 \\
\hline $\mathrm{P} 16 \mathrm{D} / 1$ & 18,60 & 22,25 & 22,65 & 22,45 & 417,57 & 2,31 & 505 & 9,31 & 0,25 & 2,33 \\
\hline $\mathrm{P} 16 \mathrm{D} / 2$ & 17,40 & 21,60 & 22,70 & 22,15 & 385,41 & 2,22 & 540 & 10,79 & 0,25 & 2,65 \\
\hline P17D/1 & 18,00 & 22,30 & 19,50 & 20,90 & 376,20 & 2,19 & 425 & 8,70 & 0,24 & 2,13 \\
\hline
\end{tabular}


(Continuação do Quadro A.3.3)

\begin{tabular}{|c|c|c|c|c|c|c|c|c|c|c|}
\hline Amostra & $\begin{array}{c}\mathrm{D} \\
(\mathrm{mm}) \\
\end{array}$ & $\begin{array}{c}\text { W1 } \\
(\mathrm{mm})\end{array}$ & $\begin{array}{c}\begin{array}{c}\mathrm{W} 2 \\
(\mathrm{~mm})\end{array} \\
\end{array}$ & $\begin{array}{c}W \\
(\mathrm{~mm})\end{array}$ & $\begin{array}{c}\text { Área } \\
\left(\mathrm{mm}^{2}\right)\end{array}$ & $\begin{array}{c}\mathrm{De} \\
(\mathrm{cm})\end{array}$ & $\begin{array}{c}\text { Carga } \\
\text { (kgf) }\end{array}$ & $\begin{array}{c}\text { Is } \\
(\mathrm{MPa})\end{array}$ & $F$ & $\begin{array}{c}1 \mathrm{Is}_{(50)} \\
(\mathrm{MPa}) \\
\end{array}$ \\
\hline $\mathrm{P} 17 \mathrm{D} / 2$ & - & - & - & - & - & - & - & - & - & - \\
\hline P18D/1 & 15,05 & 21,20 & 21,10 & 21,15 & 318,31 & 2,01 & 460 & 11,13 & 0,24 & 2,62 \\
\hline $\mathrm{P} 18 \mathrm{D} / 2$ & 18,60 & 23,60 & 24,50 & 24,05 & 447,33 & 2,39 & 410 & 7,06 & 0,25 & 1,80 \\
\hline $\mathrm{P} 19 \mathrm{D} / 1$ & 16,00 & 20,20 & 19,75 & 19,98 & 319,60 & 2,02 & 510 & 12,29 & 0,24 & 2,90 \\
\hline $\mathrm{P} 20 \mathrm{D} / 1$ & 17,80 & 19,60 & 19,40 & 19,50 & 347,10 & 2,10 & 535 & 11,87 & 0,24 & 2,85 \\
\hline $\mathrm{P} 20 \mathrm{D} / 2$ & 17,80 & 24,35 & 25,00 & 24,68 & 439,22 & 2,36 & 530 & 8,29 & 0,25 & 2,35 \\
\hline $\mathrm{P} 21 \mathrm{D} / 1$ & - & - & - & - & - & - & - & - & - & - \\
\hline $\mathrm{P} 21 \mathrm{D} / 2$ & 18,40 & 19,85 & 20,75 & 20,30 & 373,52 & 2,18 & 490 & 10,10 & 0,24 & 2,47 \\
\hline P22D/1 & 15,00 & 19,10 & 19,90 & 19,50 & 292,50 & 1,93 & 445 & 11,71 & 0,23 & 2,71 \\
\hline $\mathrm{P} 22 \mathrm{D} / 2$ & 16,55 & 20,00 & 20,45 & 20,23 & 334,72 & 2,06 & 525 & 12,08 & 0,24 & 2,88 \\
\hline $\mathrm{P} 23 \mathrm{D} / 1$ & 17,30 & 19,40 & 18,95 & 19,18 & 331,73 & 2,06 & 475 & 11,03 & 0,24 & 2,62 \\
\hline $\mathrm{P} 23 \mathrm{D} / 2$ & 17,65 & 21,15 & 21,60 & 21,38 & 377,27 & 2,19 & 520 & 10,61 & 0,24 & 2,60 \\
\hline $\mathrm{P} 24 \mathrm{D} / 1$ & 19,45 & 20,25 & 20,20 & 20,23 & 393,38 & 2,24 & 390 & 7,63 & 0,25 & 1,89 \\
\hline $\mathrm{P} 24 \mathrm{D} / 2$ & 17,70 & 19,55 & 19,45 & 19,50 & 345,15 & 2,10 & 300 & 6,69 & 0,24 & 1,61 \\
\hline $\mathrm{P} 25 \mathrm{D} / 1$ & 17,25 & 21,05 & 21,85 & 21,45 & 370,01 & 2,17 & 405 & 8,43 & 0,24 & 2,05 \\
\hline $\mathrm{P} 25 \mathrm{D} / 2$ & 16,90 & 17,90 & 17,80 & 17,85 & 301,67 & 1,96 & 290 & 7,40 & 0,23 & 1,72 \\
\hline $\mathrm{P} 26 \mathrm{D} / 1$ & 15,00 & 18,25 & 17,40 & 17,83 & 267,38 & 1,85 & 290 & 8,35 & 0,23 & 1,89 \\
\hline PA1D & 17,10 & 18,90 & 27,05 & 22,98 & 392,87 & 2,24 & 20 & 0,39 & 0,25 & 0,10 \\
\hline PA2D & 17,50 & 25,95 & 28,40 & 27,18 & 475,56 & 2,46 & 5 & 0,08 & 0,26 & 0,02 \\
\hline PA3D & 19,00 & 22,90 & 21,60 & 22,25 & 422,75 & 2,32 & 40 & 0,73 & 0,25 & 0,18 \\
\hline PA4D & 15,95 & 25,70 & 27,70 & 26,70 & 425,87 & 2,33 & 110 & 1,99 & 0,25 & 0,50 \\
\hline
\end{tabular}


Quadro A.3.4 - Ensaios de Resistência à Compressão Uniaxial (RCU), indices físicos, velocidade de propagação de ondas ultra-sônicas e resistência à compressão uniaxial.

\begin{tabular}{|c|c|c|c|c|c|c|c|c|}
\hline \multirow{2}{*}{ Amostra } & \multicolumn{2}{|c|}{ Posição no furo } & \multirow{2}{*}{$\begin{array}{c}\text { Massa Esp.Ap. } \\
\text { Seca }\left(\mathrm{kg} / \mathrm{m}^{3}\right)\end{array}$} & \multirow{2}{*}{$\begin{array}{l}\text { Massa Esp.Ap. } \\
\text { Saturada }\left(\mathrm{kg} / \mathrm{m}^{3}\right)\end{array}$} & \multirow{2}{*}{$\begin{array}{c}\text { Porosidade } \\
\text { Aparente (\%) }\end{array}$} & \multirow{2}{*}{$\begin{array}{c}\text { Absorção de } \\
\text { Água (\%) }\end{array}$} & \multirow{2}{*}{$\begin{array}{c}\text { Emissão } \\
\text { Acústica }(\mathrm{m} / \mathrm{s})\end{array}$} & \multirow{2}{*}{$\begin{array}{l}\mathrm{RCU} \\
(\mathrm{MPa}) \\
\end{array}$} \\
\hline & Trecho & $(m)$ & & & & & & \\
\hline RCU-1 & 20,96 & 21,10 & 2670 & 2676 & 0,61 & 0,23 & 5420 & 83,38 \\
\hline $\mathrm{RCU}-2$ & 21,17 & 21,30 & 2673 & 2679 & 0,55 & 0,21 & 5340 & 69,20 \\
\hline RCU-3 & 21,34 & 21,47 & 2703 & 2708 & 0,58 & 0,22 & 5310 & 62,77 \\
\hline RCU-4 & 21,71 & 21,84 & 2702 & 2712 & 0,94 & 0,35 & 5020 & 43,97 \\
\hline RCU-5 & 21,96 & 22,09 & 2728 & 2731 & 0,36 & 0,13 & 5560 & 90,89 \\
\hline RCU-6 & 23,00 & 23,14 & 2749 & 2760 & 1,05 & 0,38 & 5210 & 26,13 \\
\hline RCU-7 & 23,20 & 23,33 & 2719 & 2724 & 0,56 & 0,20 & 5400 & 64,85 \\
\hline & & Média: & 2706 & 2713 & 0,66 & 0,24 & 5323 & 63,03 \\
\hline \multicolumn{3}{|c|}{ Desvio Padrão: } & 29 & 29 & 0,24 & 0,09 & 172 & 22,20 \\
\hline \multicolumn{3}{|c|}{$\begin{array}{r}\text { Coeficiente Variação } \\
(\%):\end{array}$} & 1,05 & 1,08 & 36,38 & 35,80 & 3,23 & 35,22 \\
\hline
\end{tabular}




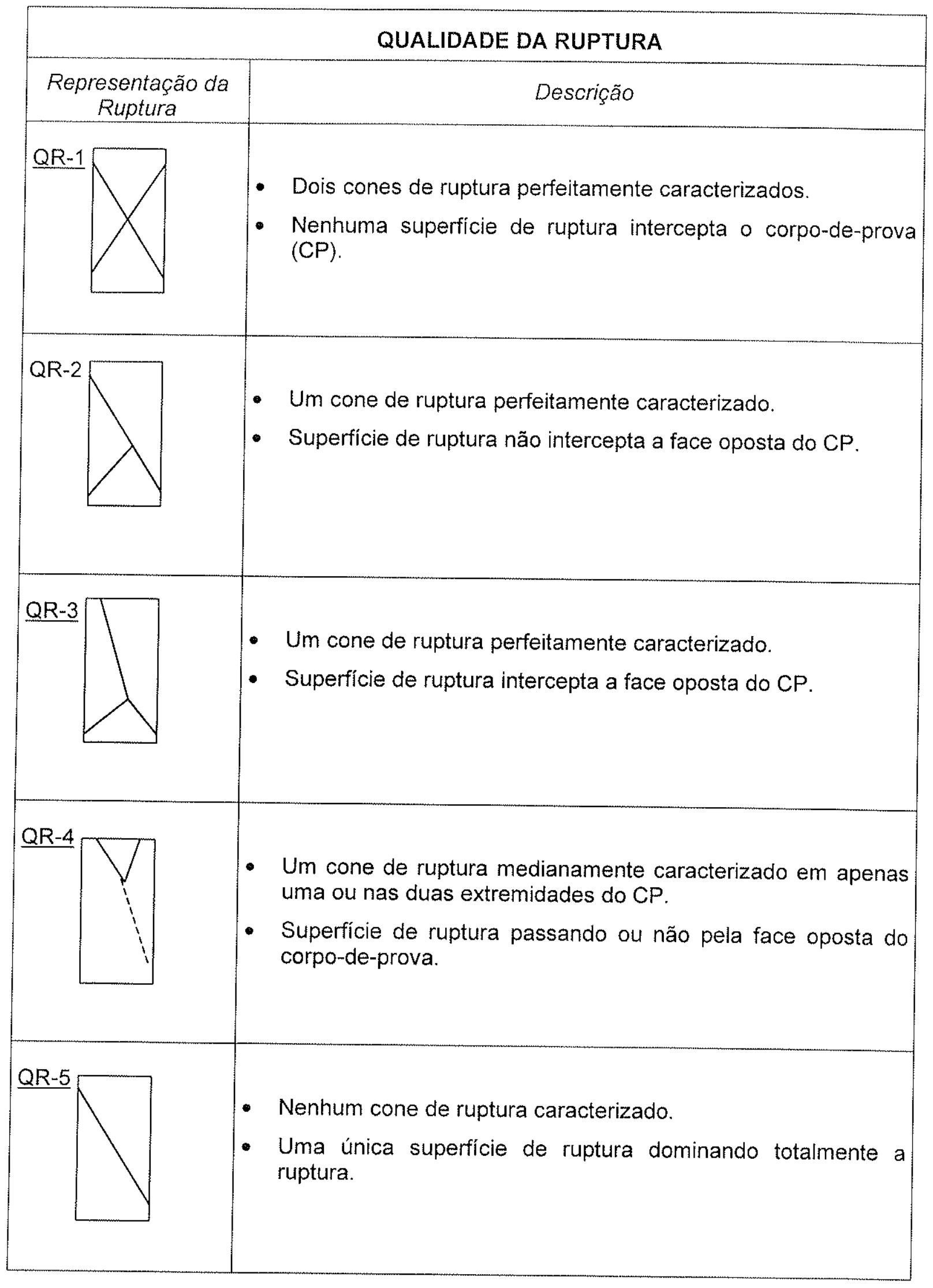

Figura A.3.2 - Qualidade da ruptura das amostras RCU 


\section{ALTERACÃO NA SUPERFICIE DE RUPTURA (SR) DOS CORPOS-DE-PROVA}

- AD-1 Sem alteração: quando as superficies de ruptura encontram-se praticamente limpas, sem indicios de materiais oxidados;

- AD-2 Alteração fraca: quando a alteração é perceptivel através de uma fina camada de material oxidado, cor amarela ou marrom claro, sendo ainda pouco representativa, considerando-se as superfícies de ruptura;

- AD-3 Alterada: quando a alteração é muito perceptivel (material oxidado amarelo ou marrom claro) e ainda muito representativa, considerando as superficies de ruptura;

- MD-4 Muito alterada: quando a alteração é observada através da presença de material oxidado (amarelo e marrom claro) em praticamente toda(s) a(s) superficie(s) de ruptura. A "espessura" submilimétrica dessa camada chega a ser observada em alguns pontos.

Figura A.3.3 - Condições de alteração das superficies de ruptura (Ensaio de RCU).

Segundo o modelo proposto, as classificações das amostras RCU-1 a RCU-7 são apresentadas com as respectivas fotografias dos corpos de prova rompidos, a seguir: 


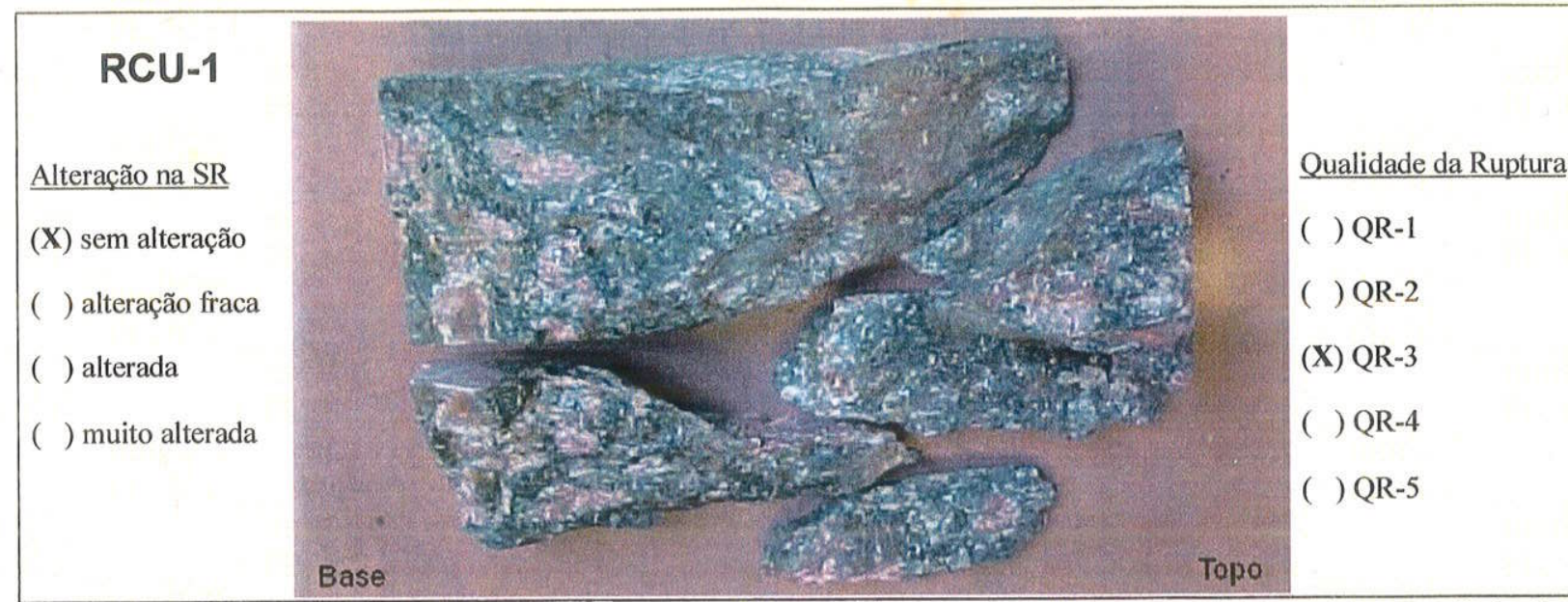

Descrição da Ruptura - Cone de ruptura bem caracterizado no topo. Na base do CP a superfície de ruptura intercepta a base aproximadamente na região central. Superfície de ruptura com alteração incipiente.

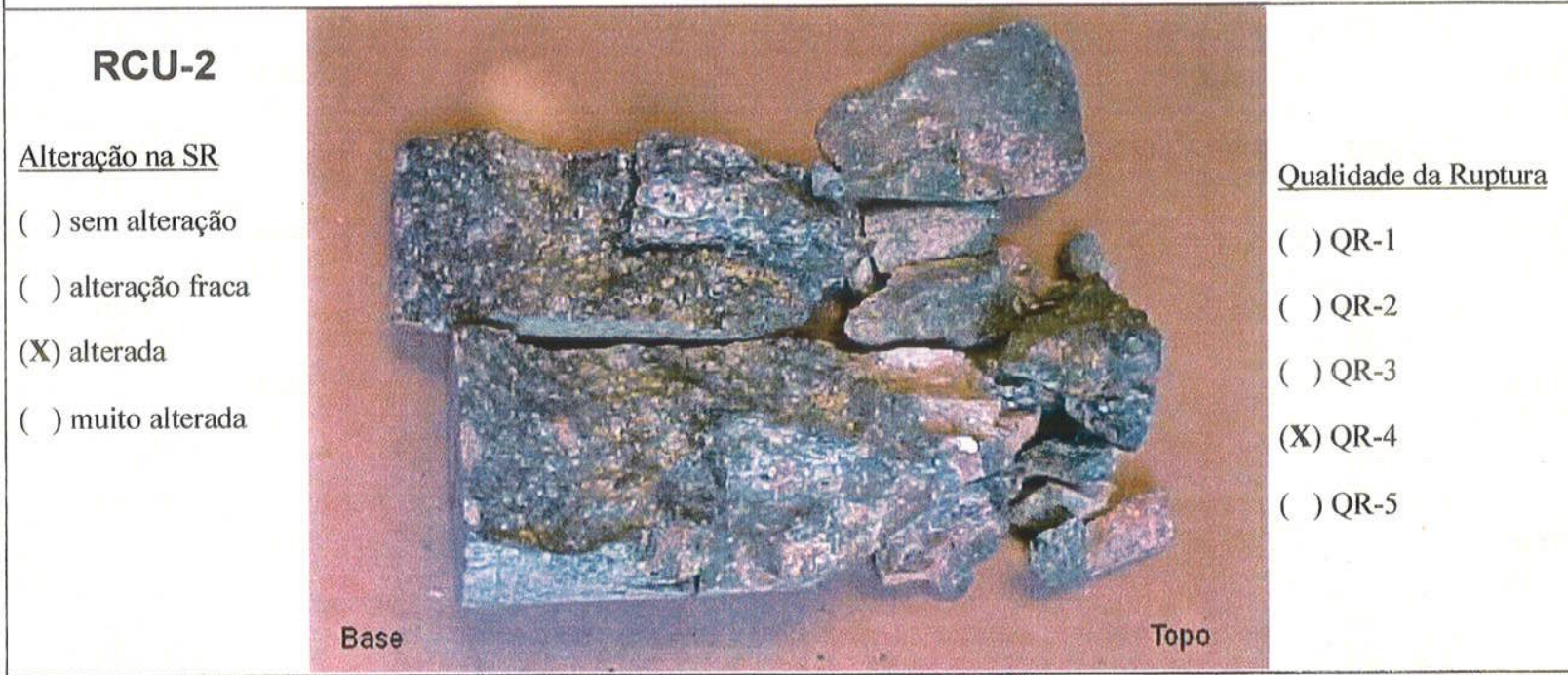

Descrição da Ruptura - Cone de ruptura medianamente caracterizado no topo da amostra. Na base do CP a superfície de ruptura intercepta a base aproximadamente na região central. Superfície de ruptura com alteração incipiente.

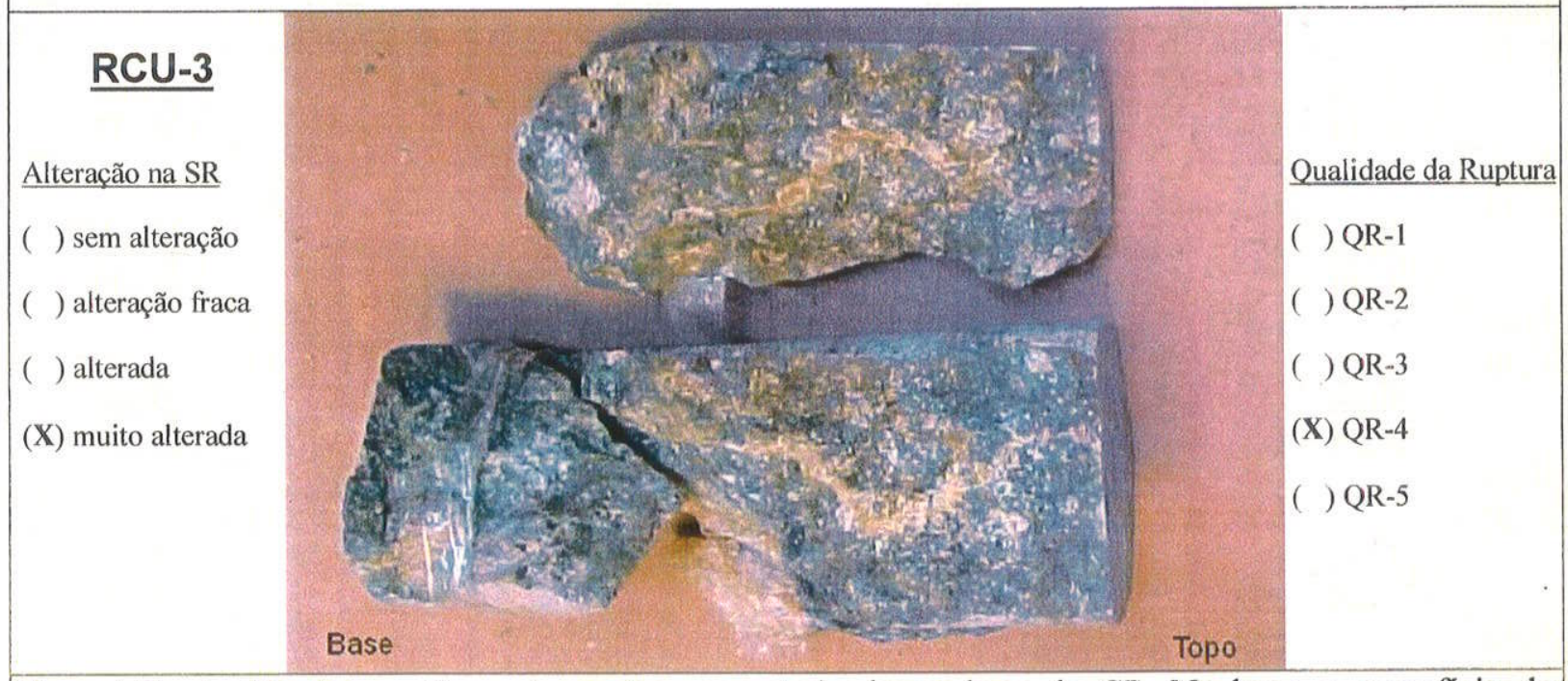

Descrição da Ruptura - Cone de ruptura caracterizado na base do CP. Na base, a superfície de ruptura intercepta a base do cone. Superfície de ruptura bastante alterada. 


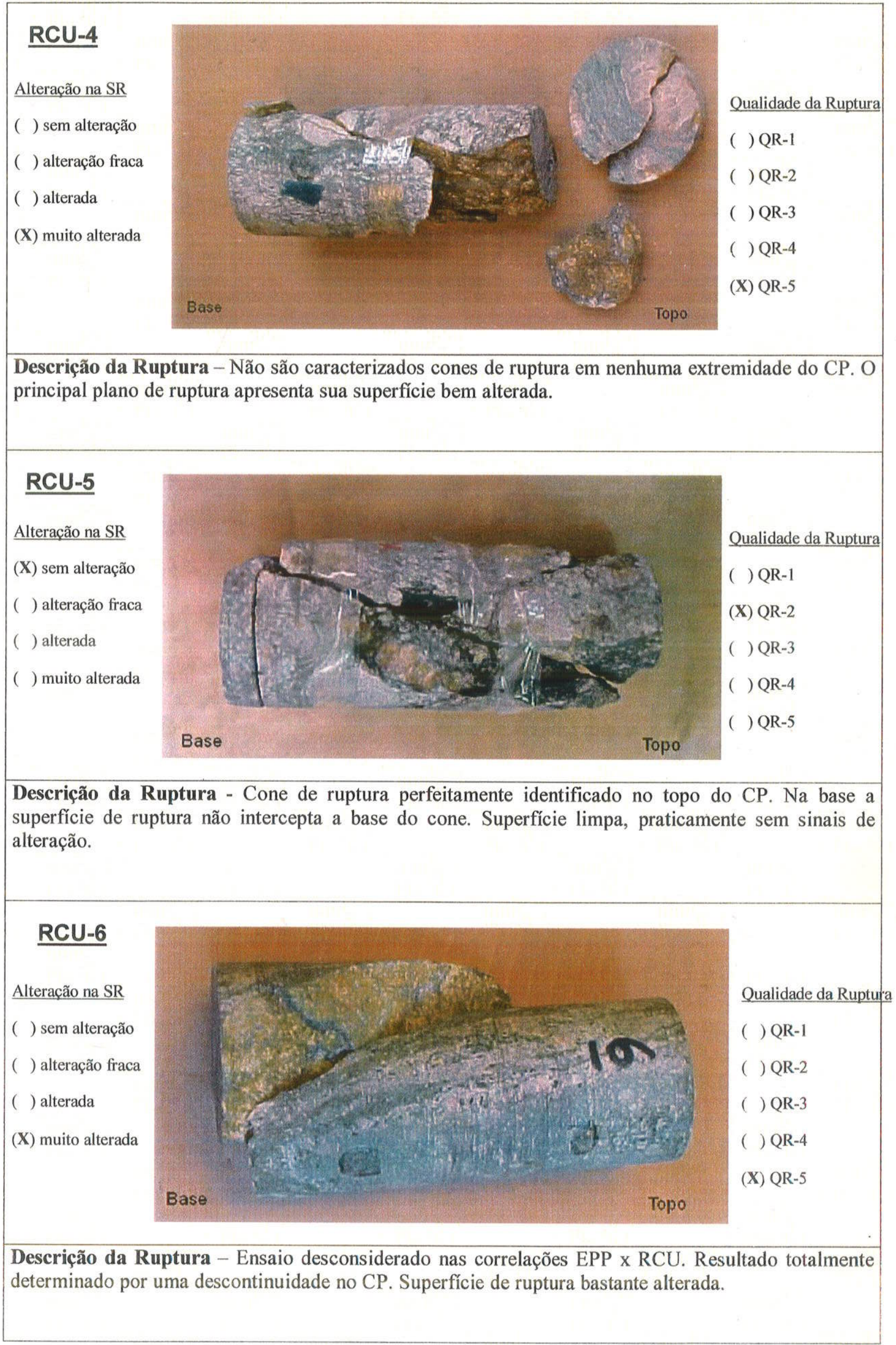




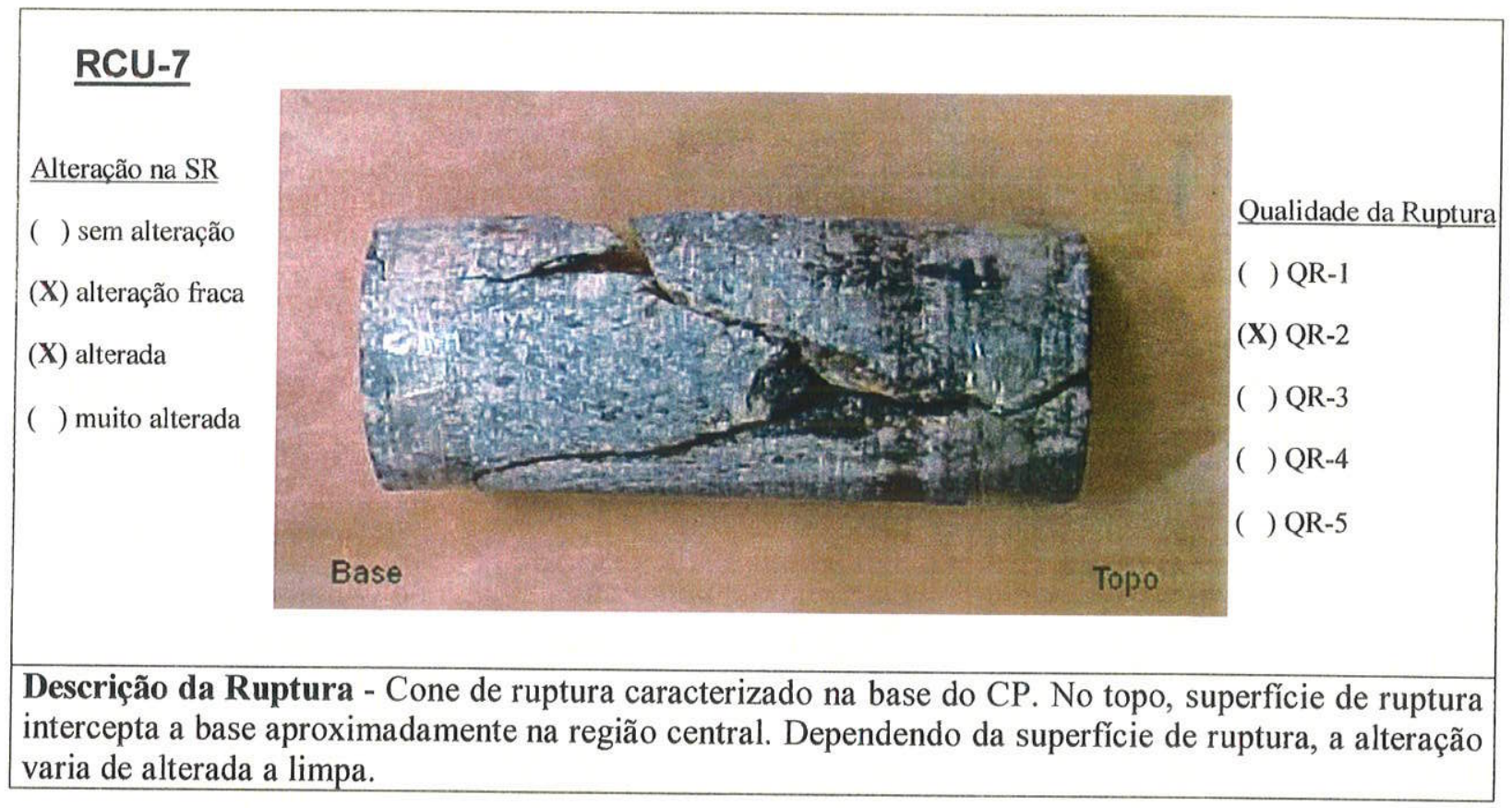

As estimativas mineralógicas volumétricas das amostras dos ensaios de RCU são apresentadas no Quadro A.3.5. Na seqüência, são apresentadas ainda as fichas petrográficas das Amostras RCU -1 a 7, com as imagens dos corpos-de-prova antes da ruptura e fotografias das lâminas.

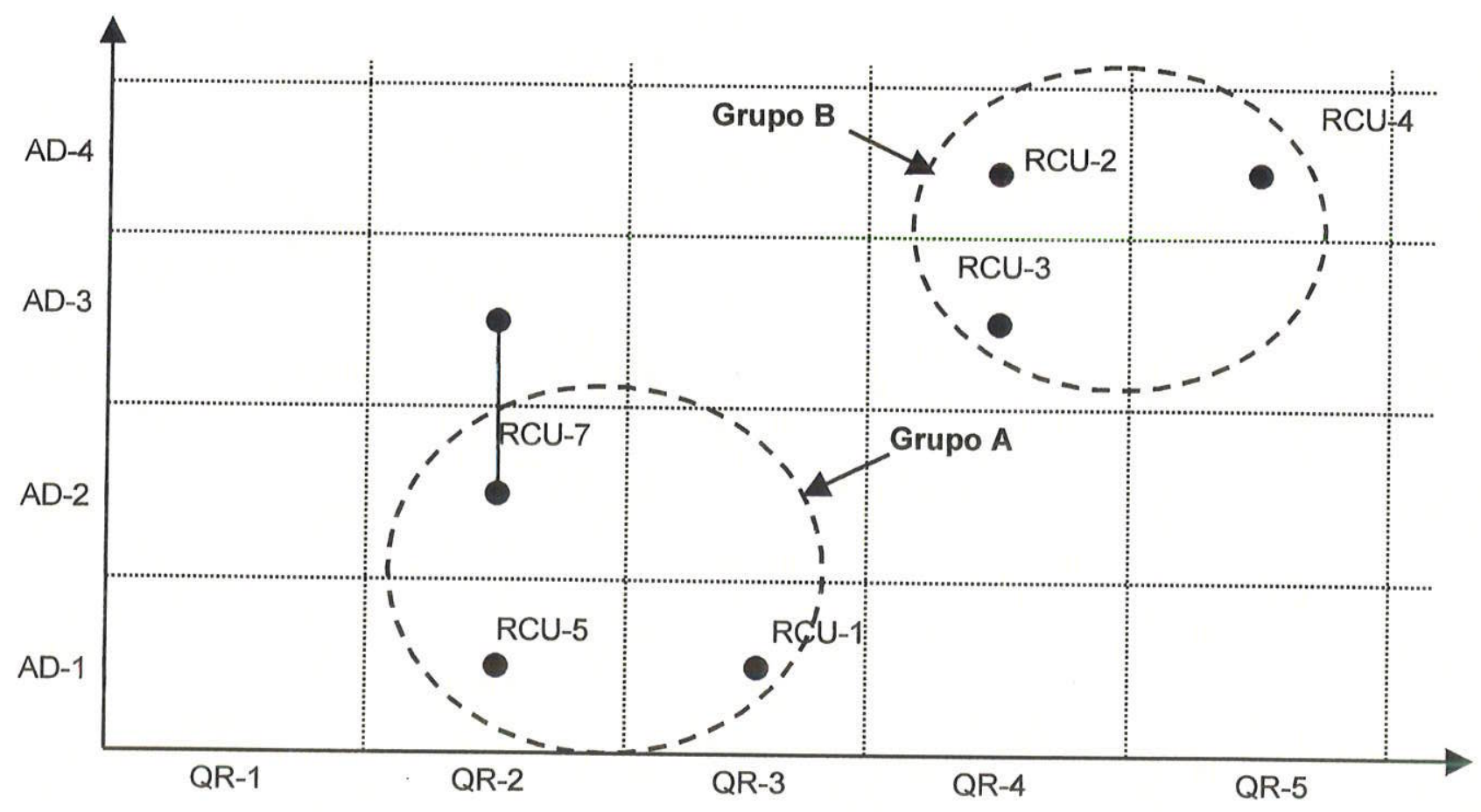

Figura A.3.4 - Distribuição dos dois grupos de amostras do ensaio RCU (Qualidade de Ruptura - QR x Alteração de Descontinuidade - AD). 


\begin{tabular}{|ll|}
\hline \multicolumn{2}{|c|}{ LEGENDA } \\
Feldspatos & \\
Plagioclásio & Plag \\
Microclinio & Micr \\
Quartzo & Qzo \\
Hornblenda & Hrnb \\
Biotita & Biot \\
Oxidos/hidróxidos de ferro & OFe \\
\hline
\end{tabular}


Quadro A.3.5 - Tabela para estimativa de porcentagem volumétrica dos minerais das amostras do ensaio de RCU.

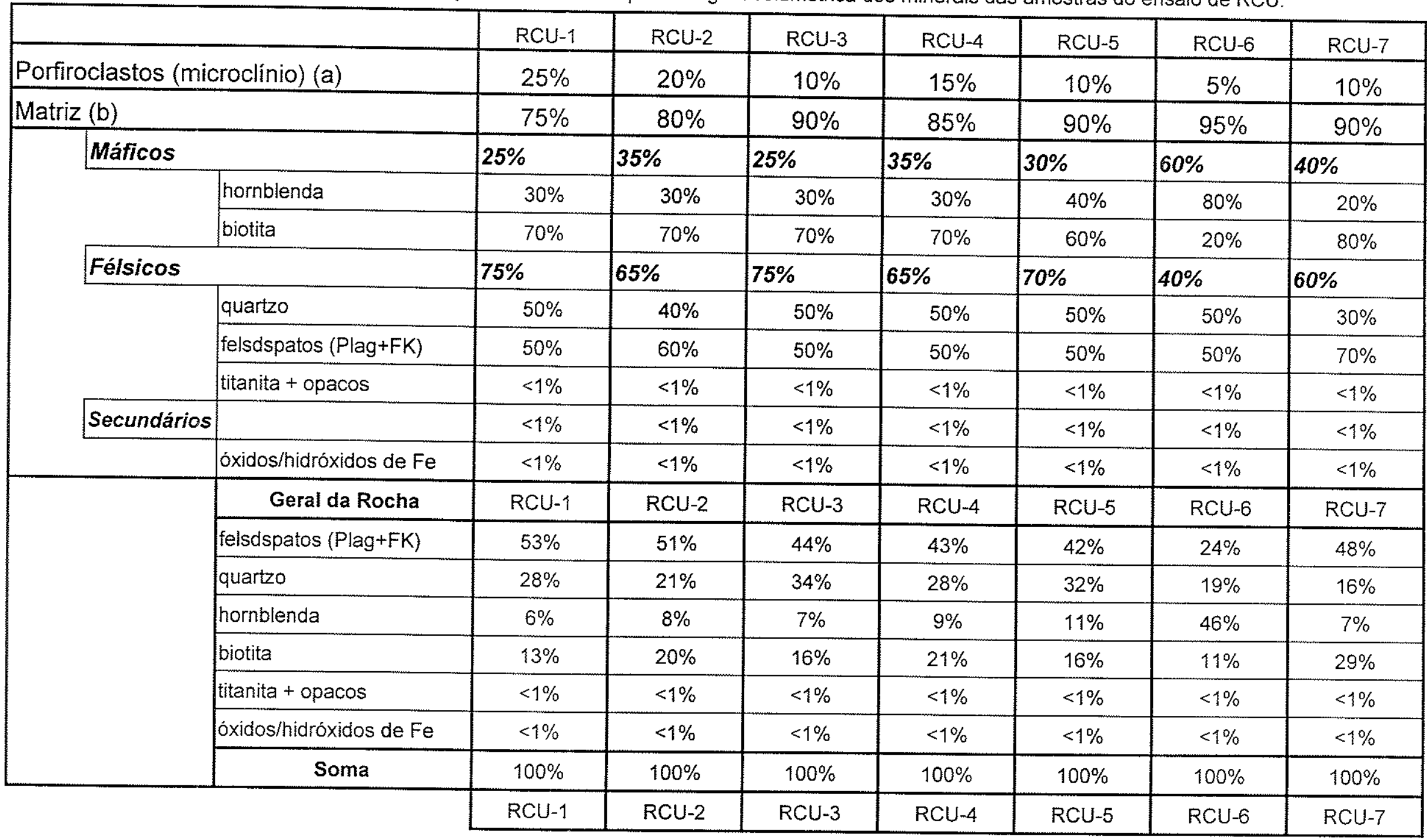

(a) Porfiroclastos (microclínio) com diâmetro maior que $2 \mathrm{~cm}$

$\vec{\omega}$

(b) Demais minerais com diametro menor que $2 \mathrm{~cm}$. 


\begin{tabular}{|c|c|c|c|}
\hline Amostra RCU-1 & \multicolumn{3}{|c|}{ DESCRIÇÃO PETROGRÁFICA } \\
\hline $\begin{array}{l}\text { Interessado: Flávio A. da Silva } \\
\text { Data: março/2001 } \\
\text { Localização: São Paulo, SP }\end{array}$ & \multirow{2}{*}{\multicolumn{3}{|c|}{$\begin{array}{l}\text { Descrição Macroscópica: Gnaisse milonitizado com bandamento e } \\
\text { foliação subverticais. Marcante estiramento de minerais (principalmente } \\
\text { plagioclásios). Porfiroclastos centimétricos de felsdspato alcalino. } \\
\text { Matriz máfica fina com cristais milimétricos de plagioclásio e quartzo. }\end{array}$}} \\
\hline $\begin{array}{l}\text { Formação Geológica: Zona de } \\
\text { Cisalhamento dentro } \\
\text { Complexo Embu }\end{array}$ & & & \\
\hline \multicolumn{4}{|c|}{ Tipos Petrográficos eMineralogia } \\
\hline \multirow{7}{*}{$\begin{array}{l}\quad \text { Porcentag } \\
\text { Porfiroclastos cent } \\
25 \% \\
\text { Matriz mais fina: } \\
75 \%\end{array}$} & Mineral & Volumétrica \% & Tamanho dos grãos \\
\hline & Feldspatos (Plag+FK) & 53 & 0,2 a $50 \mathrm{~mm}$ \\
\hline & Quartzo & 28 & $<0,1 \mathrm{~mm}$ \\
\hline & Hornblenda & 6 & $<2 \mathrm{~mm}$ \\
\hline & Biotita & 13 & - \\
\hline & Óxidos/hidróxidos de ferro & $<1$ & - \\
\hline & Titanita + opacos & $<1$ & - \\
\hline
\end{tabular}

Observações gerais da lâmina: Alteração incipiente. Óxidos de ferro em fraturas mais ou menos persistentes. Presença de quartzo recristalizado (cordões de quartzo ou "ribbons").

Classificação petrográfica: Biotita Gnaisse Milonítico

Imagem da superfície do corpo de prova: altura $14 \mathrm{~cm}$ e diâmetro $5,4 \mathrm{~cm}$
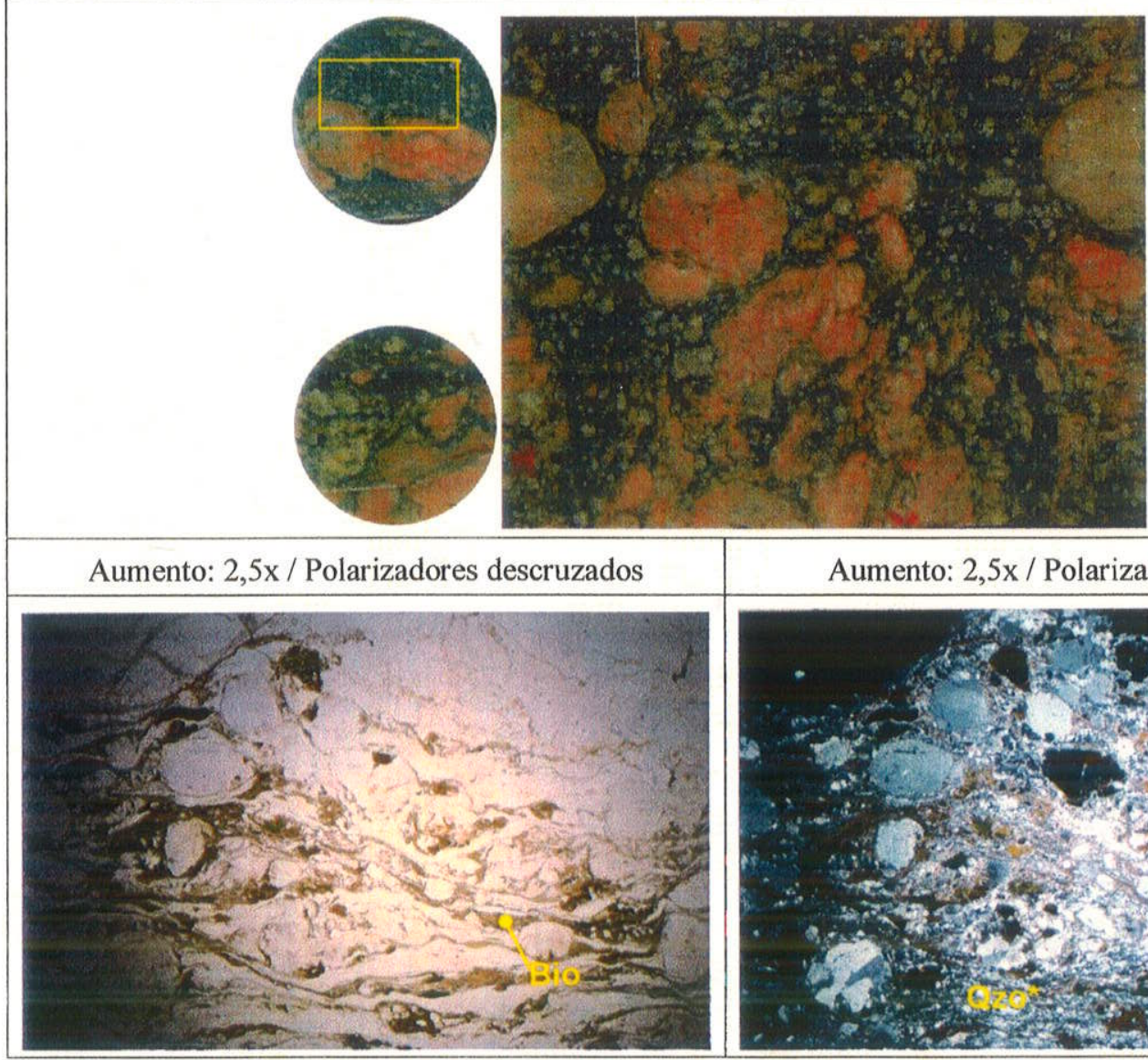

Aumento: 2,5x / Polarizadores cruzados

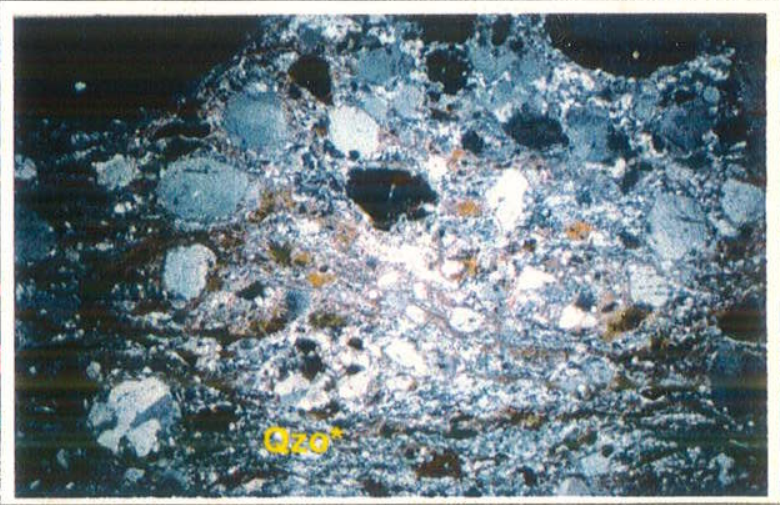

* Quartzo microcristalino 


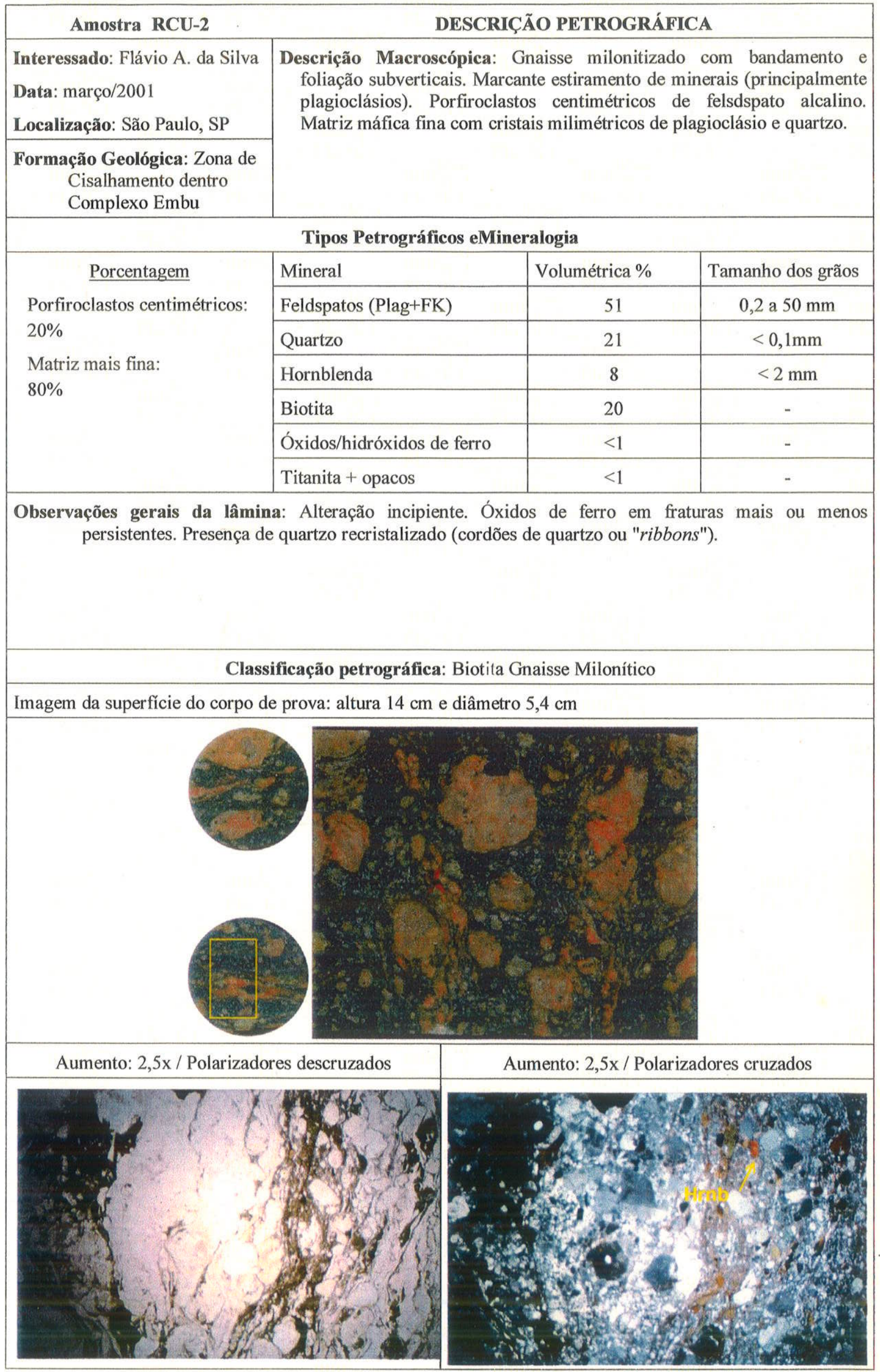




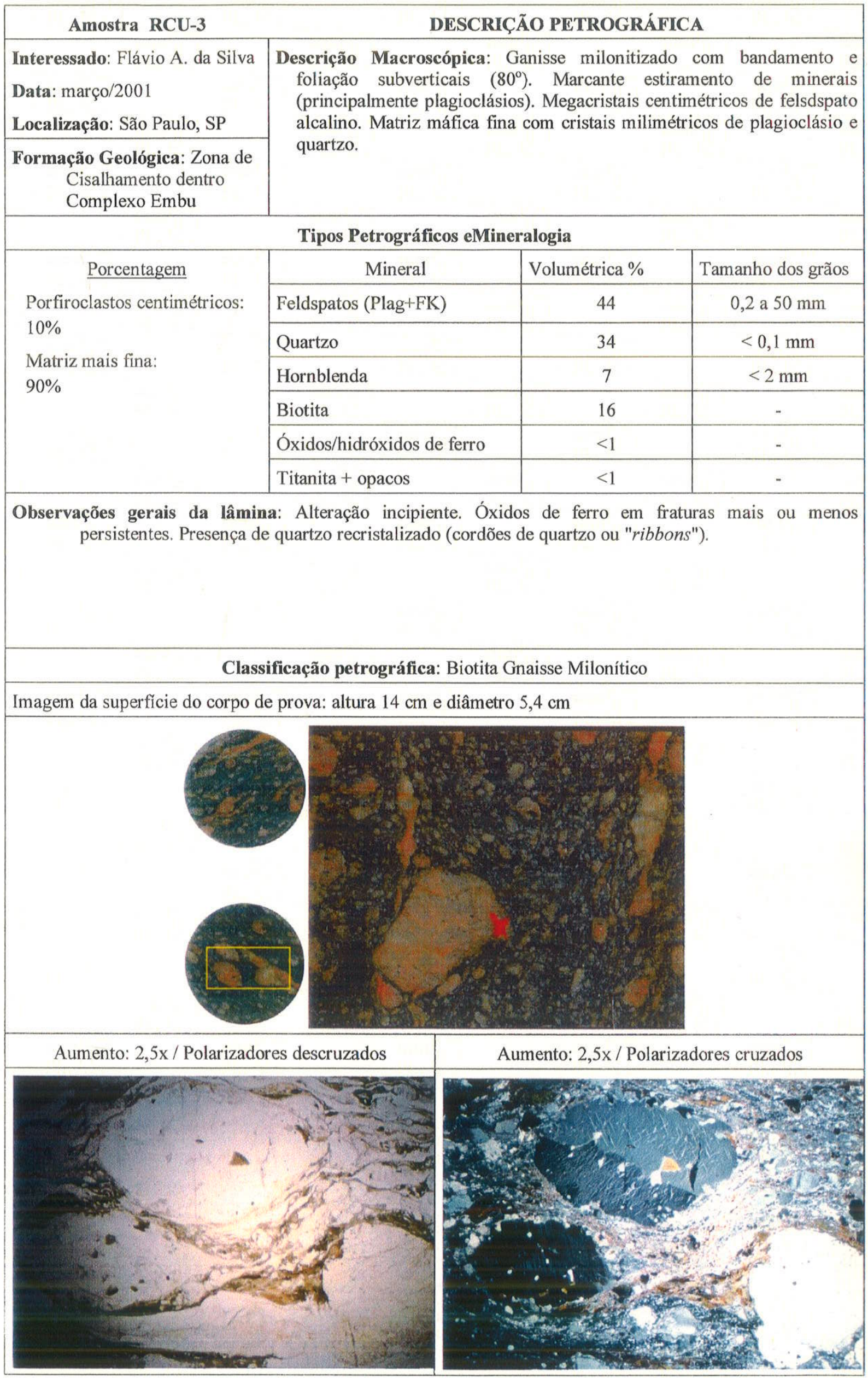




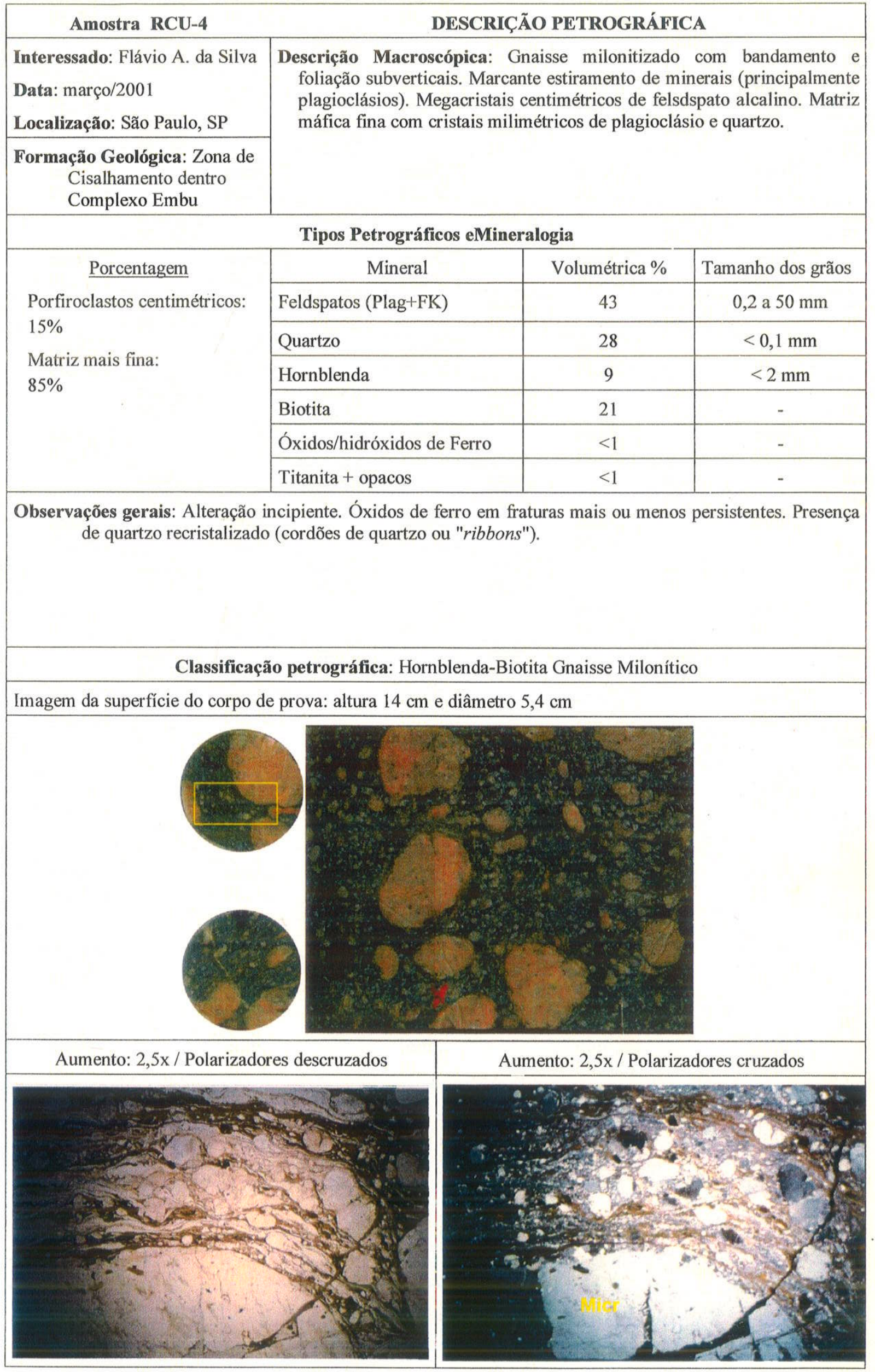




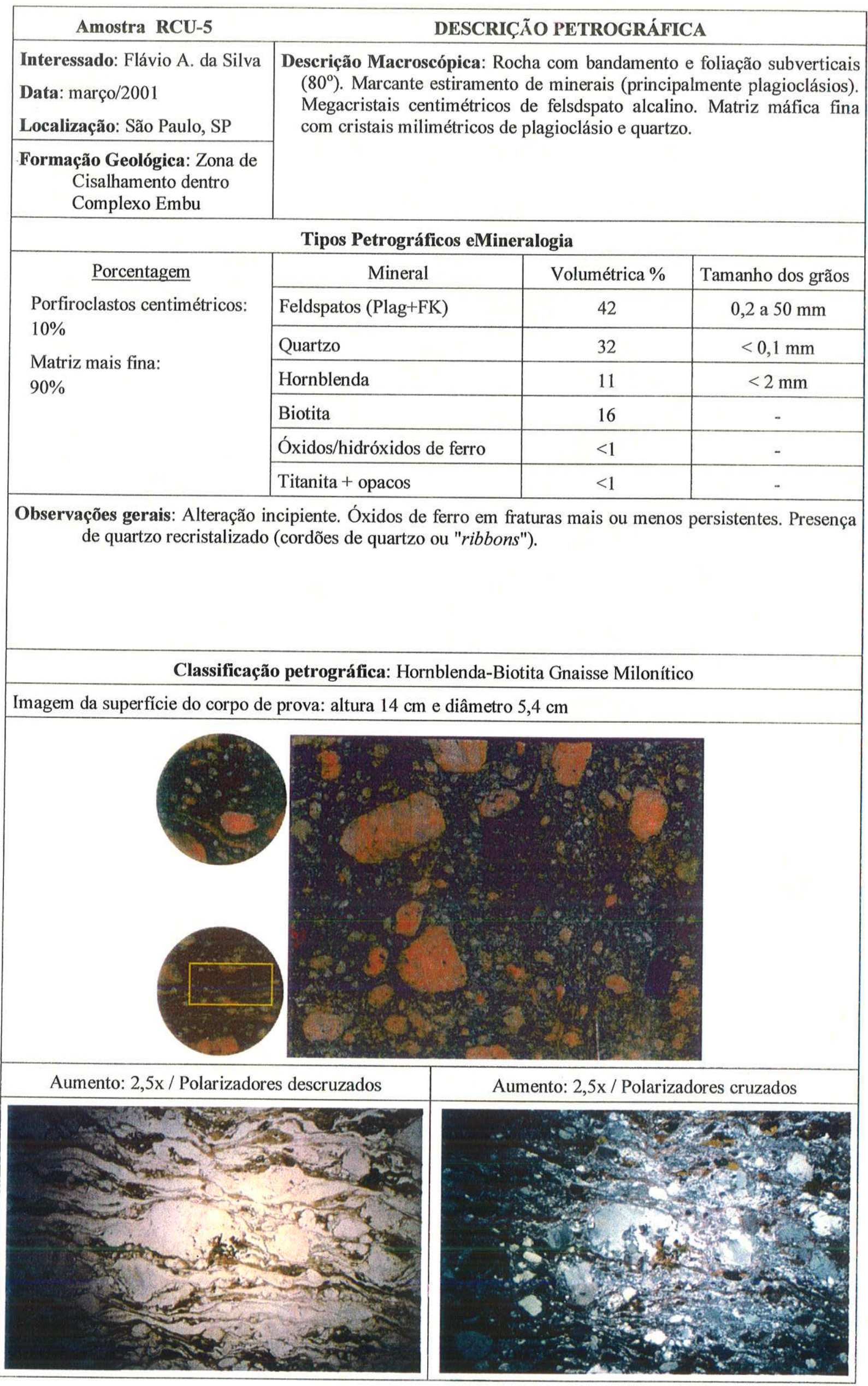




\begin{tabular}{|c|c|c|c|}
\hline Amostra RCU-6 & \multicolumn{3}{|c|}{ DESCRIÇÃO PETROGRÁFICA } \\
\hline $\begin{array}{l}\text { Interessado: Flávio A. da Silva } \\
\text { Data: março/2001 } \\
\text { Localização: São Paulo, SP } \\
\text { Formação Geológica: Zona de } \\
\text { Cisalhamento dentro } \\
\text { Complexo Embu }\end{array}$ & \multicolumn{3}{|c|}{$\begin{array}{l}\text { Descrição Macroscópica: Gnaisse milonitizado com bandamento e } \\
\text { foliação subverticais }\left(80^{\circ}\right) \text {. Marcante estiramento de minerais } \\
\text { (principalmente plagioclásios). Megacristais centimétricos de felsdspato } \\
\text { alcalino. Matriz máfica fina com cristais milimétricos de plagioclásio e } \\
\text { quartzo. }\end{array}$} \\
\hline \multicolumn{4}{|c|}{ Tipos Petrográficos eMineralogia } \\
\hline \multirow{7}{*}{$\begin{array}{l}\text { Porcentag } \\
\text { Porfiroclastos cen } \\
5 \% \\
\text { Matriz mais fina: } \\
95 \%\end{array}$} & Mineral & Volumétrica \% & Tamanho dos grãos \\
\hline & Feldspatos (Plag+FK) & 24 & 0,2 a $50 \mathrm{~mm}$ \\
\hline & Quartzo & 19 & $<0,1 \mathrm{~mm}$ \\
\hline & Hornblenda & 46 & $<2 \mathrm{~mm}$ \\
\hline & Biotita & 11 & - \\
\hline & Óxidos/hidróxidos de ferro & $<1$ & - \\
\hline & Titanita + opacos & $<1$ & - \\
\hline
\end{tabular}

Observações gerais: Alteração incipiente. Óxidos de ferro em fraturas mais ou menos persistentes. Presença de quartzo recristalizado (cordões de quartzo ou "ribbons").

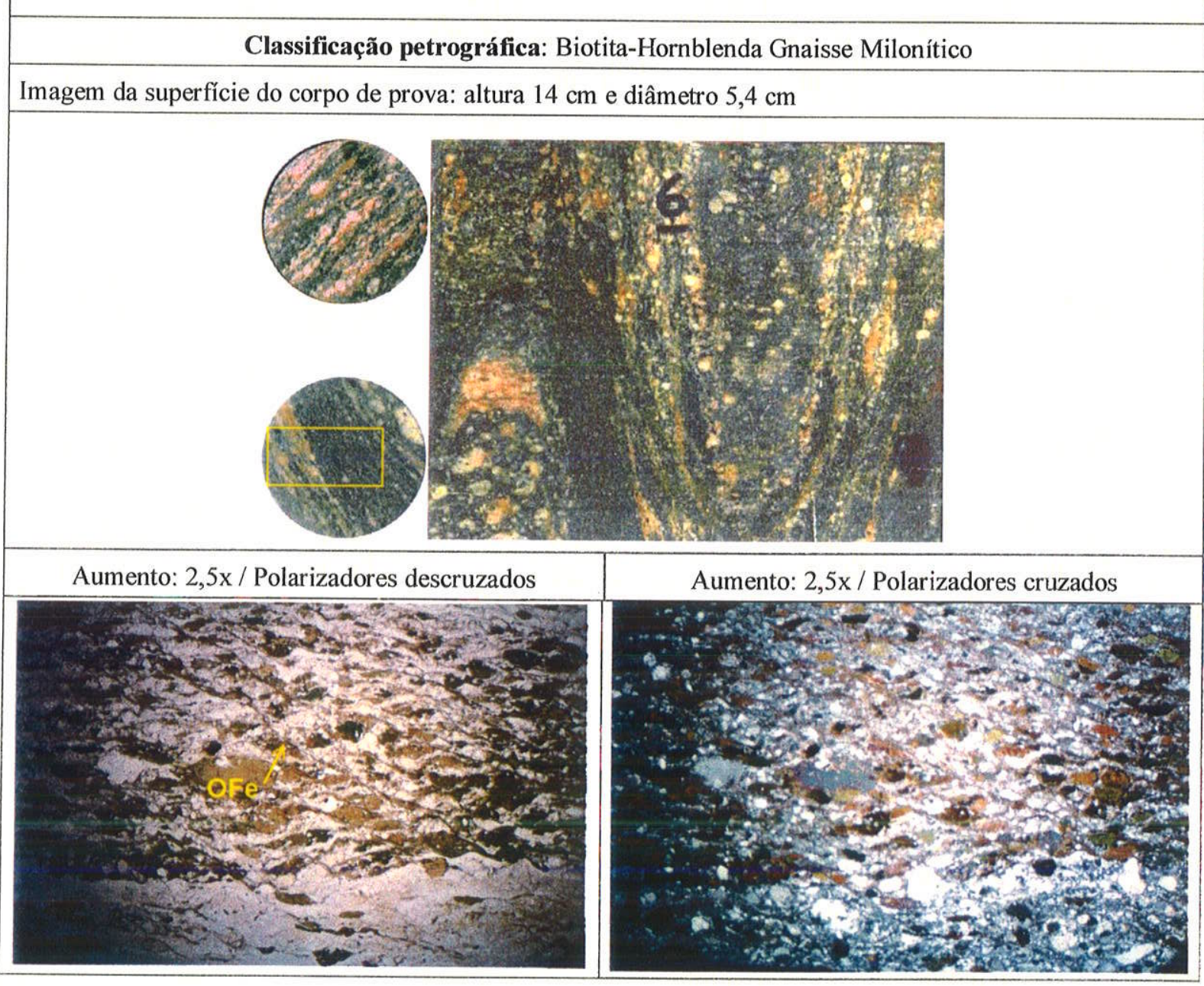


Anexo A3 - Ensaios de Mecânica de Rochas

\begin{tabular}{|c|c|c|c|}
\hline Amostra $\mathbb{R} \mathbb{C U}-7$ & \multicolumn{3}{|c|}{ DESCIRICCÃO PETIROGRÁIFICA } \\
\hline $\begin{array}{l}\text { Innteressadlo: Flávio A. da Silva } \\
\text { Data: março/2001 } \\
\text { Locallização: São Paulo, SP }\end{array}$ & \multirow{2}{*}{\multicolumn{3}{|c|}{$\begin{array}{l}\text { Descrição Macroscópica: Gnaisse milonitizado com bandamento e } \\
\text { foliação subverticais }\left(80^{\circ}\right) \text {. Marcante estiramento de minerais } \\
\text { (principalmente plagioclásios). Megacristais centimétricos de felsdspato } \\
\text { alcalino. Matriz máfica fina com cristais milimétricos de plagioclásio e } \\
\text { quartzo. }\end{array}$}} \\
\hline $\begin{array}{l}\text { Formação Geollógica: Zona de } \\
\text { Cisalhamento dentro } \\
\text { Complexo Embu }\end{array}$ & & & \\
\hline \multicolumn{4}{|c|}{ Tipos Petrográficos e Minerallogia } \\
\hline \multirow{7}{*}{$\begin{array}{l}\text { Porcentagem } \\
\text { Porfiroclastos centim } \\
10 \% \\
\text { Matriz mais fina: } \\
90 \%\end{array}$} & Mineral & Volumétrica \% & Tamanho dos grãos \\
\hline & Feldspatos (Plag+FK) & 48 & 0,2 a $50 \mathrm{~mm}$ \\
\hline & Quartzo & 16 & $<0,1 \mathrm{~mm}$ \\
\hline & Hornblenda & 7 & $<2 \mathrm{~mm}$ \\
\hline & Biotita & 29 & - \\
\hline & Óxidos/hidróxidos de ferro & $<1$ & - \\
\hline & Titanita + opacos & $<1$ & - \\
\hline
\end{tabular}

Observações gerais: Alteração incipiente. Óxidos de ferro em fraturas mais ou menos persistentes. Presença de quartzo recristalizado (cordões de quartzo ou "ribbons").

\section{Classificação petrográfica: Biotita Gnaisse Milonítico}

Imagem da superfície do corpo de prova: altura $14 \mathrm{~cm}$ e diâmetro $5,4 \mathrm{~cm}$
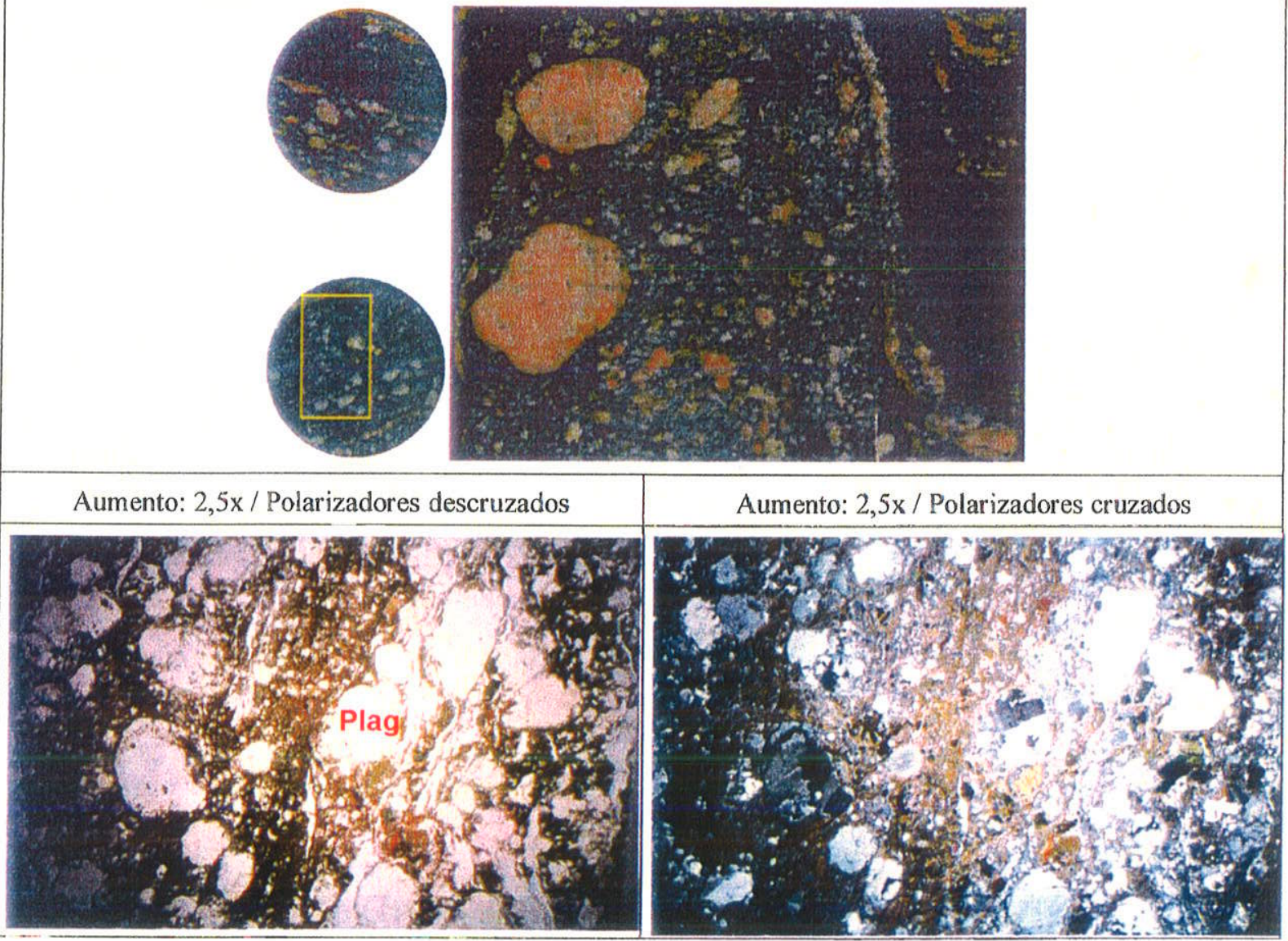


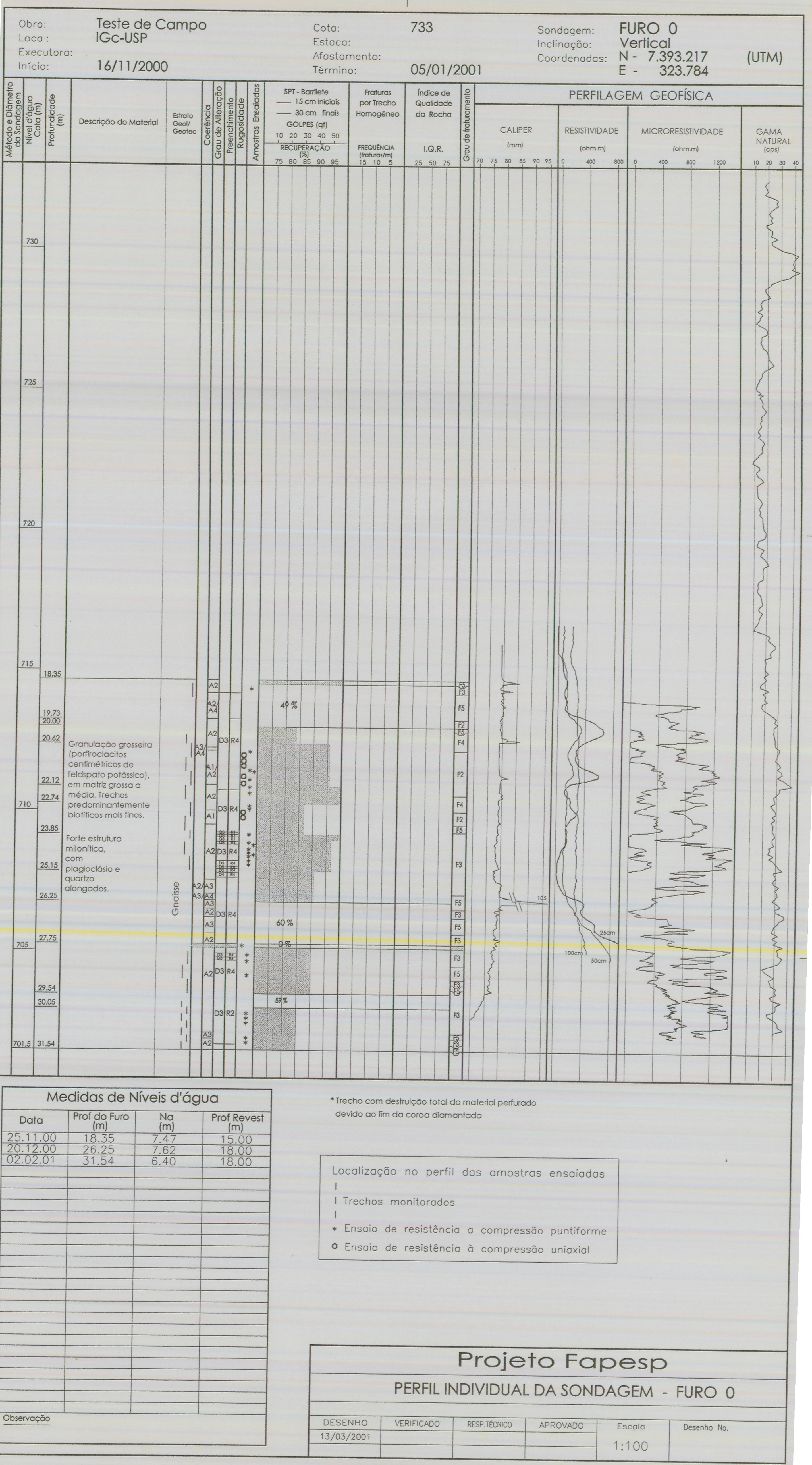




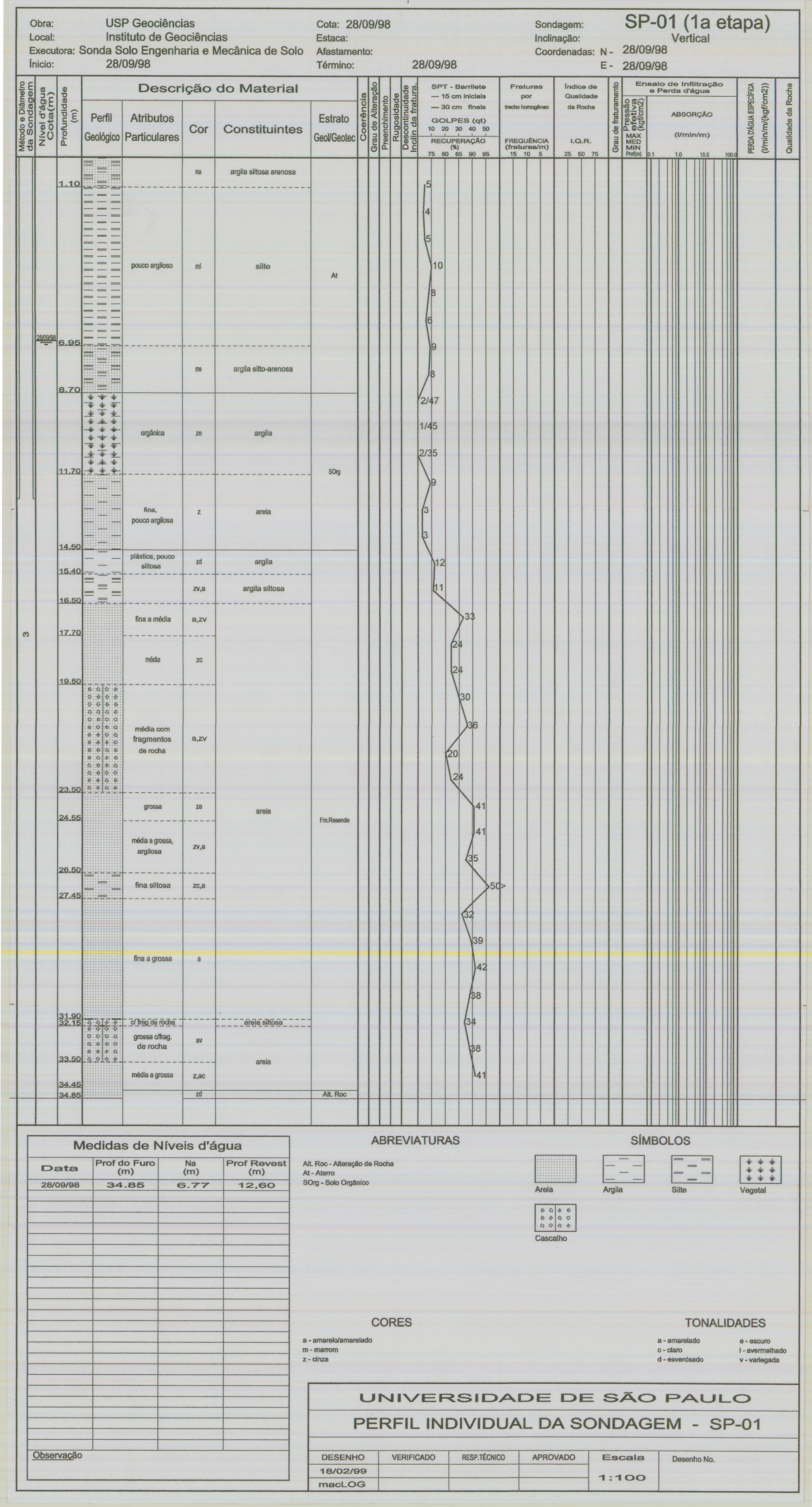


